Portland State University

PDXScholar

\title{
Breaking Barriers to Bike Share: Insights from Residents of Traditionally Underserved Neighborhoods
}

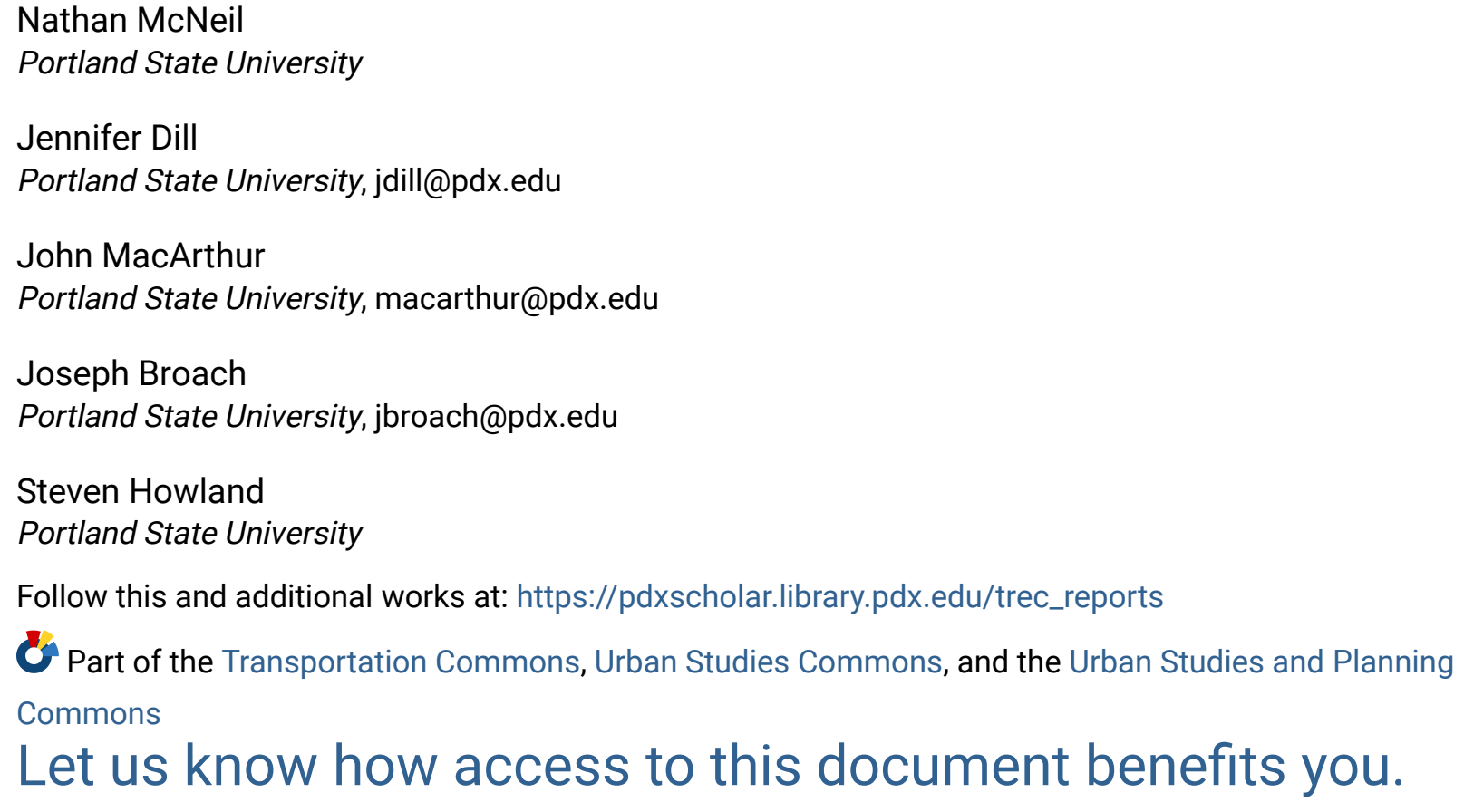

\section{Recommended Citation}

McNeil, N., Dill, J., MacArthur, J., Broach, J., and Howland, S. Breaking Barriers to Bike Share: Insights from Residents of Traditionally Underserved Neighborhoods. NITC-RR-884b. Portland, OR: Transportation Research and Education Center (TREC), 2017. https://doi.org/10.15760/trec.176

This Report is brought to you for free and open access. It has been accepted for inclusion in TREC Final Reports by an authorized administrator of PDXScholar. Please contact us if we can make this document more accessible: pdxscholar@pdx.edu. 


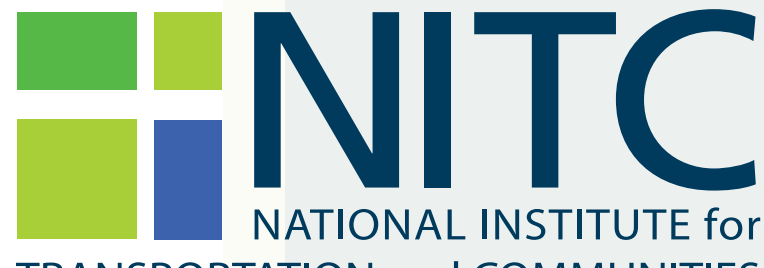

TRANSPORTATION and COMMUNITIES

FINAL REPORT

Breaking Barriers to Bike Share: Insights from Residents of Traditionally Underserved Neighborhoods

NITC-RR-884b June 2017

NITC is a U.S. Department of Transportation national university transportation center.

=IIT TREC 



\title{
BREAKING BARRIERS TO BIKE SHARE: INSIGHTS FROM RESIDENTS OF TRADITIONALLY UNDERSERVED NEIGHBORHOODS
}

\author{
Final Report \\ NITC-RR-884b \\ Prepared by: \\ Transportation Research and Education Center (TREC) \\ Portland State University \\ Nathan McNeil \\ Jennifer Dill \\ John MacArthur \\ Joseph Broach \\ Steven Howland
}

Prepared for:

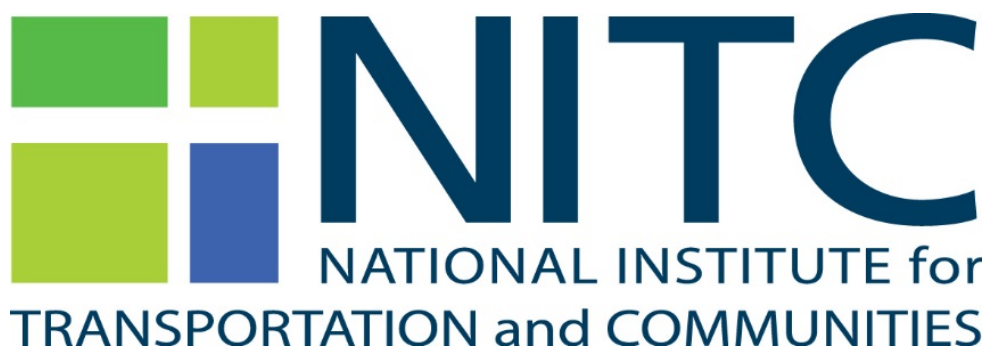

National Institute for Transportation and Communities (NITC)

June 2017 



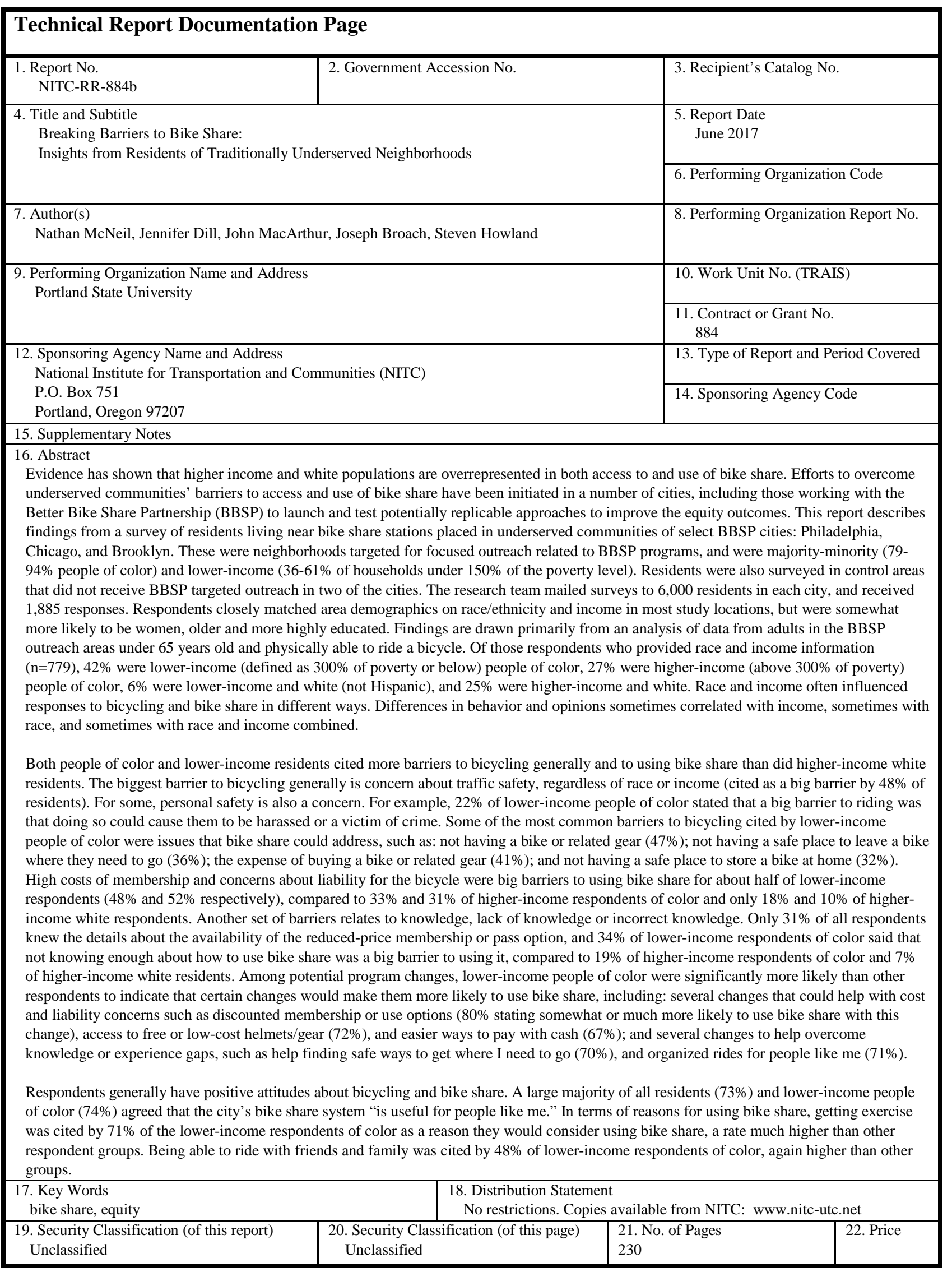





\section{Acknowledgements}

This research was funded by the Better Bike Share Partnership (BBSP), a collaboration made possible by The JPB Foundation; and the National Institute for Transportation and Communities (NITC) under grant number 884, a program of the Transportation Research and Education Center at Portland State University and a U.S. Department of Transportation university transportation center.

The research could not have been conducted without the significant participation of our city partners. These individuals shared their time and expertise, provided data, hosted our field visits, and provided feedback on surveys and findings: Carniesha Kwashie, Aaron Ritz and Cara Ferrentino (City of Philadelphia); Claudia Setubal and Kiera Smalls (Bicycle Transit Systems); Katie Monroe and Waffiyyah Murray (Bicycle Coalition of Greater Philadelphia); Amanda Woodall and Sean Wiedel (Chicago Department of Transportation); Eliot Greenberger (Motivate); Ronnie Harris and Rebecca Noble (Go Bronzeville); Jennifer McClain and Lynnette Washington (LISC Chicago); Dan Black (Slow Roll Chicago); Tracey Capers, Verna Ademu-John, Joanna Lee Jacob and Aysu Kirac (Bedford Stuyvesant Restoration Corporation); Anne Krassner and William Bissell (Citi Bike); Dani Simons (Motivate); Beth Heyde (New York City Department of Transportation), Philip Noyes (New York City Department of Health and Mental Hygiene); along with Ted Graves and Kate Fillin-Yeh (NACTO), Zoe Kircos, Martha Roskowski and Jennifer Boldry (PeopleForBikes).

Thanks also to the students who worked on this project, including Kenneth Rankins, Michael Harpool, Layne Wise, Carlos Callava, and Jamaal Green.

\section{Disclaimer}

The contents of this report reflect the views of the authors, who are solely responsible for the facts and the accuracy of the material and information presented herein. This document is disseminated under the sponsorship of the U.S. Department of Transportation University Transportation Centers Program in the interest of information exchange. The U.S. government assumes no liability for the contents or use thereof. The contents do not necessarily reflect the official views of the U.S. government. This report does not constitute a standard, specification, or regulation.

\section{Recommended Citation}

McNeil, Nathan, Jennifer Dill, John MacArthur, Joseph Broach, Steven Howland. Breaking Barriers to Bike Share: Insights from Residents of Traditionally Underserved Neighborhoods. NITC-RR-884b. Portland, OR: Transportation Research and Education Center (TREC), 2017. 



\section{TABLe OF CONTENTS}

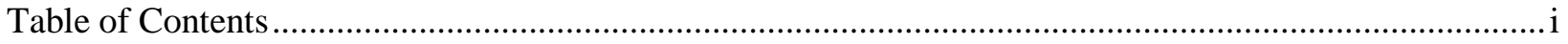

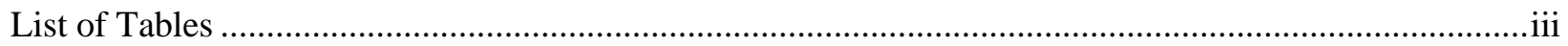

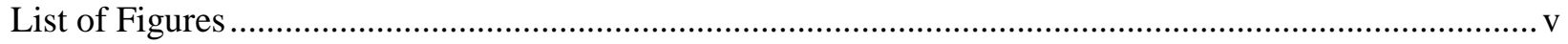

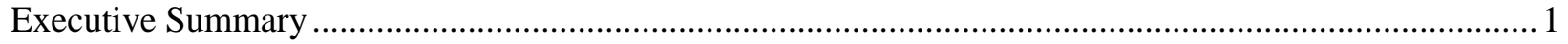

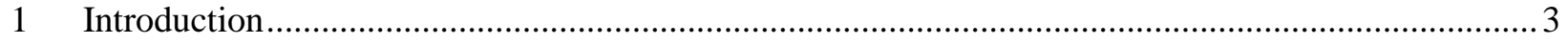

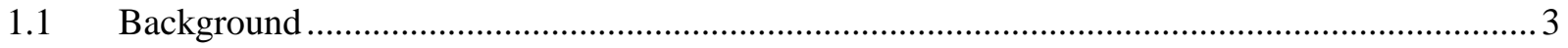

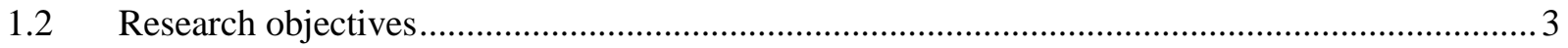

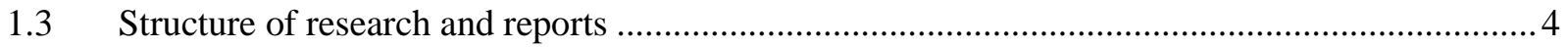

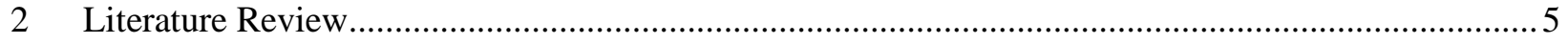

2.1 Existing studies of equity and bike share demographics ....................................................... 5

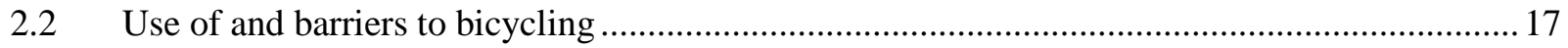

2.3 Bike share potential for underserved communities ............................................................... 22

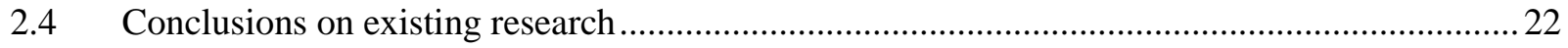

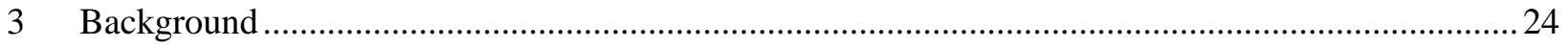

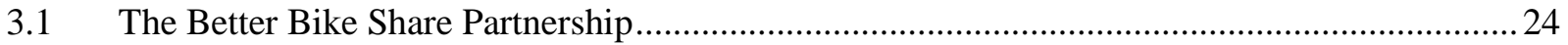

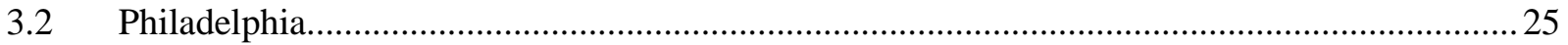

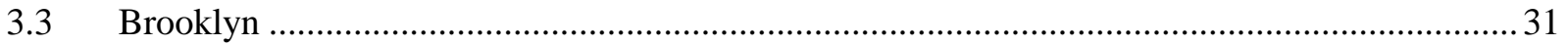

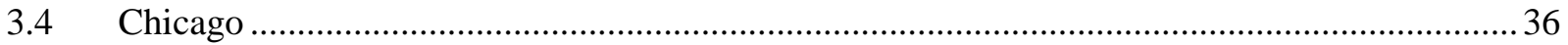

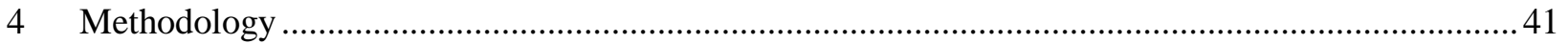

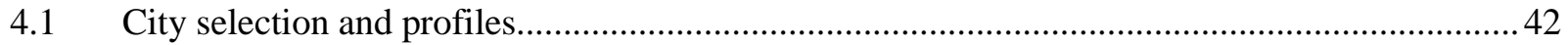

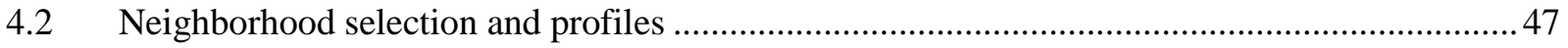

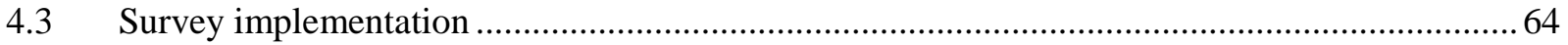

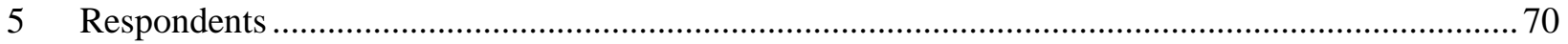

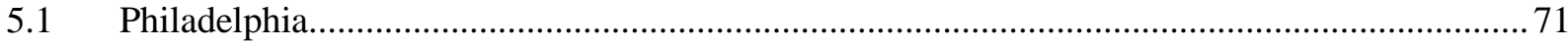

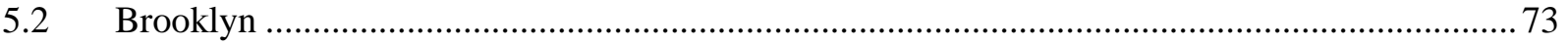

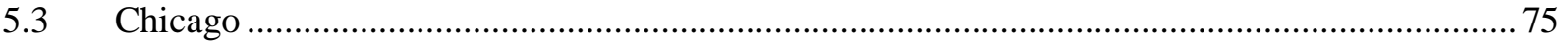

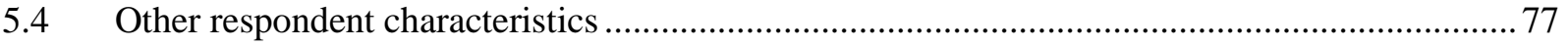

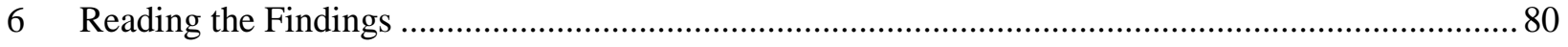

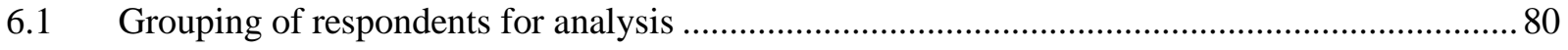

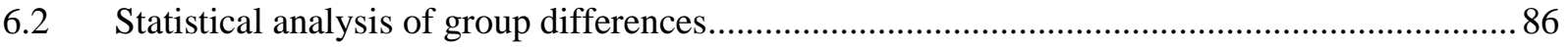

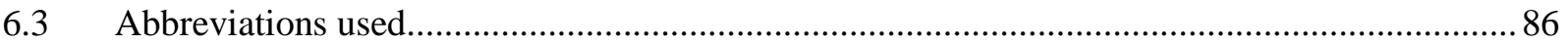

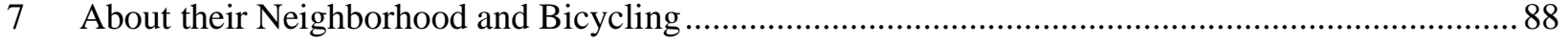

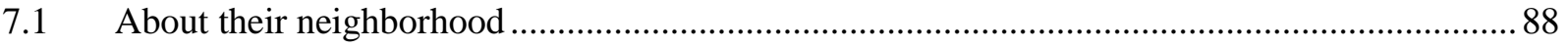




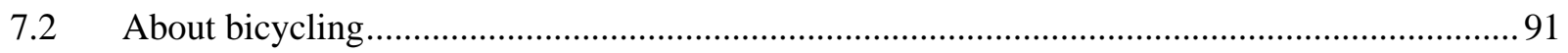

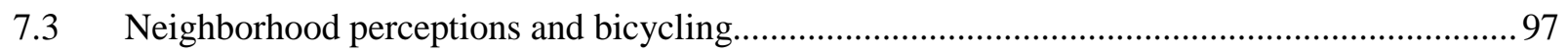

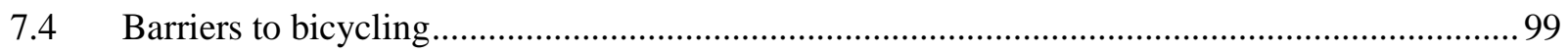

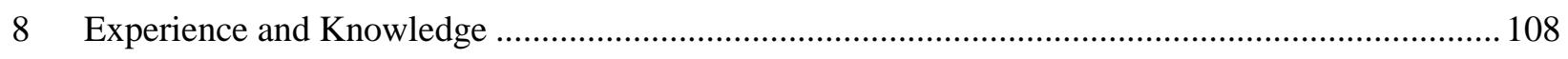

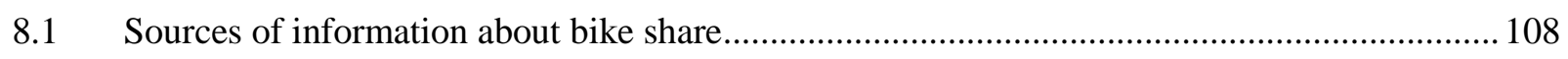

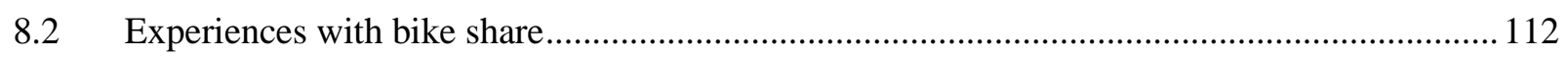

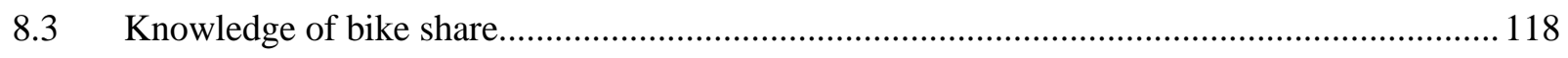

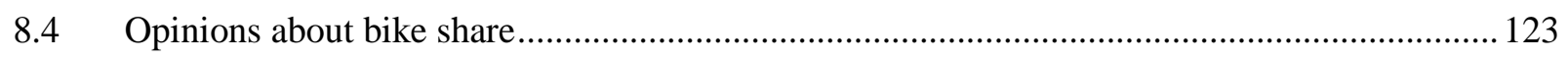

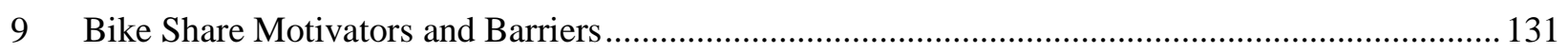

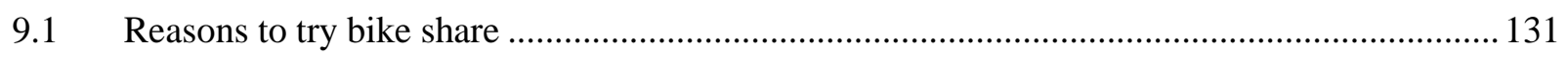

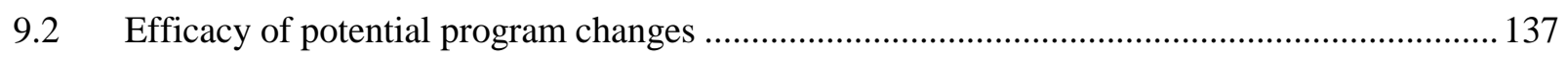

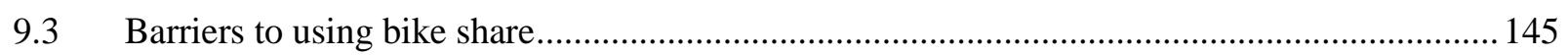

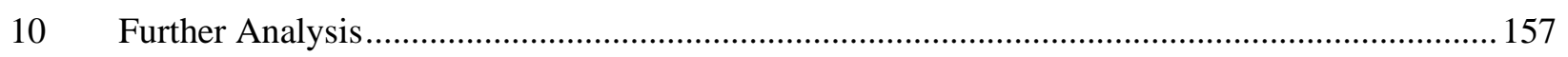

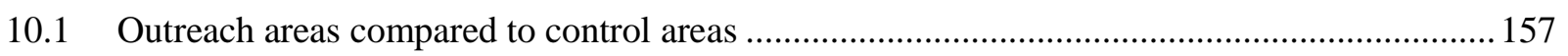

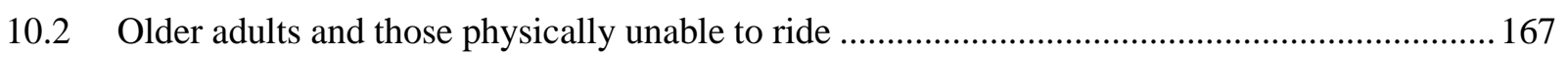

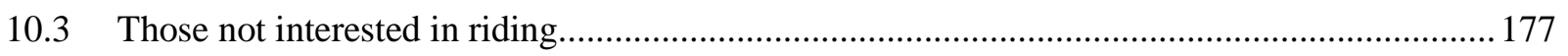

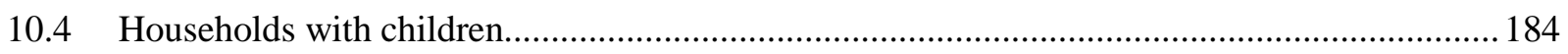

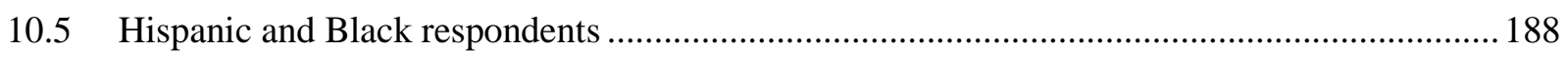

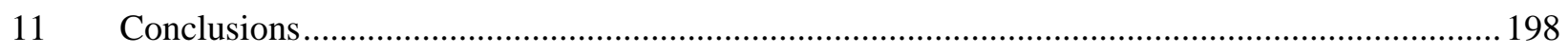

11.1 How does bike share work for specific underserved and understudied populations?...............199

11.2 How might needs and use patterns differ from other user groups?........................................ 199

11.3 Are there specific barriers among people of color and lower-income residents? ....................199

11.4 Are there specific opportunities for increasing bike share use among people of color and lower-

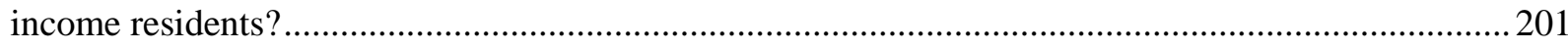

11.5 Which interventions are most effective in increasing awareness and use of bike share? .........202

11.6 Are the promotion and outreach efforts reaching target populations? ....................................203

11.7 How effective are the various efforts employed to increase the equity of bike share systems?203

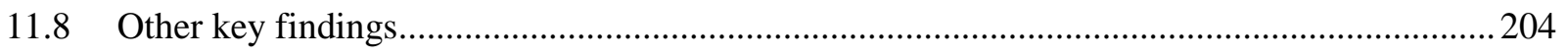

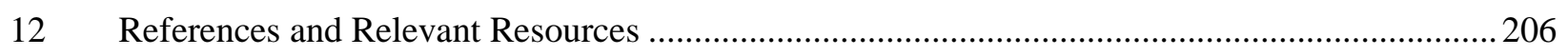

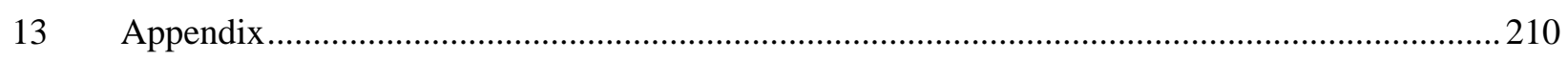

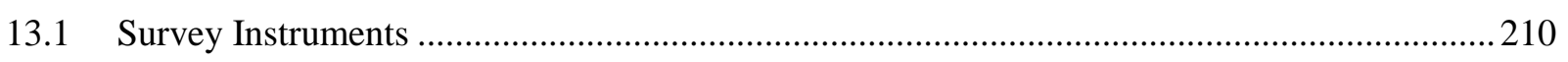

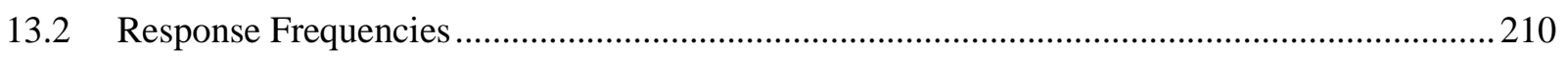




\section{LIST OF TABLES}

Table 2-1 U.S. Bike Share Systems by Launch Year .................................................................... 5

Table 2-2 Studies Related to Bike Share User, Member, and Nonuser Demographics ............................... 7

Table 2-3 Research on Bicycling and Barriers to Bicycling for Low-Income and People of Color........... 19

Table 3-1 Overview of BBSP Context and Program Elements by Study City ......................................... 25

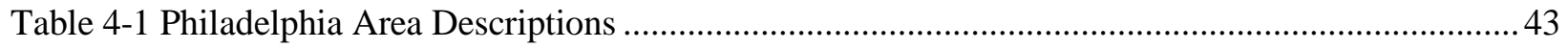

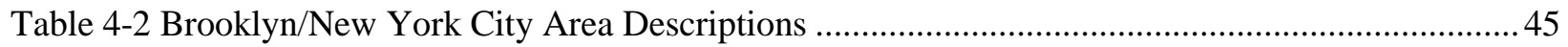

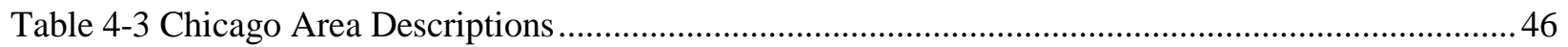

Table 4-4 Undeliverable Surveys and Final Sample by City and Neighborhood .................................... 69

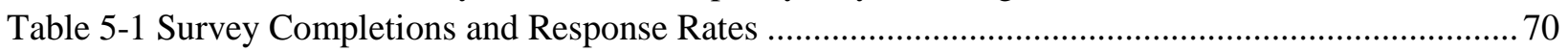

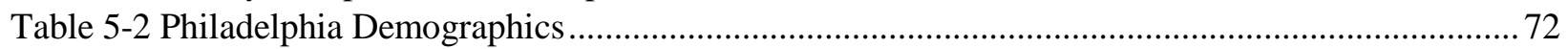

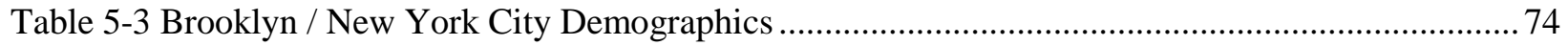

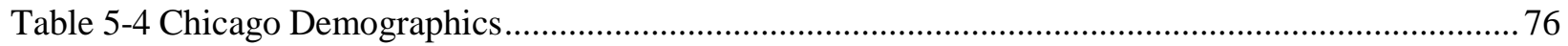

Table 5-5 Transportation Characteristics by Neighborhood .................................................................. 78

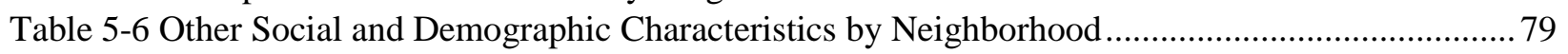

Table 6-1 300\% of Poverty Guideline Thresholds by Family Size ...................................................... 81

Table 6-2 Respondents' Stated Income and Ability to get along, by Income Threshold ........................... 82

Table 6-3 Percentage of each Race-Income Group from each Study Area ............................................... 83

Table 6-4 Transportation Characteristics by Race-Income Groups ........................................................... 84

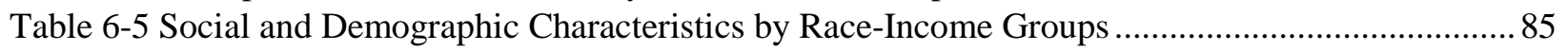

Table 6-6 Binary Variables Created from Categorical Response Scales ................................................... 86

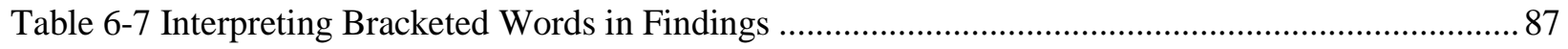

Table 7-1 Neighborhood Perceptions, by Gender and Race-Income Groups ............................................ 89

Table 7-2 Neighborhood Perceptions, by City and Neighborhood.....................................................91

Table 7-3 Perceptions of Bicycling, by Gender and Race-Income Groups ............................................. 93

Table 7-4 Perceptions of Bicycling, by City and Neighborhood .........................................................97

Table 7-5 Satisfaction with Travel Options and Opinions about Bicycling ............................................9 98

Table 7-6 Concerns about Neighborhood Changes and Opinions about Bicycling...................................99

Table 7-7 Barriers to Bicycling, by Gender and Race-Income Groups .................................................. 100

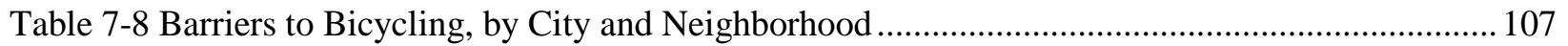

Table 8-1 Knowledge about Bike Share, by Gender and Race-Income Groups...................................... 108

Table 8-2 Sources of Information about Bike Share, by Gender and Race-Income Groups .................... 109

Table 8-3 Knowledge about Bike Share, by City and Neighborhood..................................................... 111

Table 8-4 Sources of Information about Bike Share, by City and Neighborhood ....................................112

Table 8-5 Experiences with Bike Share, by Gender and Race-Income Groups ......................................114

Table 8-6 Experiences with Bike Share, by City and Neighborhood ..................................................116

Table 8-7 True-or-False Questions, Correct Responses ......................................................................... 119

Table 8-8 Bike Share Knowledge, by Gender and Race-Income Groups............................................. 121

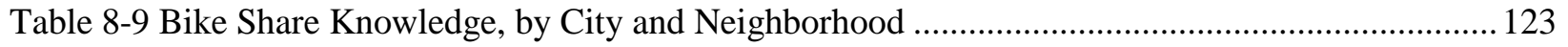

Table 8-10 Opinions about Bike Share, by Gender and Race-Income Groups...................................... 125

Table 8-11 Opinions about Bike Share, by City and Neighborhood .................................................... 129

Table 9-1 Reasons to Try Bike Share, by Gender and Race-Income Groups ........................................ 132

Table 9-2 Reasons to Try Bike Share, by City and Neighborhood........................................................ 136

Table 9-3 Efficacy of Potential Program Changes, by Gender and Race-Income Groups .......................138

Table 9-4 Efficacy of Potential Program Changes, by City and Neighborhood...................................... 144

Table 9-5 Bike Share Barriers, by Gender and Race-Income Groups ................................................... 146 
Table 9-6 Bike Share Barriers, by City and Neighborhood.

Table 9-7 Efficacy of Program Changes, by Perceived Barrier................................................................ 156

Table 10-1 Sources of Bike Share Information for Outreach and Control Areas .......................................158

Table 10-2 Experiences with Bike Share for Outreach and Control Areas ................................................159

Table 10-3 Opinions about Bike Share, Outreach and Control Areas ………………………………….....160

Table 10-4 Knowledge about the Bike Share System, by Outreach and Control Areas .............................161

Table 10-5 Reasons to Try Bike Share, by Outreach and Control Areas ..................................................162

Table 10-6 Efficacy of Potential Changes, by Outreach and Control Areas...............................................163

Table 10-7 Barriers to Bicycling, by Outreach and Control Areas................................................................. 164

Table 10-8 Barriers to Using Bike Share, by Outreach and Control Areas ...............................................165

Table 10-9 Demographics of the Older Adult Population ........................................................................168

Table 10-10 Opinions about Neighborhood and City by Age and Physical Ability to Ride a Bike..........169

Table 10-11 Opinions about Bicycling by Age and Physical Ability to Ride a Bike ................................170

Table 10-12 Rankings of Top Ten Barriers to Bicycling for Older Adults by Age and Physical Ability to

Ride a Bike

171

Table 10-13 Barriers to Bicycling for Older Adults Planning to Bike More in the Future by the Last Time

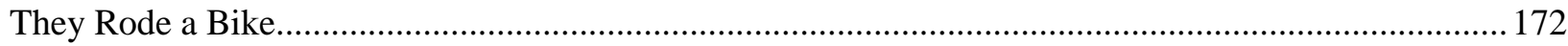

Table 10-14 Opinions about Bike Share By Age Groups and Physical Ability to Ride A Bike ...............173

Table 10-15 Barriers to Using Bike Share for Older Adults Stating They Plan to Bike More in the Next 12

Months by When They Last Rode a Bike ......................................................................................... 174

Table 10-16 Efficacy of Potential Program Changes on Populations Willing to Bike by Age Group and

Stated Likelihood of Riding a Bike Share Bike in the Current System................................................... 175

Table 10-17 Reasons to Try Bike Share for Populations Willing to Bike by Age Group and Stated

Likelihood of Riding Bike Share in the Next 6 Months ....................................................................... 176

Table 10-18 Perceptions of Neighborhood and Transportation, by Interest in Bicycling, Respondents of

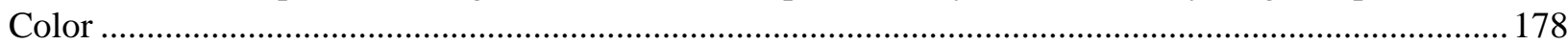

Table 10-19 Opinions on Bicycling, by Interest in Bicycling, Respondents of Color............................... 180

Table 10-20 Opinions about Bike Share, by Interest in Bicycling, Respondents of Color.........................181

Table 10-21 Barriers to Bicycling, by Interest in Bicycling, Respondents of Color ................................ 182

Table 10-22 Barriers to using Bike Share, by Interest in Bicycling, Respondents of Color....................... 183

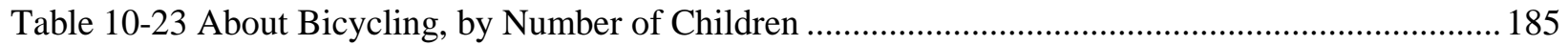

Table 10-24 Opinions about Bike Share, by Number of Children............................................................ 186

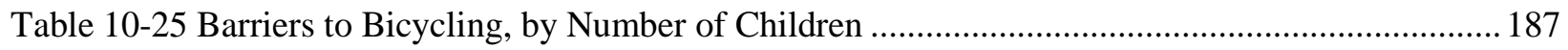

Table 10-26 Barriers to Bike Share, by Number of Children ................................................................. 188

Table 10-27 Hispanic and Black Respondents, by City and Income Category ........................................ 189

Table 10-28 Sources of Bike Share Information, Hispanic and Black Respondents .................................. 190

Table 10-29 Experiences with Bike Share, Hispanic and Black Respondents ..........................................191

Table 10-30 Opinions about Bike Share, Hispanic and Black Respondents ............................................. 192

Table 10-31 Reasons to Try Bike Share, Hispanic and Black Respondents.............................................. 193

Table 10-32 Knowledge about the Bike Share system, Hispanic and Black Respondents.........................194

Table 10-33 Barriers to Bicycling, Hispanic and Black Respondents .....................................................195

Table 10-34 Barriers to Using Bike Share, Hispanic and Black Respondents ........................................... 196

Table 10-35 Efficacy of Potential Changes, Hispanic and Black Respondents...........................................197 


\section{LIST OF FIGURES}

Figure 3-1 Philadelphia Strategic Business Plan (2013) deployment zones........................................... 26

Figure 3-2 Indego bike share system development from launch through July, 2016, including initial

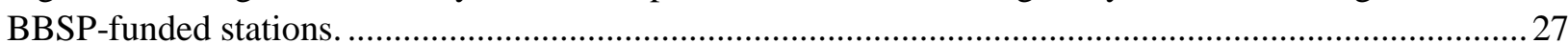

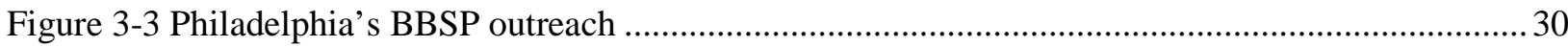

Figure 3-4 Citi Bike bike share system development from launch through July 2016............................ 32

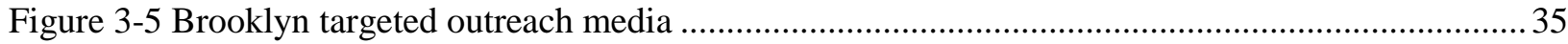

Figure 3-6 Divvy bike share system development from launch through July, 2016. ............................. 37

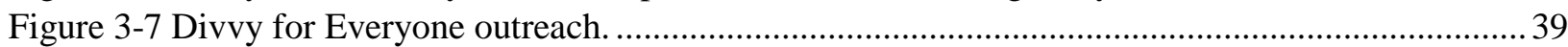

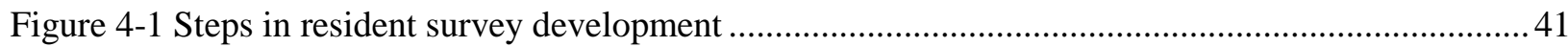

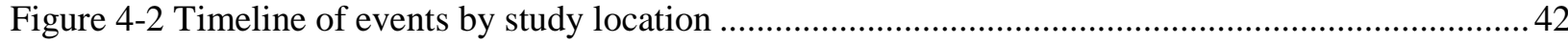

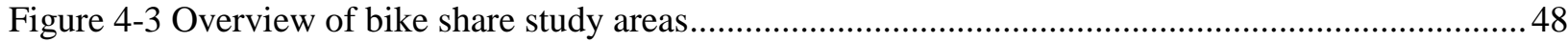

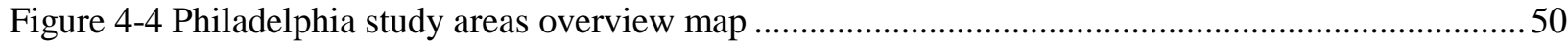

Figure 4-5 Philadelphia population, percentage people of color map................................................ 51

Figure 4-6 Philadelphia study areas, percentage of citywide median income map ..................................52

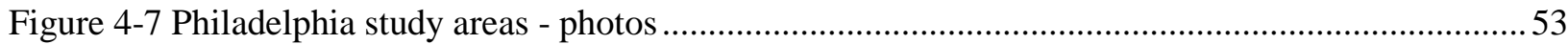

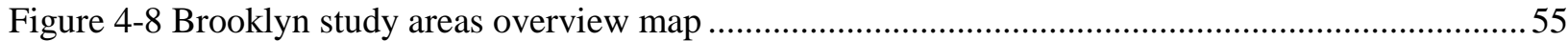

Figure 4-9 Brooklyn study areas people of color population map.........................................................5 56

Figure 4-10 Brooklyn study areas and percentage of boroughwide median income map ........................ 57

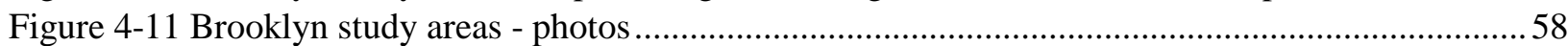

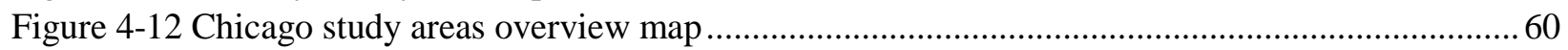

Figure 4-13 Chicago percent people of color population map................................................................61

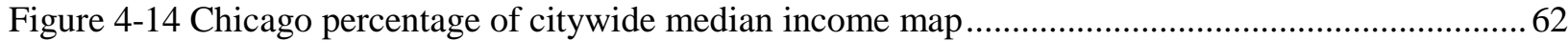

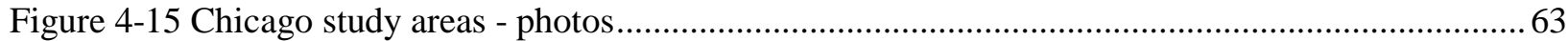

Figure 6-1 Breakdown of respondents included in primary analysis grouping ......................................8 81

Figure 7-1 Race and income difference in agreement from average of all areas.....................................95

Figure 7-2 Differences in bicycling barriers by race and income groups ............................................ 102

Figure 7-3 Difference between race-income groups on select bicycling barriers, percent stating "big

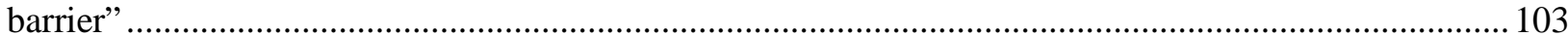

Figure 7-4 Average number of items rated as a "big barrier” to bicycling, by race and income groups .. 104

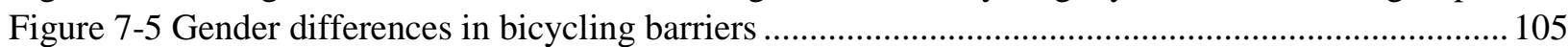

Figure 8-1 Differences in bike share information sources by race and income groups ......................... 110

Figure 8-2 Bike share intentions by source of information................................................................117

Figure 8-3 Bike share opinions — demographic differences........................................................ 127

Figure 9-1 Recreational and utilitarian reasons for trying bike share, differences by race-income groups

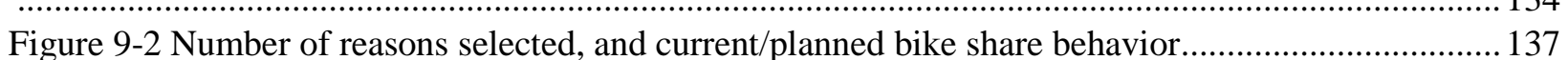

Figure 9-3 Efficacy of potential program changes, race and income differences...................................141

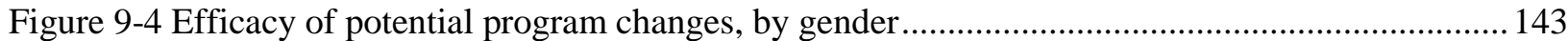

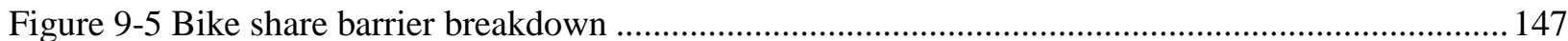

Figure 9-6 Race and income differences for bike share barriers ................................................... 150

Figure 9-7 Average number of items rated as a "big barrier" to bike share, by race and income groups 151

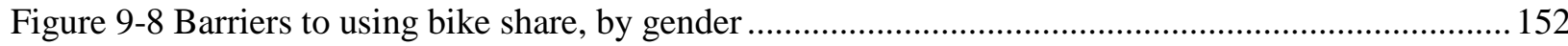

Figure 10-1 Increases in Citi Bike use by area for existing and expansion stations ............................... 166 


\section{EXECUTIVE SUMMARY}

As bike sharing systems become increasingly common in U.S. cities, evidence has shown that higher income and white populations are overrepresented in both access to and use of bike share. A number of cities have initiated efforts to overcome underserved communities' barriers to access and use of bike share, including those working with the Better Bike Share Partnership (BBSP) to launch and test potentially replicable approaches to improve the equity-related outcomes. This research project studied BBSP efforts to better understand the reasons some people are not currently participating in bike sharing, the perceptions and attitudes of low-income populations and people of color toward bicycling and bike share, what strategies can be effective in attracting lower-income and diverse users, and what benefits bike share can offer these potential participants.

This report describes findings from a survey of residents living near bike share stations placed in underserved neighborhoods targeted for outreach by the BBSP program. The neighborhoods were in Philadelphia, Chicago, and Brooklyn. The survey also included residents in control areas that did not receive BBSP targeted outreach in two of the cities. The neighborhoods targeted for outreach included in the study are majority-minority (79-94\% people of color) and lower-income (36-61\% of households under $150 \%$ of the poverty level). There were 1,885 total responses, an $11 \%$ response rate. Respondents matched area demographics on race/ethnicity and income quite well, but were somewhat more likely to be women, older and more highly educated. Findings are drawn primarily from the analysis of data from adults in the target areas who were under 65 years old and physically able to ride a bicycle. Of those respondents who provided income and race information ( $\mathrm{n}=779), 42 \%$ are lower-income (defined as $300 \%$ of poverty or below) people of color, $27 \%$ are higher-income (above $300 \%$ of poverty) people of color, 6\% are lower-income and white (not Hispanic), and 25\% are higher-income and white.

Both people of color and lower-income residents cited more barriers to bicycling generally and to using bike share than higher-income white residents. The extent of the barriers sometimes differed by race and/or income, though some barriers were universal.

The biggest barrier to bicycling generally is concern about traffic safety, regardless of race or income. Nearly half (48\%) of residents cited this as a big barrier to riding a bike in their neighborhood. For respondents of color, personal safety is also a concern. Race is an important factor in whether respondents feel their personal safety could be compromised, either as a victim of crime or as a target for police attention. For people of color, being lower-income further exacerbated safety concerns. For example, 22\% of lower-income respondents of color stated that a big barrier to riding was that doing so could cause them to be harassed or a victim of crime. This compared to $17 \%$ of higher-income people of color and 7\% of higher-income white residents.

Bike share may address many of the other major barriers to bicycling for these residents. Some of the most common barriers to bicycling cited by lower-income people of color included not having a bike or related gear (47\%), not having a safe place to leave a bike where they need to go (36\%), the expense of buying a bike or related gear (41\%), not having a safe place to store a bike at home (32\%), not knowing a place to get a bike fixed (23\%), and worries about something going wrong with a bike, such as a flat tire (20\%). Nearly all of these barriers were more significant for lower-income people of color than for other respondents, and many of these factors were among the top ten barriers to bicycling. They are all barriers that can be addressed with bike share.

There is strong interest among residents in these neighborhoods in using bike share more in the future. Over half (56\%) of lower-income respondents of color agreed that they would like to use bike 
share more than they currently do. In addition, $11 \%$ of all residents expected to become a member in the next 12 months, with no differences between race and income groups. Residents also generally have positive attitudes about bicycling and bike share. A large majority of all residents (73\%) agreed that the city's bike share system "is useful for people like me.” Agreement among lower-income people of color was equally high (74\%). In terms of reasons for using bike share, getting exercise was cited by $71 \%$ of the lower-income respondents of color as a reason they would consider using bike share, a rate much higher than other respondent groups. Being able to ride with friends and family was cited by $48 \%$ of lower-income respondents of color, again higher than other demographic groups.

High costs of membership and concerns about liability for the bicycle were a big barrier for about half of lower-income people of color (48\% and 52\% respectively), compared to 33\% and 31\% of higherincome respondents of color and only $18 \%$ and $10 \%$ of higher-income white respondents. These figures reveal that concerns about price and over being charged for a problem with the bike are related to both income, but also and race.

Another set of barriers relates to lack of knowledge or incorrect knowledge. Most noticeably, 34\% of lower-income respondents of color said that not knowing enough about how to use bike share was a big barrier to using it, compared to $19 \%$ of higher-income respondents of color and $7 \%$ of higher-income white residents. There were several areas of notable misconceptions about the bike share systems. Although none of the cities has a mandatory helmet law for bicycle riders, $18 \%$ of respondents thought that a helmet was required to use the bike share system. Lower-income respondents were more likely to make this incorrect assumption. Most respondents indicated that they had "no idea" about the cost of using the system and the availability of the reduced-price membership or pass option. Across these and a number of other questions, respondents in the lower-income people of color group were more likely to indicate that they didn't know whether the statements were true or not. Finally, even when cash options are available, most residents think a credit card is required to use bike share (and lower-income people of color were least likely to know cash was an option, if it was).

More personal sources of information may be more effective. While fewer residents received information from more personal sources, such as talking with someone from the bike share outreach program or at a community center or faith-based organization, these sources were correlated with higher rates of intention to use bike share in the future. Residents who received information via more passive modes, such as the bike share station, bus shelter ads, billboards, television, and radio, had lower rates of intention to use bike share.

Overall, there were far more similarities in resident responses between the three cities than differences. This indicates that the findings are likely generalizable to other cities, particularly to people of color and lower-income populations. Of course, there are always geographic differences that will affect bicycling and bike share use. In addition, our sample of people of color was predominantly Black and non-Hispanic, though we found few differences in responses between the Hispanic and Black respondents. Still, our sample does not allow us to draw conclusions about other specific races or ethnicities. This is an area ripe for additional research. Finally, we found that race and income often influence responses to bicycling and bike share in different ways. Differences in behavior and opinions sometimes correlated with income, sometimes with race, and sometimes with race and income combined. These complexities must be considered when developing programs and policies to increase equity in bike share. 


\section{INTRODUCTION}

\subsection{Background}

Over the past ten years, public bike share systems have transitioned from operating in a few select European cities to expanding in North America at a pace of nearly two dozen cities per year (Ahillen et al., 2015). A 2015 survey found over 800 bike share programs across the world (Fishman, 2016). By our own best estimate, there are at least 153 public bike share systems operating or near-launch in the U.S. as of 2017. Current public bike share systems — sometimes referred to as "third generation" — use electronic docking stations and wireless communications for bicycle pickup, drop-off and tracking (Shaheen et al., 2013). This latest wave of bike sharing typically requires a credit card for payment, and the user can check out a bike for a 30- to 60-minute interval before returning it to another station or incurring overage fees (Fishman, 2016).

As cities plan and launch bike share systems, usually with growth strategies but limited initial resources, trade-offs are often made between building dense networks of stations in and around urban centers, and on focusing systems and stations in neighborhoods where residents may currently be underserved by existing shared and public mobility options. The focus on urban centers, which in many cases already contain more bicycle infrastructure or logical commuter corridors, as well as populations more inclined to ride a bicycle, may be more likely to attract young professionals already interested in cycling. This approach is often predicated on the assumption that a successful launch and base of ridership must be established to gain momentum and support before expanding the system to other neighborhoods. However, this approach also risks neglecting communities where residents are most in need of mobility options. In fact, existing research has shown that, across a variety of U.S. systems, bike share service areas disproportionately serve white populations versus communities of color, especially African American populations (Ursaki and Aultman-Hall, 2016).

The Better Bike Share Partnership (BBSP) — a collaboration among the City of Philadelphia, the Bicycle Coalition of Greater Philadelphia, the National Association of City Transportation Officials (NACTO), and PeopleForBikes — has been working with cities around the U.S. to bring the benefits of bike share to underserved communities, particularly communities of color and lower-income individuals, while promoting increased levels of system use. The BBSP collaboration is made possible by funding from The JPB Foundation. The primary efforts have involved the placement of bike share stations in lower-income and racially diverse neighborhoods, targeted outreach of these communities that have been traditionally underserved by bike share, and changes to the payment systems, pricing structures and, in some cases, significantly reduced prices for memberships or passes.

\subsection{Research objectives}

This research was undertaken in cooperation with the BBSP to evaluate the effectiveness of their efforts and to better understand the challenges and opportunities of expanding the reach of bike share systems to be more equitable. The key research questions we set out to answer include:

- How effective are the various efforts employed to increase the equity of bike share systems?

- Are the promotion and outreach efforts reaching target populations?

- Which interventions are most effective in increasing awareness and use of bike share?

- What differences are there in awareness, perceptions and use of bike share between residents in neighborhoods receiving targeted outreach compared to other (“control”) neighborhoods? 
- How does bike share work for specific underserved and understudied populations, and how might needs and use patterns differ from other user groups?

- Are there specific barriers and opportunities among these populations that either match, extend or differ from those identified in existing studies?

- Which improvements or changes to the system or outreach may provide the largest returns in terms of actual or planned use of bike share in underserved communities?

\subsection{Structure of research and reports}

The overall research project has three main components, each collecting information from a different set of individuals:

- Bike Share Owners and Operators. To better understand current efforts nationally to make bike share more equitable, we first conducted a survey of bike share system owners and operators. The survey asked about equity policies and metrics, the degree to which equity considerations affected a variety of system practices, what the existing barriers to utilizing bike share are for target populations, and what challenges the bike share system entity faces in addressing those barriers. The findings from that survey are available in a separate report (Howland et al., 2017).

- Residents. The primary research effort was a survey of residents living in predominantly low income and/or nonwhite neighborhoods in Philadelphia, Chicago, and Brooklyn that had been targeted by efforts associated with the BBSP. The survey sought to understand how these residents perceive and interact with bike share and bicycling more generally. The survey used a random sample of people living near bike share stations in the neighborhoods, rather than people already known to have used or shown interest in bike share. The resident survey was designed to answer all of the research questions listed above, and allows us to learn from people who have and have not used bike share. The findings from the resident survey are in this report.

- Bike Share Users. Finally, we conducted a survey of bike share users and other people who have had some interaction with BBSP outreach efforts. The objective of this survey is to get a more in depth understanding the population reached by the efforts and how the efforts may have influenced their behavior. The findings from that survey will be released in a separate report.

All three reports will be available at the project website: http://rec.pdx.edu/research/project/884.

This report focuses on the second of these three components - the resident survey. Because many of the respondents were not current users of bike share, the results provide insights into perceptions, concerns, and barriers for these individuals, along with some ideas about how people learn about bicycling and bike share, and what might motivate them to try bike share. 


\section{Literature ReVIEW}

In less than ten years, public bike share systems have increased from operating in a few select European cities to expanding in North America at an increasing pace, with over new 40 bike share systems launched in 2016. As of mid-2017, 153 bike share systems are in operation (or due to be launched this year) in the U.S., including 20 systems of 500 or more bicycles, and 50 systems of 100 to 499 bikes (Table 2-1). Smaller systems (under 100 bikes) are also becoming increasingly common, with over 21 such systems launched in 2016 alone.

Table 2-1 U.S. Bike Share Systems by Launch Year

\begin{tabular}{|c|c|c|c|c|c|}
\hline Launch Year & $>=\mathbf{5 0 0}$ bikes & $\mathbf{1 0 0 - 4 9 9}$ bikes & $<\mathbf{1 0 0}$ bikes & University & Total \\
\hline 2009 & 0 & 0 & 0 & 1 & 1 \\
\hline 2010 & 3 & 0 & 1 & 2 & 6 \\
\hline 2011 & 2 & 5 & 0 & 0 & 7 \\
\hline 2012 & 0 & 6 & 2 & 0 & 8 \\
\hline 2013 & 3 & 4 & 4 & 2 & 13 \\
\hline 2014 & 3 & 5 & 5 & 4 & 17 \\
\hline 2015 & 4 & 8 & 10 & 7 & 29 \\
\hline 2016 & 4 & 9 & 21 & 7 & 41 \\
\hline 2017 (including planned) & 1 & 13 & 15 & 2 & 31 \\
\hline Total & 20 & 50 & 58 & 25 & 153 \\
\hline
\end{tabular}

Note: Table based on compilation of bike share systems, viewable at https://goo.gl/8PrGnF.

Research interest in bike share has also increased rapidly, with the number of new studies more than tripling from 31 during 2007-2010, to 98 during 2011-2014, and 122 in 2015-2016 alone (Transportation Research Integrated Database). While most academic research to date has focused either on the complex logistics of designing and operating systems or on broad comparisons across systems, investigations of system users and local impacts have become more common.

The literature review that follows places our research in the context of existing studies, particularly those reporting on potential equity or underserved populations. We considered studies of systems throughout North America, the United Kingdom, and Ireland because of broad similarities in equity issues, populations, and bike share operations in those regions. We included any work that could speak to equity issues in bike share, whether they focused on bike share users, members, or nonusers. Excluded were studies confined to operating logistics and those that lacked demographic information to make equityrelated distinctions. Also included are selected studies of broader bicycling issues that overlap with use and barriers to use of bike share.

\subsection{Existing studies of equity and bike share demographics}

Despite the appeal and growth of bike share in the U.S., there is evidence that certain groups are participating less and enjoying fewer benefits from this new transportation option than the general population. Table 2-2 presents findings related to equity from existing studies that focus on the demographics of bike share membership, use, and nonuse. Most quantitative analysis of bike share can be categorized as: 1) comparisons of member and user characteristics to one another and to more general populations; 2) comparisons of the number of trips per station by station-area characteristics; and 3) comparisons of individual members, users, and nonusers by participation in bike share and frequency of 
use. An important distinction is often made between regular users with memberships and casual users who purchase "walk up” trips or short-term passes. Data collection methods include mail or Internet survey questionnaires and bike share station intercept surveys of users or passersby. Results of broader surveys and Census data are often used to compare bike share participants with the general population. Equity and underserved groups of interest have been defined in various ways, most commonly considering race/ethnicity, income, and gender. A smaller number of qualitative studies used interviews or focus groups of particular stakeholders to identify barriers to participation among select populations.

In general, existing studies support the conclusion that there are disparities in bike share participation by race, income, gender, age, and education level. People of color, along with lower-income, female, older and less-educated groups appear to be under-represented among bike share users, and even less likely to become regular members. Part of the divide can be attributed to a lack of bike share stations in communities where a greater share of residents are from these demographic groups, but further evidence suggests station access is necessary but not sufficient to overcome persistent barriers to use and membership.

The following subsections summarize the evidence in the literature by equity characteristics of interest. We refer to findings as statistically significant based on a 5\% significance level $(\mathrm{p}<0.05)$. 
Table 2-2 Studies Related to Bike Share User, Member, and Nonuser Demographics

\begin{tabular}{|c|c|c|c|c|c|c|c|c|c|}
\hline Authors & Location & $\begin{array}{l}\text { Units of } \\
\text { analysis } \\
\text { (N) }\end{array}$ & $\begin{array}{l}\text { Equity groups } \\
\text { of interest ( } n)\end{array}$ & $\frac{n}{0}$ & $\frac{n}{\frac{n}{8}}$ & $\begin{array}{l}n \\
8 \\
0 \\
0 \\
0 \\
0 \\
0 \\
0 \\
0\end{array}$ & $\begin{array}{l}\frac{n}{0} \\
\frac{0}{2} \\
\frac{0}{2}\end{array}$ & Data sources & Selected Equity Findings ${ }^{1}$ \\
\hline This study & $\begin{array}{l}\text { Neighborhoods } \\
\text { in Brooklyn, } \\
\text { New York; } \\
\text { Chicago; and } \\
\text { Philadelphia }\end{array}$ & $\begin{array}{l}\text { Individuals } \\
(1,854)\end{array}$ & $\begin{array}{l}\text { People of color } \\
(n=1,327) \\
\text { Below } 300 \% \text { of } \\
\text { poverty line } \\
(n=926)\end{array}$ & & $x$ & $x$ & $x$ & $\begin{array}{l}\text { Mail/ Web } \\
\text { survey of } \\
\text { residents } \\
\text { within } 1 / 4 \mathrm{mi} \\
\text { of station in } \\
\text { select } \\
\text { neighborhoods }\end{array}$ & \\
\hline $\begin{array}{l}\text { Bachand-Marleau, } \\
\text { Lee and El- } \\
\text { Geneidy } 2012\end{array}$ & $\begin{array}{l}\text { Montreal, } \\
\text { Canada }\end{array}$ & $\begin{array}{l}\text { Individuals } \\
(1,432)\end{array}$ & None & & $x$ & $x$ & $x$ & $\begin{array}{l}\text { Web survey } \\
\text { (section of } \\
\text { regional } \\
\text { travel survey) }\end{array}$ & $\begin{array}{l}\text { Income: <CAD } \$ 40,0000.5 \text { times odds of using } \\
\text { bike share, compared with higher incomes } \\
\text { Women: } 0.6 \text { times the odds of using, compared } \\
\text { with men; n.s. for frequency of use } \\
\text { Age: } 0.97 \text { times the odds of using for each } \\
\text { additional year older; n.s. for frequency } \\
\text { Stations siting (w/in } 500 \mathrm{~m} \text { of home): } 3.2 \\
\text { times the odds } \\
\text { Other motivations: convenience, to avoid } \\
\text { maintenance and risk of theft }\end{array}$ \\
\hline Buck 2012 & $\begin{array}{l}20 \text { North } \\
\text { American } \\
\text { Cities }\end{array}$ & $\begin{array}{l}\text { Bike Share } \\
\text { System } \\
\text { Managers } \\
\text { (20) }\end{array}$ & $\begin{array}{l}\text { "low-income } \\
\text { and minority } \\
\text { groups" }\end{array}$ & $\mathrm{x}$ & & & & Web survey & $\begin{array}{l}\text { Bike share systems pursuing equity goals in } \\
\text { many areas } \\
\text { Funding equity programs a challenge }\end{array}$ \\
\hline
\end{tabular}




\begin{tabular}{|c|c|c|c|c|c|c|c|c|c|}
\hline Authors & Location & $\begin{array}{l}\text { Units of } \\
\text { analysis } \\
\text { (N) }\end{array}$ & $\begin{array}{l}\text { Equity groups } \\
\text { of interest (n) }\end{array}$ & 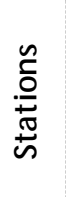 & $\begin{array}{l}\frac{n}{8} \\
\frac{8}{20} \\
\frac{\pi}{2}\end{array}$ & $\begin{array}{l}\frac{n}{8} \\
\frac{n}{2} \\
\frac{\pi}{00} \\
0 \\
0 \\
8\end{array}$ & $\begin{array}{l}n \\
0 \\
0 \\
\frac{n}{2} \\
\frac{0}{2}\end{array}$ & Data sources & Selected Equity Findings ${ }^{1}$ \\
\hline Buck et al. 2013 & $\begin{array}{l}\text { Washington, } \\
\text { D. C. }\end{array}$ & $\begin{array}{l}\text { Cyclists } \\
(832) \\
\text { Members } \\
(5,464) \\
\text { Casual } \\
\text { Users (340) }\end{array}$ & $\begin{array}{l}\text { African- } \\
\text { American } \\
\text { (n=approx. 268) } \\
\text { Hispanic } \\
\text { (n=approx. 468) }\end{array}$ & & $\mathrm{x}$ & $\mathrm{x}$ & & $\begin{array}{l}2011 \text { web } \\
\text { survey of } \\
\text { members } \\
2011 \text { web } \\
\text { survey of } \\
\text { casual users }\end{array}$ & $\begin{array}{l}\text { African-American: under-represented among } \\
\text { casual users }(-36 \%) \text { and members }(-56 \%) \\
\text { relative to regional cyclists } \\
\text { Hispanic: over-represented among casual users } \\
(+29 \%) \text { and members }(+44 \%) \text { relative to regional } \\
\text { cyclists } \\
\text { Income: Members have significantly lower } \\
\text { incomes than regional cyclists. } \\
\text { Women: Sig. higher share of bike share casual } \\
\text { users }(+49 \%) \text { and members }(+30 \%) \text { than all } \\
\text { regional cyclists } \\
\text { Age: Under } 34 \text { significantly over-represented } \\
\text { among both casual users }(+104 \%) \text { and members } \\
(+126 \%) \text { relative to cyclists in region }\end{array}$ \\
\hline Daddio 2012 & $\begin{array}{l}\text { Washington, } \\
\text { D.C. }\end{array}$ & $\begin{array}{l}\text { Bike share } \\
\text { stations } \\
(97)\end{array}$ & $\begin{array}{l}\text { Nonwhite } \\
\text { population } \\
\text { Median income }\end{array}$ & $\mathrm{x}$ & & & & $\begin{array}{l}\text { Station trip } \\
\text { data, Census }\end{array}$ & $\begin{array}{l}\text { Nonwhite (up to } 1 / 4 \text { mi station service area): } \\
\text { significant but very slight negative effect } \\
\sim 0.5 \% \text { ridership } \\
\text { Income: not a significant predictor of ridership } \\
\text { Age: } 20-39 \text { population significant increase }\end{array}$ \\
\hline Fuller et al. 2011 & Montreal & $\begin{array}{l}\text { Individuals } \\
(2,502)\end{array}$ & None & & $x$ & $x$ & & Phone survey & $\begin{array}{l}\text { Gender: not significant } \\
\text { Age: }<34 \text { sig. more likely to use } \\
\text { Education: University degree } 2.3 \text { times the } \\
\text { odds of HS or less } \\
\text { Station siting: w/ in } 250 \mathrm{~m} \text { of a station } 2 \text { times } \\
\text { the odds of using }\end{array}$ \\
\hline $\begin{array}{l}\text { Goodman and } \\
\text { Cheshire } 2014\end{array}$ & $\begin{array}{l}\text { London, } \\
\text { England }\end{array}$ & $\begin{array}{l}\text { Bike share } \\
\text { users } \\
(72,000)\end{array}$ & $\begin{array}{l}\text { Reside in highly } \\
\text { deprived area } \\
\text { based on } \\
\text { standard set of } \\
\text { items }\end{array}$ & & $\mathrm{x}$ & $\mathrm{x}$ & & $\begin{array}{l}\text { Bike share } \\
\text { user trip data }\end{array}$ & $\begin{array}{l}\text { Income: Residents of deprived areas use bike } \\
\text { share when stations sited there }\end{array}$ \\
\hline
\end{tabular}




\begin{tabular}{|c|c|c|c|c|c|c|c|c|c|}
\hline Authors & Location & $\begin{array}{l}\text { Units of } \\
\text { analysis } \\
\text { (N) }\end{array}$ & $\begin{array}{l}\text { Equity groups } \\
\text { of interest (n) }\end{array}$ & 是 & $\begin{array}{l}\frac{n}{8} \\
\frac{8}{20} \\
\frac{0}{2 \pi}\end{array}$ & 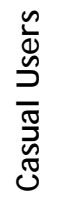 & $\begin{array}{l}n \\
\frac{n}{8} \\
\frac{6}{7} \\
\frac{8}{0} \\
2\end{array}$ & Data sources & Selected Equity Findings ${ }^{1}$ \\
\hline Hannig 2015 & $\begin{array}{l}\text { Milwaukee } \\
\text { (WI) } \\
\text { Twin Cities } \\
\text { (MN) }\end{array}$ & $\begin{array}{l}\text { Community } \\
\text { partners } \\
(26)\end{array}$ & $\begin{array}{l}\text { "underserved } \\
\text { communities" }\end{array}$ & & & & & Interviews & $\begin{array}{l}\text { Promoting bike share for recreation may be } \\
\text { more effective than transportation use as an } \\
\text { entry point in underserved communities. } \\
\text { Efforts need to consider women, families, and } \\
\text { groups. } \\
\text { Need to carefully present cost and value of } \\
\text { bike share relative to public transit. }\end{array}$ \\
\hline $\begin{array}{l}\text { Hoe and } \\
\text { Kaloustian } 2014\end{array}$ & Philadelphia & $\begin{array}{l}\text { Individuals } \\
(60)\end{array}$ & $\begin{array}{l}1-, 2 \text {-person } \\
\text { households } \\
<150 \% \text { poverty } \\
\text { line ( } n=15 \text { ) } \\
\text { 3+-person } \\
\text { households } \\
<200 \% \text { poverty } \\
\text { line ( } n=45 \text { ) } \\
\text { Also considered } \\
\text { African- } \\
\text { Americans } \\
\text { ( } n=40 \text { ) and } \\
\text { women }(n=30)\end{array}$ & & & & $\mathrm{x}$ & Focus groups & $\begin{array}{l}\text { Think of/ use bikes more for } \\
\text { recreation/ exercise } \\
\text { Generally interested in bike share, but safety } \\
\text { (theft and traffic), convenience, and lack of } \\
\text { bike culture are key barriers }\end{array}$ \\
\hline Hoe $2015(a)$ & Philadelphia & $\begin{array}{l}\text { Individuals } \\
\text { familiar } \\
\text { with bike } \\
\text { share } \\
\text { system } \\
\text { (530) }\end{array}$ & $\begin{array}{l}\text { Less than } 150 \% \\
\text { of poverty line } \\
\text { (1-, 2-person } \\
\text { HHs) or } 200 \% \\
(3+\text { person HHs) } \\
(n=506)\end{array}$ & & $x$ & $x$ & $x$ & $\begin{array}{l}\text { Station } \\
\text { intercept } \\
\text { surveys }\end{array}$ & $\begin{array}{l}\text { African-American: more likely to learn from } \\
\text { TV and family. } \\
\text { Lower-income: more likely to learn from } \\
\text { people they know or TV. } \\
65 \% \text { of people know about Indego but } \\
\text { knowledge limited. Main reason for not using } \\
\text { was lack of information; many nonusers saw } \\
\text { Indego as cost-prohibitive }\end{array}$ \\
\hline
\end{tabular}




\begin{tabular}{|c|c|c|c|c|c|c|c|c|c|}
\hline Authors & Location & $\begin{array}{l}\text { Units of } \\
\text { analysis } \\
\text { (N) }\end{array}$ & $\begin{array}{l}\text { Equity groups } \\
\text { of interest }(n)\end{array}$ & 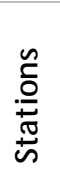 & $\begin{array}{l}\frac{n}{8} \\
\frac{8}{2} \\
\sum\end{array}$ & $\begin{array}{l}\frac{n}{8} \\
\frac{8}{2} \\
\frac{\pi}{0} \\
\frac{5}{6} \\
0\end{array}$ & $\begin{array}{l}n \\
\frac{n}{2} \\
\frac{n}{2} \\
\frac{1}{2} \\
2\end{array}$ & Data sources & Selected Equity Findings ${ }^{1}$ \\
\hline Hoe 2015 (b) & Philadelphia & $\begin{array}{l}\text { Individuals } \\
\text { familiar } \\
\text { with } \\
\text { system, } \\
\text { who live or } \\
\text { work } \\
\text { within 10- } \\
\text { min walk } \\
\text { (510) }\end{array}$ & $\begin{array}{l}\text { Nonwhite } \\
(n=a p p r o x .413) \\
\text { Less than } 150 \% \\
\text { of poverty line } \\
\text { (1-, 2-person } \\
\text { HHs) or } 200 \% \\
(3+\text { person } \mathrm{HHs}) \\
(n=195)\end{array}$ & & $\mathrm{x}$ & $\mathrm{x}$ & $\mathrm{x}$ & $\begin{array}{l}\text { Station } \\
\text { intercept } \\
\text { survey }\end{array}$ & $\begin{array}{l}\text { Race: Those identifying as white significantly } \\
\text { more likely to have used bike share than those } \\
\text { identifying as Black ( } 31 \% \mathrm{v} \text {. 19\%); significantly } \\
\text { larger shares of Black (57\%) and Hispanic ( } 80 \% \text { ) } \\
\text { users had used for recreation (vs. } 29 \% \text { of white } \\
\text { users); } 18 \% \text { of members Black v. } 58 \% \text { of casual } \\
\text { users; nonwhite respondents more likely to } \\
\text { learn about bike share from TV or bus ads } \\
\text { Income and Gender: no significant differences } \\
\text { between users/ nonusers or casual/ members } \\
\text { Age: average user sig. younger than nonusers } \\
\text { (-6 years), and members sig. younger than } \\
\text { casual users }\end{array}$ \\
\hline $\begin{array}{l}\text { Murphy and Usher } \\
2015\end{array}$ & $\begin{array}{l}\text { Dublin } \\
\text { (Ireland) }\end{array}$ & $\begin{array}{l}\text { Individuals } \\
(360)\end{array}$ & $\begin{array}{l}\text { Income less } \\
\text { than 30k } \\
\text { euro/ year } \\
\text { ( } n=\text { approx. } 66 \text { ) } \\
\text { Female users } \\
\text { ( } n=\text { approx. } 79 \text { ) }\end{array}$ & & $\mathrm{x}$ & $\mathrm{x}$ & & $\begin{array}{l}\text { Station } \\
\text { intercept } \\
\text { survey }\end{array}$ & $\begin{array}{l}\text { Gender: only } 22 \% \text { female } \\
\text { Income: only } 17.2 \% \text { under } 30 \mathrm{k} \text { euro/ year } \\
\text { Age: } 59 \% \text { between } 25 \text { and } 36 \text {, only } 5 \% \text { over } 48\end{array}$ \\
\hline $\begin{array}{l}\text { Ogilvie and } \\
\text { Goodman } 2012\end{array}$ & London (UK) & $\begin{array}{l}\text { Individuals } \\
(99,615)\end{array}$ & $\begin{array}{l}\text { Most deprived } \\
\text { income quintile } \\
\text { areas } \\
\text { Nonwhite British } \\
\text { Females } \\
\text { registered }\end{array}$ & & $x$ & $x$ & & $\begin{array}{l}\text { System trip } \\
\text { data for } \\
\text { registered } \\
\text { users, Census } \\
\text { area data for } \\
\text { demographics } \\
\text { (gender } \\
\text { imputed from } \\
\text { titles) }\end{array}$ & $\begin{array}{l}\text { Nonwhite British: more diverse areas slightly } \\
\text { over-represented among registered users } \\
(+5 \%) \text {, fewer trips made by users in more } \\
\text { diverse areas }(-0.6 / \mathrm{mo}) \\
\text { Income: Registered users less likely from most } \\
\text { deprived areas ( }-30 \% \text {, less likely to live close } \\
\text { to a station, }+0.9 \text { trips/ mo } \\
\text { Women: under-represented }(-47 \%), 0.64 \times \text { odds } \\
\text { making any trip, }-1.6 \text { trips/ mo } \\
\text { Station siting: } 0.77 \times \text { odds/ }-1.9 / \text { mo } 500-999 m \\
\text { from station, } 0.56 \times-3.2 / \text { mo } 1,000-1,999\end{array}$ \\
\hline
\end{tabular}




\begin{tabular}{|c|c|c|c|c|c|c|c|c|c|}
\hline Authors & Location & $\begin{array}{l}\text { Units of } \\
\text { analysis } \\
\text { (N) }\end{array}$ & $\begin{array}{l}\text { Equity groups } \\
\text { of interest }(n)\end{array}$ & $\frac{n}{0}$ & $\frac{n}{\frac{n}{8}}$ & 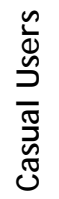 & $\begin{array}{l}n \\
\frac{n}{2} \\
\frac{1}{2} \\
\frac{1}{2}\end{array}$ & Data sources & Selected Equity Findings ${ }^{1}$ \\
\hline Rixey 2013 & $\begin{array}{l}\text { Washington } \\
\text { DC, Denver, } \\
\text { Minneapolis }\end{array}$ & $\begin{array}{l}\text { Bike share } \\
\text { stations } \\
(264)\end{array}$ & $\begin{array}{l}\text { Nonwhite } \\
\text { population, } \\
\text { median income }\end{array}$ & $x$ & & & & $\begin{array}{l}\text { Station trip } \\
\text { data, Census }\end{array}$ & $\begin{array}{l}\text { Nonwhite }(\mathbf{4 0 0 m}) \text { : model predicts } \sim 23 \% \text { drop } \\
\text { in ridership per } 10 \text { pctg. point increase in } \\
\text { proportion nonwhite } \\
\text { Median income }(\mathbf{4 0 0} \mathrm{m}): \text { predicts } \sim 0.6 \% \\
\text { increase in ridership per } \$ 1,000 \text { increase in } \\
\text { median income } \\
\text { Education: } n \text {. s. share w/ Bachelor's Degree } \\
\text { Proximity: Stations w/ in } 4,800 \mathrm{~m}: \sim 3 \% \text { increase } \\
\text { Other: Retail jobs }(400 \mathrm{~m}):-2.6 \% \text { per } 100\end{array}$ \\
\hline $\begin{array}{l}\text { Shaheen, } \\
\text { Christensen and } \\
\text { Viegas de Lima } \\
2015\end{array}$ & San Francisco & $\begin{array}{l}\text { Individuals } \\
(170)\end{array}$ & $\begin{array}{l}\text { Nonwhite } \\
\text { ( } n=\text { approx. } 32 \\
\text { users) } \\
\text { Income } \$ 15 \mathrm{k} \\
\text { (n=approx. } 5 \\
\text { users) }\end{array}$ & & & $x$ & $x$ & $\begin{array}{l}\text { Station } \\
\text { intercept } \\
\text { survey (2 } \\
\text { stations) }\end{array}$ & $\begin{array}{l}\text { Nonwhite: made up } 5 \text { pctg. points more casual } \\
\text { users than members } \\
\text { Income: } \$ 15 \mathrm{k} 5 \% \text { casual users vs. } 1 \% \\
\text { members, }>\$ 200 \mathrm{k} \text { made up } 24 \% \text { of annual } \\
\text { members vs. } 13 \% \text { of casual users } \\
\text { Women: } 35 \% \text { of casual users vs. } 28 \% \text { members } \\
\text { Age: Casual users younger ( }<30) \text {; annual } \\
\text { members older ( }>40 \text { ) } \\
\text { Education: } 87 \% \text { members and } 82 \% \text { casual users } \\
\text { have at least bachelor's degree, versus } 30 \% \text { of } \\
\text { all city residents } 25 \text { or older }\end{array}$ \\
\hline $\begin{array}{l}\text { Shaheen et al. } \\
2012\end{array}$ & $\begin{array}{l}\text { Minneapolis, } \\
\text { Toronto, } \\
\text { Montreal, } \\
\text { Washington } \\
\text { DC }\end{array}$ & $\begin{array}{l}\text { Individuals } \\
(10,661)\end{array}$ & $\begin{array}{l}\text { African- } \\
\text { American } \\
(n=243) \\
\text { Hispanic }(n=391) \\
\text { Income } \$ 35 k \\
(n=?)\end{array}$ & & $x$ & & & $\begin{array}{l}\text { Web survey of } \\
\text { members }\end{array}$ & $\begin{array}{l}\text { All: } 98 \% \text { agree that bike share enhances public } \\
\text { transportation, }>60 \% \text { agree that they get more } \\
\text { exercise since joining }\end{array}$ \\
\hline
\end{tabular}




\begin{tabular}{|c|c|c|c|c|c|c|c|c|c|}
\hline Authors & Location & $\begin{array}{l}\text { Units of } \\
\text { analysis } \\
\text { (N) }\end{array}$ & $\begin{array}{l}\text { Equity groups } \\
\text { of interest (n) }\end{array}$ & $\frac{n}{0}$ & $\begin{array}{l}\frac{n}{8} \\
\frac{8}{\pi} \\
\frac{\pi}{2}\end{array}$ & $\begin{array}{l}\frac{n}{8} \\
\frac{n}{3} \\
\frac{\pi}{00} \\
0 \\
0 \\
0\end{array}$ & $\begin{array}{l}n \\
0 \\
\frac{n}{2} \\
\frac{2}{2} \\
2\end{array}$ & Data sources & Selected Equity Findings ${ }^{1}$ \\
\hline \multirow[t]{6}{*}{$\begin{array}{l}\text { Shaheen et al. } \\
2014 \\
\text { (separate studies } \\
\text { in same report) }\end{array}$} & \multirow[t]{5}{*}{$\begin{array}{l}\text { Minneapolis, } \\
\text { Toronto, } \\
\text { Montreal, Salt } \\
\text { Lake City, } \\
\text { Mexico City }\end{array}$} & \multirow[t]{5}{*}{$\begin{array}{l}\text { Individuals } \\
(6,373)\end{array}$} & & \multirow[t]{5}{*}{$x$} & \multirow[t]{5}{*}{$x$} & \multirow[t]{5}{*}{$x$} & \multirow{5}{*}{\multicolumn{2}{|c|}{$\begin{array}{l}\text { Web member } \\
\text { survey } \\
\text { User intercept } \\
\text { survey }\end{array}$}} & $\begin{array}{l}\text { Income: } \$ 100 \mathrm{k} / \mathrm{yr} \text { or more } 67 \% 88 \% \text { higher } \\
\text { among members than general population (Mex: } \\
>9,714 \text { pesos } / \text { mo }+245 \% \text { ), } \$ 25 \mathrm{k} / \mathrm{yr} 41-81 \% \\
\text { lower than population (Mex: }<3,886 \text { pesos/ mo } \\
79 \% \text { lower) }\end{array}$ \\
\hline & & & & & & & & & \\
\hline & & & & & & & & & \\
\hline & & & & & & & & & $\begin{array}{l}\text { Women: } 10-42 \% \text { lower, except in Montreal } \\
\text { Age: } 25-34 \text { from } 105 \% \text { to } 121 \% \text { (Can/ Mex) and } \\
19 \% \text { to } 39 \% \text { (US) higher among members }\end{array}$ \\
\hline & & & & & & & & & $\begin{array}{l}\text { Education: Bachelor's degree or greater 39\% to } \\
98 \% \text { (Can/ US), } 221 \% \text { (Mex) higher among } \\
\text { surveyed members }\end{array}$ \\
\hline & $\begin{array}{l}23 \text { North } \\
\text { American } \\
\text { systems }\end{array}$ & $\begin{array}{l}\text { System } \\
\text { operators } \\
\text { (23) }\end{array}$ & & $x$ & & & & Interviews & $\begin{array}{l}\text { Station siting: } 43 \%(9) \text { equity was a factor, } 16 \% \\
\text { (3) to serve low-income communities, } 11 \%(2) \\
\text { equity factored into expansion plans } \\
\text { Other barriers: credit/ debit card } \\
\text { requirements, inexperience serving low-income } \\
\text { communities, specialized marketing needs }\end{array}$ \\
\hline $\begin{array}{l}\text { Smith, Oh, and Lei } \\
2015\end{array}$ & $\begin{array}{l}42 \text { U.S. Bike } \\
\text { Share Systems }\end{array}$ & $\begin{array}{l}\text { Census } \\
\text { tracts } \\
\text { served by } \\
\text { bike share }\end{array}$ & $\begin{array}{l}\text { Economic } \\
\text { hardship index } \\
\text { (unemployment, } \\
\text { age-related } \\
\text { dependency, } \\
\text { education, rent } \\
\text { burden, } \\
\text { crowded } \\
\text { housing, and } \\
\text { lack of health } \\
\text { insurance) }\end{array}$ & $x$ & & & & $\begin{array}{l}\text { Station } \\
\text { locations and } \\
\text { Census Tract } \\
\text { demographics }\end{array}$ & $\begin{array}{l}\text { Fewer than } 25 \% \text { of stations located in top } 60 \% \\
\text { of economic hardship tracts but considerable } \\
\text { variation across systems. }\end{array}$ \\
\hline
\end{tabular}




\begin{tabular}{|c|c|c|c|c|c|c|c|c|c|}
\hline Authors & Location & $\begin{array}{l}\text { Units of } \\
\text { analysis } \\
\text { (N) }\end{array}$ & $\begin{array}{l}\text { Equity groups } \\
\text { of interest (n) }\end{array}$ & 昂 & $\frac{n}{\frac{n}{8}}$ & $\begin{array}{l}\frac{n}{8} \\
\frac{8}{2} \\
\frac{\pi}{00} \\
0 \\
0 \\
0\end{array}$ & $\begin{array}{l}n \\
\frac{n}{8} \\
\frac{6}{2} \\
\frac{2}{2} \\
2\end{array}$ & Data sources & Selected Equity Findings ${ }^{1}$ \\
\hline $\begin{array}{l}\text { Stewart, J ohnson, } \\
\text { and Smith } 2013\end{array}$ & $\begin{array}{l}\text { Minneapolis } \\
\text { neighborhood }\end{array}$ & $\begin{array}{l}\text { Community } \\
\text { members }\end{array}$ & & & & & $x$ & Focus groups & $\begin{array}{l}\text { Most viewed Nice Ride positively, but saw lack } \\
\text { of knowledge, computer/credit card } \\
\text { requirements, and traffic safety, personal } \\
\text { safety, and time limits as barriers } \\
\text { Installing stations in low-income area not } \\
\text { sufficient to increase resident use }\end{array}$ \\
\hline $\begin{array}{l}\text { Ursaki and } \\
\text { Aultman-Hall } 2015\end{array}$ & $\begin{array}{l}\text { New York } \\
\text { City, Boston, } \\
\text { Washington } \\
\text { DC, Arlington, } \\
\text { Chicago, } \\
\text { Denver, } \\
\text { Seattle }\end{array}$ & $\begin{array}{l}\text { Census } \\
\text { block } \\
\text { groups }\end{array}$ & $\begin{array}{l}\text { USA Today } \\
\text { Diversity Index } \\
\text { Race (Black v. } \\
\text { white) } \\
\text { No college } \\
\text { degree } \\
\text { HH income } \\
\$ 20,000\end{array}$ & $x$ & & & & $\begin{array}{l}\text { Census } \\
\text { demographics } \\
\text { w/ in and } \\
\text { outside of } \\
\text { station areas } \\
(500 \mathrm{~m})\end{array}$ & $\begin{array}{l}\text { Black: \%Black lower w/ in service area of } 6 \text { of } 7 \\
\text { cities (Arlington, Virginia, exception; DC n.s.) } \\
\text { Income: share } \$ 20 \mathrm{k} \text { significantly higher in } \\
\text { service area for } 3 \text { of } 7 \text { cities, lower in } 1 \text { of } 7 \\
\text { (DC); }>\$ 100 \mathrm{k} \text { sig. higher in } 3 \text { of } 7 \text { cities, sig. } \\
\text { lower in } 1 \text { of } 7 \text { (Seattle) } \\
\text { Age: }>60 \text { less likely to live w/ in service area in } \\
\text { all } 7 \text { cities (sig. } 3 \text { of } 7 \text { ) } \\
\text { Education: \%college degree higher w/ in } \\
\text { service areas in all } 7 \text { cities (sig. } 4 \text { of } 7) ; \% \text { high } \\
\text { school sig. higher in only } 2 \text { of } 7 \text { (Chi, NYC), sig. } \\
\text { lower in } 3 \text { of } 7 \text { (DC, Den, Sea) }\end{array}$ \\
\hline Virginia Tech 2012 & $\begin{array}{l}\text { Washington } \\
\text { DC }\end{array}$ & $\begin{array}{l}\text { Individuals } \\
\text { (approx. } \\
340 \text { ) }\end{array}$ & $\begin{array}{l}\text { Nonwhite or } \\
\text { Hispanic } \\
\text { (n=approx. } 74)\end{array}$ & & $x$ & $x$ & & $\begin{array}{l}\text { Station } \\
\text { intercept } \\
\text { survey }\end{array}$ & $\begin{array}{l}\text { Black: casual users more likely to be nonwhite } \\
\text { than annual members ( } 5 \% \text { v. } 2 \%) \text {, but still much } \\
\text { lower than DC area ( } 50 \%) \\
\text { Hispanic: casual users slightly more likely to } \\
\text { be Hispanic ( } 4 \% \mathrm{v} .3 \% \text { than members, but still } \\
\text { lower than DC region ( } 9 \%) \\
\text { Women: more likely to be casual users ( } 52 \% \mathrm{v} \text {. } \\
33 \% \text {, also higher than DC region cyclists ( } 33 \%) \\
\text { Education: casual users more likely to have HS } \\
\text { diploma or less ( } 6 \% \text { compared with members } \\
\text { (<1\%), but well below DC ( } 53 \%) \\
\text { Age: no difference in casual users/ members } \\
\text { for } 18-34(59 \%)\end{array}$ \\
\hline
\end{tabular}

\footnotetext{
${ }^{1}$ sig. refers to statistically significant findings at the $5 \%$ level $(p \varangle 0.05)$; n. s. to findings of nonsignificance
} 


\subsubsection{Race}

People of color in North America have been found to participate considerably less in public bike share, compared to the white, non-Hispanic population. Part of this disparity has been attributed to station siting decisions, but even when controlling for station access, it appears that minority populations often participate at lower rates, and that stations in neighborhoods with larger shares of these groups have seen lower use. It has been suggested that additional economic and cultural factors may explain the remaining observed differences (Kodransky and Lewenstein, 2014).

Studies across a number of systems have shown wide disparities in participation by race. Generally speaking, Black populations experience the largest disparities, and racial divides are wider for bike share members than for casual, walk-up users. A study of members in Minneapolis, Salt Lake City, Toronto, and Montreal reported shares of Black members substantially lower than among the general population (Shaheen et al., 2014). Hispanic membership shares were also lower, except in Montreal. Surveys of Washington, D.C.'s, Capital Bikeshare system also found lower participation rates among Black residents, whether comparing to the D.C. area general population or regional cyclists (Buck et al., 2013; Virginia Tech University, 2012). Interestingly, the same studies found that Hispanics were underrepresented as Capital Bikeshare users relative to the general D.C. population, but over-represented relative to regional cyclists.

When people of color do participate in bike share, they are more likely to do so as casual users than as members (Buck et al., 2013; Shaheen, Christensen, and Viegas de Lima, 2015; Virginia Tech University, 2012). Findings differed in London, where areas with higher shares of nonwhite British (as opposed to nonwhite immigrants) were actually slightly over-represented among registered users (Ogilvie and Goodman, 2012). The different result may represent different system elements and programs as well as unique cultural histories and barriers for people of color in each place.

One factor that could explain racial differences in bike share use is station siting. Research has consistently shown that bike share use falls dramatically when stations are more than about a quarter-mile walk (Bachand-Marleau et al., 2012; Fuller et al., 2011; Ogilvie and Goodman, 2012). Ursaki and Aultman-Hall (2015) reported significantly lower-than-expected Black population shares within bike share service areas of 6 out of 7 U.S. cities (Arlington, Virginia, was the exception). Chicago, New York, and Boston were particularly unbalanced, with shares of Black residents near bike share stations less than half that of areas without stations.

Even in studies controlling for bike share proximity, participation appears to lag behind for people of color and in neighborhoods with fewer white residents. A 2015 study in Philadelphia sampled residents or employees within a 10-minute walk of specific bike share stations (Hoe, 2015b). Despite similar station access, Black respondents were significantly less likely to have used bike share than white respondents, and Black respondents still made up a much smaller share of members than casual users among those surveyed. Rixey (2013) modeled station use in Washington, D.C.; Denver; and Minneapolis, controlling for a range of neighborhood characteristics, including population and station density. For each 10 percentage-point increase in nonwhite population share, ridership for a neighborhood station was predicted to be about 23\% lower, with all else equal. Daddio (2012) also reported a significant negative association of station use with nonwhite population share in Washington, D.C., although the estimated effect was small. In London, Ogilvie and Goodman (2012), after controlling for a range of factors, found registered users in more racially diverse areas were likely to make somewhat fewer bike share trips $(-0.6$ trips/month). 


\subsubsection{Income and related factors}

Lower-income populations have also been thought to participate in bike share at lower rates, though the evidence is somewhat more mixed than for race. Shaheen et al. (2014) reported lower-than-expected membership rates across four U.S. and Canadian systems for those with annual income less than $\$ 25,000$, while those earning $\$ 100,000$ or more joined at rates considerably higher than their share in the general population. Similar disparities were noted for Mexico City's bike share. On the other hand, Buck et al. (2013) reported that compared with just the Washington, D.C. cycling population, Capital Bikeshare members had somewhat lower incomes. Ogilvie and Goodman (2012) found that residents of the most economically deprived areas of London made up about 30\% less than their expected share of bike share members, and Murphy and Usher (2015) found just 17\% of Dublin bike share users had incomes under EUR \$30,000 (about US\$25,000, at the time ${ }^{1}$ ) per year. In San Francisco, those earning less than $\$ 15,000$ per year made up $5 \%$ of surveyed casual users versus just $1 \%$ of Bay Area Bike Share members, while those earning more than $\$ 200,000$ comprised $24 \%$ of members but just $13 \%$ of walk-up users (Shaheen et al., 2015).

Income disparity in station siting has been noted as one barrier to bike share use. Ridership goals may favor wealthier, higher-density station locations. A study of 42 U.S. bike share systems found that the $60 \%$ of census tracts with greatest economic hardship contained less than $25 \%$ of bike share stations (Smith, Oh and Lei, 2015). However, Ursaki and Aultman-Hall (2015) presented more mixed results from New York City; Boston; Washington, D.C.; Arlington, Virginia; Chicago; Denver; and Seattle. The share of residents earning less than $\$ 20,000$ per year was actually significantly higher near bike share stations in three of the seven cities and significantly lower only in Washington, D.C. On the other hand, the share of those earning more than $\$ 100,000$ was also significantly higher near stations in three of the cities, but significantly lower only in Seattle. Research in London found residents of the most deprived areas were less likely to live close to a bike share station (Ogilvie and Goodman, 2012).

Once station proximity is considered, evidence of further barriers to participation among low-income groups is more mixed. A model of station ridership in three U.S. systems predicted a $0.6 \%$ increase in ridership for every \$1,000 rise in area median income (Rixey, 2013). Among a random sample of Montreal residents, those earning less than CAD $\$ 40,000$ per year had only half the odds of using BIXI bike share relative to those earning more, after controlling for station access and other variables (Bachand-Marleau et al., 2012). Other work has found no significant differences based on income once station access is considered (Daddio, 2012; Hoe, 2015b; Goodman and Cheshire, 2014). In London, members in the lowest-income areas actually made significantly more bike share trips, accounting for other factors (Ogilvie and Goodman, 2012). A limitation of these studies (with the exception of BachandMarleau et al., 2012 and Hoe, 2015b) is the use of aggregate area statistics that may not match the demographics of individual bike share users in those locations.

Three additional income-related factors - access to credit/debit cards, the Internet, and smartphones may serve as additional barriers to bike share participation. Most of the bike share programs require a credit card to be a member, but many people in the U.S. do not have a bank account (the "unbanked") or credit card. Approximately 7\% of U.S. households did not have a bank account in 2015, and among those earning less than \$30,000 per year, unbanked rates ranged from 12\% to 26\% (FDIC, 2015). Operators of 23 North American systems cited credit or debit card requirements and equipment liability responsibilities (via credit card payment holds) as one of the main issues to solve in extending access to lower-income users (Shaheen et al., 2014). For example, the Divvy bike share program in Chicago, like most systems,

\footnotetext{
${ }^{1}$ http://www.X-rates.com/historical/?from=USD\&amount=1\&date=2015-01-01
} 
initially required a credit card for use or membership. Carney (2012) noted that almost 300,000 Chicago residents did not have bank accounts (up to $30 \%$ in certain areas), and, as a result, were initially excluded from the program. Bike share systems in a handful of cities, including Chicago, have implemented cash payment systems to address this barrier.

Many programs also require Internet access to sign up for their memberships, but many lower-income residents do not have reliable access to the Internet at home. Just over a quarter of U.S. adults in households making less than \$30,000 per year report not using the Internet, compared with just 3\% in households earning $\$ 75,000$ or more (Perrin and Duggan, 2015). Some cities, including Philadelphia, have partnered with local organizations to provide Internet access and assistance for prospective bike share members.

Even those having regular Internet access might be disadvantaged in using modern bike share systems if they do not have a smartphone to, for example, aid in locating stations with available bikes or return slots. In U.S. households earning less than $\$ 30,000$ per year, only half of adults reported owning a smartphone, compared with $84 \%$ in household earning \$75,000 or more (Pew Research Center, 2015).

\subsubsection{Gender}

While women have not typically been identified as a targeted equity population, they have traditionally participated in both bicycling in general and bike share at lower rates than men. There is substantial evidence that women are under-represented among bike share members and users in many North American systems and in the United Kingdom and Ireland (Bachand-Marleau et al., 2012; Murphy and Usher, 2015; Ogilvie and Goodman, 2012; Shaheen et al., 2014). However, there are some exceptions. Studies in Montreal (Fuller et al., 2011; Shaheen et al., 2014) and Philadelphia (Hoe, 2015b) reported no significant gender differences in bike share use between women and men. Buck et al. (2013) found that both casual users and members of Capital Bikeshare had significantly larger shares of women than Washington, D.C., cycling overall.

Evidence is similarly mixed on whether female bike share users use the system more or less frequently than men. A study in Montreal (Bachand-Marleau et al., 2012) reported no significant difference in frequency of use by female users, while research in London (Ogilvie and Goodman, 2012) reported that women made between one and two fewer bike share trips per month compared with male members in similar locations. Buck et al. (2013) found that women were not significantly more likely to be casual users instead of members, but separate research on Capital Bikeshare users reported a considerably higher share of women among casual users in an intercept sample (Virginia Tech University, 2012).

The balance of evidence suggests women are less likely than men to participate in bike share but perhaps more likely than they are to bicycle in general. Among those women who do use bike share, evidence to date on their membership and frequency of use patterns is limited and mixed. To our knowledge, no studies have considered lower-income women or women of color separately in examining membership and use patterns.

\subsubsection{Age and education}

Bike share participation tends to be higher among younger, more educated populations. Whether focused on age in general (Bachand-Marleau et al., 2012; Hoe, 2015b) or specific age groups such as those under 34 (Buck et al., 2013; Fuller et al., 2011), those 25 to 34 (Shaheen et al., 2014), or those 20 to 39 (Daddio, 2012), research from a wide range of systems has found younger people consistently overrepresented as bike share members and users. Whether older adults are more likely to participate as members or casual users varies by study and system. Older users may be less likely (Hoe, 2015b), no less 
likely (Virginia Tech, 2102), or even more likely (Shaheen et al., 2015) to be members of bike share than casual users. Among older users, at least one study found no significant difference in frequency of use by age group (Bachand-Marleau et al., 2012). There is some evidence that older populations (over 60 years old) may be less likely to reside in areas served by a bike share station (Ursaki and Aultman-Hall, 2015).

Education has similarly been found positively correlated with bike share use and membership. Research across multiple systems has found increasing use among those with college degrees (Fuller et al., 2011; Shaheen et al., 2015; Shaheen et al., 2014). Less-educated residents may be more likely to participate as casual users rather than as members (Virginia Tech, 2012). Evidence varies on whether less-educated people are less likely to live near a bike share station. Ursaki and Aultman-Hall (2015) found college degrees were significantly more common near bike share stations in four of seven cities, while the share with high school educations only was significantly lower near stations in three of seven cities but actually higher in the two largest U.S. systems (Chicago and New York City). Controlling for station siting and other factors, Rixey (2013) found no relationship between station use and surrounding areas' education level. In general, less-educated residents seem to utilize bike share less, but there is considerable variation in usage patterns and station access across systems in North America.

\subsection{Use of and barriers to bicycling}

In addition to understanding existing research on issues related to equity in bike share, past findings related to equity in bicycling in general are also important to address. For this section, we focus on literature directly addressing bicycling and people of color. Table 2-3 summarizes several key findings from past research on bicycling use and barriers for low-income, Black, and Hispanic individuals.

A PeopleForBikes survey conducted in 2015 found that low-income respondents (making under \$20,000 per year) were the most likely to have ridden a bicycle in the past year, compared with other income groups. Hispanic respondents were also more likely to have reported riding in the past year (at 43\%), compared to 32\% of Black respondents and 33\% of white respondents. Among all respondents, people were twice as likely to ride for recreation as for transportation. Among those who had not ridden in the past year, Black and Hispanic respondents were more likely to have never ridden a bicycle before; they were also more likely to indicate that they intended to ride a bike in the future.

\subsubsection{Cost}

Barriers related to the cost of bicycling arise frequently in studies looking into equity and bicycling. The cost of buying a bicycle was perceived a barrier to bicycling by anywhere from a quarter to $70 \%$ of study participants (CCC, 2012; Dixon et al., 2015; Brown and Sinclair, 2016). Dixon et al. (2015) noted that being able to afford a good quality bike in particular was a barrier for many people, along with not having the right bicycling gear, such as a helmet or lock. Not being able to afford bike maintenance has been noted as a barrier as well (CCC, 2012; Brown and Sinclair, 2016). Not having a bike was a bigger barrier for Black respondents surveyed in large metro areas (52\%) than for white, non-Hispanic respondents (46\%) (NAR and PSU, 2015)

\subsubsection{Safety and the built environment}

Concern about traffic safety, including fear of being hit by a motor vehicle, consistently emerges as a top barrier to bicycling among Black and Hispanic individuals, with 31\% citing fear of a traffic collision as something that keeps them from bicycling more in one study (Brown and Sinclair, 2016), and 28\% in another (Dixon et al., 2015). Equal shares of Black (40\%), Hispanic (40\%), and white (41\%) respondents in large metro areas cited traffic safety as a barrier to bicycling, though a larger share of Blacks cited lack of bike lanes and trails as a barrier than whites (42\% vs. 36\%) (NAR and PSU, 2015). Further, Brown and 
Sinclair (2016) found that 54\% of Black and Hispanic survey respondents didn’t think their local government would build bike lanes in their community if requested. Long distances and destinations' being too far away are also frequently cited barriers (see Dixon et al., 2015; Brown and Sinclair, 2016). A survey of large metro areas found this to be less of a barrier for Black respondents (44\%) than white, nonHispanic respondents (52\%) (NAR and PSU, 2015).

Beyond fear related to traffic safety, people in lower-income and minority neighborhoods may also face personal safety fears that can act as barriers to riding a bicycle. Brown and Sinclair (2016) noted that Black focus group participants expressed concern about the possibility of being stopped by police, while Hispanic focus group participants expressed concern over being victims of crime while biking. Lusk et al. (in press) also found that Black and Hispanic respondents were much more likely to want to park a bicycle inside their home, perhaps due to fear of bicycle theft.

\subsubsection{Social and cultural perceptions}

Perceptions of bicycling as a stigmatizing or negative activity can serve as a barrier to riding. One study found that some African-Americans have associations of bicycling as being for children, or alternatively, for drug dealers, while others view bicycles as symbols of gentrification (CCC, 2012). Brown and Sinclair (2016) found some Black and Hispanic focus group participants felt riding a bike would suggest they could not afford a car, or that their car was broken down. Lusk et al. (in press) found that around a quarter of Black and Hispanic survey respondents thought of bicyclists as mostly women, children, or seniors.

Basic knowledge about how to ride a bicycle is a prerequisite for riding, and not knowing where to ride safely can be a barrier as well. One study found that these themes around basic bicycle knowledge and education were particularly prevalent among immigrant populations (CCC, 2012). 


\section{Table 2-3 Research on Bicycling and Barriers to Bicycling for Low-Income and People of Color}

\begin{tabular}{|c|c|c|c|}
\hline Authors & Location & Method & Selected Equity Findings \\
\hline $\begin{array}{l}\text { PeopleFor } \\
\text { Bikes } 2015\end{array}$ & National & $\begin{array}{l}\text { Individuals, } \\
\text { online survey } \\
\text { ( } n=16,193 \\
\text { adults, plus } \\
\text { adults } \\
\text { reporting on } \\
8,858 \text { children } \\
\text { in their } \\
\text { households) } \\
\text { Black ( } n=1,912 \\
\text { adults }+ \\
\text { children); } \\
\text { Hispanic } \\
\text { ( } n=1,823 \\
\text { adults }+ \\
\text { children); } \\
\text { Income }<\$ 20 k \\
\text { ( } n=11,830 \text { ) }\end{array}$ & $\begin{array}{l}\text { - Low-income respondents (income under } \$ 20,000 / \text { year) were most likely to have ridden a bicycle in the } \\
\text { past year, at } 39 \% \text { compared to } 34 \% \text { for all respondents. Black respondents were equally likely as white } \\
\text { respondents to have ridden in the past year (at } 32-33 \% \text { ). Hispanic respondents were much more likely to } \\
\text { have ridden ( } 43 \% \text { rode in the past year). } \\
\text { - Across all respondents, riding for recreation ( } 32 \% \text { of respondents) was more than twice as common as } \\
\text { riding for transportation ( } 15 \% \text {. } \\
\text { - Among those who did not ride in the past year, respondents of color were nearly twice as likely to have } \\
\text { never ridden a bicycle before ( } 18 \% \text { of Black respondents and } 17 \% \text { of Hispanic respondents, compared to } 10 \% \\
\text { of white respondents). However, among those who had not ridden, Black and Hispanic respondents were } \\
\text { more likely to express an intention to ride in the future (36-37\% did so, compared to } 27 \% \text { among white } \\
\text { respondents). }\end{array}$ \\
\hline $\begin{array}{l}\text { Community } \\
\text { Cycling } \\
\text { Center } \\
\text { (CCC) } 2012\end{array}$ & $\begin{array}{l}\text { Portland, } \\
\text { OR }\end{array}$ & $\begin{array}{l}\text { Individuals, } \\
\text { focus groups } \\
\text { (49) } \\
46 \% \text { Latino; } \\
36 \% \text { African } \\
\text { Immigrant; } \\
15 \% \text { African- } \\
\text { American, } 4 \% \\
\text { multiracial or } \\
\text { Caucasian. }\end{array}$ & $\begin{array}{l}\text { - Cost of bike as barrier: } 60 \% \text { cite cost of buying a bicycle ( } 29 \% \text { of African-Americans, } 62 \% \text { of Hispanic } \\
\text { participants, and } 74 \% \text { of African participants); } 25 \% \text { cite cost of bicycle maintenance. } \\
\text { - Safety: } 35 \% \text { cite not having safe places to store bikes ( } 29 \% \text { of African-Americans, } 57 \% \text { of Hispanic } \\
\text { participants, and } 16 \% \text { of African participants); all African-American respondents cited concerns that drivers } \\
\text { would be hostile to them as bicyclists. Some immigrants had fears of being vulnerable for deportation if on } \\
\text { a bicycle. } \\
\text { - Cultural perceptions: Themes among African-American participants included that bicycles were "toys" or } \\
\text { "for kids," associated with "drug dealers," or as symbols of gentrification. } \\
\text { - Knowledge: Themes among immigrants included that navigating a new place on a bicycle was intimidating, } \\
\text { while some had never learned to ride a bicycle. } \\
\text { - Institutional barriers: Bike shops can be intimidating for some. Bicycling events are often not accessible or } \\
\text { not based in minority communities. }\end{array}$ \\
\hline
\end{tabular}




\begin{tabular}{|c|c|c|c|}
\hline Authors & Location & Method & Selected Equity Findings \\
\hline $\begin{array}{l}\text { Dixon et al. } \\
2015\end{array}$ & $\begin{array}{l}\text { St. Paul, } \\
\text { MN }\end{array}$ & $\begin{array}{l}\text { Individuals, } \\
\text { Listening } \\
\text { sessions, } \\
\text { Surveys (over } \\
100 \text { ) } \\
\text { Survey - } 62 \% \\
\text { African- } \\
\text { American, 70\% } \\
\text { female }\end{array}$ & 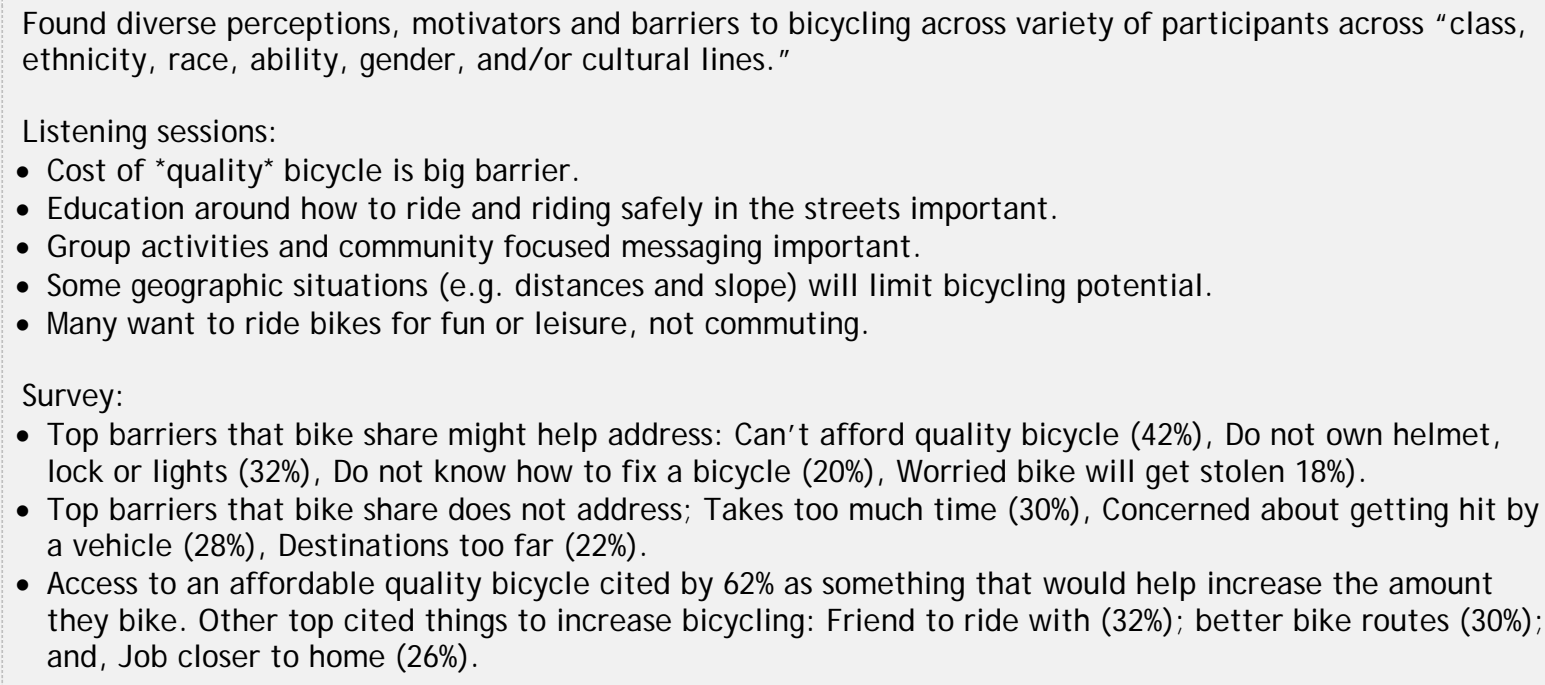 \\
\hline $\begin{array}{l}\text { Brown and } \\
\text { Sinclair } \\
2016\end{array}$ & $\begin{array}{l}34 \\
\text { locations } \\
\text { in New } \\
\text { J ersey } \\
\text { (survey); } \\
\text { New } \\
\text { Brunswick, } \\
\text { NJ (focus } \\
\text { groups) }\end{array}$ & $\begin{array}{l}\text { Individuals } \\
\text { ( } n=2062 \\
\text { surveys; } 26 \\
\text { focus groups) } \\
\text { Black, Hispanic } \\
\text { or Mixed Race } \\
\text { ( } n=1660 \text { ) for } \\
\text { survey; Focus } \\
\text { groups: Black } \\
\text { ( } n=16) \text { ), } \\
\text { Hispanic } \\
\text { ( } n=10)\end{array}$ & $\begin{array}{l}\text { Focus group findings: } \\
\text { - Top reasons to bike in focus groups were exercise, fun, and leisure for Black respondents, and family, fun } \\
\text { and fitness for Hispanic respondents. } \\
\text { - Top reasons not to bike were long distance, unsafe routes, and hygiene for Black respondents, and long } \\
\text { distances, fear of crime, and need for a car for emergencies for Hispanic respondents. } \\
\text { - Both focus groups felt there could be negative perceptions associated with bicycling (e.g., their car was } \\
\text { broken down). } \\
\text { - Black respondents expressed concern over being stopped by police, while Hispanic respondents expressed } \\
\text { concern over being victims of crime while biking. } \\
\text { Survey findings: } \\
\text { - } 24 \% \text { felt a bicycle was expensive to own and maintain } \\
57 \% \text { had not heard of bike share programs in New York City (Citi Bike) or Indego (Philadelphia), but } 85 \% \\
\text { - said they would use bike share if it were available in their community. } \\
\text { requested. } \\
\text { - Reports of being stopped unfairly by police while bicycling among respondents: } 16 \% \text { among Black, } 9 \% \\
\text { among Hispanic, and } 20 \% \text { among mixed-race respondents. Men were } 6 \text { - } 7 \text { times more likely than women to } \\
\text { report being stopped. } \\
\text { - A third reported having a bicycle stolen in the past. } \\
\text { - Top reported barriers to bicycling were traffic safety fears, fear of robbery or assault, and poor quality of } \\
\text { pavement. } \\
\text { - Bike lanes, off-street paths, and bike parking at destinations were the top reported things that would } \\
\text { encourage more bicycling. }\end{array}$ \\
\hline
\end{tabular}




\begin{tabular}{|c|c|c|c|}
\hline Authors & Location & Method & Selected Equity Findings \\
\hline $\begin{array}{l}\text { Lusk et al., } \\
\text { in press }\end{array}$ & $\begin{array}{l}\text { Roxbury, } \\
\text { MA }\end{array}$ & $\begin{array}{l}\begin{array}{l}\text { Individuals } \\
\text { ( } n=252\end{array} \\
\text { resident mail } \\
\text { survey; } 120 \\
\text { cyclist } \\
\text { intercept } \\
\text { survey) } \\
\text { Black ( } n=94 \\
\text { resident } \\
\text { survey; } 38 \\
\text { intercept } \\
\text { survey); } \\
\text { Hispanic ( } n=27 \\
\text { resident } \\
\text { survey, } 19 \\
\text { intercept } \\
\text { survey) }\end{array}$ & $\begin{array}{l}\text { Perceptions on bicycling: } \\
\text { - Black respondents were less likely than white respondents to think bicyclists might be hit by a car ( } 67 \% \text { to } \\
88 \%) \text {. } \\
\text { - Black and Hispanic respondents were more likely to think of cyclists as mostly women, children or seniors } \\
\text { ( } 24 \% \text { and } 30 \% \text { respectively, compared to } 5 \% \text { for white respondents) } \\
\text { - Hispanic respondents were more likely to view biking with family and friends as a reason to bike ( } 81 \% \\
\text { compared to } 54 \% \text { for Black respondents and } 40 \% \text { for white respondents) } \\
\text { - Preferred bicycle parking location for Black and Hispanic respondents was inside their home }(47 \% \text { and } 52 \% \\
\text { respectively, compared to } 28 \% \text { for white respondents). }\end{array}$ \\
\hline $\begin{array}{l}\text { National } \\
\text { Association } \\
\text { of Realtors } \\
\text { (NAR) and } \\
\text { Portland } \\
\text { State } \\
\text { University } \\
\text { (PSU), } 2015\end{array}$ & $\begin{array}{l}50 \text { largest } \\
\text { U.S. metro } \\
\text { areas }\end{array}$ & $\begin{array}{l}\text { Phone and } \\
\text { internet survey } \\
\text { of } 3,000 \text { adults }\end{array}$ & $\begin{array}{l}\text { Biking in the past } 30 \text {-days, of those physically able to ride a bike: } \\
\text { - Black respondents were equally as likely }(76 \%) \text { to have not ridden as white, non-Hispanic respondents } \\
\text { ( } 78 \% \text { ). Hispanic respondents are less likely }(70 \% \text { to have not ridden than whites. } \\
\text { - } 17 \% \text { of Hispanic and } 11 \% \text { of Black respondents had ridden a bike for transportation, significantly more than } \\
\text { whites ( } 7 \%) \text {. } \\
\text { - Adults in households with incomes under } \$ 50 \mathrm{k} \text { and } \$ 100 \mathrm{k} \text { and over equally likely to have not ridden, but } \\
\text { lower-income more likely to bike for transportation and higher-income more likely to bike only for } \\
\text { exercise. } \\
\text { Barriers to biking or biking more: } \\
\text { - Not having a bike to ride was cited by } 52 \% \text { of Black respondents, compared to } 46 \% \text { of white (non-Hispanic) } \\
\text { respondents. There were larger differences based on income, with } 54 \% \text { of those with incomes under } \\
\$ 50,000 \text { citing not having a bike compared to } 37 \% \text { of those with incomes of } \$ 100,000 \text { and above. } \\
\text { - Only } 44 \% \text { of Black respondents stated that places being too far to bike was a barrier, compared to } 52 \% \text { of } \\
\text { white (non-Hispanic) respondents. } \\
\text { - Not feeling safe because of traffic was of about equal concern to Blacks, white, and Hispanic respondents } \\
\text { (40-41\%, though Blacks and Hispanics were more likely to cite a lack of bike lanes or trails as a barrier } \\
\text { (42\%and } 41 \% \text { respectively) compared to } 36 \% \text { of white respondents. }\end{array}$ \\
\hline
\end{tabular}




\subsection{Bike share potential for underserved communities}

Bike share has the potential to benefit underserved or disadvantaged communities if service could better match community needs. In London, a study found that residents in poorer areas would use bike share if stations were sited locally and prices were affordable relative to other modes (Goodman and Cheshire, 2014). Bike share can serve as an important link to transit and to work. A survey of users in four North American cities found that trips to/from work or school were the most common bike share trip purpose (Shaheen et al., 2012). It has also been identified by underserved groups in Philadelphia as a potentially lower-cost, more reliable substitute for transit (Hoe and Kaloustian, 2014).

The prevalence of certain diseases related to physical inactivity, including cardiovascular disease, diabetes and obesity, are higher among Black and Hispanic populations (CDC, 2013), and low-income communities are associated with higher rates of sedentariness, obesity and diabetes (Levine, 2006). Many studies have found that there are many potential health benefits of using bike share. Molina-Garcia (2013) found that bike share users in Spain can potentially prevent $2 \mathrm{~kg} /$ year of weight gain. In a 2012 study of over 3,100 Capital Bikeshare users, 31.5\% reported reduced stress, and about 30\% indicated they lost weight as a result of being bike share users (Alberts, Palumbo, and Pierce, 2012).

Efforts to address equity and bike sharing are underway in a number of cities. System operators do seem to be aware of siting disparities. One study found that 10 of 23 (43\%) surveyed bike share programs factored equity considerations into bike share station siting decisions (Shaheen et al., 2014). A more recent survey of 54 operators found that for $68 \%$ of the systems, equity was considered in and influenced station siting decisions (Howland et al., 2017).

However, even with this awareness, research shows limited success in addressing these underserved communities. A recent set of case studies discussing several U.S. cities' attempts to connect low-income individuals to bike share found that despite some successes via subsidized memberships to overcome cost barriers, difficulties persisted through a lack of stations in communities with poor transit access and in low-income communities in some cases, and low use of stations in such communities in other cases (Kodransky and Lewenstein, 2014). Community engagement is likely a key factor in efforts to make bike sharing more equitable and to serve low-income and communities of color. One early study found that siting stations in low-income communities in Minneapolis yielded limited ridership, likely due to a lack of ongoing community engagement (Stewart et al., 2011).

\subsection{Conclusions on existing research}

The bike share studies above describe typical current users of bike share, how they participate in the program, and which groups have tended to participate in bike share systems at lower rates. Some of these studies have focused on how well existing station siting serves different demographic groups. These have shown that low-income and communities of color often have lower access to bike share stations. This may explain part of the lower participation numbers from these groups. Existing research has also found that women and older adults tend to participate less in bike share, though women might make up a larger share of bike share users than of cyclists in general. Some income-related factors unique to bike share such as credit card and Internet requirements — probably impose additional barriers.

The studies also describe some user or member perceptions and opinions on bicycling and bike share systems, along with barriers to use. Some of these studies focus on the total population and have not specifically explored low-income and minority communities and the barriers and motivators of using the bike share system or bicycling in general for these groups. 
Some recent research has focused on barriers to using bike share or to bicycling in general for lowincome and communities of color. However, in most cases these have been limited to specific cities or states, or derived findings from relatively small sample sizes or focus groups. Only three studies were identified that included bike share members, casual users, and nonusers (two at the same sites in Philadelphia, and one in Montreal). There is a need to better understand these barriers and motivators, and to explore whether current findings can be extrapolated beyond specific geographies or samples.

Of note is the limited evidence to date on how identified demographic barriers to participation interact with one another. For example, do both higher- and lower-income people of color use bike share at lower rates than white residents? What about lower-income or women of color? Research is also needed to better understand the impact of intensive, targeted, community-based outreach paired with siting stations in low-income and communities of color.

This study explores the efforts of the Better Bike Share Partnership efforts to improve bike share equity, and seeks to push forward what we know about how to make bike share work for low-income and people of color, and, in doing so, to fill some of the current gaps in the bike share equity literature. To do this, the study also looks to fill in gaps in knowledge both on barriers to bicycling in general and bike share specifically. 


\section{BACKGROUND}

This report describes findings from resident surveys conducted near bike share stations in three cities: Philadelphia, Pennsylvania; Chicago, Illinois; and Brooklyn/New York City, New York. These cities were engaged in efforts to improve the equity outcomes of their bike share systems as participants in the Better Bike Share Partnership (BBSP or the partnership). This chapter provides a description of the BBSP and the setting and specific efforts in each study city. Further details on how the specific cities and neighborhoods were selected for study are provided in Chapter 4 Methodology.

\subsection{The Better Bike Share Partnership}

In mid-2014, the partnership got underway with funding from The JPB Foundation. The stated goal of the partnership is "to build equitable and replicable bike share systems." The City of Philadelphia took a lead role in managing BBSP activities, along with partners including the Bicycle Coalition of Greater Philadelphia, the National Association of City Transportation Officials (NACTO), and PeopleForBikes.

The partnership, particularly through the City of Philadelphia and the Bicycle Coalition, focused considerable effort on making the launch and operation of Philadelphia's bike share system, Indego, a system that worked for underserved communities. The initial effort in Philadelphia employed a multitiered approach including: grant-funded placement of bike share stations in underserved neighborhoods; targeted outreach including education, organized rides and media; and improvements to earlier bike share system membership and payment standards (including monthly as opposed to annual passes, and cash payment options).

Beyond Philadelphia, PeopleForBikes administered BBSP-funded grants to cities around the country to carry out activities geared toward making their bike share systems more equitable. In year one (20152016), six cities received grants ranging from $\$ 20,000$ to $\$ 75,000$ to carry out a variety of efforts. Recipients included Austin, Texas; Boston, Massachusetts; Brooklyn; Charlotte, North Carolina; Chicago; and Washington, D.C. Ten cities received grant funding in year two (2016-2017). Chicago, Boston and Brooklyn received ongoing funding, and new awards were granted to Atlanta, Georgia; Basalt, Colorado; Los Angeles, California; Milwaukee, Wisconsin; Minneapolis, Minnesota; Oakland/Berkeley, California; and Portland, Oregon. Grant recipients within each locale included bike share operators, community based nonprofits including bicycle-focused organizations, city agencies or departments, or combinations of these. Many BBSP grantees have also sought additional funding to complement their grant-related efforts.

Grantee cohorts receive technical assistance from PeopleForBikes and other BBSP partners. Each cohort was launched with a meeting for grantees to discuss barriers, approaches, and programs related to bike share equity efforts. Monthly conference calls provide forums to discuss challenges and accomplishments with peer practitioners and organizations in other cities. In several cases, delegations from grantee cities, have visited other grantee cities to learn about the challenges and successes of their peers. The partnership also hosted a national Bike Share Equity Conference in Philadelphia in June 2016.

A goal of both the Philadelphia and nationwide efforts is to pilot and evaluate a range of efforts geared toward improving equity outcomes of bike share, with the knowledge that because this challenge has only recently been identified, empirical data and research are currently limited. Therefore, BBSP also provided funding for research and development of practical tools to improve understanding of equity and bike share, and access to tools for public agencies and practitioners. Research funding was provided to Temple University and Portland State University (this research). NACTO worked to develop tools for practice 
and to disseminate BBSP-related knowledge more broadly. This includes reports on improving station placement and density to maximize equity outcomes (NACTO, 2015a), and exploring the impact of monthly payment options on low-income riders (NACTO, 2015b). In addition, many grantees are conducting their own evaluations and research related to local experiences with BBSP.

Through the BBSP's efforts, cities hope to learn more about the effectiveness, cost, and sustainability of a range of potential approaches. Promising projects could then be carried on beyond the grant timeline, and hopefully inform other cities, bike share systems, and community partners around the country as they seek to improve equity outcomes in their own bike share programs. An overview of BBSP efforts is provided for each study city in Table 3-1, and specific details are presented by city in the remainder of this chapter.

\section{Table 3-1 Overview of BBSP Context and Program Elements by Study City}

\begin{tabular}{|c|c|c|c|}
\hline & $\begin{array}{l}\text { Philadelphia } \\
\text { (Indego) }\end{array}$ & $\begin{array}{l}\text { Chicago } \\
\text { (Divvy) }\end{array}$ & $\begin{array}{c}\text { Brooklyn } \\
\text { (Citi Bike) }\end{array}$ \\
\hline $\begin{array}{l}\text { Bike share } \\
\text { system } \\
\text { development }\end{array}$ & $\begin{array}{l}\text { Launch: April } 2015 \\
\text { Access: } 17 \text { BBSP-funded } \\
\text { stations in targeted outreach } \\
\text { area at launch }\end{array}$ & $\begin{array}{l}\text { Launch: J une } 2013 \\
\text { Access: Some stations } \\
\text { throughout Bronzeville with } \\
\text { additional stations added in } \\
\text { spring } 2015\end{array}$ & $\begin{array}{l}\text { Launch: May } 2013 \\
\text { Access: A few stations on the } \\
\text { western edge of the Bedford- } \\
\text { Stuyvesant (Bed-Stuy) } \\
\text { neighborhood with additional } \\
\text { expansion into central Bed- } \\
\text { Stuy in summer } 2015\end{array}$ \\
\hline $\begin{array}{l}\text { Discount pass } \\
\text { option }\end{array}$ & $\begin{array}{l}\text { Launch: April } 2016 \text { as } \\
\text { Indego } 30 \text { Access } \\
\text { Eligible: PA ACCESS low- } \\
\text { income medical benefit } \\
\text { cardholders } \\
\text { Price: } \$ 5 / \text { month ( } 67 \% \text { off) }\end{array}$ & $\begin{array}{l}\text { Launch: J uly } 2015 \text { as Divvy for } \\
\text { Everyone } \\
\text { Eligible: Households earning } \\
\text { up to } 300 \% \text { of the poverty } \\
\text { guideline } \\
\text { Price: } \$ 5 / \text { year initial ( } 95 \% \text { off) } \\
\text { and } \$ 50 / \text { year renewal ( } 50 \% \\
\text { off) }\end{array}$ & $\begin{array}{l}\text { Launch: May } 2013 \text {, same as } \\
\text { system, multiple programs } \\
\text { Eligible: NYCHA public } \\
\text { housing residents and } \\
\text { community-based credit union } \\
\text { members } \\
\text { Price: } \$ 5 / \text { month ( } 67 \% \text { off) }\end{array}$ \\
\hline $\begin{array}{l}\text { Cash } \\
\text { payment } \\
\text { option }\end{array}$ & Yes, anyone & Yes, only for D4E & No \\
\hline $\begin{array}{l}\text { Key outreach } \\
\text { activities }\end{array}$ & $\begin{array}{l}\text { Cash payment system; group } \\
\text { rides; attended local } \\
\text { events/ meetings; advertising } \\
\text { campaign; digital literacy and } \\
\text { bike riding classes ("Digital } \\
\text { Skills and Bicycle Thrills"); } \\
\text { surveys and focus groups }\end{array}$ & $\begin{array}{l}\text { Divvy for Everyone program } \\
\text { promotion, group rides; } \\
\text { attended local events; } \\
\text { incorporated into personal } \\
\text { credit-building program }\end{array}$ & $\begin{array}{l}\text { Demonstrations of } \\
\text { bicycle/ system use; special } \\
\text { events; organized rides, } \\
\text { surveys and focus groups; } \\
\text { targeted promotion to NYCHA } \\
\text { residents; incorporated into } \\
\text { financial literacy program; } \\
\text { and prescribe-a-bike at two } \\
\text { Bed-Stuy locations }\end{array}$ \\
\hline
\end{tabular}

\subsection{Philadelphia}

\subsubsection{System: Indego}

The City of Philadelphia began exploring bike share as early as 2009. A 2013 bike share strategic business plan proposed a phased bike share rollout focusing on the downtown core first (Zone 1A), and a year-one expansion into inner neighborhoods (Zone 1B) (Figure 3-1). Then-Mayor Michael Nutter tasked the Mayor's Office of Transportation and Utilities (MOTU - now the Managing Director's Office of Transportation and Infrastructure Systems, or OTIS) with ensuring that bike share served all Philadelphia residents, including traditionally underserved communities. In late 2013 and early 2014, MOTU applied to The JPB Foundation for funding for the Better Bike Share Partnership with the goal of prioritizing 
equity in the Philadelphia bike share system, and promoting bike share equity around the country. Philadelphia used a portion of the grant funding to include both zones in the initial rollout in an "accelerated" version of the plan (Figure 3-1). Intensive outreach throughout the entire Zone 1 designated area culminated in the launch of a 71-station system in April 2015, with two neighborhood stations added shortly afterward to cover all of Zone 1.
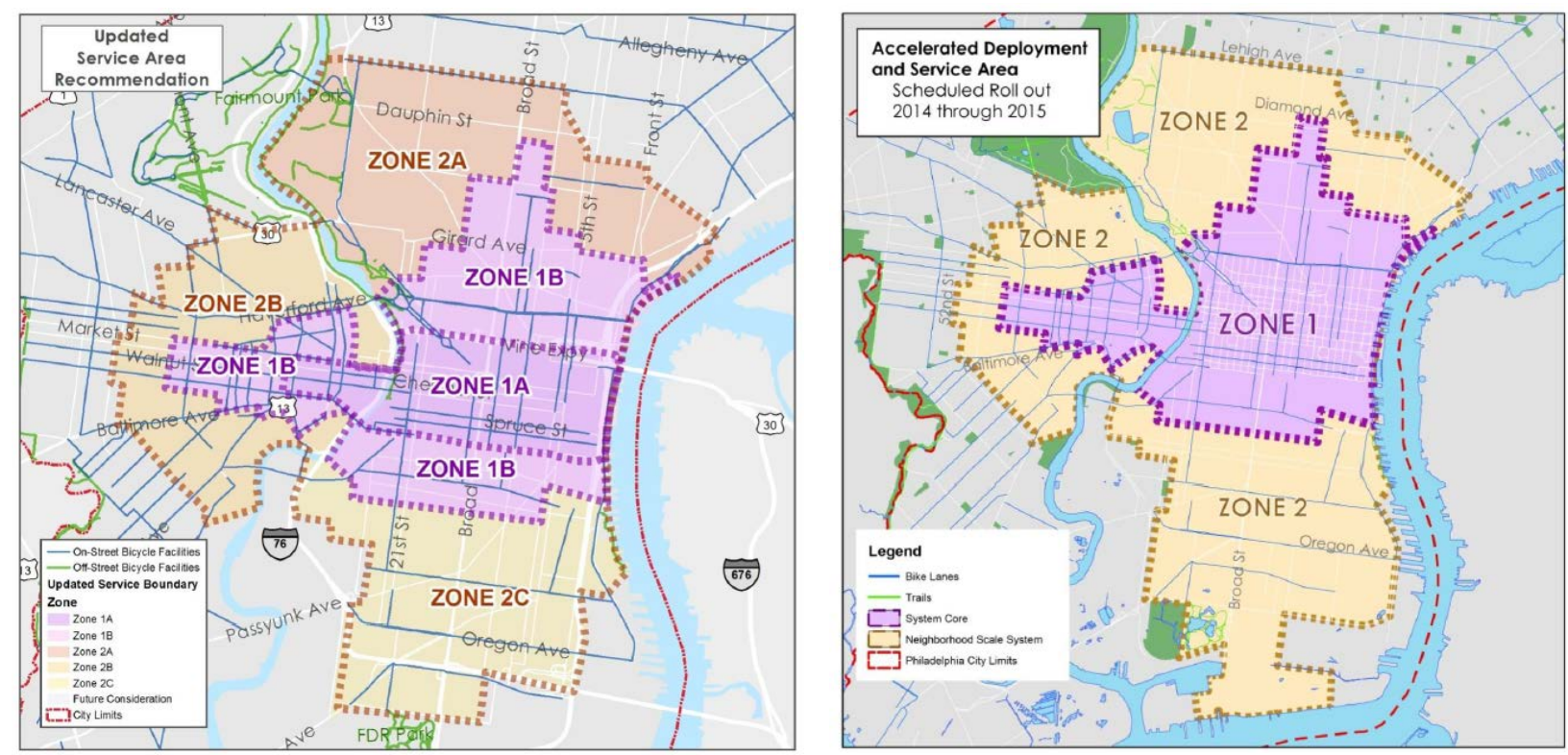

Figure 3-1 Philadelphia Strategic Business Plan (2013) conservative (left) and accelerated (right) deployment zones.

Philadelphia's bike share system, Indego, including the bicycles and station equipment, is owned by the City of Philadelphia and managed by OTIS. The title sponsor of the system is Independence Blue Cross. The equipment is manufactured by BCycle, and is operated by Bicycle Transit Systems. By the end of 2015, the 73 stations were stocked with approximately 700 bicycles. From April 2016, the system has subsequently expanded with additional stations and bicycles. As of summer 2016, there were 105 active stations in the system. ${ }^{2}$ The development of the system up to the point of our survey is shown in Figure 3-2.

\subsubsection{Equity initiative}

Philadelphia's priority focus on equity from the planning stages of their bike share system made Indego unique among large U.S. systems. Along with the system's owner and operator, the Bicycle Coalition of Greater Philadelphia (BCGP) has been a key partner in Indego equity efforts, particularly around outreach and education.

Bike share stations in low-income communities. BBSP funding provided for up to 20 bike share stations in underserved communities in Philadelphia. Philadelphia has several relatively dense lowincome neighborhoods directly adjacent to the city center. In the planning phase of the system, the city identified neighborhoods and specific site locations for stations in areas of South Philadelphia (Point Breeze), West Philadelphia (Powelton Village, Mantua, University City and Spruce Hill), and North Philadelphia (Spring Garden, Poplar and Francisville).

\footnotetext{
${ }^{2}$ https://www.rideindego.com/about/data/
} 


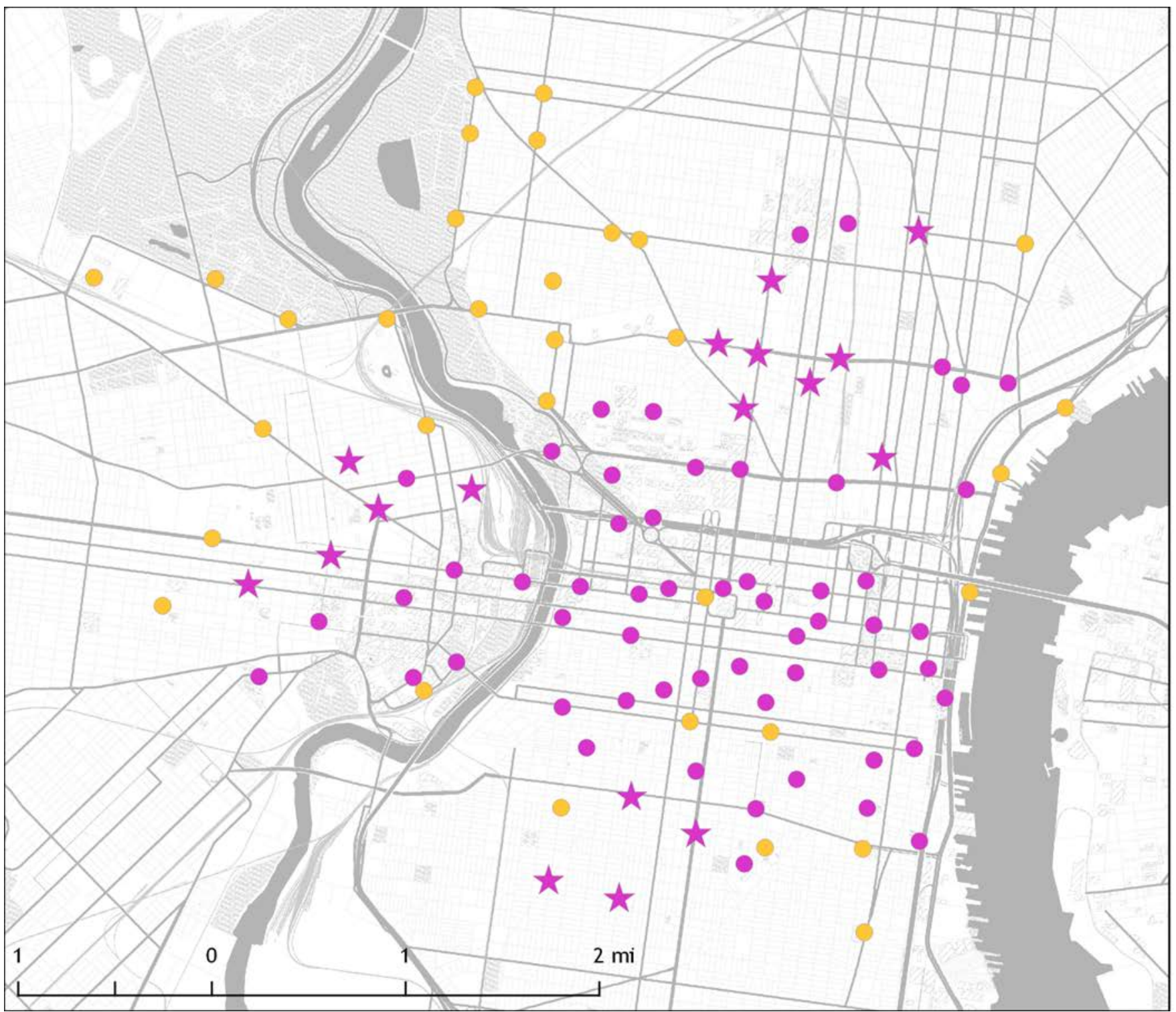

\begin{tabular}{|l} 
Indego System \\
$\quad 2015$ \\
$\star \quad 2015$, BBSP-funded \\
$\quad 2016$
\end{tabular}

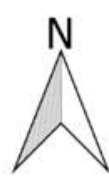

Data: City of Philadelphia, Indego, Stamen Design

Figure 3-2 Indego bike share system development from launch through J uly, 2016, including initial BBSP-funded stations. 
The city began outreach in these neighborhoods (and other Philadelphia neighborhoods targeted for bike share stations) in summer 2014, and scheduled between two and five community meetings for each location in the fall. Decisions about site locations were focused on connecting people to transit, parks, community centers, and grocery stores. In conjunction with community input, site visits to specific potential locations were conducted. Due to the limited right-of-way on many Philadelphia streets, station location decisions were often constrained to a small number of feasible sites. Stations were generally placed on sidewalks and other areas where parking removal was not required. In general, community feedback was positive; however, in a few instances, particularly in North Philadelphia, specific station locations met with community resistance and were not installed.

At the time of the system launch, 17 stations were purposefully located in underserved areas and supported by BBSP funding. These stations were originally in the designated Zone 1B, but in fact opened at system launch.

Payment systems. Payment system characteristics may present an additional challenge to lower-income and minority communities. Indego undertook several measures aimed at making the payment options more appealing and accessible for a broader spectrum of users who may not be able to or be interested in committing to long-term memberships or using credit or debit cards for payment.

Pass and use options. With many bike share systems that launched prior to Indego, users who wanted the best deal to use bike share regularly had to commit to annual memberships, typically priced from $\$ 75$ to \$150. Depending on the system, this amount might be due up front or, less commonly, split into monthly payments with an annual commitment (and often at a higher total price than a single payment). For lowerincome users, committing to pay these larger sums (particularly for new users who might still be testing out whether they are truly interested in bike sharing) could represent a considerable financial or psychological barrier. Frequent users without such an annual membership would likely be required to purchase more day or week passes, targeted more toward tourists, that cost considerably more per ride or per day - in some cases approaching the cost of a full month's membership for just a day of riding.

To better address payment barriers, Philadelphia created multiple options: a \$15 monthly bike share pass with no annual commitment (Indego30); a \$10 annual pass that allows check-outs for $\$ 4$ per hour; and a $\$ 4$ per 30 minutes walk-up option. The walk-up option would allow prospective users to try out Indego for less than the lowest-cost option in most other systems (typically an \$8-\$10 day pass). These measures were designed in part to allow curious customers to try out the system without a major commitment. The payment structure also allows longer check-outs (the first hour is no extra charge for pass-holders) than most systems, and additional time is charged at a flat rate ( $\$ 4 /$ hour with a pass, $\$ 4 /$ half-hour for walk-up users). This may be a particular benefit to new users who are not familiar with all of the stations or routes.

Although the initial annual rate of $\$ 15$ per month, up to $\$ 180$ per year, was more expensive than typical bike share systems, the structure also allowed users to join and opt out at will. Users could, for example, join only for one month when they had a particular need, or only during the summer, not paying for months when they were not using the system.

Payment options, including cash option. Indego was also the first major U.S. bike share system to offer a cash payment option. The City of Philadelphia decided that providing a cash payment option was a priority based on studies showing that lower-income and minority individuals were more likely to lack a credit or debit card.

Bicycle Transit Systems researched potential options and developed a system wherein people could sign up online (including using publicly accessible internet locations such as “Keyspot” sites — 
https://www.phillykeyspots.org/), and receive a code through the vendor PayNearMe. That code could be taken to a local 7-Eleven or Family Dollar store and presented to the cashier along with the appropriate payment, and the funds would be credited to the user's Indego account. New members would then be mailed an Indego pass.

Discounted membership option. In April 2016, Indego added a \$5 per month pass option for those meeting income qualifications (Indego30 Access), with overage charges at a reduced rate of \$2 per hour. Eligibility is tied to the PA Access cards the State of Pennsylvania issues to eligible recipients of various benefits such as cash assistance programs, Supplemental Nutrition Assistance Program (SNAP), and medical assistance. By August 2016, nearly 700 members had joined via the Access program, with almost $20 \%$ opting to pay with cash. ${ }^{3}$

Outreach efforts. The Bicycle Coalition of Greater Philadelphia (BCGP) played a leading role in community outreach and education, particularly around barriers more specific to bicycling generally. Full-time coalition staff and several teams of part-time and stipend-supported people conducted extensive outreach in each of the three focus areas (North, South, and West Philadelphia). In general, BCGP sought representatives who already had standing in the specific communities, including key community agencies, organizations, and leaders. Both pre and post-launch, BCGP staff attended numerous meetings, events, and gatherings in each of the neighborhoods to discuss Indego and explain how the system worked. They brought Indego bikes to the events and offered rides to those interested. Over time, outreach included more organized rides and classes.

Outside of BCGP full-time staff, two groups of outreach leaders were brought on board:

- The "Street Team" consisted of young adults in the community who were hired on a part-time basis over the summer and on weekends. Street team members were tasked with being the outward face of Indego at community events and providing one-on-one interaction with community members.

- The Ambassadors program consisted of about 20 people who lived or worked in the various outreach communities and were active in the community. The role of the Ambassadors was to build on their existing relationship to strengthen support for bike share in the community. For a modest stipend, they were expected to attend a training, organize bicycling street skills classes and community rides, and attend Indego-related events.

BCGP staff, Street Team members and Ambassadors attended events such as festivals and fairs, markets, block parties and community days, setting up pop-up information tables at busy locations or centers. They also led bike rides, some of them using Indego bikes, and trained people through classes and ad hoc lessons on bicycling and how to use bike share. A month-long adult education course was offered"Digital Thrills and Bicycle Thrills" - that combined digital literacy with learning about Indego. ${ }^{4}$ Those who completed the course were eligible for a free six-month bike share pass.

The City of Philadelphia and Bicycle Transit Systems also sought to spread the word about Indego through social media campaigns, and advertising on billboards, buses and bus shelters. In each of these campaigns, staff members, informed by focus groups, worked to ensure that images and information would appeal and be accessible to all residents, included those in traditionally underserved populations. Some of the models in the advertising campaign were part of the BCGP Ambassadors team. Examples are

\footnotetext{
${ }^{3}$ http://betterbikeshare.org/2016/08/29/philly-offering-bike-share-discounts-food-stamp-cards-working-great/

${ }^{4}$ https://www.rideindego.com/blog/sign-up-for-digital-skills-and-bicycle-thrills/
} 
provided in Figure 3-3.

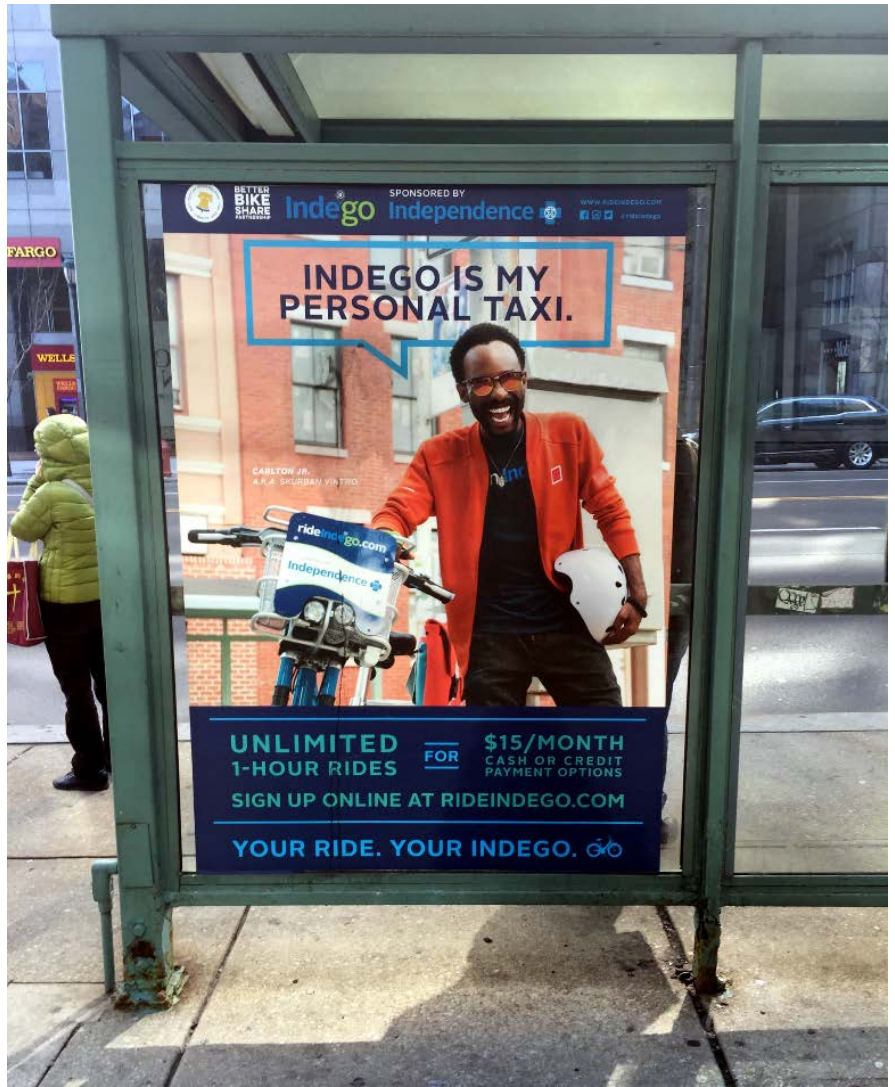

Clockwise from top left: Indego advertisement at bus shelter, contact card handed out at events, and Twitter promotion for member sign up at public Internet location (Keyspot)
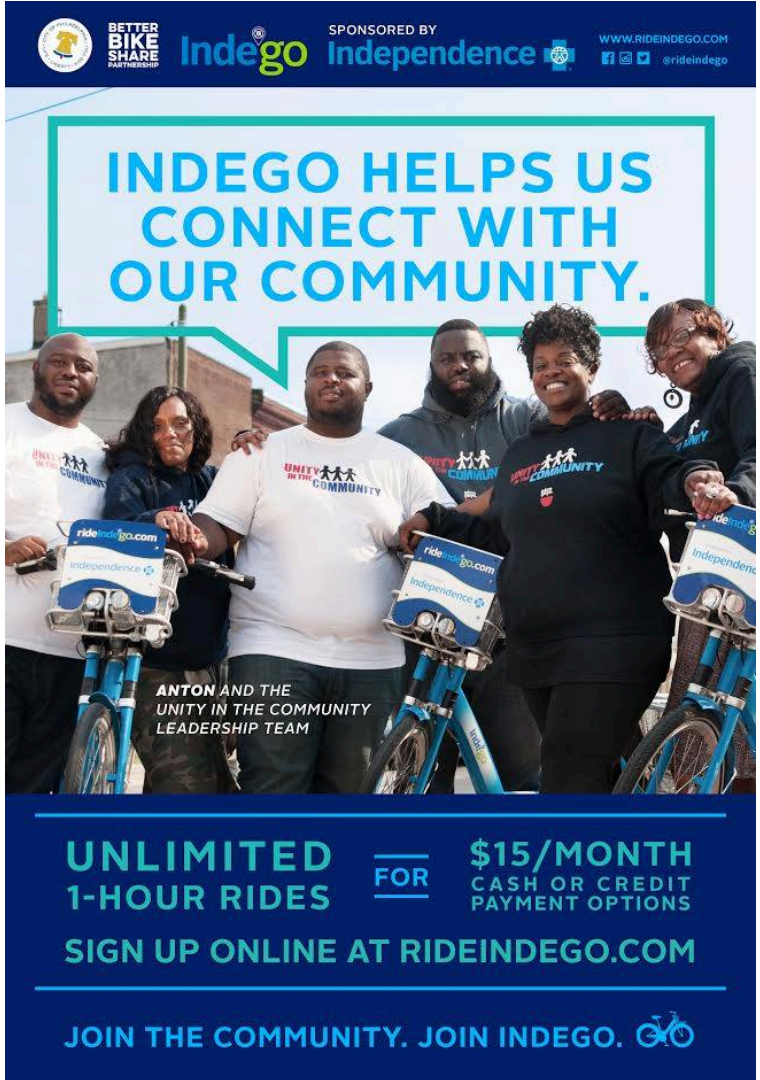

Indego @Ridelndego · 22 Sep 2016

Improve your computer skills \& get comfortable biking in the city with Digital Skills \& Bicycle Thrills ow.ly/iPQi304qY9m

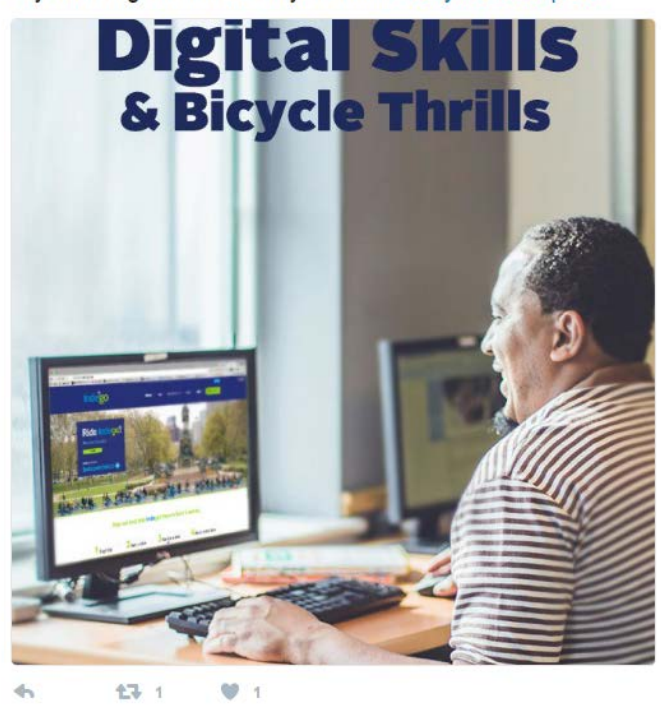

Figure 3-3 Philadelphia's BBSP outreach included a media and education campaign targeted to underserved populations. 
Data collection and research. Local BBSP-related research and data collection was conducted by Temple University. Focus groups were held and summarized before Indego's launch, and two follow-up intercept studies were undertaken to better understand the distribution of system knowledge and persistent barriers to use (Hoe, 2015a; Hoe, 2015b; Hoe and Kaloustian, 2014). Additional related research was being done at Drexel University, focusing on longitudinal health outcomes of Indego.

\subsection{Brooklyn}

\subsubsection{System: Citi Bike}

Citi Bike launched in May 2013 in New York City with 6,000 bikes and 330 stations. The New York City Department of Transportation (NYC DOT) planned the system, which uses PBSC bicycles and is operated by Motivate (formerly Alta Bicycle Share). A community-driven planning effort had selected 600 station locations, including 36 covering the western and central portions of the Bedford-Stuyvesant (Bed-Stuy) neighborhood in Brooklyn. The development of the system up to the point of our survey is shown in Figure 3-4. Prior to the system launch, the storm surge from Hurricane Sandy inundated the warehouse in which many Citi Bike bikes were being stored. Due to the resulting damage and other operator issues, the system launch was delayed and the number of bikes and stations was reduced from the initial plan. Only 10 of the planned Bed-Stuy stations opened at launch, and they were in the wealthier western portion of the neighborhood that is contiguous with rest of the bike share system. In August 2015, the remaining stations opened as part of the first Citi Bike expansion, completing the bike share network as originally planned. As of December 2016, the system had over 600 active stations and 9,400 bikes, making it the largest public bike share system in the U.S. Before the expansion, a partnership formed among several local agencies, coordinated by the Bedford-Stuyvesant Restoration Corporation (BSRC), to focus on equity outcomes at the new stations in Bed-Stuy.

Pass and use options. At launch, Citi Bike offered \$95 annual memberships along with daily and weekly passes. Current offerings include an annual membership for \$163, or for \$14.95 per month with an annual commitment (\$179.40 per year), along with daily and three-day passes. Annual members receive unlimited 45-minute rides, while daily and 3-day memberships are limited to 30-minute rides before extra charges accrue.

New York City Housing Authority (NYCHA) (public housing) residents and members of select Community Development Credit Unions are eligible for $\$ 60$ annual (or $\$ 5$ per month) memberships. Some other discounts are available, including a first year 15\% discount for IDNYC (city issued government ID available to anyone age 14 or older) cardholders, and a $10 \%$ discount for holders of Citi credit or Citibank debit cards. 

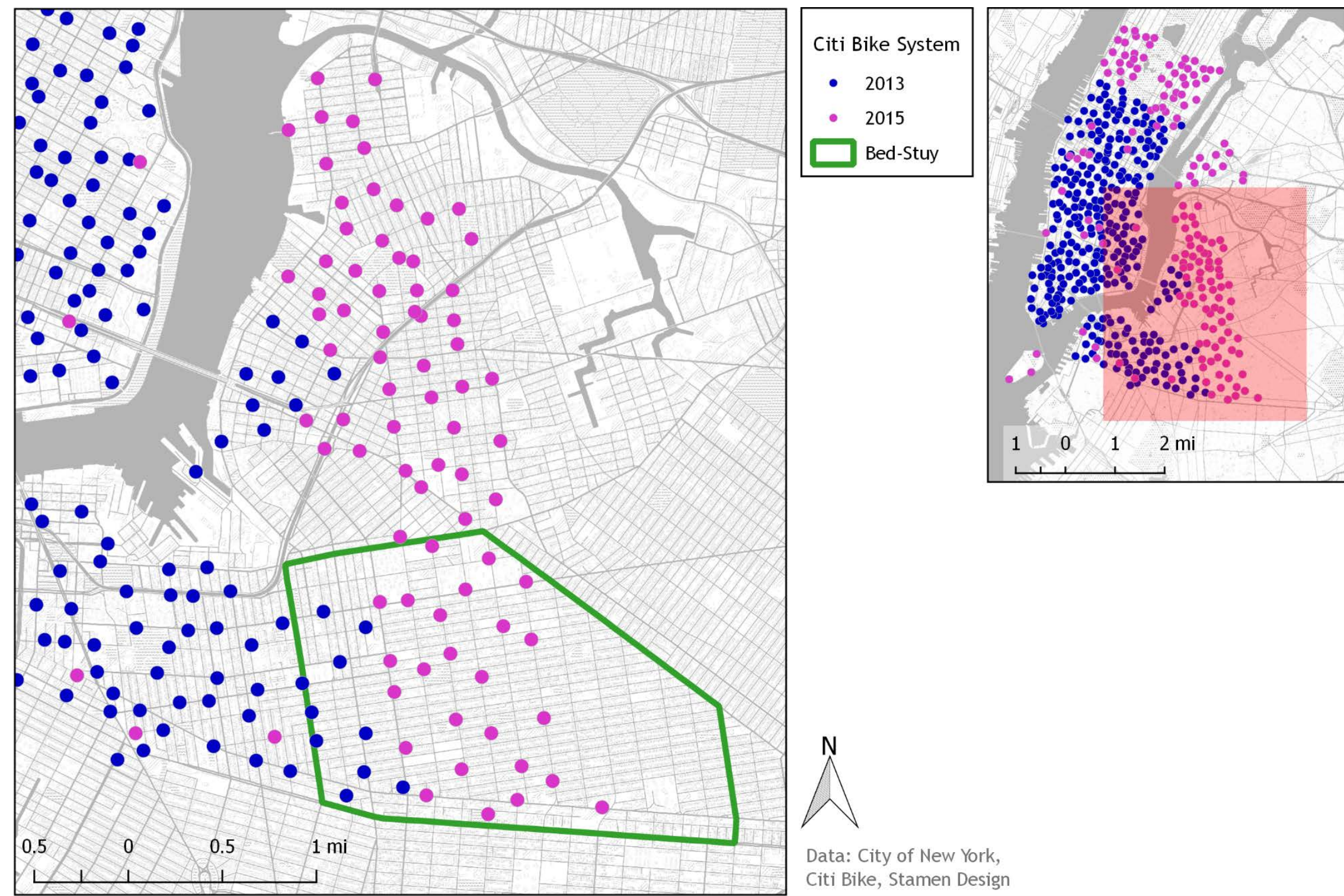

Figure 3-4 Citi Bike bike share system development from launch through J uly 2016. 


\subsubsection{Equity initiative}

Bedford-Stuyvesant (Bed-Stuy) is a majority Black neighborhood in Brooklyn with relatively high levels of poverty and a high concentration of public housing. Although it was originally slated to be included in the Citi Bike system at launch, various delays slowed Citi Bike’s arrival in much of the neighborhood for two years.

With the plan to expand further into Bedford-Stuyvesant (Bed-Stuy) in 2015, NYC Department of Transportation (NYC DOT); NYC Department of Health and Mental Hygiene (DOHMH); the BedfordStuyvesant Restoration Corporation (BSRC), a community development organization; and Citi Bike sought to ensure that the system provided a benefit and value to all residents, including lower-income and residents of color.

BSRC noted three key barriers to Citi Bike use by community residents. First, there were initially only 10 stations in the neighborhood, clustered around its western (and more affluent) edge. Most of the neighborhood, and the vast majority of lower-income residents, did not have bike share stations nearby. Second, the cost of bike share (\$149 per year at the time) represented a significant financial outlay for Bed-Stuy's many lower-income residents, and many were not aware of discounted membership options through NYCHA and credit unions. Finally, community perceptions of bicycling were thought also to play a deterring role. These included perceptions that biking on Brooklyn streets was not safe or easy, and that increases in bicycling might come at the expense of other modes of transportation as bikes competed for space with public transit, motor vehicles, and pedestrians. BSRC also noted that many residents view bike lanes and cyclists as a sign of gentrification. Efforts were made to address each of these barriers, as detailed below.

Bike share stations in low-income communities. As discussed above, 26 new Citi Bike stations were added in Bed-Stuy in August 2015, bringing the total number of stations in the area to 36 and extending the coverage area to the majority of the neighborhood. While the stations were not planned or funded as part of a specific equity policy, the areas served are considerably more diverse and farther from Manhattan than the initial service areas.

Discounted membership option promotion. BSRC has worked to raise awareness among Bed-Stuy residents about discounted Citi Bike options for NYCHA residents and for Brooklyn Cooperative Federal Credit Union members. BSRC specifically targeted public housing residents, located mainly in the northern half of the neighborhood, for tailored outreach. This included setting up individual meetings to help residents understand how to enroll in the discount programs and how to use the system.

General outreach efforts. BSRC sought to educate Bed-Stuy residents about bicycling in general, and about signing up for and participating in Citi Bike specifically. Outreach efforts included hosting major outreach events for public housing and community residents in June and August, and attending community events to demonstrate the Citi Bike bicycles and offer test rides, helmet fittings, member signups, and free day passes, among other activities. Classes were offered to learn to ride a bike, and group rides and riding safety workshops were also made available. Generally, organized bike rides took places on a bi-weekly basis. BSRC efforts were led by a project manager, and coordinated in partnership with NYC DOT and Citi Bike.

BSRC assembled a team of Community Outreach Ambassadors, who generally were residents of BedStuy and surrounding communities, aged 21 or younger, and hired over the summer through a summer youth employment program. BSRC specifically targeted NYCHA residents to join the Ambassadors. The Ambassadors attended many of the outreach events, and assisted with data collection for a neighborhood 
intercept survey to better understand barriers to bike share use. They also served to generally broadcast the message of bike share throughout the community.

BSRC and its partners also provide a variety of other services to Bed-Stuy residents, and looked for opportunities to connect their clients to bike share. Integration of Citi Bike information into financial counseling services was viewed as one way to take advantage of services already being provided by BSRC. Ambassadors also played a role in these efforts, educating people on the potential financial benefits of bike share, including saving on transit or taxi costs, and enrolling people at locations including the Brooklyn Cooperative Federal Credit Union.

Outreach marketing materials were tailored to the community in hopes of addressing persistent myths that the bikes were not intended for everyone. This included producing brochures and posters that showed people of color and members of the community. Advertisements were placed on bus shelters, in community newspapers, and in other forms of media (Figure 3-5).

BSRC, working with the NYC Department of Health and Mental Hygiene (DOHMH), also developed connections to two medical centers - Woodhull Medical Center and Interfaith Medical — for a prescribe-a-bike program. Between 2015 and 2016, 148 individuals were "prescribed” a subsidized bike share membership (at no cost to the patient). 


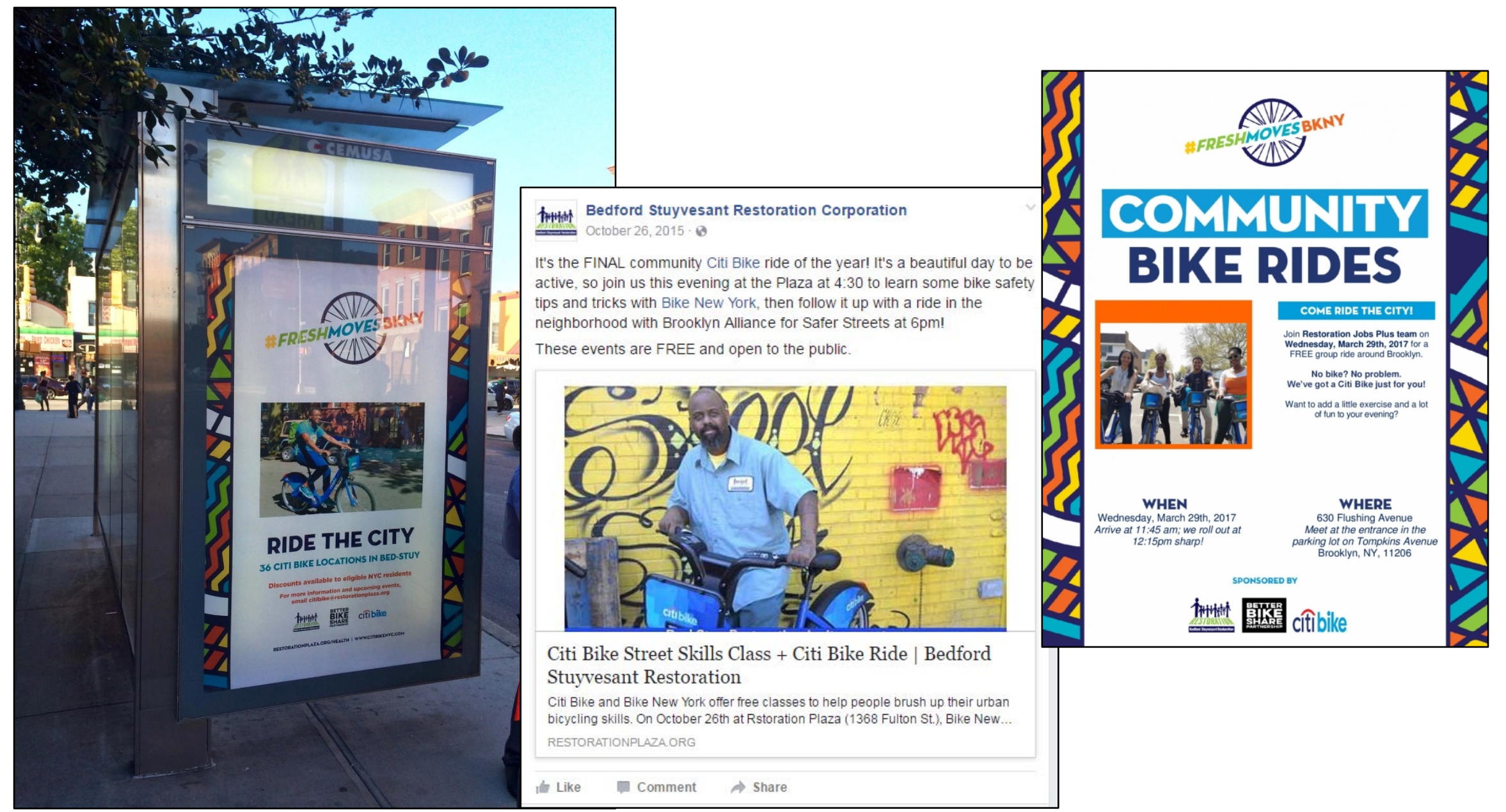

Figure 3-5 Brooklyn targeted outreach media (Left to Right): bus shelter advertisement, Facebook promotion for Skills Class and Citi Bike Ride, Community Bike Rides Event Flyer 
Data collection and research. DOHMH conducted focus groups with 30 Bed-Stuy residents in 2015. In addition, BSRC, in partnership with the DOHMH, conducted an intercept survey of Bed-Stuy residents. This survey captured basic data on use of and barriers to use of bike share from 230 residents in summer 2015.

BSRC and NACTO (2017) reported on station use and the activities of BSRC during the expansion of Citi Bike in Bed-Stuy. Success stories noted included large numbers of participants in BBSP-related events: all events (2,500), group rides (450 on 84 rides), stakeholder trainings and meetings (nearly 200). The report highlights a substantial one-year increase in Citi Bike trips in Bedford Stuyvesant with the additional twenty-six stations in operation, and ridership growth above the citywide average. In addition, Bed-Stuy experienced increases in Citi Bike membership at a faster rate (56\%) than the city as a whole (46\%) from March 2015 to December 2016. NYCHA resident enrollment also grew faster than in the city overall.

\subsection{Chicago}

\subsubsection{System: Divvy}

The development of the Divvy system up to the point of our survey is shown in Figure 3-6. Divvy launched in June 2013 in Chicago with about 70 stations. Supplier issues slowed plans to expand, but the system grew to about 300 stations by fall 2013, and the initial buildout of 475 stations was completed two summers later, in 2015. Beginning in 2016, the system also operated in two nearby cities, Oak Park and Evanston. By January 2017, there were 580 stations and 6,000 bicycles. A community-driven planning effort had suggested many of the station locations. The Chicago Department of Transportation (CDOT) formed a partnership with other local organizations to participate in the BBSP program with both citywide and neighborhood-level components. The Divvy system and equipment are owned by the City of Chicago. The equipment is manufactured by PBSC and the system is operated by a subsidiary of Motivate International LLC. CDOT secured matching funds from Blue Cross and Blue Shield of Illinois, Divvy's system sponsor.

Payment options include an annual membership (which cost $\$ 75$ per year at launch, and is now $\$ 99$ per year, or $\$ 9.95$ per month with an annual commitment) and a walk-up day pass for \$9.95 (\$7 at launch).

\subsubsection{Equity initiative}

CDOT served as the lead on the Chicago BBSP initiative. The initiative was undertaken as a multi-tiered approach to address a number of perceived barriers, both in a specific neighborhood (Bronzeville, discussed below) and citywide. In its BBSP application, CDOT noted that white residents were dramatically overrepresented among Divvy riders compared to the overall population. CDOT and its local partners suggested that key reasons were cost, awareness, and general perceptions of bike share specifically and bicycling in general.

Potential solutions identified included: placing stations in neighborhoods with higher shares of residents of color and in other underserved communities; conducting outreach in those communities to raise awareness about bike share and the viability of biking as a form of transportation; and addressing cost and payment barriers associated with joining Divvy. 

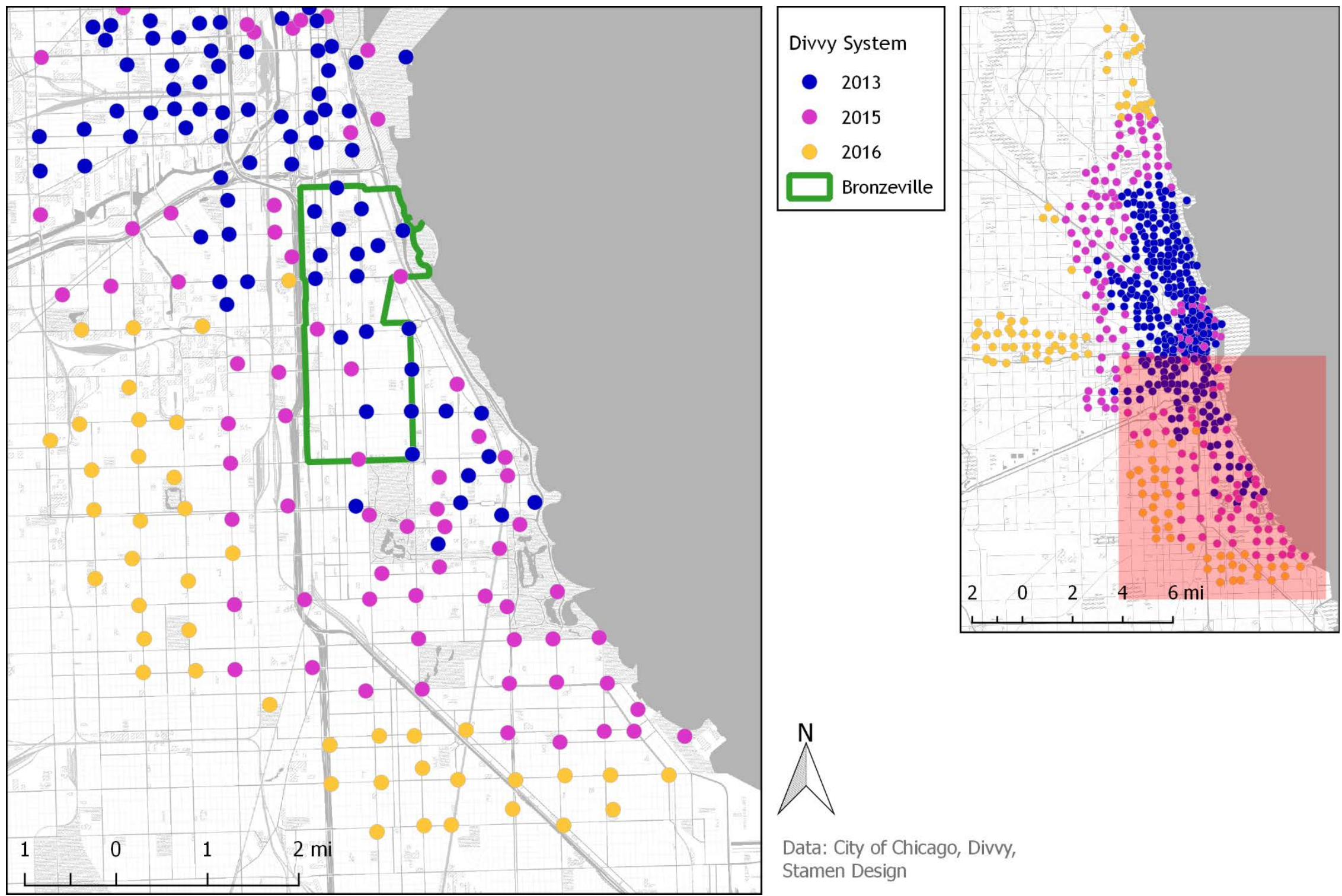

Figure 3-6 Divvy bike share system development from launch through J uly, 2016. 
Bike share stations in low-income communities. There were Divvy stations throughout the Bronzeville neighborhood at launch, including one directly in front of the Cara Center, a LISC Financial Opportunity Center (see below for more detail on LISC and FOCs) participating in the Divvy for Everyone (D4E) program. Additional stations were added in spring 2015.

Discounted membership options. Divvy's primary citywide equity effort is centered around D4E, which offers a \$5 first-year membership to enrollees, a significant discount from full price, and accepts cash payments. The program is open to Chicago households making $300 \%$ or less of the federal poverty guideline (approximately $\$ 35,000$ annual income for a one-person household, $\$ 48,000$ for two, $\$ 60,000$ for three, $\$ 72,000$ for four, and so on). Divvy subsequently created an ongoing membership plan for D4E members continuing in year two, which included an annual membership at $\$ 50$ per year (half the full price) or $\$ 5$ per month (\$60 per year total), then transitioning to a full cost membership in year three.

Divvy partnered with the Local Initiatives Support Coalition (LISC) Chicago to administer the D4E program. Among other programs, LISC Chicago operates 12 Financial Opportunity Centers (FOCs) around Chicago where residents can go for assistance in employment and personal finance. CDOT identified five centers in the 2015 Divvy expansion areas to process D4E applications. A dedicated staff member at each FOC was trained to evaluate and process D4E applications, accept payment from enrollees (including cash), help with activation, and provide information about bicycling, including maps and safety information. It is a "one-stop" process, and qualified applicants can ride away on a Divvy bike. They have also worked to clarify any overage charges for trips over 30 minutes so that new members are not surprised by charges. Participating FOC locations are identified on the D4E website and dedicate specific hours to handling membership inquiries. A sixth FOC location has been added to the D4E network as the system has expanded. Although they provide information about Divvy and the D4E program to existing clients, the vast majority of sign-ups have been first-time visitors to the FOCs, coming only to enroll as bike share members. The FOCs see particular value in then connecting these people to health, transit, and information about the wider suite of services they offer the community. They have also expanded their credit-building program, Twin Accounts, to include D4E renewal payments.

Divvy for Everyone outreach and promotion benefited from considerable coverage by major media news outlets (Figure 3-7). Mayor Rahm Emanuel attended the D4E program's launch, which led to considerable press coverage. Enrollments started July 7, 2015. Although CDOT had a goal of 750 signups in year one, it received over 650 signups in the first month and over 1000 before the winter season. CDOT estimates that 80\% of D4E members had used the system as of March 2016. A loss liability fund was established to protect against lost or damaged bikes, but this has not been a problem for the D4E program in practice.

General outreach efforts. Chicago's BBSP-related outreach efforts around bike share included citywide outreach in partnership with Slow Roll Chicago and CDOT's Bicycling Ambassadors outreach and education team, and targeted outreach in the system expansion neighborhood of Bronzeville on the South Side, in partnership with Go Bronzeville.

Slow Roll Chicago is a nonprofit community organization that promotes quality of life through bicycling in communities of color and low- to middle-income neighborhoods throughout Chicago. Slow Roll's primary BBSP outreach consisted of promoting and hosting rides citywide. Slow Roll hosts rides every Wednesday during nice weather, and on some Saturdays. Rides are often based around a community theme such as neighborhood music, gardens, history, or art. Many rides start and stop near Divvy stations to allow people to use bike share bikes, and rides frequently have as many as 100 riders and 10 to 12 
leaders. One important mechanism of promotion was to use Slow Roll's popular weekly calendar of bikerelated events.

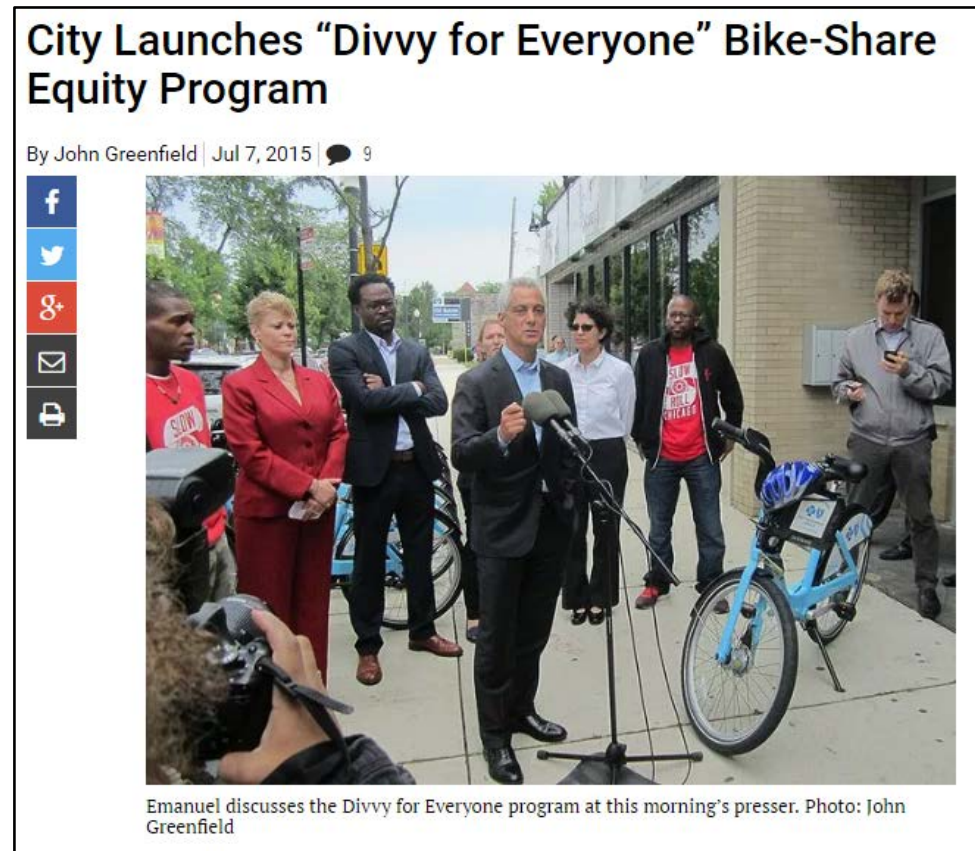

\section{SURTIMES}

News

Low-income Chicagoans eligible for $\$ 5$ annual Divvy memberships CHICAGO NEWS 07/07/2015, 10:27am Jordan Owen

Sign-Up for our Nev @byjordanowen | email

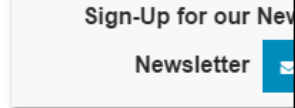

Mayor Emanuel announced a "Divvy for Everyon Tuesday morning, allowing Chicago residents wit affordable access to the popular bike-share progr

Above: chi.streetsblog.org

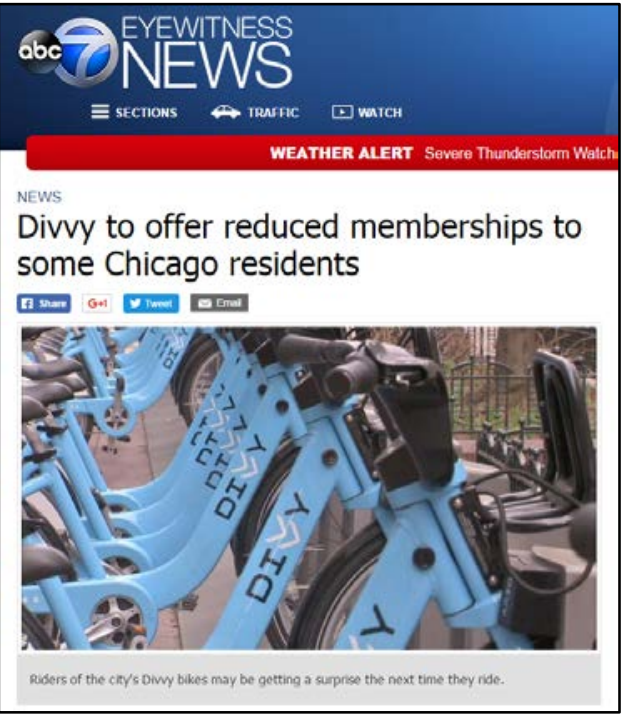

\section{Chicano đribume}

One-year Divvy discount coming for low-income Chicagoans

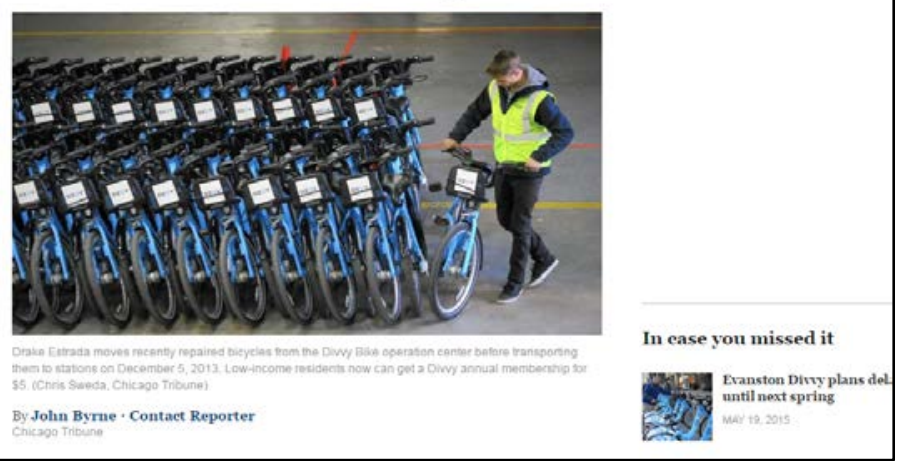

Figure 3-7 Divvy for Everyone outreach included major media coverage, including a speech by the mayor at a launch event in Bronzeville.

Go Bronzeville began as a City of Chicago transportation demand management (TDM) program in 2013. In the subsequent years, local volunteers took over running the program to further the cause of promoting local transportation options including bicycling in the Bronzeville neighborhood. Go Bronzeville has a team of outreach specialists focused on the D4E's “deep-dive” education and outreach pilot program. Go Bronzeville's team consisted of an outreach manager, a well-connected community member, and an ambassador who often leads Slow Roll rides in Bronzeville along with conducting other outreach. The community rides, along with Go Bronzeville’s presence at events and broader work in the community, 
were the primary outreach strategies. Typically, two to three ride participants used Divvy bikes on the neighborhood rides.

Between July 2015 and October 2016, Slow Roll reported conducting 89 events with over 3,500 participants, while Go Bronzeville reported 36 events with over 1,500 participants. Though outreach was planned to coordinate with the launch of D4E in July, most happened in fall and winter, due to contracting delays.

Data collection and research. CDOT tracked and analyzed D4E membership and use data to inform and evaluate outreach efforts. Participating FOC sign-up centers gathered data on new members. The Illinois Institute of Technology (IIT) Institute of Design led a graduate workshop on the adoption of bike share on the South Side. The students planned to use secondary data, surveys, and ethnographic techniques to better understand barriers and motivators of bike share use. 


\section{Methodology}

The primary data collection method was a survey of residents living near bike share stations placed in underserved communities of the three selected BBSP cities. In general, these were neighborhoods targeted for focused outreach related to BBSP programs, though we also identified control areas in two of the three cities that did not receive BBSP targeted outreach as comparison sites. Figure 4-1 presents an overview of the survey development, and Figure 4-2 provides a timeline of events related to this research, marked by location. The rest of this chapter describes the selection of cities, selection of specific neighborhood study areas, development of the resident survey questionnaire, and our recruitment and data collection efforts.

2014: PeopleForBikes and BBSP release RFP for "pilot strategies to address barriers to and increase the use of bike share systems in underserved communities."

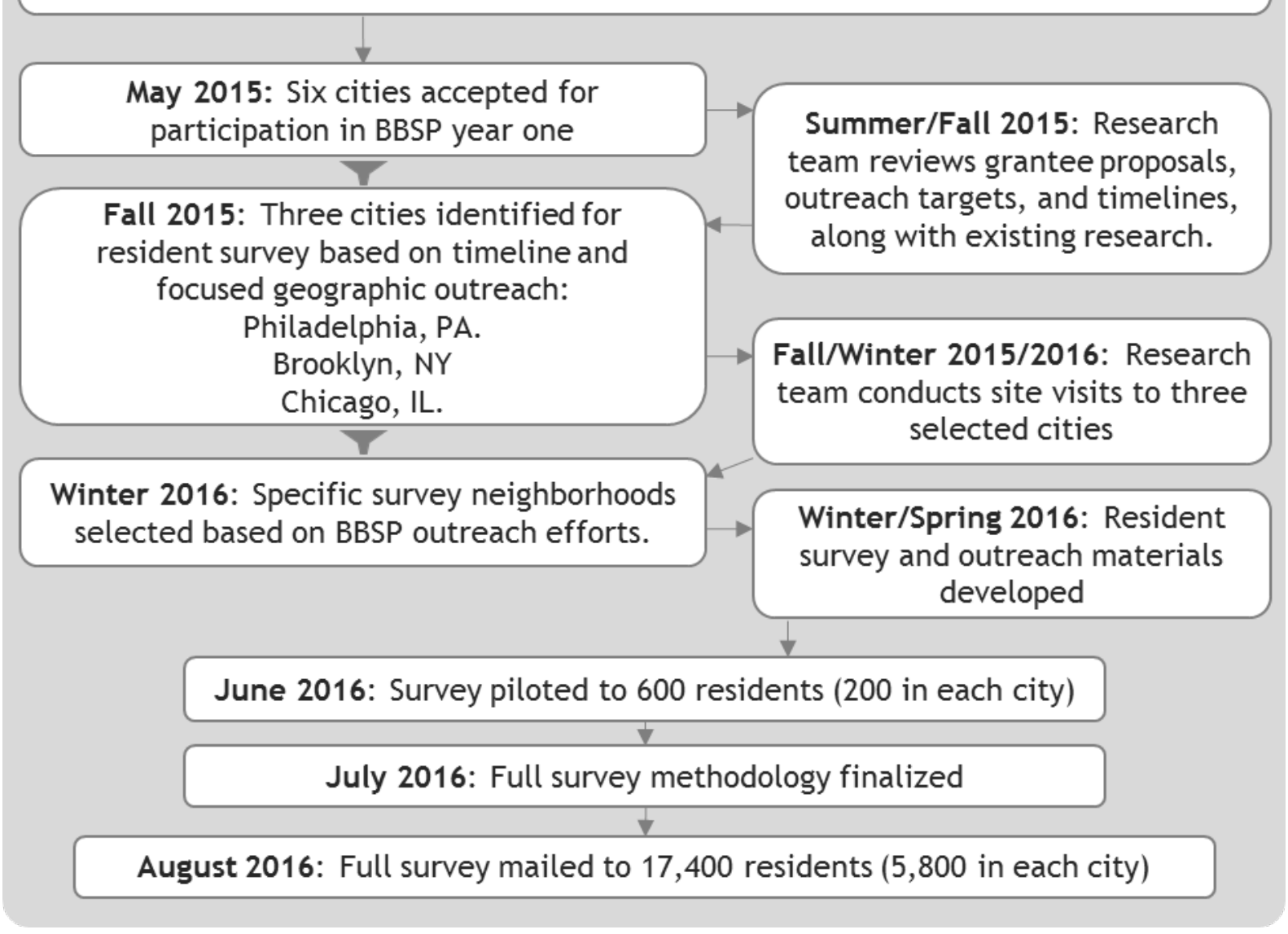

Figure 4-1 Steps in resident survey development 


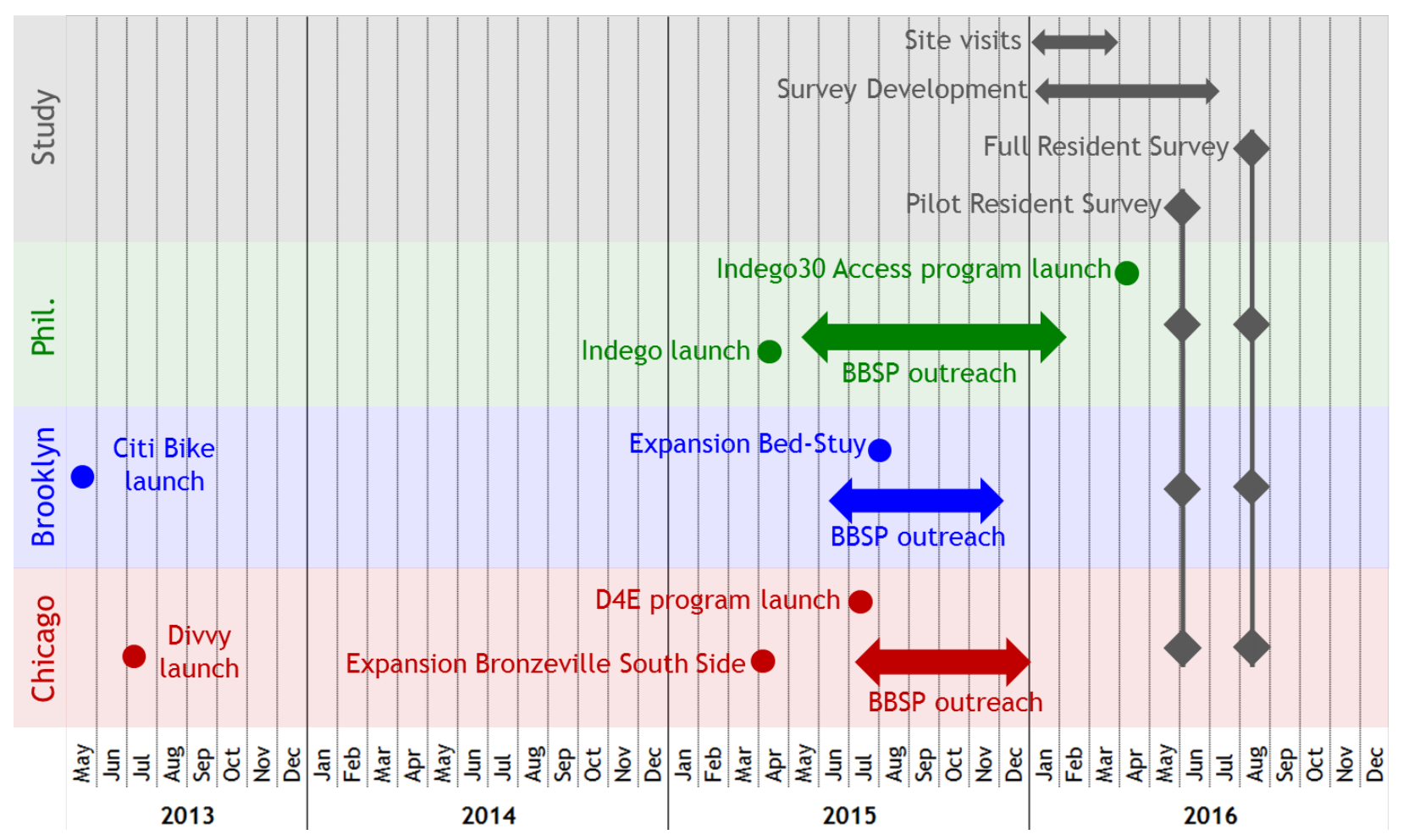

Figure 4-2 Timeline of events by study location

\subsection{City selection and profiles}

An initial step was to understand the local context and outreach strategy in each BBSP grant city. The project team attended a launch meeting of all BBSP partners in Boulder, Colorado, in May 2015, at which partners from each city explained their bike share systems, challenges, barriers for underserved communities, and planned efforts and initiatives. The research team also reviewed materials provided by grantees about their proposed projects and efforts. After meeting with representatives of each city over the phone, the project team identified the best potential cities to include in the survey. Key factors included projects that were far enough along in terms of implementation for there to be an impact in the community, specific geographic targets for outreach that could be used for survey distribution, and stations on the ground in outreach areas. Based on the project budget and the need to have a large enough sample in each city, three cities were selected for inclusion in the final survey: Philadelphia, Chicago, and Brooklyn/New York.

\subsubsection{Philadelphia/ Indego}

Having launched in 2015 at the same time the BBSP program began, Philadelphia's Indego bike share system covered a relatively small portion of the city at the time of this research. Only about $6 \%$ of the city's area and $13 \%$ of residents were within a quarter-mile of Indego's 73 stations. Compared with the city as a whole, Indego's service area was higher-income and had a higher concentration of white, nonHispanic residents (Table 4-1). The initial wave of stations was concentrated in the central city. The average straight-line distance from City Hall was just over a mile. Probably partly attributable to this downtown proximity, the average station was used frequently, generating about 8,000 trips per year. The membership rate was about 3.9 per 100 people within a quarter-mile. Indego riders benefit from Central Philadelphia's relatively dense grid of one-way streets. The average station was within one-tenth of a mile from the nearest bike lane or paved off-street path. 
Table 4-1 Philadelphia Area Descriptions

\begin{tabular}{|c|c|c|c|c|c|}
\hline Philadelphia Area Descriptions & $\begin{array}{l}\text { West } \\
\text { Study } \\
\text { Area }\end{array}$ & $\begin{array}{l}\text { North } \\
\text { Study } \\
\text { Area }\end{array}$ & $\begin{array}{l}\text { South } \\
\text { Study } \\
\text { Area }\end{array}$ & $\begin{array}{l}\text { Indego } \\
\text { Coverage } \\
\text { Area }^{1}\end{array}$ & Philadelphia \\
\hline Land area (square miles) & 0.5 & 0.6 & 0.4 & 8.9 & 142.8 \\
\hline Population & 9,317 & 7,998 & 11,823 & 215,000 & 1.6 mil. \\
\hline Population density (per square mile) & 18,634 & 13,330 & 29,558 & 24,157 & 11,204 \\
\hline Housing vacancy rate & $22 \%$ & $20 \%$ & $22 \%$ & $14 \%$ & $13 \%$ \\
\hline People of color & $83 \%$ & $84 \%$ & $82 \%$ & $46 \%$ & $64 \%$ \\
\hline Median income (average over tracts, for areas) & $\$ 17,855$ & $\$ 18,585$ & $\$ 37,343$ & $\$ 54,183$ & $\$ 42,111$ \\
\hline Below $150 \%$ of poverty guideline & $66 \%$ & $55 \%$ & $40 \%$ & $31 \%$ & $38 \%$ \\
\hline Below $300 \%$ of poverty guideline & $83 \%$ & $80 \%$ & $67 \%$ & $51 \%$ & $64 \%$ \\
\hline No car in household & $55 \%$ & $58 \%$ & $49 \%$ & $42 \%$ & $32 \%$ \\
\hline Commute by bicycle & $4.7 \%$ & $7.5 \%$ & $7.4 \%$ & $6.3 \%$ & $2.1 \%$ \\
\hline Commute by public transit & $39 \%$ & $41 \%$ & $41 \%$ & $24 \%$ & $26 \%$ \\
\hline \multicolumn{6}{|c|}{ Following calculations include $1 / 4-$ mile buffers around study and outreach areas } \\
\hline Size (square miles, including $1 / 4$-mile buffer) & 1.3 & 1.7 & 1.3 & 8.9 & \\
\hline Indego bike share stations $(2015)^{2}$ & 6 & 9 & 6 & 73 & \\
\hline Average station density (per square mile) & 4.6 & 5.3 & 4.6 & 8.2 & \\
\hline Average number of other stations within $1 / 4$ mile & 0.3 & 0.4 & 0.2 & 0.9 & \\
\hline Average number of other stations within $1 / 2$ mile & 4.0 & 3.4 & 3.2 & 4.7 & \\
\hline Average number of other stations within 1 mile & 12.7 & 16.1 & 15 & 18.4 & \\
\hline $\begin{array}{l}\text { Average station distance to City Hall (straight-line, } \\
\mathrm{mi} \text { ) }\end{array}$ & 1.8 & 1.2 & 1.2 & 1.1 & \\
\hline $\begin{array}{l}\text { Average annual trips starting from bike share } \\
\text { station }(2015)^{3}\end{array}$ & 5,558 & 4,155 & 5,958 & 7,996 & \\
\hline $\begin{array}{l}\text { Average annual bike share trips per } 100 \text { people } \\
\text { within quarter-mile }(2015)^{3}\end{array}$ & 133 & 122 & 107 & 212 & \\
\hline $\begin{array}{l}\text { Indego Bike Share Annual Members (per } 100 \text { adults } \\
\text { ages } 18-64)^{4}\end{array}$ & & & & 5.0 & \\
\hline Street network density (miles per square mile) & 28.8 & 35.6 & 43.1 & 35.4 & 19.3 \\
\hline Total miles of bicycle facilities (lanes or paths) & 8.7 & 3.8 & 2.3 & 44.8 & 280.0 \\
\hline Total miles of standard bicycle lane & 7.6 & 3.8 & 2.3 & 33.8 & 228.7 \\
\hline Total miles of buffered bicycle lane & 0.5 & 0 & 0 & 9.0 & 11.3 \\
\hline Total miles of off-street bicycle path & 0.6 & 0 & 0 & 2.1 & 40.0 \\
\hline Density of bicycle facilities (miles per square mile) & 6.7 & 2.2 & 1.7 & 5.0 & 2.0 \\
\hline $\begin{array}{l}\text { Average distance (straight-line, mi) from bike } \\
\text { share station to nearest bicycle facility (lane or } \\
\text { path) }\end{array}$ & 0.05 & 0.10 & 0.14 & 0.09 & \\
\hline
\end{tabular}




\subsubsection{Brooklyn}

The launch of Citi Bike in 2013 included 10 stations in Bed-Stuy. With an expansion in 2015, the neighborhood had a total of 36 Citi Bike stations. Area statistics comparing the Citi Bike coverage area (following the 2015 expansion) to the outreach study area, control study area, and the city overall are shown in Table 4-2 (excluding the Jersey City expansion in New Jersey). Following the 2015 expansion, Citi Bike covered approximately 7\% of the land area of New York City, but included about $15 \%$ of the city's population. The Citi Bike coverage area had a population density over twice that of the city as a whole ( 60,000 people per square mile compared to 27,000 for the city). People in the coverage area were wealthier, more likely to be white, more likely to live in a car-less household, and 2.4 times as likely to commute by bicycle. 
Table 4-2 Brooklyn/New York City Area Descriptions

\begin{tabular}{|c|c|c|c|c|}
\hline Brooklyn/New York City Area Descriptions & $\begin{array}{c}\text { Outreach } \\
\text { Study } \\
\text { Area }\end{array}$ & $\begin{array}{c}\text { Control } \\
\text { Study } \\
\text { Area }\end{array}$ & $\begin{array}{c}\text { Citi Bike } \\
\text { Coverage } \\
\text { Area }^{2}\end{array}$ & $\begin{array}{l}\text { New } \\
\text { York } \\
\text { City }\end{array}$ \\
\hline Land area (square miles) & 1.2 & 0.3 & 22.2 & 306.8 \\
\hline Population & 72,337 & 25,331 & 1.3 mil. & $8.4 \mathrm{mil}$. \\
\hline Population density (per square mile) & 60,281 & 84,437 & 60,684 & 27,379 \\
\hline Housing vacancy rate & $12 \%$ & $5 \%$ & $14 \%$ & $9 \%$ \\
\hline People of color & $89 \%$ & $80 \%$ & $43 \%$ & $67 \%$ \\
\hline Median income (average over tracts, for areas) & $\$ 40,622$ & $\$ 28,841$ & $\$ 86,928$ & $\$ 53,373$ \\
\hline Below $150 \%$ of poverty guideline & $44 \%$ & $48 \%$ & $23 \%$ & $31 \%$ \\
\hline Below $300 \%$ of poverty guideline & $67 \%$ & $73 \%$ & $31 \%$ & $53 \%$ \\
\hline No car in household & $69 \%$ & $74 \%$ & $75 \%$ & $55 \%$ \\
\hline Commute by bicycle & $3.1 \%$ & $2.8 \%$ & $2.4 \%$ & $1.0 \%$ \\
\hline Commute by public transit & $70 \%$ & $75 \%$ & $57 \%$ & $57 \%$ \\
\hline \multicolumn{5}{|c|}{ Following calculations include $1 / 4$-mile buffers around study and outreach areas } \\
\hline Size (square miles, including $1 / 4$-mile buffer) & 3.1 & 1.2 & 22.2 & \\
\hline Citi Bike stations $(2015)^{3}$ & 33 & 19 & 470 & \\
\hline Average station density (per square mile) & 10.5 & 16.3 & 21.2 & \\
\hline Average number of other stations within $1 / 4$ mile & 2.0 & 3.2 & 4.0 & \\
\hline Average number of other stations within $1 / 2$ mile & 10.7 & 13.5 & 16.5 & \\
\hline Average number of other stations within 1 mile & 34.3 & 44.3 & 55.2 & \\
\hline Average station distance to City Hall (straight-line, mi) & 3.6 & 3.1 & 2.5 & \\
\hline Average annual trips starting from bike share station $(2015)^{4}$ & 2,627 & 4,305 & 28,673 & \\
\hline $\begin{array}{l}\text { Average annual bike share trips per } 100 \text { people within quarter- } \\
\text { mile }(2015)^{4}\end{array}$ & 24.1 & 40.1 & 223 & \\
\hline Citi Bike Annual Members (per 100 adults ages $18-64)^{5}$ & & & 8.4 & \\
\hline Street network density (miles per square mile) & 25.5 & 32.7 & 32.9 & 22.7 \\
\hline Total miles of bicycle facilities (lanes or paths) & 10.2 & 3.4 & 124.1 & 451.5 \\
\hline Total miles of standard bicycle lane & 10.2 & 3.3 & 83.3 & 278.7 \\
\hline Total miles of separated/ protected bicycle lane & 0 & 0.08 & 22.6 & 30.4 \\
\hline Total miles of off-street bicycle path & 0 & 0 & 18.2 & 141.1 \\
\hline Density of bicycle facilities ${ }^{6}$ (miles per square mile) & 3.3 & 2.8 & 5.6 & 1.5 \\
\hline $\begin{array}{l}\text { Average distance (straight-line, mi) from bike share station to } \\
\text { nearest bicycle facility (lane or path) }\end{array}$ & 0.11 & 0.11 & 0.09 & \\
\hline
\end{tabular}

\subsubsection{Chicago}

Divvy launched in June 2013 with 70 stations, and had reached 475 stations in 2015. Area statistics comparing the Divvy coverage area (following the 2015 expansion) to the outreach study area, control study area, and the city overall are shown in Table 4-3. The 2015 system covers $25 \%$ of the city land area, 
and reaches about $44 \%$ of the city population. The population density in the coverage area is twice that of the city overall (at about 21,000 people per square mile in the system area and 11,800 in the city overall). In contrast to Philadelphia and New York, people in the Divvy system area were more likely to be people of color, and had incomes only slightly above the city average.

Table 4-3 Chicago Area Descriptions

\begin{tabular}{|c|c|c|c|c|}
\hline Chicago Area Descriptions & $\begin{array}{l}\text { Outreach } \\
\text { Study } \\
\text { Area }\end{array}$ & $\begin{array}{c}\text { Control } \\
\text { Study } \\
\text { Area }\end{array}$ & $\begin{array}{c}\text { Divvy } \\
\text { Coverage } \\
\text { Area }^{1}\end{array}$ & Chicago \\
\hline Land area (square miles) & 2.0 & 0.7 & 56.6 & 227.6 \\
\hline Population & 30,395 & 16,099 & 1.2 mil. & $2.7 \mathrm{mil}$. \\
\hline Population density (per square mile) & 15,198 & 22,999 & 21,201 & 11,863 \\
\hline Housing vacancy rate & $19 \%$ & $28 \%$ & $12 \%$ & $13 \%$ \\
\hline People of color & $95 \%$ & $97 \%$ & $55 \%$ & $68 \%$ \\
\hline Median income (average over tracts, for areas) & $\$ 39,077$ & $\$ 25,695$ & $\$ 57,077$ & $\$ 49,489$ \\
\hline Below $150 \%$ of poverty guideline & $47 \%$ & $61 \%$ & $31 \%$ & $34 \%$ \\
\hline Below $300 \%$ of poverty guideline & $67 \%$ & $82 \%$ & $50 \%$ & $58 \%$ \\
\hline No car in household & $41 \%$ & $51 \%$ & $32 \%$ & $27 \%$ \\
\hline Commute by bicycle & $0.8 \%$ & $0.9 \%$ & $2.5 \%$ & $1.6 \%$ \\
\hline Commute by public transit & $32 \%$ & $36 \%$ & $34 \%$ & $28 \%$ \\
\hline \multicolumn{5}{|c|}{ Following calculations include $1 / 4-$ mile buffers around study and outreach areas } \\
\hline Size (square miles, including 1/4-mile buffer) & 3.7 & 1.9 & 56.6 & \\
\hline Divvy bike share stations $(2015)^{2}$ & 14 & 5 & 477 & \\
\hline Average station density (per square mile) & 3.8 & 2.6 & 8.4 & \\
\hline Average number of other stations within $1 / 4$ mile & 0.1 & 0 & 1.2 & \\
\hline Average number of other stations within $1 / 2$ mile & 2.4 & 2 & 6.7 & \\
\hline Average number of other stations within 1 mile & 11.8 & 10.4 & 25.5 & \\
\hline Average station distance to City Hall (straight-line, mi) & 5.1 & 7.2 & 3.7 & \\
\hline Average annual trips starting from bike share station $(2015)^{3}$ & 853 & 847 & 6,948 & \\
\hline $\begin{array}{l}\text { Average annual bike share trips per } 100 \text { people within quarter- } \\
\text { mile }(2015)^{3}\end{array}$ & 14 & 5 & 456 & \\
\hline Divvy Bike Share Annual Members (per 100 adults ages 18-64) & & & 4.0 & \\
\hline Street network density (miles per square mile) & 22.7 & 19.3 & 23.2 & 19.5 \\
\hline $\begin{array}{l}\text { Total miles of bicycle facilities (lanes, paths, neighborhood } \\
\text { greenways) }\end{array}$ & 7.6 & 3.0 & 124.3 & 219.2 \\
\hline Total miles of standard bicycle lane & 4.6 & 1.9 & 58.2 & 98.2 \\
\hline Total miles of buffered bicycle lane & 3.0 & 1.1 & 38.0 & 64.9 \\
\hline Total miles of separated/ protected bicycle lane & 0 & 0 & 11.2 & 18.6 \\
\hline Total miles of off-street bicycle path & 0 & 0 & 15.5 & 36.1 \\
\hline Density of bicycle facilities ${ }^{5}$ (miles per square mile) & 2.1 & 1.6 & 2.2 & 1.0 \\
\hline $\begin{array}{l}\text { Average distance (straight-line, mi) from bike share station to } \\
\text { nearest bicycle facility (lane, path, neighborhood greenway) }\end{array}$ & 0.16 & 0.27 & 0.14 & \\
\hline
\end{tabular}




\subsection{Neighborhood selection and profiles}

Neighborhood selection was primarily informed by the outreach plans and local knowledge of our partner cities. Figure 4-3 presents an overview of the selected study areas in each city. To control for effects of station siting noted in existing research, we drew boundaries that ensured participants would be within about one-quarter mile from the nearest bike share station. To ensure adequate numbers of lower-income and people of color, we adjusted initial boundaries based on block group-level Census demographics and other data that would limit sampling in predominantly white, higher-income, or college student areas. In some cases, survey outreach borders were adjusted to exclude areas of predominantly student housing. Many of the underserved areas identified for BBSP outreach are near the expanding edge of the bike share system. As best we could, we either excluded edge stations or truncated our boundaries to exclude populations that would likely have little daily exposure to the bike share system.

Areas selected for survey distribution included the three outreach areas in Philadelphia, and each of the outreach areas in Brooklyn and Chicago. In addition to the BBSP outreach target areas, in Chicago and Brooklyn we identified nearby areas that were demographically comparable, received bike share stations near the same time as the outreach areas, but were not receiving BBSP-related outreach. It is important to note that while these control neighborhoods did not receive the special attention that the outreach neighborhoods received, they did receive elements of citywide outreach that took place in each city, and may have benefited from the targeted outreach in adjacent neighborhoods (for example, residents in the control areas could have attended special events, visited outreach centers, seen marketing materials, or participated in community bike rides in the outreach neighborhoods).

We conducted site visits in coordination with local partners to confirm whether the identified sites appeared to meet our expectations. Final adjustments to the study area boundaries were made after each visit. 


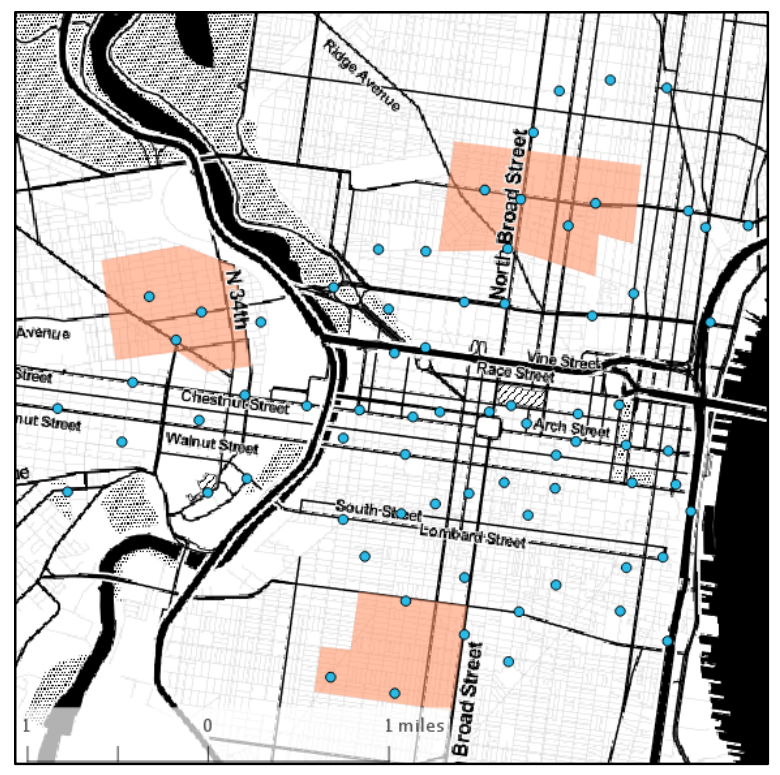

Philadelphia

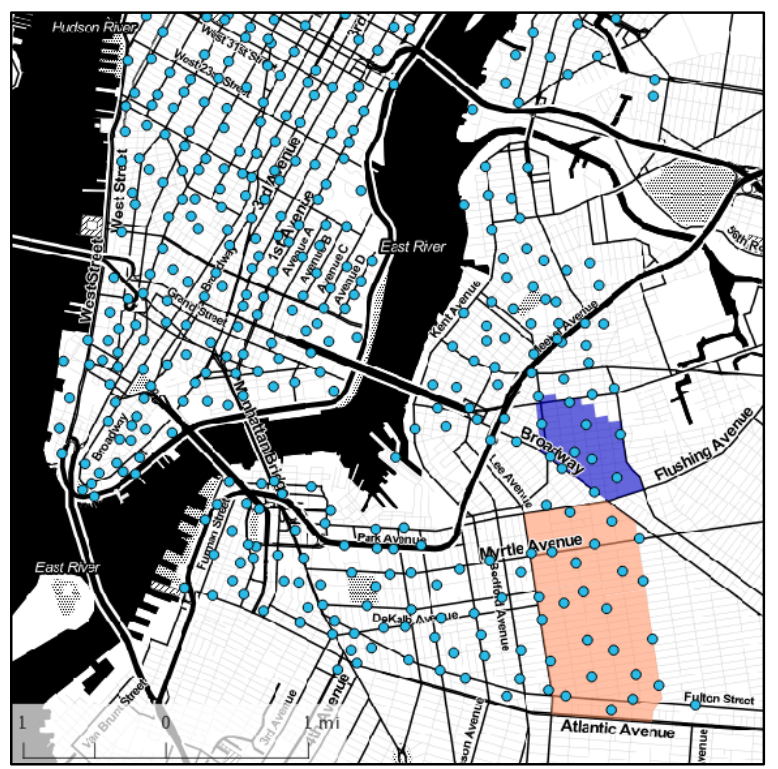

Brooklyn

Figure 4-3 Overview of bike share study areas

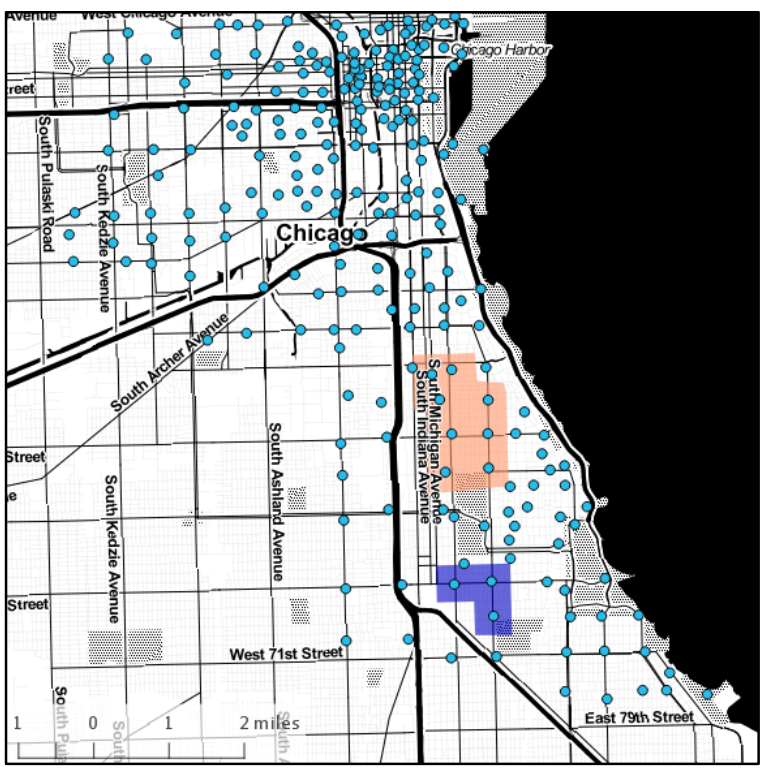

Chicago

- Bike Share Stations (2015)

Study Areas

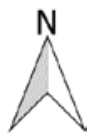

BBSP Outreach

Non-BBSP Control

Sources: Stamen Design, OpenStreetMap, Indego, Divvy, Citi Bike 


\subsubsection{Philadelphia study areas}

In Philadelphia, the partners targeted three distinct areas, including areas to the west and north of Drexel University and the University of Pennsylvania in West Philadelphia, areas between the central business district and Temple University in North Philadelphia, and the Point Breeze neighborhood in South Philadelphia. We were unable to identify a suitable control site in Philadelphia for two reasons: The bike share system had launched in a relatively small area, mostly within the central city, and the BBSP outreach efforts were less constrained to specific geographies.

A series of maps provides context for the study areas (Figure 4-4, Figure 4-5 and Figure 4-6). A selection of photos shows representative conditions in each of the three areas (Figure 4-7). The three study areas are each between 1 and 2 miles of downtown, with inner boundaries on the demographic fringe of the wealthier, whiter city center. We noted considerable variation in demographics and infrastructure across the three sites, but shares of lower-income households and people of color were substantially larger than the Indego system as a whole for each study area. The South outreach area was relatively wealthier and denser than the other two, closer in demographics to city averages.

Indego stations were placed farther apart in and around the study areas than in the larger system, and ridership was about $50-60 \%$ of the system average after adjusting for population density. With the exception of the West outreach area, bicycle infrastructure (bike lanes and off-street paths) was lacking relative to other parts of the bike share system. Members of the BBSP outreach team remarked that "West Philly is a great place to lead bike rides with newer riders because of the wider streets and plentiful bike lanes.” The West area is also the only one with stations close to an off-street path and had the highest bike share use, adjusted for population, despite being farther from downtown and having a smaller share of regular bike commuters. 


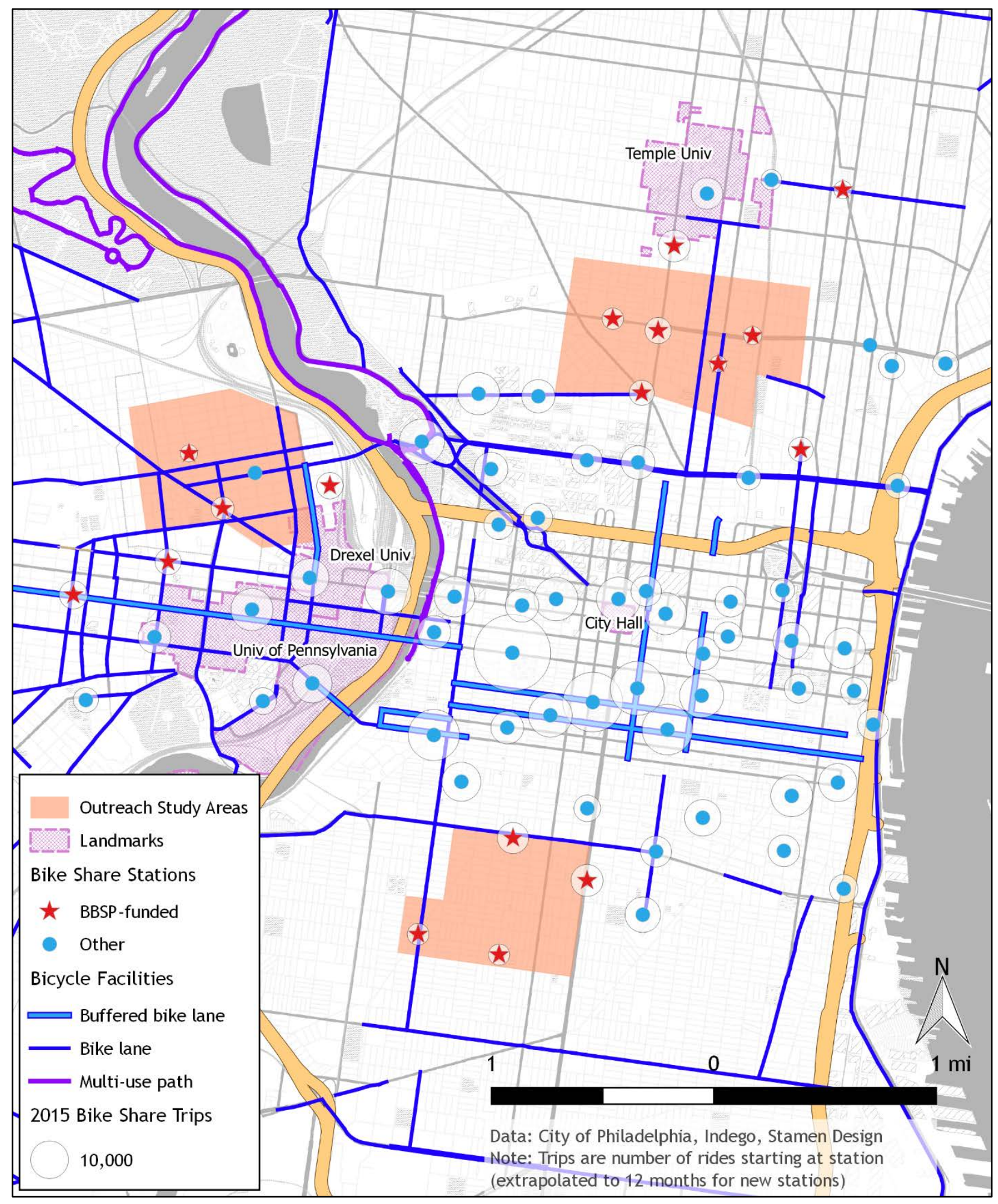

Figure 4-4 Philadelphia study areas overview map 


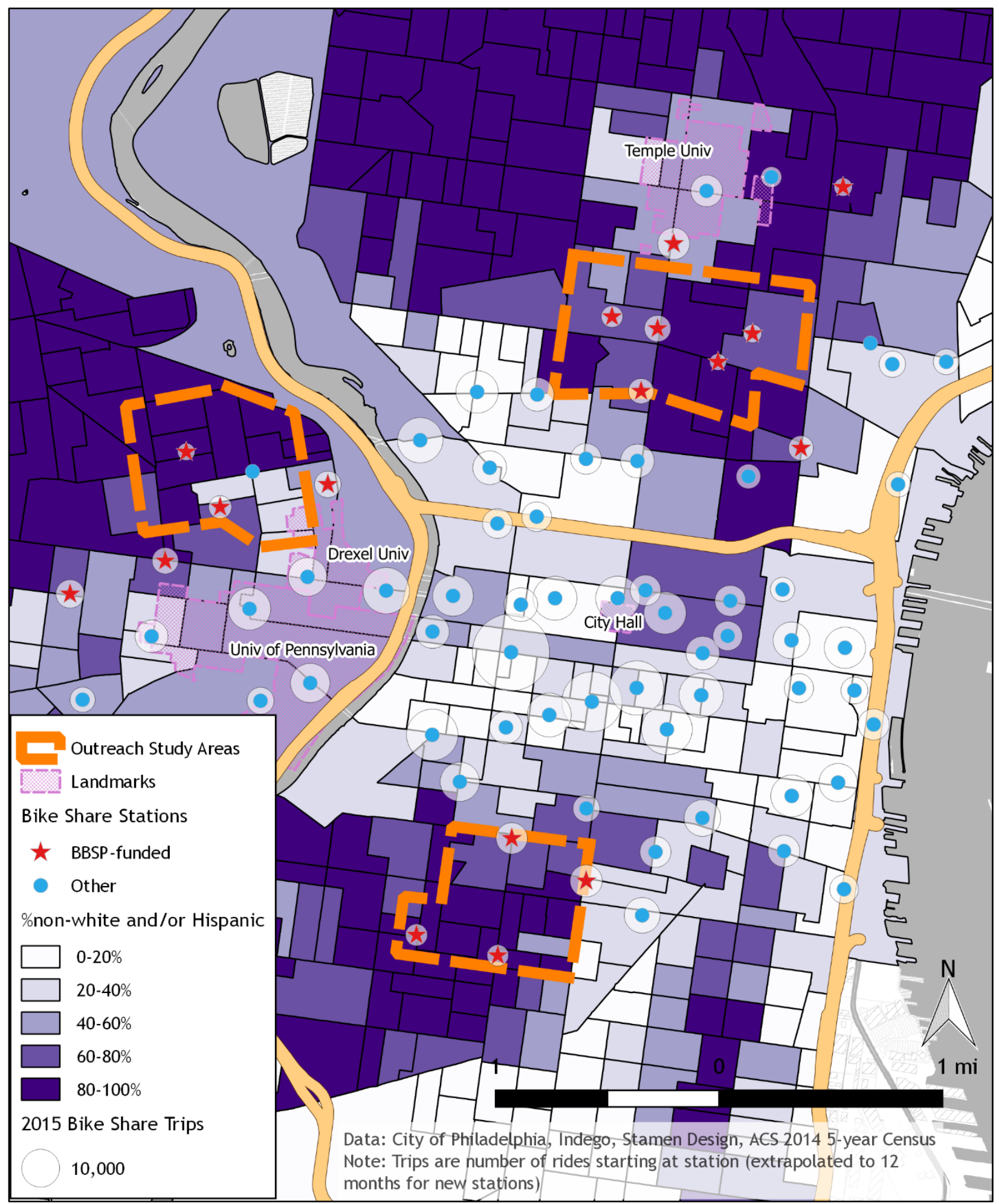

Figure 4-5 Philadelphia population, percentage people of color map 


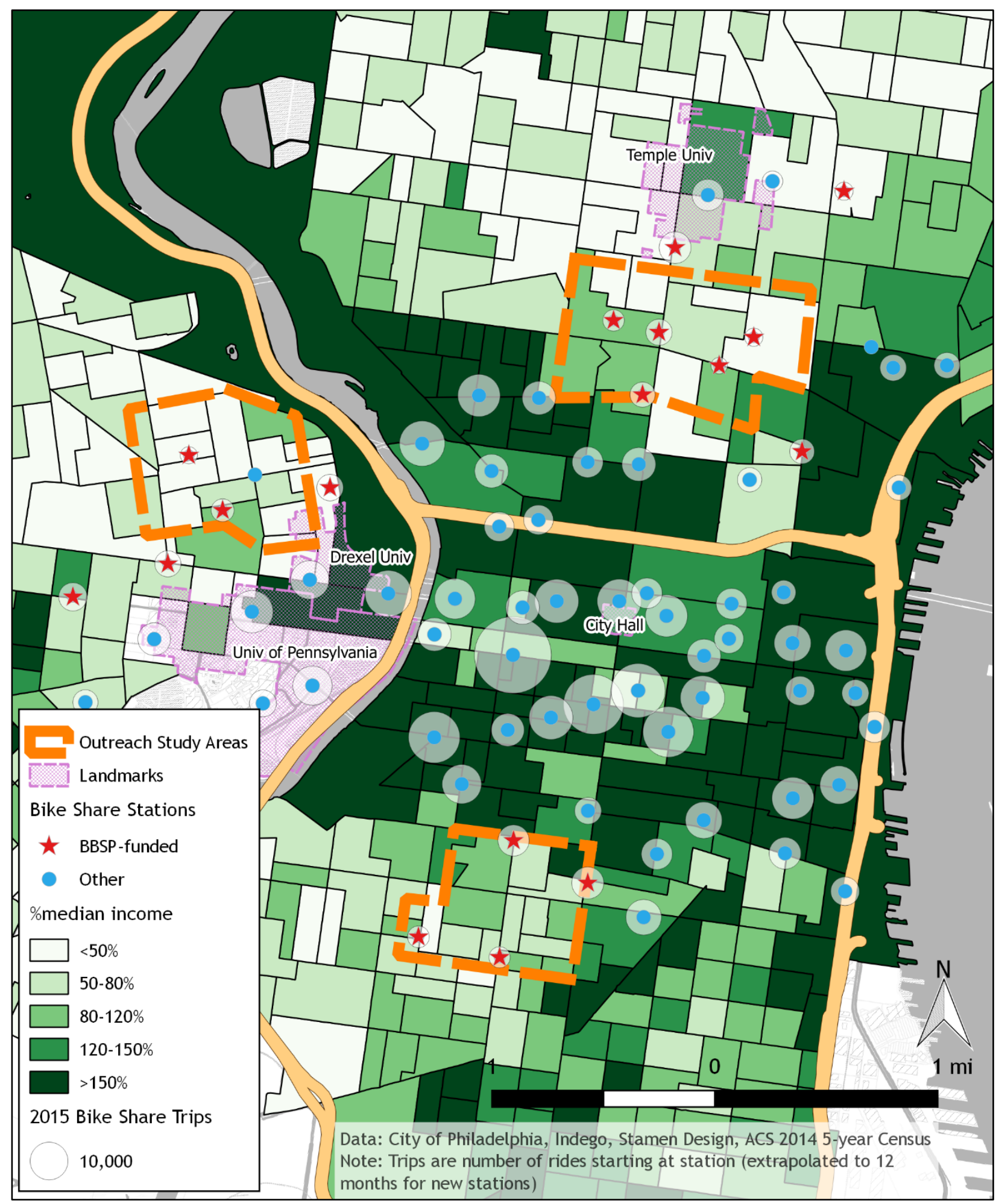

Figure 4-6 Philadelphia study areas, percentage of citywide median income $(\$ 37,460)$ map 

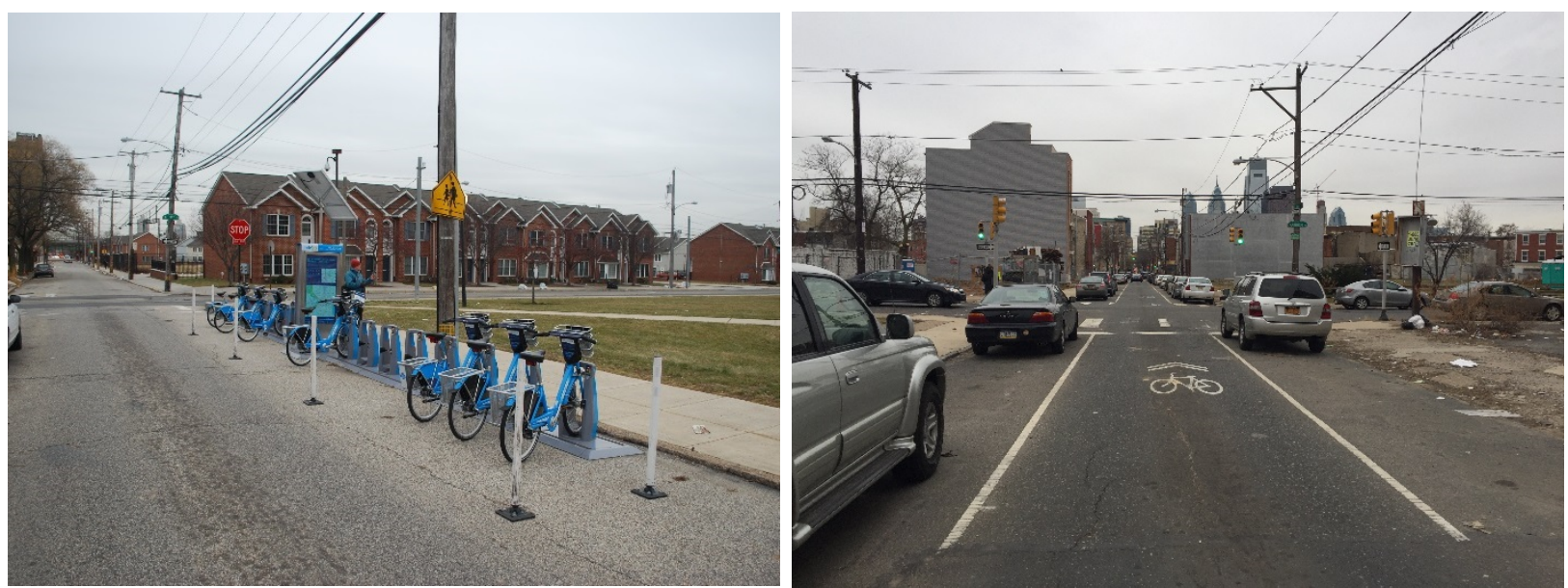

North Philadelphia study area, station and street with sharrow
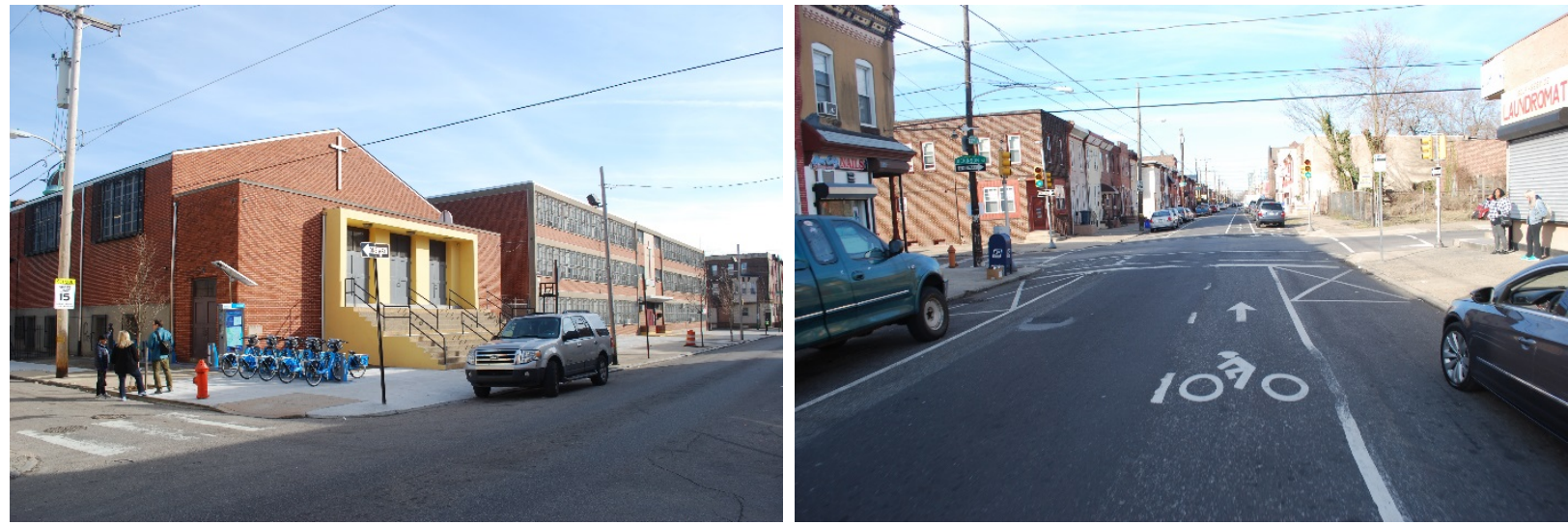

South Philadelphia / Point Breeze study area, station and street with bike lane
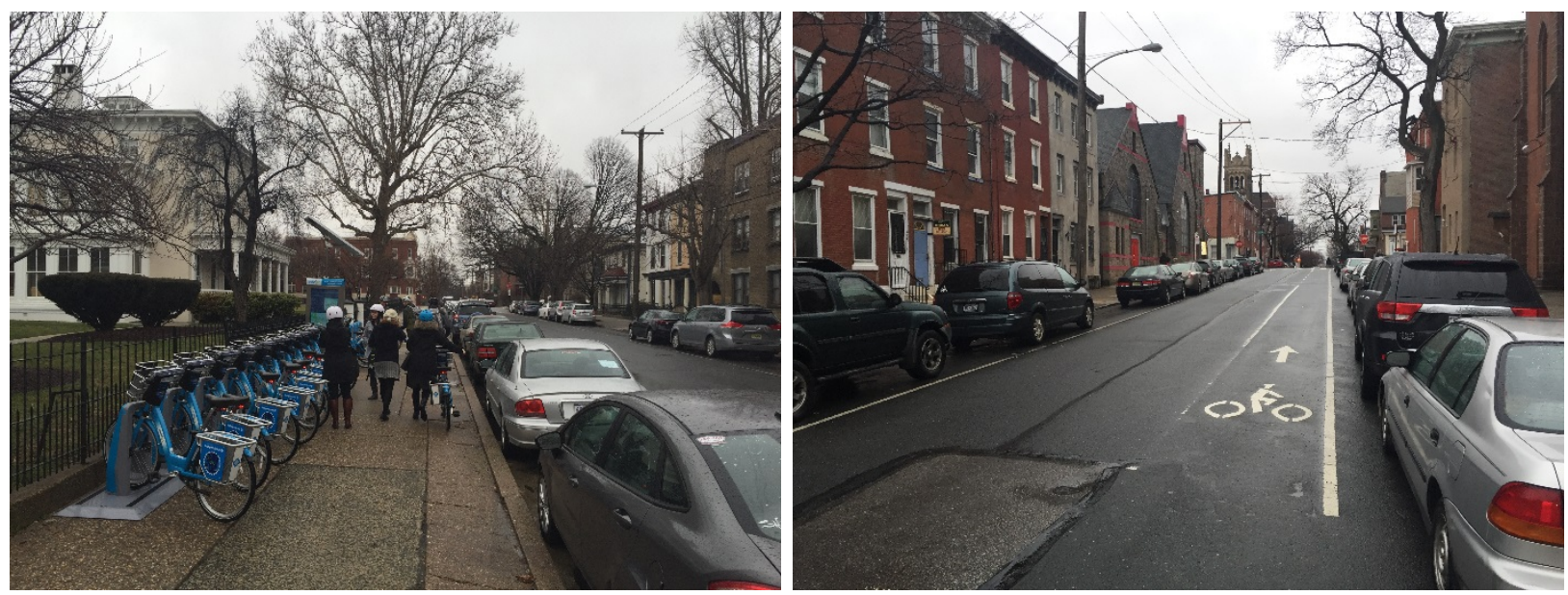

West Philadelphia study area, station and street with bike lane

Figure 4-7 Philadelphia study areas - photos 


\subsubsection{Brooklyn study areas}

In Brooklyn, outreach focused on the Bed-Stuy neighborhood, with much of the outreach centered on the areas bounded by Fulton Street on the south of the neighborhood, Flushing Avenue on the north, and between approximately Nostrand Avenue and Lewis Avenue. As a nonoutreach control location, we chose the area just to the north of Flushing Avenue from the outreach site, bounded by Broadway to the south, Grand Street to the north, and between Union and Bushwick Avenues. A series of maps provides context for the study areas (Figure 4-8, Figure 4-9 and Figure 4-10). A selection of photos shows representative conditions in both the outreach and control areas (Figure 4-11).

In comparison to the overall Citi Bike coverage area, people living in the outreach and control study areas were more likely to be people of color, and to have lower incomes. People in the study areas had slightly higher bicycle commute rates than in the Citi Bike coverage area. Citi Bike stations in the outreach area were half as densely distributed as in the system overall; the control area fell in between the two in terms of station density. Stations within the outreach study area and control area were considerably underutilized in comparison to the systemwide average, with 2,627 and 4,305 average annual bike share trips per station in the outreach and control areas respectively, compared to 28,673 overall.

Bike share stations in the study areas were about as close to the nearest bicycle lane or path as the average station in the system - just about a tenth of a mile. The study areas also had a density of bicycle facilities per square mile lower than the system average but higher than the citywide density. 


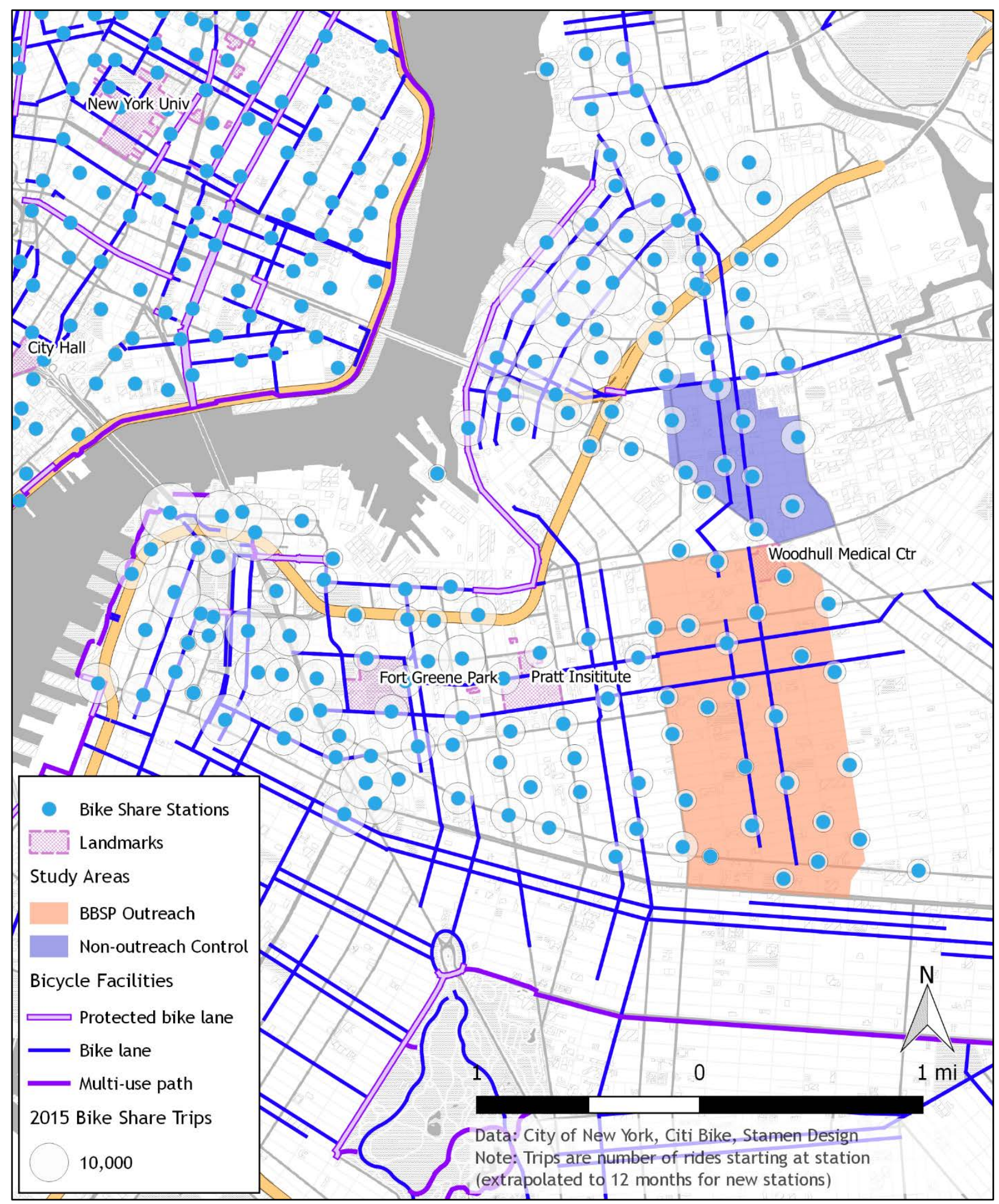

Figure 4-8 Brooklyn study areas overview map 


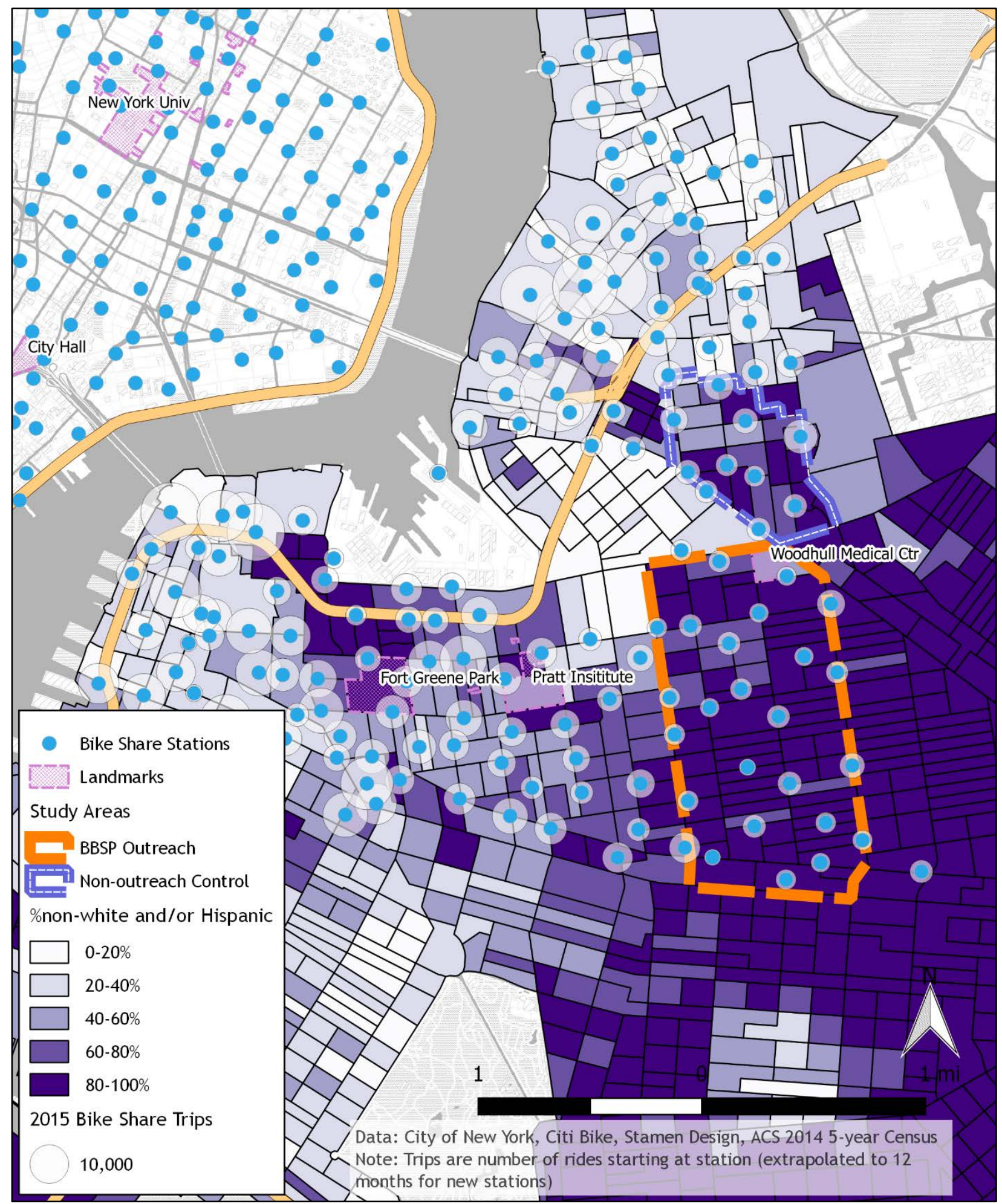

Figure 4-9 Brooklyn study areas people of color population map 




Figure 4-10 Brooklyn study areas and percentage of boroughwide median income $(\$ 46,954)$ map 

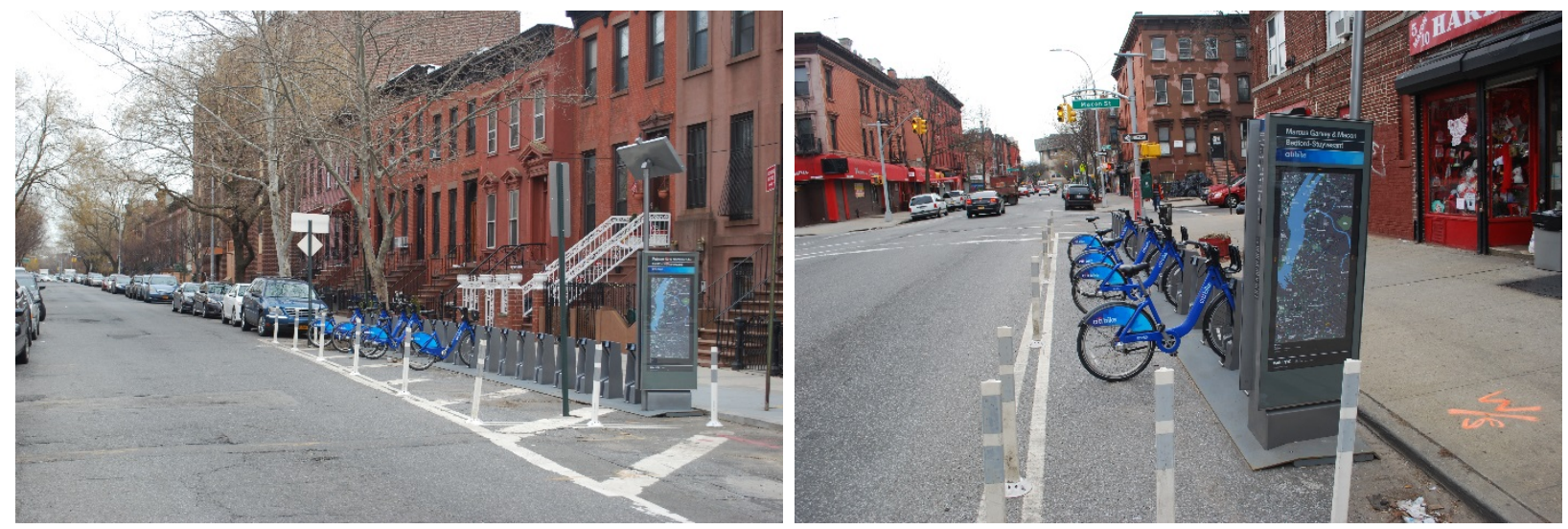

Bedford Stuyvesant Citi Bike stations

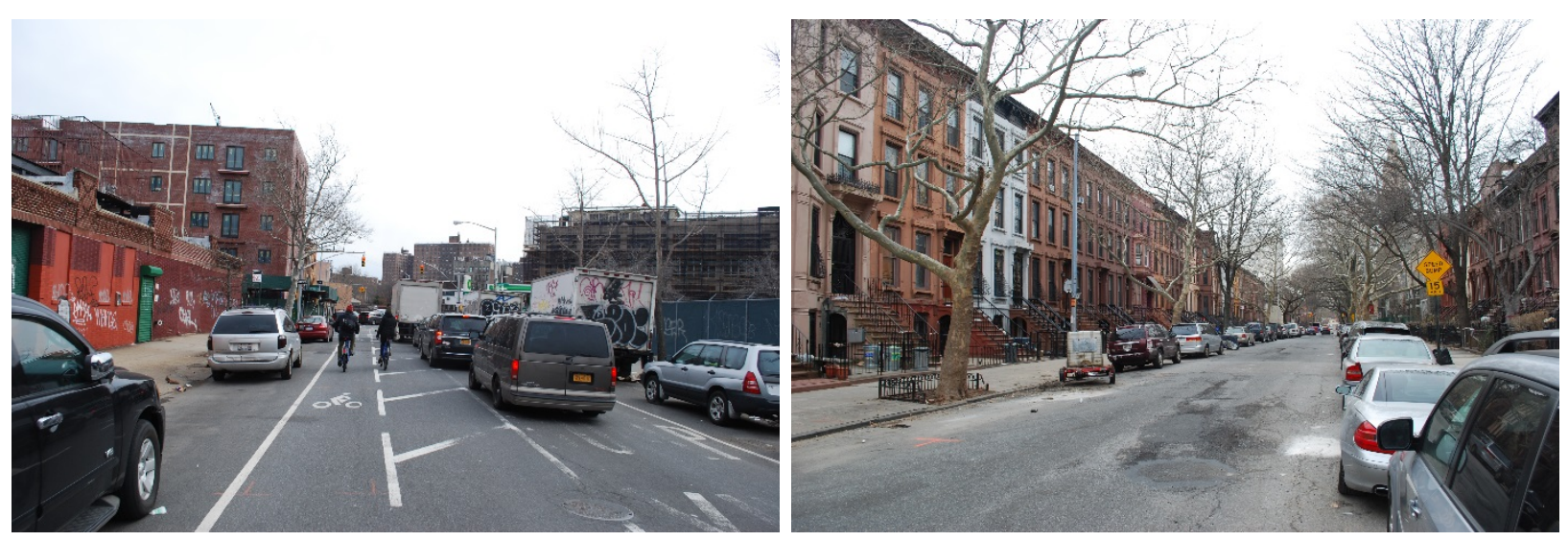

Bedford Stuyvesant street with bike lane and side street
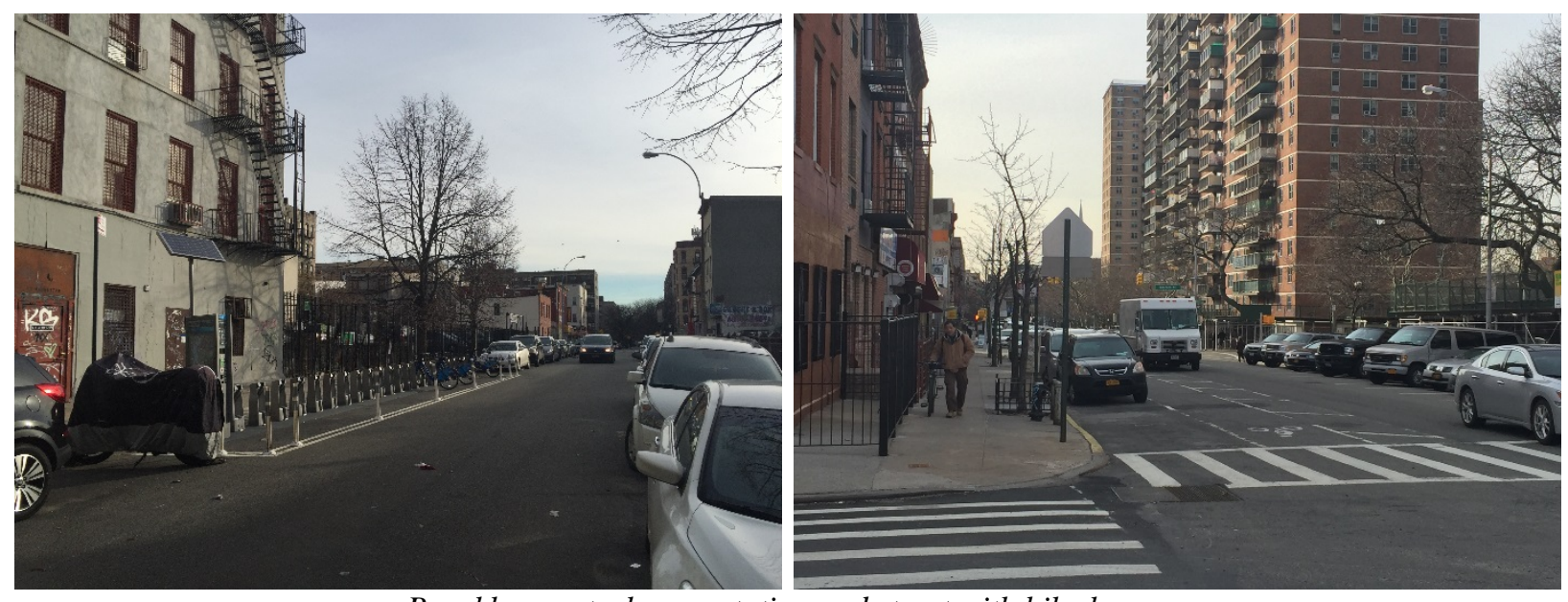

Brooklyn control area, station and street with bike lane

Figure 4-11 Brooklyn study areas - photos 


\subsubsection{Chicago study areas}

In Chicago, the central portion of the Bronzeville neighborhood was the focus of most outreach activity on Chicago's South Side between the Illinois Institute of Technology (IIT) on the north, Washington Park on the south, and east of the I-90/94 Freeway. As a control, we identified an area directly south of the outreach area, below Washington Park and north of I-94. A series of maps provides context for the study areas (Figure 4-12, Figure 4-13 and Figure 4-14). A selection of photos shows representative conditions in both the outreach and control areas (Figure 4-15).

People of color accounted for about $95 \%$ of the population in the outreach study area and control study area, compared to $45 \%$ for the system area overall. They were also lower income, particularly in the control area, more likely to be car-less households, and less likely to commute by bicycle. The large portion of the city that Divvy covers comes at the expense of station density. Systemwide, the station density was 8.4 stations per square mile and less than half that in the study areas. Stations within the study areas were receiving on average fewer than 1,000 annual trips, compared to about 7,000 for the system overall.

The study areas had a comparable density of bicycle facilities, in terms of miles of bike lanes or paths per square mile, as the Divvy system and city overall. 


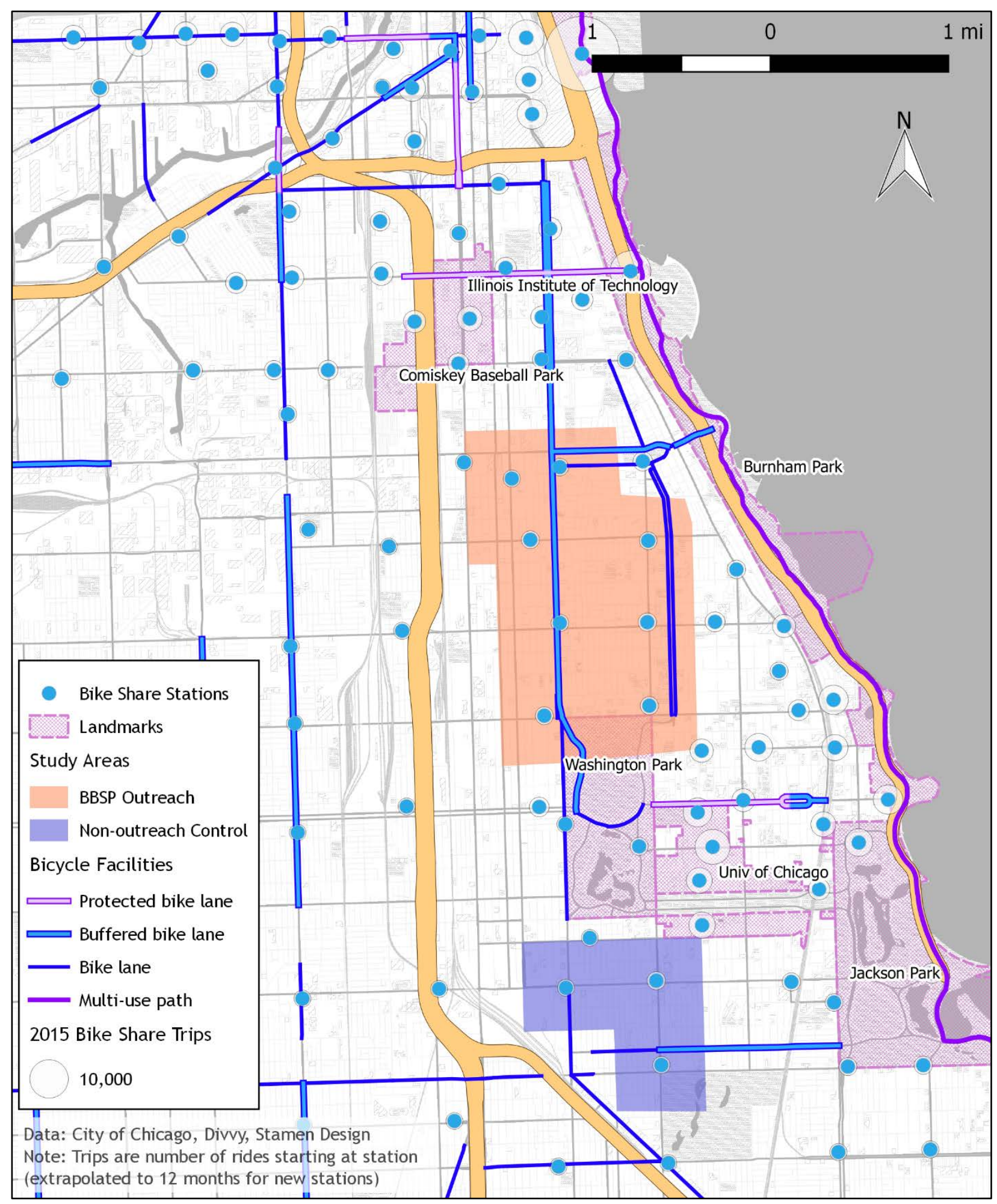

Figure 4-12 Chicago study areas overview map 


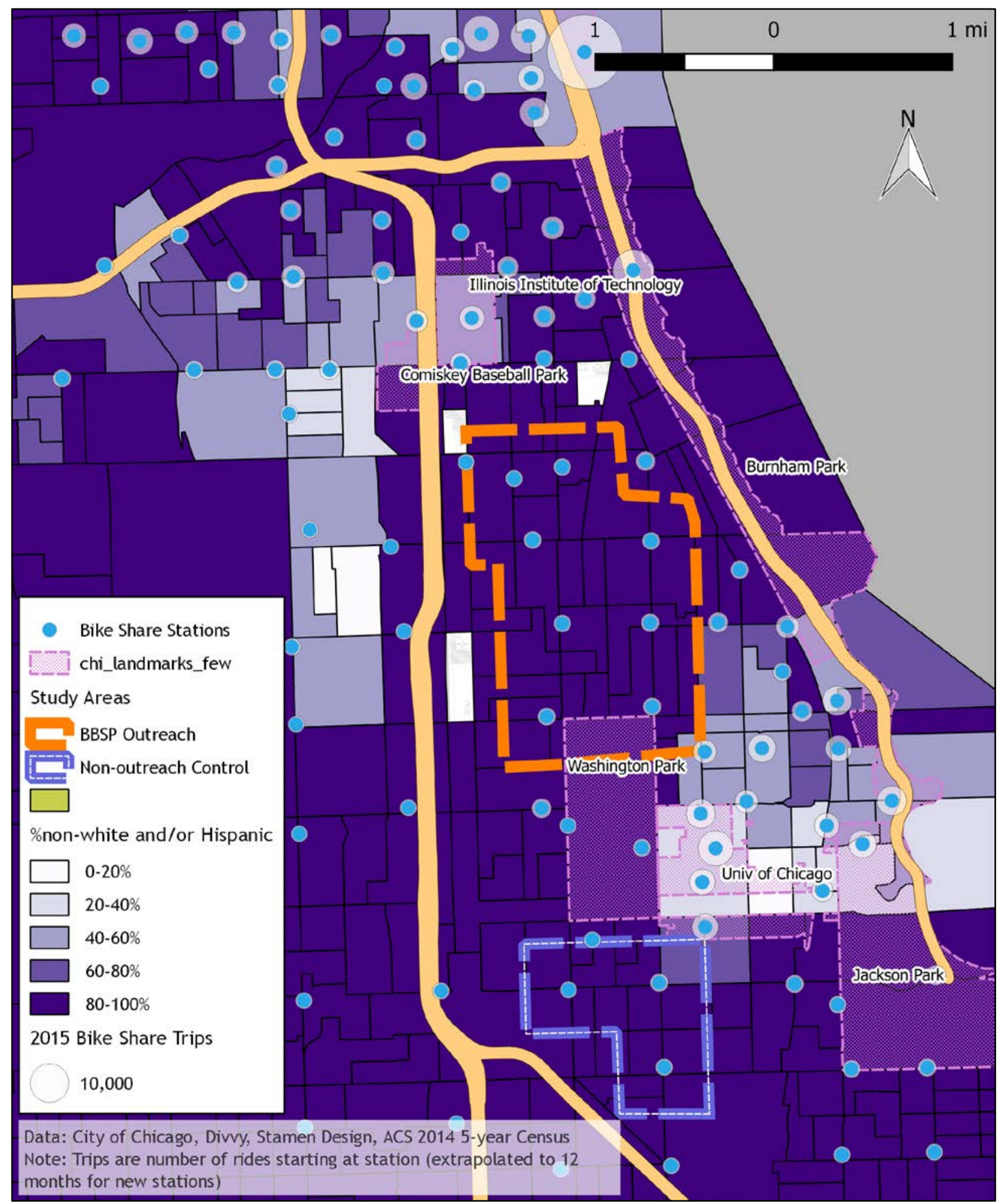

\section{Figure 4-13 Chicago percent people of color population map}




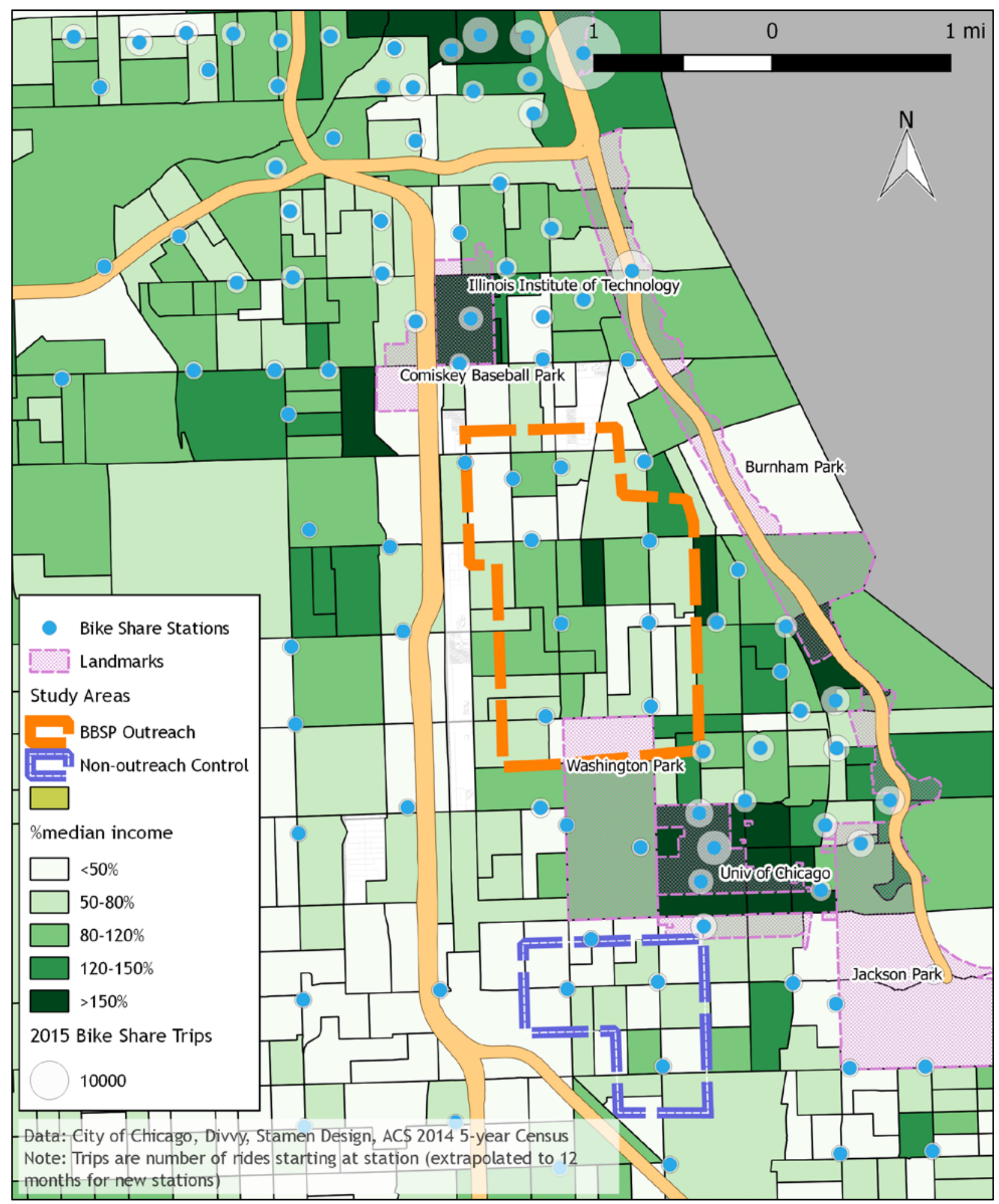

Figure 4-14 Chicago percentage of citywide median income $(\$ 47,831)$ map 

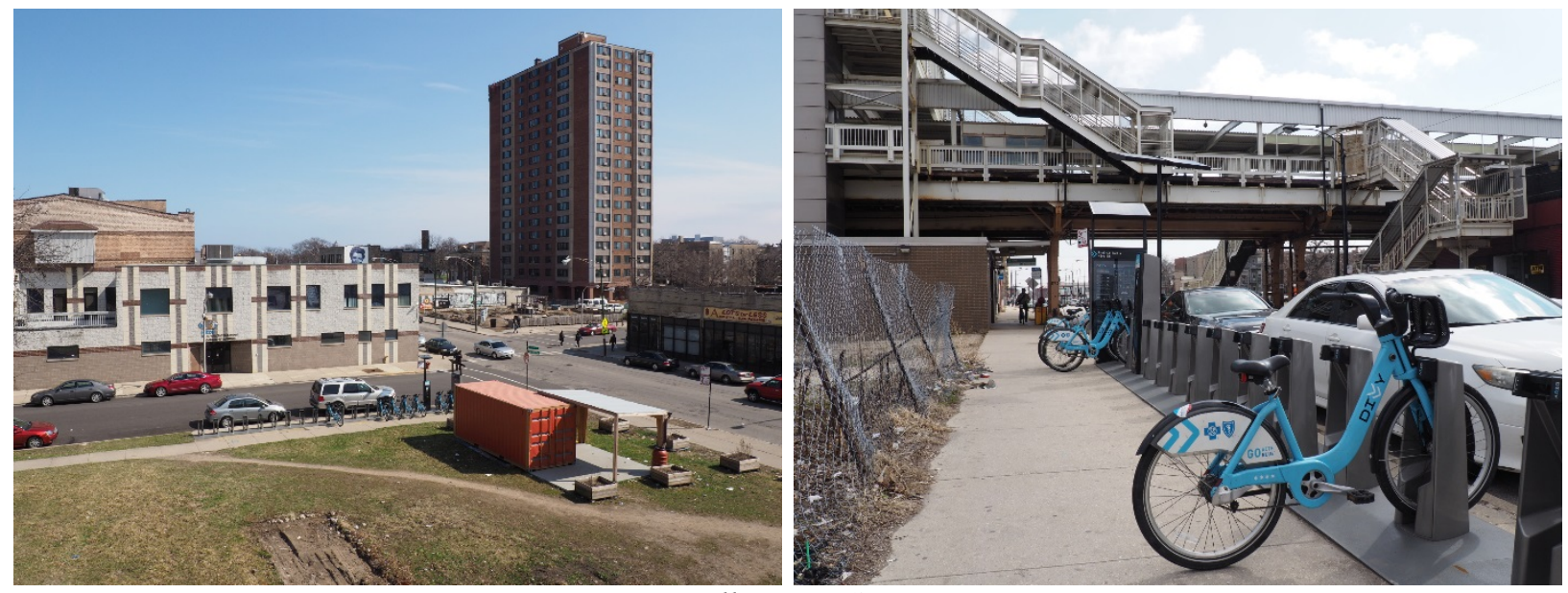

Bronzeville Divvy Stations

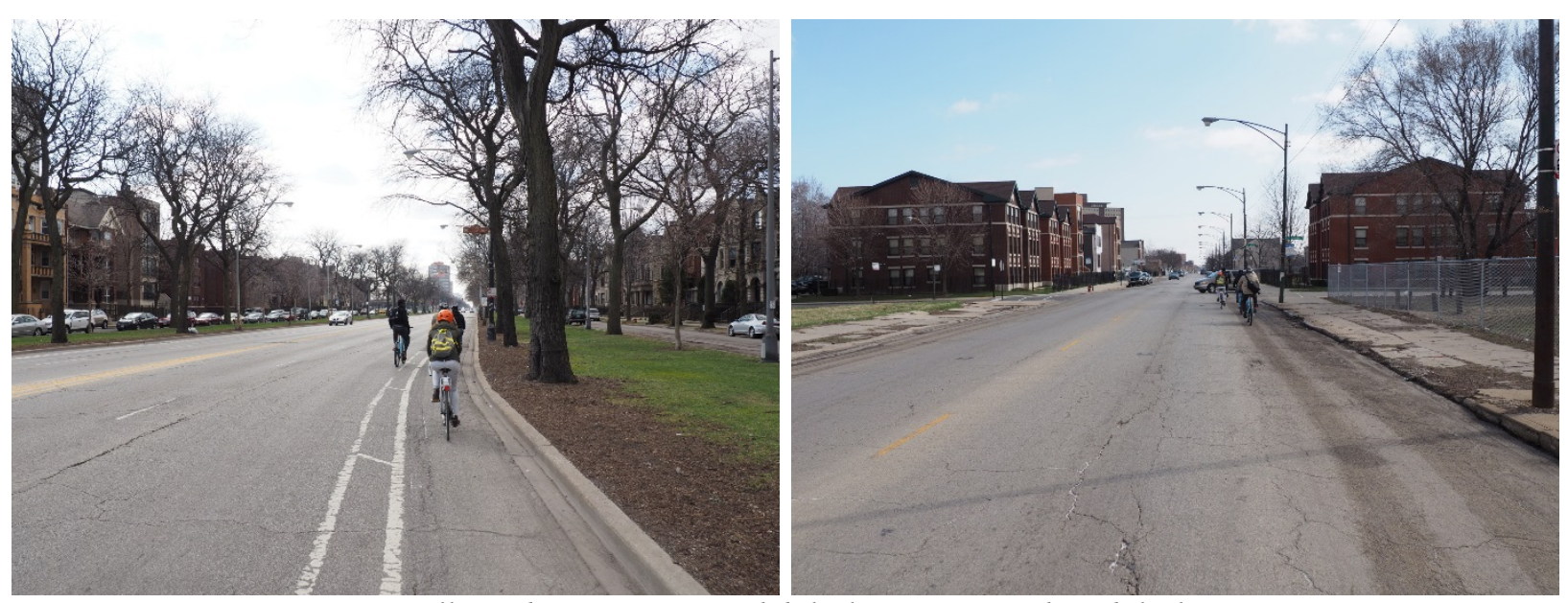

Bronzeville study area, street with bike lane, street without bike lane
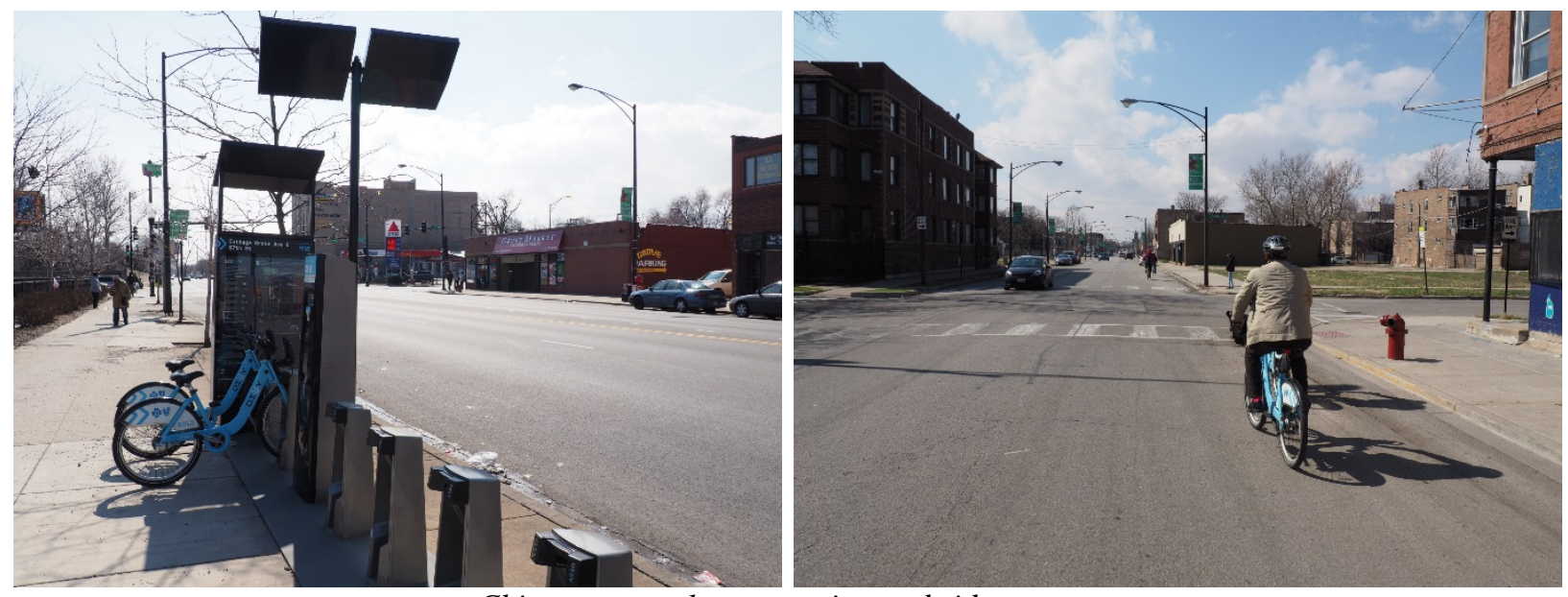

Chicago control area, station and side street

Figure 4-15 Chicago study areas - photos 


\subsubsection{Comparison of study locations}

The study cities and specific sites chosen for analysis had much in common. The three major cities and study areas had substantial populations of people of color and lower-income residents. The bike share systems in each location were relatively new (1-3 years old at the time of our survey), and the BBSP outreach areas were in neighborhoods at the expanding edges of the systems. Each neighborhood had received new stations in the year before our survey.

There were also some important differences across cities and sites that impact interpretation of the survey findings and our ability to pool or compare across locations. Indego in Philadelphia, unlike the systems in New York and Chicago, launched alongside BBSP. The system was also relatively small and located much closer to the central city (and the center of the bike share system). This located both system and study areas in areas with much higher bicycle commute shares than the other cities. These facts are likely reflected in the higher utilization of stations in the Philadelphia BBSP outreach areas. Also notable is the density of our Brooklyn sites relative to those in the other cities. This was noticeable in the feel of the neighborhood during our site visits and in some ways makes conditions more challenging for bicycling there, given the competition for street space. While not reflected in the area profiles, the Chicago sites, particularly the outreach neighborhood of Bronzeville, are relatively close to the Chicago lake front, a series of linear parks and beaches with a popular bike path that is a major recreational destination.

Finally, a note on our selected control sites. The Chicago control site is about 2 miles farther from downtown, has less dense station siting, and is closer to the edge of the system. The area within the larger South Side neighborhood also had the highest vacancy rate of any study site. The relative lack of destinations there, along with higher-speed traffic and fewer bicycle facilities, were noted on our study tour and made for less attractive cycling conditions relative to the outreach area in Bronzeville. In general, the Brooklyn control was a closer geographic match for the outreach area.

\subsection{Survey implementation}

The goal of the resident survey was to understand the knowledge, perceptions, and experiences of people living near newly installed bike share stations in neighborhoods with substantial shares of lower-income and people of color that were targeted for BBSP-related efforts. An important component of this was understanding what people think about bike share and bicycling in general, and what are specific reasons people might consider using bike share, what are potential barriers to bicycling and bike share use, and what changes might make people more likely to try bike share. By including multiple cities, each with a number of identical questions, we sought to identify areas where respondents across cities and neighborhoods shared perceptions, motivations, and concerns, and where they differed depending on the location.

In general, the expectation was that the large majority of respondents would not be current bike share users, but rather people who live near bike share and are the target for the BBSP efforts. Thus, the survey would yield information about what the general public in these traditionally underserved neighborhoods thinks about bicycling and bike share. As explained in Section 1.3, a separate survey was conducted of bike share users and individuals in target communities who have expressed interest in bike share. Findings from that survey will be discussed in a separate report.

In the calls and meetings with partners in each city, the research team sought input on questions the partners in each city would want to have answered, including what might be barriers to bicycling and bike share, how they expect people are hearing about bike share in the community, what attitudes and opinions are being expressed, and what perceptions or misconceptions might exist. This information, along with a 
literature review of attitudes and barriers toward bicycling and bike share, informed the survey development and design.

\subsubsection{Survey instrument}

The survey was designed as a paper, mail out survey, and included the option of being mailed back or completed online. The surveys were generally identical, with only minor specifications/modifications based the city or neighborhood. Each city's survey specified the name of the local bike share system (Indego in Philadelphia, Divvy in Chicago, and Citi Bike in Brooklyn) each time the system was asked about. In section headers, the system name was followed by the clarification that it was in fact the city's bike share system (e.g. "Divvy — Chicago's bike share system”). A copy of one of the surveys is in Appendix A.

Specific sections included in the survey were:

- General questions about their neighborhood and how they get around, including:

o How frequently the respondent traveled by various modes in the past week, with options for each mode of no trips, some trips, or most trips.

o Level of agreement with 12 statements about their neighborhood, including statements about their satisfaction with transportation, recent changes to the neighborhood, their sense of input on community decision-making, and how good the city and transit agencies are at serving them. Response options included strongly disagree, disagree, agree, or strongly agree; with a "no opinion" option provided as well.

- Questions about bicycling in general, including:

o Level of agreement with 17 statements about bicycling in general (e.g., "getting people to ride bikes is good for the environment or for community health," or, "people on bikes make roads less safe"), and about their perception of bicycling as it related specifically to them. Examples of this include whether they want to ride a bicycle more often, or whether they think riding a bike would help them spend less on transportation or get more exercise. Response options included strongly disagree, disagree, agree, or strongly agree; with a "no opinion" option provided as well.

o Three basic questions about whether they know how to ride a bicycle, whether they are physically able to ride a bicycle, and when they last rode.

o Rating 23 potential barriers to bicycling as not a barrier, small barrier, or big barrier, with a does not apply option.

- General questions about residents' experience with the bike share system, including a brief description of the system providing the name, a photo of one of the bike share bikes, and the statement that people can check out a bike from any station, ride it, and return it to any other station.

o A checklist of where they have gotten information about the bike share system, if they have. There is also an area for respondents to write in how and where they first learned about the system.

o A set of 14 questions about whether they have had any experience with the bike share system, ranging from seeing the stations, riding a bike share bike or knowing people who have used the system through to whether they expect to become members, or how likely they are to seek out more information about it.

o A set of 12-13 true/false statements about details of the bike share system aimed at understanding knowledge, perceptions and potential misconceptions about the system. Topics include questions about payment and cost, rules, and restrictions on use. Response 
options for each statement include definitely false, probably false, probably true, and definitely true; a "no idea" option was also available.

- Information on what residents think about the bike share system, including reasons they might be interested in using bike share, measures that might make them more likely to use bike share, and barriers to using the system. These include:

o A set of 15 level-of-agreement questions about the bike share system. These focus on opinions about the bike share system, whether it serves people like the respondents, whether it's useful to them, and whether they feel they had a voice in planning for the system. Response options included strongly disagree, disagree, agree, or strongly agree; with a "no opinion" option provided as well.

o A checklist of reasons the respondent might consider using the bike share system, including for fun or recreation, getting to transportation or other destinations, and getting to jobs and social services.

o A set of 12 hypothetical changes, and whether they would make the respondent more likely to use the bike share system. Response options include no more likely, somewhat more likely, or much more likely; for each option, the respondent could also select does not apply.

o Rating 16 potential barriers to using the bike share system as not a barrier, small barrier, or big barrier, with a does not apply option. There is a space to specify in writing the most important barrier as well.

- The final section of the survey pertains to information about the respondent and their household, including demographic questions.

The complete survey was 8 pages long for each city, which included the picture of the appropriate bike share bike for each, along with two to three city-specific graphics to fill empty space on the page. Once the first draft of the survey had been completed, we adapted the paper survey to be an online survey using a Portland State University subscription to Qualtrics.

The project team tested the completed survey by having students take the survey and provide feedback, including noting any confusing questions or wording, and recording the time it took to complete. The surveys were also shared with project partners in each city for content specific feedback.

The surveys were also checked for appropriate reading level for comprehension by a diverse audience. We used the Flesch-Kincaid Grade Level (F-K) test that is available in Microsoft Word 2013, aiming for a reading level no higher than 10th grade. A few updates were made with the goal of making the survey comprehensible to as broad an audience as possible. The reading level of the final survey ranged from grade five to grade 11 on the F-K scale.

We also made available a Spanish-language version of the full survey, both on paper and on the web. A campus survey research lab recommended a translator, and a native Spanish speaker reviewed the translation to ensure the intent was clear and reflected the English version.

The entire survey process was approved by PSU’s Human Research Subjects Committee.

\subsubsection{Sampling frame}

The sampling areas were selected based roughly on a quarter-mile buffer around selected bike share stations in selected neighborhoods. Some areas were selected with a polygon to capture households in between a number of stations, but in gaps between station buffers, or with the intent to exclude households from census block groups where the population differed substantially from our target 
population — for example, where a specific street represents a hard break between neighborhoods. We used those boundaries to pull one address per household from the list of available addresses at www.infoUSA.com. Addresses were dropped from the list when it was clear the address was not complete, such as a series of repeat addresses with no apartment unit information.

\subsubsection{Pilot survey and respondent compensation options}

To test the survey instrument and methodology, and gain some better expectation of a realistic response rate, the research team piloted surveys in each of the three target cities. A main component of the pilot was to test two different compensation options to identify which would be most effective among the target population.

The two compensation options tested included one set in which each survey envelope had a $\$ 1$ bill as a token of our appreciation for their feedback, and another set for which each person who completed a survey was promised a transit pass good for two rides (in Chicago and New York) or a \$5 gift card to Family Dollar (in Philadelphia). In Philadelphia, the gift card was chosen because buying paper transit tickets in bulk was not an option. The goal of the pilot was to identify which compensation option would be likely to yield the higher response rate, while providing some way of expressing appreciation to everyone who completed a survey. It also allowed the research team to get a better sense of the logistics of each incentive method in the full-scale mailing.

For each city, 100 individuals were randomly selected from the sampling areas to receive the $\$ 1$ bill package, and 100 were selected to receive the package with the transit or gift card option. Each package also included an introduction/invitation letter with a link to the electronic version of the survey, a paper survey and a return envelope. The transit or gift card option group also received a slip to complete and return with their name and mailing address for fulfillment. Those who did not respond initially were sent a second mailing (though the $\$ 1$ bill group did not receive another dollar) requesting that they complete the survey. A power analysis suggested that the pilot design would be sufficient to distinguish at least between large differences in incentive response (+/- about 10 percentage-point differences).

Overall, the response rates were not significantly different between the two compensation options. However, we did observe a higher response for lower-income residents and people of color among those who responded to the transit pass or gift card option. As this matched the target audience for the survey, and seemed to better match the neighborhood demographics, we opted to go with the transit pass option for the full survey. However, the response rate in Philadelphia lagged behind New York and Chicago; we hypothesized one reason could be due to the different gift card option there, and decided to proceed with transit tokens in Philadelphia for the full survey.

By measuring who responded to the first and second pilot mailings, the research team also made several other decisions about the full survey launch. We expected to get about a $10 \%$ response rate from the first mailing, and an additional 2-3\% from the second mailing. However, the demographics of those who responded to the first and second mailings showed no significant difference. We decided, for the full mailing, to send just one full mailing, along with a reminder postcard several days later. This allowed us to expand the total number of invitations. We were able to expand our sample to 18,000 addresses overall (6,000 per city) up from an initial plan of 12,000 (or 4,000 per city). In order to maximize the response rate for the full survey, we also decided to offer a drawing for one larger gift card, a \$250 Amazon gift card, per city. 


\subsubsection{Full survey mailing}

From the cleaned address list, we followed a stratified random sampling technique by area. We set a target number for each city and area to ensure adequate responses for analysis, and then randomly selected addresses from the master list until the target was reached. An additional 5,800 addresses were selected for each city, for a total of 6,000 households per city including the 200 pilot surveys (addresses selected in the same manner), and a grand total of 17,400 additional households and 18,000 total households between all three cities.

These surveys were mailed in August 2016. Each survey packet included an invitation letter explaining the survey, a paper copy of the survey, a prepaid and preaddressed return envelope, a compensation/raffle drawing slip to be returned with the completed survey, and a brightly colored Spanish-language slip explaining the survey. The letter and survey each included a URL address and code if the participant preferred to take the survey online rather than returning the paper survey. URLs were created using a URL shortener to make them easier to remember and type; for example, the Brooklyn URL was "http://bit.ly/SurveyBrooklyn".

The introductory letter and compensation/raffle drawing slip explained that every person who returned the completed survey, along with the slip with their name and address, would be mailed transit passes good for 2 rides ( 3 in Philadelphia). Each slip also had a box to check if the participant wanted to opt into a drawing for a \$250 Amazon gift card (one per city). The letter and slip explained that the information on the slip would be used only for fulfilling the compensation.

The Spanish-language slip explained in Spanish what the survey was, that the online version was available in Spanish through the URL, and that they could return the slip in the prepaid envelope to receive a paper version of the survey in Spanish.

Two days after the surveys were mailed, we sent a follow-up postcard reminding addressees about the recently sent packet, and including the survey URL and code. Participants were given approximately three weeks to complete the survey.

The post office returned some surveys as undeliverable for a number of reasons. We attempted to send a second survey to such households with the addressee changed to "Current Resident." If the second survey was returned, we counted that survey as undeliverable and removed it from the sample. Any surveys returned after September were not resent and thus were counted as undeliverable and removed from the sample. We were unable to resend surveys for a number of reasons, including the address' being for a vacant unit or the number not existing (if, for instance, the building had been torn down). Such addresses were removed from the sample. Table 4-4 shows the number of surveys sent, resent surveys, those dropped from the sample, and the final sample size for each neighborhood. Ultimately, about $6 \%$ of our sample was dropped from the study, with over half of those coming from Chicago. 
Table 4-4 Undeliverable Surveys and Final Sample by City and Neighborhood

\begin{tabular}{|c|c|c|c|c|}
\hline City / Area & Sent & Resent & $\begin{array}{c}\text { Undeliverable / } \\
\text { Removed }\end{array}$ & $\begin{array}{c}\text { Delivered } \\
\text { (Final Sample) }\end{array}$ \\
\hline Brooklyn & 6,000 & 528 & 204 & 5,796 \\
\hline North & 2,007 & 220 & 79 & 1,928 \\
\hline South & 1,993 & 180 & 65 & 1,928 \\
\hline Control & 2,000 & 128 & 60 & 1,940 \\
\hline Chicago & 6,000 & 1,538 & 564 & 5,436 \\
\hline Bronzeville & 4,001 & 1,011 & 308 & 3,693 \\
\hline Control & 1,999 & 527 & 256 & 1,743 \\
\hline Philadelphia & 6,000 & 648 & 325 & 5,675 \\
\hline North & 2,001 & 307 & 119 & 1,882 \\
\hline South & 1,999 & 184 & 114 & 1,885 \\
\hline West & 2,000 & 157 & 92 & 1,908 \\
\hline Total & 18,000 & 2,714 & 1,093 & 16,907 \\
\hline
\end{tabular}




\section{Respondents}

An overview of survey response rates and completions, including those completed online and those completed on paper and returned by mail, is shown in Table 5-1. After accounting for surveys removed from the sample as undeliverable, we estimated that survey packets were received by a total of 16,907 individuals (and no more than one per household). A total of 1,885 completed surveys were received. Of those, 517 (or about 27\%) were completed online, while 1,368 (or about 73\%) were completed via the mail-back paper survey.

The overall response rate, calculated by dividing the number of completions by the number of surveys delivered, was just over $11 \%$. This is slightly better than our projected response rate of $10 \%$. Response rates ranged from about $9 \%$ in Brooklyn to $13 \%$ in Philadelphia.

Table 5-1 Survey Completions and Response Rates

\begin{tabular}{|c|c|c|c|c|c|}
\hline City / Area & $\begin{array}{l}\text { Surveys } \\
\text { Delivered }\end{array}$ & $\begin{array}{l}\text { Completions } \\
\text { Online }\end{array}$ & $\begin{array}{c}\text { Completions by } \\
\text { Mail }\end{array}$ & $\begin{array}{c}\text { Total } \\
\text { Completions }\end{array}$ & $\begin{array}{c}\text { Response } \\
\text { Rate }\end{array}$ \\
\hline \multicolumn{6}{|l|}{ Brooklyn } \\
\hline Brooklyn total & 5,796 & 143 & 380 & 523 & $9 \%$ \\
\hline North & 1,928 & 42 & 137 & 179 & $9 \%$ \\
\hline South & 1,928 & 54 & 123 & 177 & $9 \%$ \\
\hline Control & 1,940 & 47 & 120 & 167 & $9 \%$ \\
\hline \multicolumn{6}{|l|}{ Chicago } \\
\hline Chicago total & 5,436 & 148 & 495 & 643 & $12 \%$ \\
\hline Bronzeville & 3,693 & 116 & 345 & 461 & $12 \%$ \\
\hline Control & 1,743 & 32 & 150 & 182 & $10 \%$ \\
\hline \multicolumn{6}{|l|}{ Philadelphia } \\
\hline Philadelphia total & 5,675 & 226 & 493 & 719 & $13 \%$ \\
\hline North & 1,882 & 66 & 187 & 253 & $13 \%$ \\
\hline South & 1,885 & 93 & 159 & 252 & $13 \%$ \\
\hline West & 1,908 & 67 & 147 & 214 & $11 \%$ \\
\hline Total & 16,907 & 517 & 1,368 & 1,885 & $11 \%$ \\
\hline
\end{tabular}

Compared to the populations of the neighborhoods they come from, survey respondents overall were more likely to be women, comparatively older, and more highly educated. However, on many measures, including race/ethnicity, and income, the respondent demographics matched the neighborhood population quite well. A city-by-city breakdown of the representativeness of the survey respondents follows. All comparisons were made to 2015 ACS 5-year estimates (2011-2015 data) at the census tract level, and it should be noted that these data do not align precisely with our survey in time, nor are they free of sampling error. 


\section{1 Philadelphia}

A comparison of the demographics of Philadelphia survey respondents to the overall city and area populations is shown in Table 5-2. The survey respondents matched very closely to the race/ethnicity proportions of their respective neighborhoods with the exception of the South Philadelphia neighborhood. In the South study area, white, non-Hispanic populations were over represented by 23 percentage points while Black populations were underrepresented by 24 percentage points. Our survey respondents skewed more female and older compared to the populations of both the city and the specific study areas. In the South Philadelphia neighborhood, survey respondents' ages matched well with the neighborhood Census estimates. Respondents were slightly more likely to be employed and slightly more highly educated than area residents. They were also skewed slightly toward higher incomes. 
Table 5-2 Philadelphia Demographics

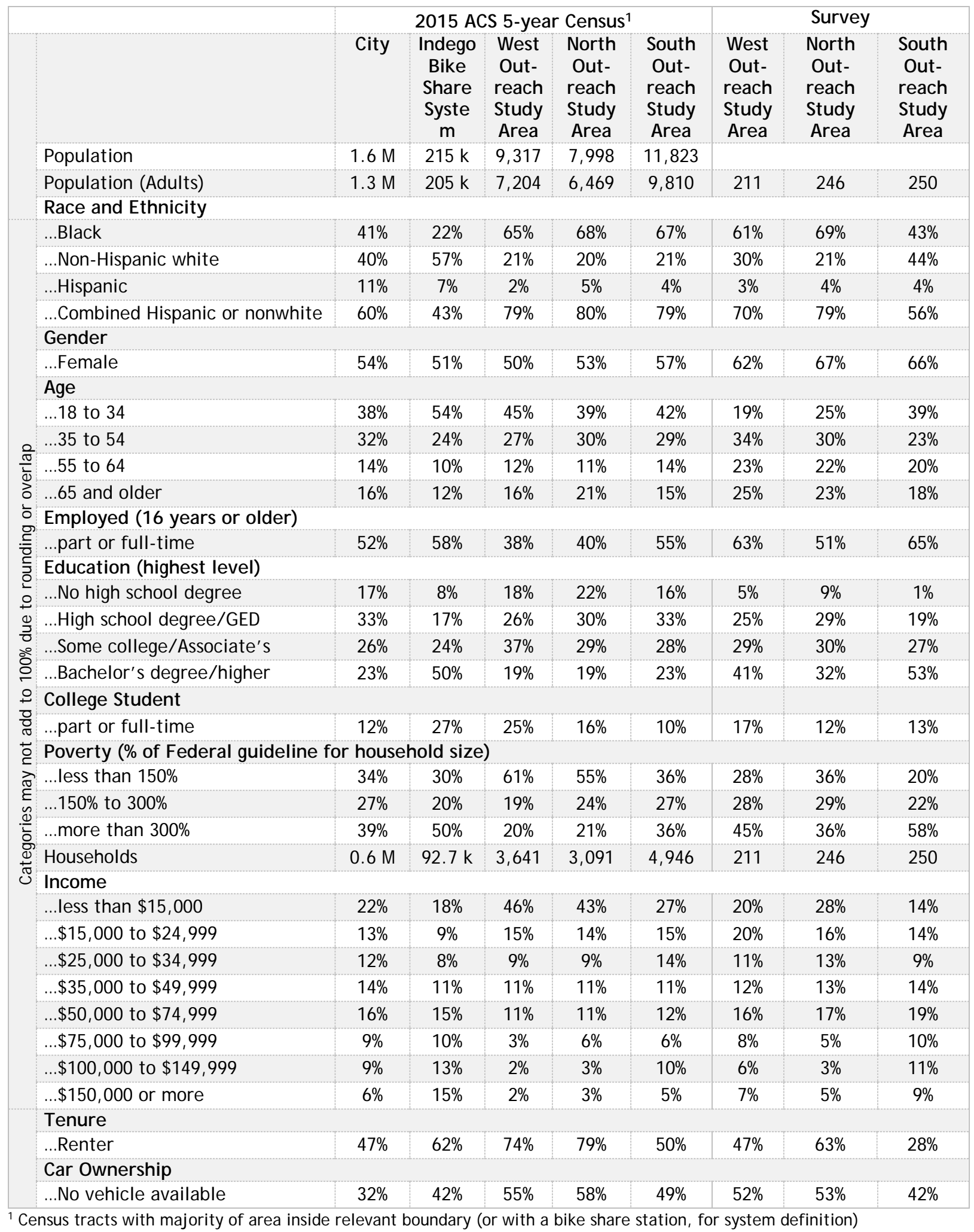




\subsection{Brooklyn}

A comparison of the demographics of Brooklyn survey respondents to the overall city and area populations is shown in Table 5-3. Respondents to our surveys matched our race/ethnicity expectations from the Census neighborhood data. Survey respondents in the outreach area were more likely to be female and older than area residents overall, while the control area respondents were closer to matching the area population. Respondents in both areas were more likely to be college graduates than the population overall. Households living in less than $150 \%$ poverty level were fewer than expected, but the income breakdowns were about as expected. Thus we were likely reaching smaller households. 
Table 5-3 Brooklyn / New York City Demographics

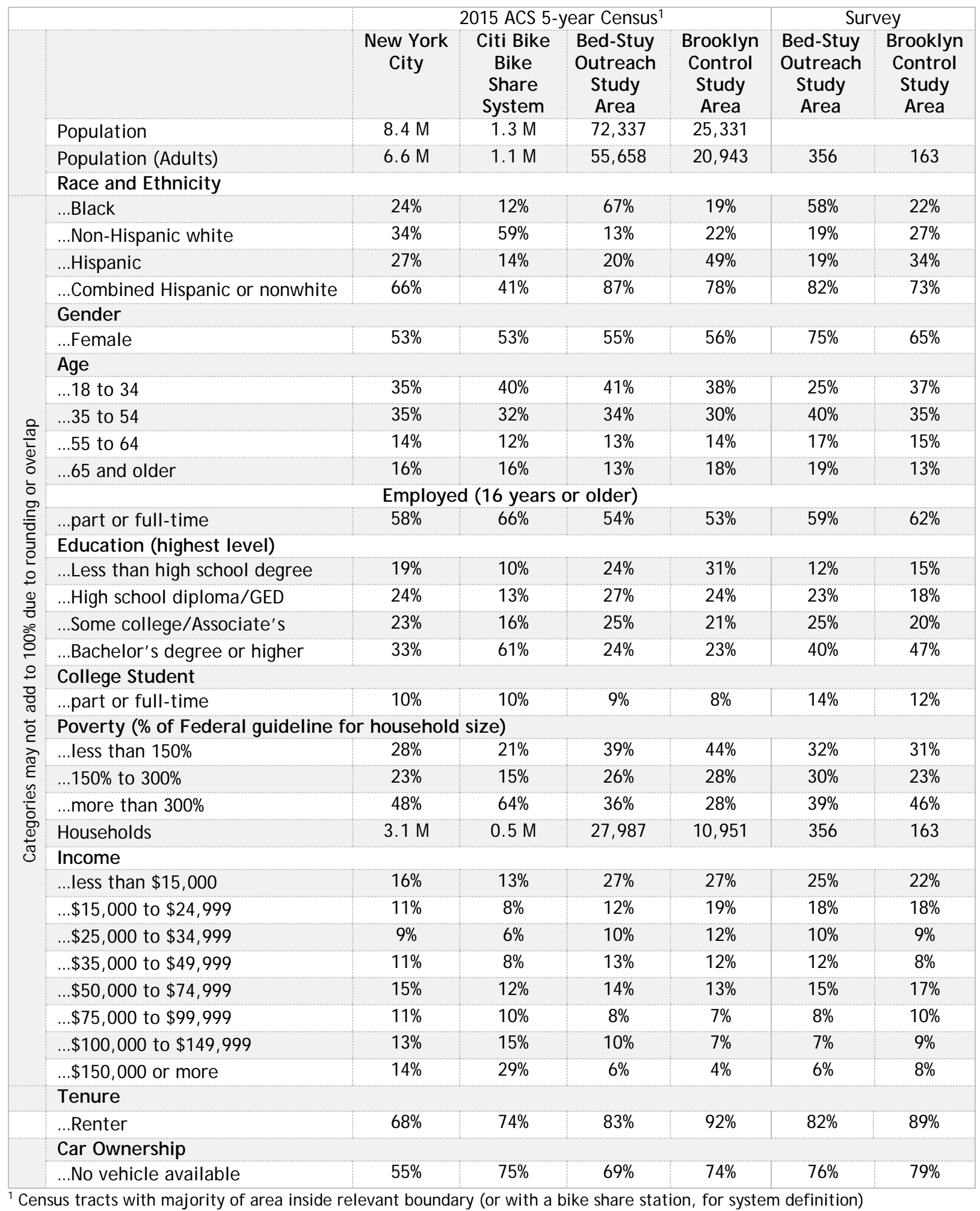




\subsection{Chicago}

A comparison of the demographics of Chicago survey respondents to the overall city and area populations is shown in Table 5-4. Respondents to our surveys very closely matched the neighborhoods on race/ethnicity and income measures. However, survey respondents were older, more likely to be female, and more likely to be college graduates than the area populations overall. 
Table 5-4 Chicago Demographics

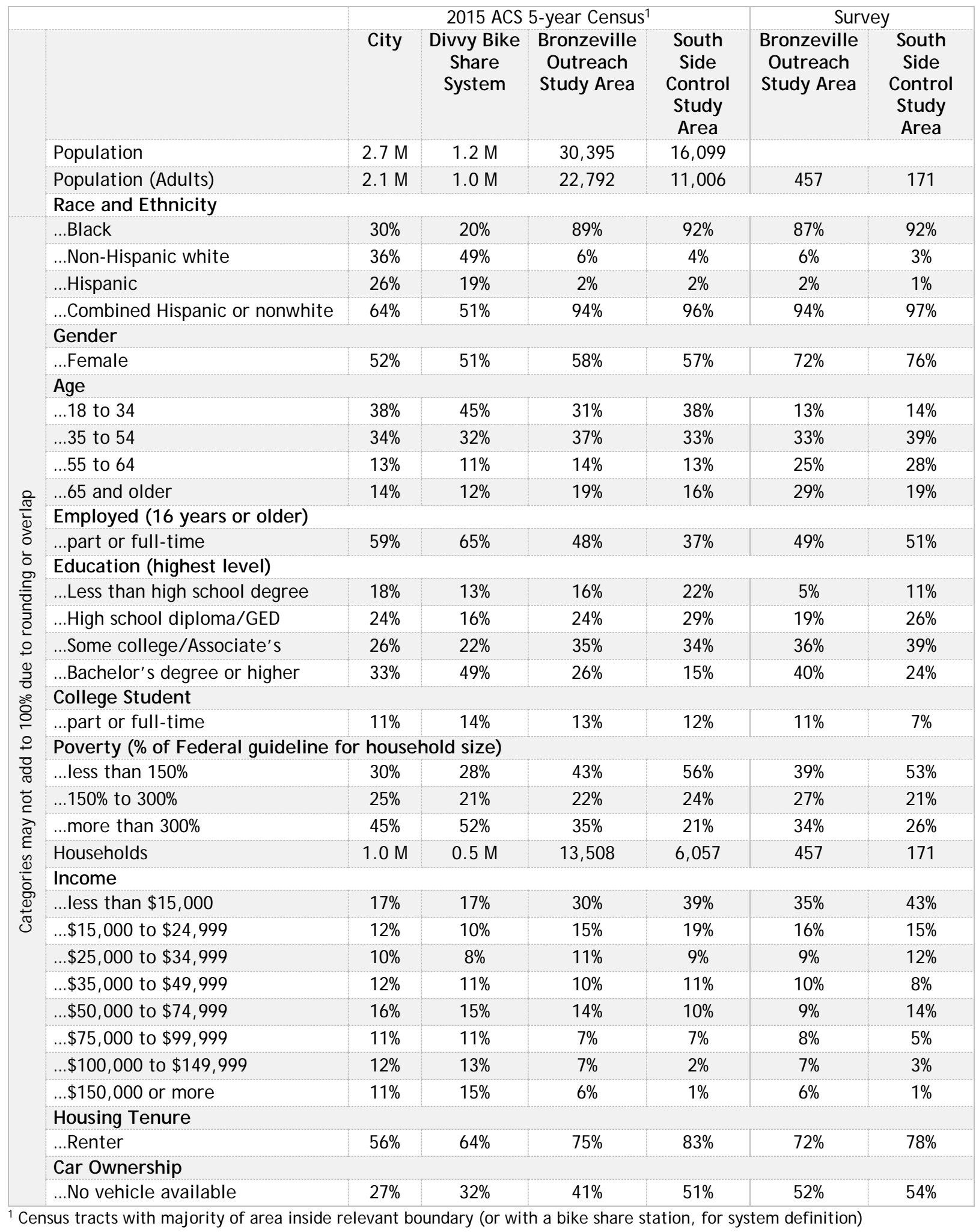




\subsection{Other respondent characteristics}

To better understand the survey respondents, we asked questions about how they get around, and about items that might affect their transportation options (such as if they have a driver's license, car, transit pass, bicycle, etc.), and about their options for getting information and making purchases (such as if they have a credit or debit card, smartphone, or internet). We asked how long they had lived in their current home and neighborhood, and to provide a self-report on their overall health and level of physical activity. Responses to the transportation related questions by survey area are shown in Table 5-5, while responses to other questions are shown in Table 5-6.

Respondents in Chicago were most likely to make most trips in the past week by car (37-40\% of Chicago respondents did), while those in Brooklyn were least likely to do so (7\%-13\%). Public transit use was most prevalent in Brooklyn, with 67\%-71\% of respondents making most trips in the past week by that mode. Chicago had the lowest rate of people making most trips by bicycle — around 3\% — while Brooklyn and Philadelphia were closer to $7 \%-10 \%$ between those who used a personal bicycle or bike share for most trips.

In many cases, there were quite a few respondents lacking certain items that would help them in terms of getting around, getting information or making purchases. The percentage of respondents who reported having each item were: driver's license (54\%-79\%), transit pass (28\%-66\%), working bicycle (14\%-37\%, compared to $41 \%$ in a national survey of metro areas (National Association of Realtors, 2015)), car share membership (2\%-12\%), smartphone (53\%-74\%, compared to 64\% nationally in 2014 (Pew Research Center, 2015)), credit card (42\%-75\%), debit card (67\%-81\%), and reliable internet access (45\%-73\%). 
Table 5-5 Transportation Characteristics by Neighborhood

\begin{tabular}{|c|c|c|c|c|c|c|c|c|}
\hline & $\begin{array}{c}\text { BKLN } \\
\text { Study } \\
\text { Area }\end{array}$ & $\begin{array}{c}\text { BKLN } \\
\text { Control } \\
\text { Area }\end{array}$ & $\begin{array}{c}\text { CHI } \\
\text { Study } \\
\text { Area }\end{array}$ & $\begin{array}{c}\text { CHI } \\
\text { Control } \\
\text { Area }\end{array}$ & $\begin{array}{c}\text { PHI } \\
\text { Study } \\
\text { Areas } \\
\text { All }\end{array}$ & $\begin{array}{c}\text { PHI } \\
\text { Study } \\
\text { Area } \\
\text { West }\end{array}$ & $\begin{array}{l}\text { PHI } \\
\text { Study } \\
\text { Area } \\
\text { North }\end{array}$ & $\begin{array}{c}\text { PHI } \\
\text { Study } \\
\text { Area } \\
\text { South }\end{array}$ \\
\hline \multicolumn{9}{|c|}{ In the past week, how did you get around? (\% Selected) } \\
\hline \multicolumn{9}{|l|}{ Drove a personal car } \\
\hline ...most trips & $13 \%$ & $7 \%$ & $37 \%$ & $40 \%$ & $28 \%$ & $26 \%$ & $31 \%$ & $28 \%$ \\
\hline ...some trips & $17 \%$ & $17 \%$ & $27 \%$ & $19 \%$ & $31 \%$ & $35 \%$ & $27 \%$ & $32 \%$ \\
\hline \multicolumn{9}{|c|}{ Got a ride from a friend or family member } \\
\hline ...most trips & $4 \%$ & $2 \%$ & $9 \%$ & $10 \%$ & $7 \%$ & $6 \%$ & $10 \%$ & $5 \%$ \\
\hline ...some trips & $41 \%$ & $33 \%$ & $47 \%$ & $52 \%$ & $44 \%$ & $45 \%$ & $45 \%$ & $41 \%$ \\
\hline \multicolumn{9}{|l|}{ Taxi/Uber/Lyft } \\
\hline ...most trips & $2 \%$ & $2 \%$ & $2 \%$ & $6 \%$ & $5 \%$ & $4 \%$ & $4 \%$ & $6 \%$ \\
\hline ...some trips & $49 \%$ & $44 \%$ & $36 \%$ & $21 \%$ & $39 \%$ & $32 \%$ & $32 \%$ & $52 \%$ \\
\hline \multicolumn{9}{|l|}{ Car Share } \\
\hline ...most trips & $3 \%$ & $2 \%$ & $2 \%$ & $6 \%$ & $2 \%$ & $4 \%$ & $1 \%$ & $1 \%$ \\
\hline ...some trips & $7 \%$ & $8 \%$ & $5 \%$ & $3 \%$ & $5 \%$ & $4 \%$ & $4 \%$ & $5 \%$ \\
\hline \multicolumn{9}{|l|}{ Public Transit } \\
\hline ...most trips & $71 \%$ & $67 \%$ & $44 \%$ & $76 \%$ & $41 \%$ & $44 \%$ & $46 \%$ & $33 \%$ \\
\hline ...some trips & $23 \%$ & $30 \%$ & $36 \%$ & $21 \%$ & $40 \%$ & $37 \%$ & $34 \%$ & $48 \%$ \\
\hline \multicolumn{9}{|l|}{ Walking } \\
\hline ...most trips & $33 \%$ & $43 \%$ & $13 \%$ & $34 \%$ & $20 \%$ & $24 \%$ & $20 \%$ & $18 \%$ \\
\hline ...some trips & $61 \%$ & $51 \%$ & $65 \%$ & $60 \%$ & $65 \%$ & $63 \%$ & $62 \%$ & $69 \%$ \\
\hline \multicolumn{9}{|l|}{ Bicycling - Bike share } \\
\hline ...most trips & $1 \%$ & $3 \%$ & $1 \%$ & $0 \%$ & $1 \%$ & $1 \%$ & $0 \%$ & $2 \%$ \\
\hline ...some trips & $7 \%$ & $11 \%$ & $6 \%$ & $4 \%$ & $5 \%$ & $5 \%$ & $5 \%$ & $8 \%$ \\
\hline \multicolumn{9}{|l|}{ Bicycling - Personal bike } \\
\hline ...most trips & $6 \%$ & $5 \%$ & $2 \%$ & $3 \%$ & $9 \%$ & $11 \%$ & $4 \%$ & $13 \%$ \\
\hline ...some trips & $13 \%$ & $17 \%$ & $13 \%$ & $9 \%$ & $13 \%$ & $11 \%$ & $9 \%$ & $18 \%$ \\
\hline \multicolumn{9}{|c|}{ Do you currently have a...? (\% Yes) } \\
\hline Driver's license & $57 \%$ & $64 \%$ & $68 \%$ & $54 \%$ & $72 \%$ & $71 \%$ & $66 \%$ & $79 \%$ \\
\hline Transit pass & $54 \%$ & $56 \%$ & $66 \%$ & $60 \%$ & $29 \%$ & $30 \%$ & $29 \%$ & $28 \%$ \\
\hline Working bicycle & $21 \%$ & $24 \%$ & $22 \%$ & $14 \%$ & $27 \%$ & $27 \%$ & $17 \%$ & $37 \%$ \\
\hline Car share membership & $10 \%$ & $12 \%$ & $3 \%$ & $2 \%$ & $7 \%$ & $7 \%$ & $4 \%$ & $8 \%$ \\
\hline Min. number of responses ${ }^{1}$ & 246 & 123 & 317 & 115 & 515 & 148 & 177 & 190 \\
\hline Max. number of responses ${ }^{1}$ & 333 & 156 & 438 & 161 & 670 & 202 & 231 & 237 \\
\hline
\end{tabular}

${ }^{1}$ varies by question due to missing 
Table 5-6 Other Social and Demographic Characteristics by Neighborhood

\begin{tabular}{|c|c|c|c|c|c|c|c|c|}
\hline & $\begin{array}{c}\text { BKLN } \\
\text { Study } \\
\text { Area }\end{array}$ & $\begin{array}{c}\text { BKLN } \\
\text { Control } \\
\text { Area }\end{array}$ & $\begin{array}{l}\text { CHI } \\
\text { Study } \\
\text { Area }\end{array}$ & $\begin{array}{c}\text { CHI } \\
\text { Control } \\
\text { Area }\end{array}$ & $\begin{array}{l}\text { PHI } \\
\text { Study } \\
\text { Areas } \\
\text { All }\end{array}$ & $\begin{array}{l}\text { PHI } \\
\text { Study } \\
\text { Area } \\
\text { West }\end{array}$ & $\begin{array}{c}\text { PHI } \\
\text { Study } \\
\text { Area } \\
\text { North }\end{array}$ & $\begin{array}{l}\text { PHI } \\
\text { Study } \\
\text { Area } \\
\text { South }\end{array}$ \\
\hline \multicolumn{9}{|c|}{ Do you currently have a...? (\% Yes) } \\
\hline Smartphone & $66 \%$ & $74 \%$ & $65 \%$ & $53 \%$ & $68 \%$ & $68 \%$ & $63 \%$ & $73 \%$ \\
\hline Credit card & $56 \%$ & $65 \%$ & $56 \%$ & $42 \%$ & $65 \%$ & $59 \%$ & $58 \%$ & $75 \%$ \\
\hline Debit card & $73 \%$ & $74 \%$ & $74 \%$ & $67 \%$ & $75 \%$ & $71 \%$ & $71 \%$ & $81 \%$ \\
\hline Reliable internet access & $60 \%$ & $69 \%$ & $61 \%$ & $45 \%$ & $66 \%$ & $68 \%$ & $58 \%$ & $73 \%$ \\
\hline None of these & $5 \%$ & $5 \%$ & $4 \%$ & $5 \%$ & $3 \%$ & $4 \%$ & $4 \%$ & $1 \%$ \\
\hline \multicolumn{9}{|c|}{ Subsidized housing or discount? } \\
\hline Yes & $34 \%$ & $25 \%$ & $44 \%$ & $45 \%$ & $29 \%$ & $30 \%$ & $44 \%$ & $6 \%$ \\
\hline \multicolumn{9}{|c|}{ How long have you lived at your current address? } \\
\hline $0-2$ years & $19 \%$ & $16 \%$ & $25 \%$ & $24 \%$ & $24 \%$ & $18 \%$ & $19 \%$ & $34 \%$ \\
\hline 2.1-5 years & $16 \%$ & $20 \%$ & $25 \%$ & $22 \%$ & $18 \%$ & $17 \%$ & $22 \%$ & $15 \%$ \\
\hline $6-10$ years & $19 \%$ & $18 \%$ & $25 \%$ & $22 \%$ & $15 \%$ & $14 \%$ & $18 \%$ & $13 \%$ \\
\hline $11-20$ years & $23 \%$ & $22 \%$ & $17 \%$ & $21 \%$ & $19 \%$ & $19 \%$ & $27 \%$ & $10 \%$ \\
\hline $21+$ years & $24 \%$ & $24 \%$ & $9 \%$ & $12 \%$ & $24 \%$ & $31 \%$ & $15 \%$ & $28 \%$ \\
\hline \multicolumn{9}{|c|}{ How long have you lived in your current neighborhood? } \\
\hline $0-2$ years & $15 \%$ & $9 \%$ & $18 \%$ & $18 \%$ & $19 \%$ & $14 \%$ & $14 \%$ & $18 \%$ \\
\hline 2.1-5 years & $12 \%$ & $18 \%$ & $20 \%$ & $15 \%$ & $17 \%$ & $14 \%$ & $22 \%$ & $16 \%$ \\
\hline $6-10$ years & $18 \%$ & $22 \%$ & $21 \%$ & $20 \%$ & $14 \%$ & $13 \%$ & $15 \%$ & $13 \%$ \\
\hline $11-20$ years & $24 \%$ & $22 \%$ & $21 \%$ & $27 \%$ & $15 \%$ & $16 \%$ & $20 \%$ & $9 \%$ \\
\hline $21+$ years & $32 \%$ & $30 \%$ & $20 \%$ & $20 \%$ & $35 \%$ & $43 \%$ & $28 \%$ & $34 \%$ \\
\hline \multicolumn{9}{|l|}{ Health } \\
\hline Excellent & $20 \%$ & $17 \%$ & $12 \%$ & $13 \%$ & $15 \%$ & $16 \%$ & $13 \%$ & $17 \%$ \\
\hline Very good & $24 \%$ & $38 \%$ & $33 \%$ & $19 \%$ & $28 \%$ & $27 \%$ & $25 \%$ & $33 \%$ \\
\hline Good & $36 \%$ & $32 \%$ & $35 \%$ & $38 \%$ & $33 \%$ & $35 \%$ & $32 \%$ & $32 \%$ \\
\hline Fair & $16 \%$ & $11 \%$ & $17 \%$ & $23 \%$ & $19 \%$ & $19 \%$ & $24 \%$ & $14 \%$ \\
\hline Poor & $5 \%$ & $2 \%$ & $4 \%$ & $7 \%$ & $5 \%$ & $5 \%$ & $6 \%$ & $4 \%$ \\
\hline \multicolumn{9}{|l|}{ Physically active } \\
\hline Not at all & $4 \%$ & $3 \%$ & $3 \%$ & $7 \%$ & $4 \%$ & $4 \%$ & $5 \%$ & $3 \%$ \\
\hline Not very & $12 \%$ & $13 \%$ & $16 \%$ & $12 \%$ & $15 \%$ & $17 \%$ & $14 \%$ & $14 \%$ \\
\hline Somewhat & $52 \%$ & $47 \%$ & $54 \%$ & $57 \%$ & $50 \%$ & $52 \%$ & $52 \%$ & $47 \%$ \\
\hline Very & $29 \%$ & $38 \%$ & $27 \%$ & $23 \%$ & $30 \%$ & $27 \%$ & $28 \%$ & $34 \%$ \\
\hline Don't know/ not sure & $3 \%$ & $0 \%$ & $1 \%$ & $1 \%$ & $1 \%$ & $1 \%$ & $2 \%$ & $0 \%$ \\
\hline Min. number of responses ${ }^{1}$ & 270 & 137 & 316 & 128 & 393 & 121 & 160 & 112 \\
\hline Max. number of responses ${ }^{1}$ & 334 & 159 & 438 & 166 & 676 & 202 & 235 & 242 \\
\hline
\end{tabular}




\section{READING THE FINDINGS}

The rest of this report covers findings and conclusions from the survey of residents living near bike share stations. Chapters 7, 8 and 9 focus on specific sections of the survey. Chapter 7 covers questions dealing with the respondents' views toward getting around in and changes to their neighborhood, their opinions and perceptions about bicycling in general, and what things might be barriers to riding a bike (or biking more). Chapter 8 covers information about the respondents' experience with, knowledge of, and opinions about the bike share system in their city. Chapter 9 covers sections of the survey dealing with reasons people might consider trying bike share, changes that would make them more likely to do so, and what barriers might exist to using the bike share system in their cities.

The findings in chapters 7, 8 and 9 are specifically focused on respondents who are under 65 years old and physically able to ride a bicycle, unless otherwise noted. This limitation is meant to focus on the individuals most likely to be targeted for participation in bike share.

Chapter 10 focuses on several groups who are not covered or not covered extensively in other chapters. In the first section we examine the differences between respondents in these outreach areas and in our select control neighborhoods. Then there is a section on older adults (65 or older) and those physically unable to ride a bicycle that addresses their experiences with, views toward, and interest in using bike share. We also address those who state they are not interested in using bike share to understand how they view it in relation to their community. Chapter 10 includes a section focusing on households with children and if/how they differ from other households in relation to bike share, and concludes with a section examining if there were observed differences between Hispanic and Black respondents.

Unless otherwise noted, the findings relate to respondents in the areas targeted for outreach through the Better Bike Share Partnership-affiliated efforts.

\section{1 Grouping of respondents for analysis}

Each of the cities expressed objectives for making bike share more equitable in slightly different ways, reflecting the diversity of each city. The City of Philadelphia sought for their bike share system to "benefit Philadelphians of all income levels, and for bike share users to reflect the diversity of Philadelphia," ${ }^{5}$ while Better Bike Share Partnership efforts put stations in and sought to engage “underserved communities.” ${ }^{6}$ In Brooklyn, the Bedford Stuyvesant Restoration Corporation worked with partners to "promote equity through bike share within the low-income and communities of color" that they serve. ${ }^{7}$ In Chicago, the Chicago Department of Transportation worked with Go Bronzeville to reduce barriers to bike share use for lower-income Chicagoans and residents of Bronzeville.

To understand the experience of the people these efforts were intended to serve, the research team broke respondents into four comparison groups based on stated income and stated race or ethnicity. As explained above, for most of the analysis we excluded respondents who were over 65 years old or who could not physically ride a bicycle. In addition, several respondents did not provide the key demographic information needed for our analysis (race/ethnicity, income, age, and/or physical ability). As shown in

\footnotetext{
${ }^{5}$ City of Philadelphia, Philadelphia Bike Share Station Planning Update, December 2014, Page 5, available for download at http://www.phila.gov/bikeshare/PDF/BikeShare_StationPlanningUpdate_December2014.pdf.

${ }^{6}$ Better Bike Share Partnership, About US. Available at http://betterbikeshare.org/about/

${ }^{7}$ Bedford Stuyvesant Restoration Corporation and NACTO, Bringing Equitable Bike Share to Bed-Stuy, page 4, available online at http://www.restorationplaza.org/sites/default/files/Restoration-

NACTO_BikeShareEquity_Report_WEB_FINAL.pdf
} 
Figure 6-1, 779 respondents provided enough demographic data, were physically able to ride, and were under 65 years old. There were 241 respondents unable to ride and 316 over 65; data from these respondents are analyzed separately.

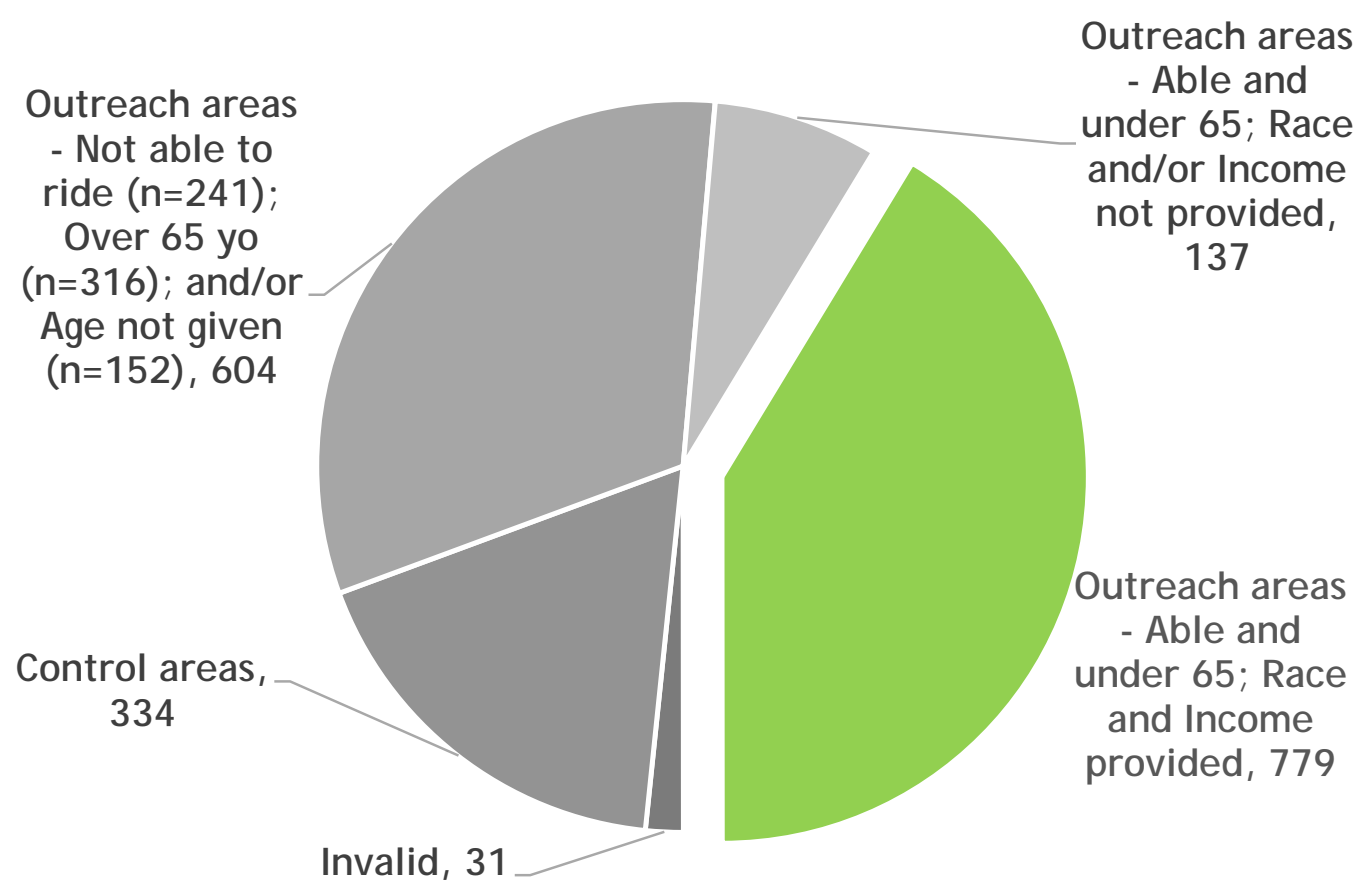

Figure 6-1 Breakdown of respondents included in primary analysis grouping

To identify an income cutoff, we looked at thresholds used for accessing benefits or bike share discount rates in each of the study cities, federal poverty thresholds, and the available information from our respondents about their household's ability to manage with their income. We used a cut-off of $300 \%$ of the federal poverty threshold (see Table 6-1) because it appeared to yield groups generally separated by their sense of whether they had spare income available in their household and was consistent with some other analyses. Table 6-2 provides the percentage of the 779 respondents who fell above or below the income cut-off based on their stated household income, and by their stated ability to get by with that income - $70 \%$ of those below the $300 \%$ threshold stated they had no spare income, while $77 \%$ of those above the cut-off stated they had money left over or a little extra sometimes.

Table 6-1 300\% of Poverty Guideline Thresholds by Family Size

\begin{tabular}{|c|c|c|}
\hline Family Size & Guideline (\$) & $300 \%$ of guideline \\
\hline 1 & 11,800 & 35,400 \\
\hline 2 & 16,020 & 48,060 \\
\hline 3 & 20,160 & 60,480 \\
\hline 4 & 24,300 & 72,900 \\
\hline 5 & 28,440 & 85,320 \\
\hline 6 & 32,580 & 97,740 \\
\hline $7+$ & $36,730+$ & $110,190+$ \\
\hline
\end{tabular}

Source: Federal Health and Human Services Poverty Guidelines 
Table 6-2 Respondents' Stated Income and Ability to get along, by Income Threshold

\begin{tabular}{|c|c|c|c|}
\hline & $\begin{array}{l}\text { Above } 300 \% \text { of } \\
\text { poverty threshold } \\
\text { (higher-income) }\end{array}$ & $\begin{array}{l}\text { At or below } 300 \% \text { of } \\
\text { poverty thresholds } \\
\text { (lower-income) }\end{array}$ & Everyone \\
\hline \multicolumn{4}{|l|}{ What is your annual household income? } \\
\hline Less than $\$ 15,000$ & $0 \%$ & $37 \%$ & $18 \%$ \\
\hline$\$ 15,000-\$ 24,999$ & $0 \%$ & $26 \%$ & $13 \%$ \\
\hline$\$ 25,000-\$ 34,999$ & $0 \%$ & $20 \%$ & $9 \%$ \\
\hline$\$ 35,000-\$ 49,999$ & $17 \%$ & $10 \%$ & $13 \%$ \\
\hline$\$ 50,000-\$ 59,999$ & $10 \%$ & $6 \%$ & $8 \%$ \\
\hline$\$ 60,000-\$ 74,999$ & $15 \%$ & $1 \%$ & $8 \%$ \\
\hline$\$ 75,000-\$ 99,999$ & $20 \%$ & $0 \%$ & $10 \%$ \\
\hline$\$ 100,000-\$ 124,999$ & $12 \%$ & $0 \%$ & $6 \%$ \\
\hline$\$ 125,000-\$ 149,999$ & $6 \%$ & $0 \%$ & $3 \%$ \\
\hline \multirow[t]{2}{*}{$\$ 150,000$ or more } & $19 \%$ & $0 \%$ & $10 \%$ \\
\hline & $\begin{array}{c}100 \% \\
403\end{array}$ & $\begin{array}{c}100 \% \\
376\end{array}$ & $\begin{array}{c}100 \% \\
779\end{array}$ \\
\hline \multicolumn{4}{|c|}{ Which one of the following four statements best describes your ability to get along on your household income? } \\
\hline I/ we can't make ends meet & $2 \%$ & $26 \%$ & $13 \%$ \\
\hline I/ we have just enough, no more & $21 \%$ & $44 \%$ & $32 \%$ \\
\hline I/ we have enough, with a little extra sometimes & $47 \%$ & $27 \%$ & $37 \%$ \\
\hline \multirow[t]{2}{*}{ I/ we always have money left over } & $30 \%$ & $4 \%$ & $17 \%$ \\
\hline & $\begin{array}{c}100 \% \\
398\end{array}$ & $\begin{array}{c}100 \% \\
369\end{array}$ & $\begin{array}{c}100 \% \\
767\end{array}$ \\
\hline
\end{tabular}

Includes respondents in outreach areas under 65 years and physically able to ride a bicycle.

To maintain adequate sample sizes for analysis, we opted to break the respondents down into just two race/ethnicity groups. Because current research has shown that bike share users have tended to be disproportionately white, we opted to break respondents into groups of non-Hispanic white respondents, and people of color including Hispanic respondents.

These income and race breakdowns yielded the following race-income groups.

- Lower-income people of color (abbreviated “POC” in tables): 331 respondents

- Higher-income people of color: 212 respondents

- Lower-income white: 45 respondents

- Higher-income white: 191 respondents

The breakdown of the percentage of each analysis group coming from each study area is shown in Table 6-3. The low number of respondents in the lower-income white category (45) is in part due to the demographics of the outreach areas in the study, and to the fact that most white respondents were in the higher income category. The low number limits our ability in terms of findings for this particular group. 
Table 6-3 Percentage of each Race-Income Group from each Study Area

\begin{tabular}{|c|c|c|c|c|c|}
\hline & $\begin{array}{l}\text { Lower-Income } \\
\text { People of } \\
\text { Color (POC) }\end{array}$ & $\begin{array}{l}\text { Higher-Income } \\
\text { POC }\end{array}$ & $\begin{array}{c}\text { Lower-Income } \\
\text { White }\end{array}$ & $\begin{array}{c}\text { Higher-Income } \\
\text { White }\end{array}$ & $\begin{array}{c}\text { All } \\
\text { groups }\end{array}$ \\
\hline \multicolumn{6}{|c|}{ Percentage of group respondents area (summed down) } \\
\hline Brooklyn Study Area & $28 \%$ & $20 \%$ & $18 \%$ & $23 \%$ & $24 \%$ \\
\hline Chicago Study Area & $32 \%$ & $42 \%$ & $7 \%$ & $10 \%$ & $28 \%$ \\
\hline Philadelphia West & $12 \%$ & $10 \%$ & $24 \%$ & $16 \%$ & $13 \%$ \\
\hline Philadelphia North & $17 \%$ & $12 \%$ & $18 \%$ & $14 \%$ & $15 \%$ \\
\hline Philadelphia South & $11 \%$ & $17 \%$ & $33 \%$ & $38 \%$ & $20 \%$ \\
\hline$n$ & 331 & 212 & 45 & 191 & 779 \\
\hline \multicolumn{6}{|c|}{ Percentage of area respondents in group (summed across) } \\
\hline Brooklyn Study Area & $50 \%$ & $23 \%$ & $4 \%$ & $23 \%$ & 185 \\
\hline Chicago Study Area & $49 \%$ & $41 \%$ & $1 \%$ & $9 \%$ & 218 \\
\hline Philadelphia West & $39 \%$ & $21 \%$ & $11 \%$ & $29 \%$ & 102 \\
\hline Philadelphia North & $49 \%$ & $22 \%$ & $7 \%$ & $22 \%$ & 116 \\
\hline Philadelphia South & $22 \%$ & $22 \%$ & $9 \%$ & $46 \%$ & 158 \\
\hline All areas & $42 \%$ & $27 \%$ & $6 \%$ & $25 \%$ & 779 \\
\hline
\end{tabular}

Includes respondents in outreach areas under 65 years and physically able to ride a bicycle.

Table 6-4 and Table 6-5 show select transportation, demographic and social information for the four groups of respondents. On many points, the two higher-income groups were very similar, including having driver's licenses (above 90\%), having a car available for use (70\%), having a smartphone (over $90 \%$ ), rates of home ownership (59\%), and rate of employment (about 95\%). They differed in that the higher-income people of color group was less likely to have a bicycle (34\% compared to 59\% for the higher-income white group), a bit less likely to have a credit card (88\% compared to 98\%) and a bit less likely to have reliable internet access (87\% compared to $100 \%$ ). Also notable is that a higher percentage of the higher-income white group had annual household incomes over \$150,000 (27\%) in comparison to higher-income people of color (12\%)

Lower-income respondents differed from the higher-income respondents on many of these questions. The lower-income respondents of color also varied considerably from lower-income white respondents in many cases. Lower-income respondents of color were the least likely to have a driver's license (49\%), a working bicycle (17\%), a car available for use (30\%), a smartphone (66\%), a credit card (43\%), a debit card (56\%), or reliable internet access (56\%). The lower-income white group fell in between the lowerincome people of color group and the higher income groups in terms of having a driver's license, car available, smartphone, credit card, and debit card.

Respondents of color had lived in their homes and neighborhoods longer than white respondents. The white respondents were significantly younger than the respondents of color, which is due in part to receiving fewer than expected responses among low-income people of color in the 18-34 age bracket (around $30-45 \%$ of what would be expected based on the ACS data for the target neighborhoods, compared to $80-108 \%$ for whites aged 18-34). However, the white populations in the target neighborhoods were also somewhat younger, particularly in Brooklyn and Philadelphia. 
Table 6-4 Transportation Characteristics by Race-Income Groups

\begin{tabular}{|c|c|c|c|c|}
\hline & $\begin{array}{l}\text { Lower-Income } \\
\text { POC }\end{array}$ & $\begin{array}{l}\text { Higher-Income } \\
\text { POC }\end{array}$ & $\begin{array}{l}\text { Lower-Income } \\
\text { White }\end{array}$ & $\begin{array}{l}\text { Higher-Income } \\
\text { White }\end{array}$ \\
\hline \multicolumn{5}{|c|}{ In the past week, how did you get around? (\% Selected) } \\
\hline \multicolumn{5}{|l|}{ Drove a personal car } \\
\hline ...most trips & $19 \%$ & $41 \%$ & $17 \%$ & $26 \%$ \\
\hline ... some trips & $19 \%$ & $29 \%$ & $27 \%$ & $39 \%$ \\
\hline \multicolumn{5}{|c|}{ Got a ride from a friend or family member } \\
\hline ...most trips & $9 \%$ & $2 \%$ & $5 \%$ & $0 \%$ \\
\hline ... some trips & $48 \%$ & $34 \%$ & $21 \%$ & $34 \%$ \\
\hline \multicolumn{5}{|l|}{ Taxi/Uber/Lyft } \\
\hline ...most trips & $4 \%$ & $4 \%$ & $5 \%$ & $3 \%$ \\
\hline ...some trips & $33 \%$ & $47 \%$ & $31 \%$ & $62 \%$ \\
\hline \multicolumn{5}{|l|}{ Car Share } \\
\hline ...most trips & $3 \%$ & $1 \%$ & $0 \%$ & $1 \%$ \\
\hline ...some trips & $4 \%$ & $3 \%$ & $8 \%$ & $7 \%$ \\
\hline \multicolumn{5}{|l|}{ Public Transit } \\
\hline ...most trips & $65 \%$ & $40 \%$ & $39 \%$ & $31 \%$ \\
\hline ... some trips & $25 \%$ & $39 \%$ & $43 \%$ & $46 \%$ \\
\hline \multicolumn{5}{|l|}{ Walking } \\
\hline ...most trips & $28 \%$ & $13 \%$ & $37 \%$ & $31 \%$ \\
\hline ...some trips & $\mathbf{5 7 \%}$ & $70 \%$ & $58 \%$ & $66 \%$ \\
\hline \multicolumn{5}{|l|}{ Bicycling - Bike share } \\
\hline ...most trips & $0 \%$ & $0 \%$ & $3 \%$ & $2 \%$ \\
\hline ... some trips & $7 \%$ & $6 \%$ & $3 \%$ & $11 \%$ \\
\hline \multicolumn{5}{|l|}{ Bicycling - Personal bike } \\
\hline ...most trips & $4 \%$ & $4 \%$ & $13 \%$ & $20 \%$ \\
\hline ...some trips & $13 \%$ & $15 \%$ & $15 \%$ & $25 \%$ \\
\hline \multicolumn{5}{|l|}{ Do you currently have a ...? } \\
\hline Driver's license & $49 \%$ & $92 \%$ & $80 \%$ & $97 \%$ \\
\hline Transit pass & $42 \%$ & $56 \%$ & $31 \%$ & $36 \%$ \\
\hline Working bicycle & $17 \%$ & $34 \%$ & $36 \%$ & $59 \%$ \\
\hline Car available for use & $30 \%$ & $70 \%$ & $49 \%$ & $70 \%$ \\
\hline Car share membership & $3 \%$ & $8 \%$ & $13 \%$ & $17 \%$ \\
\hline Maximum number of responses ${ }^{1}$ & 244 & 172 & 38 & 168 \\
\hline Minimum number of responses ${ }^{1}$ & 330 & 212 & 45 & 191 \\
\hline
\end{tabular}

${ }^{1}$ varies by question due to missing

Includes respondents in outreach areas under 65 years and physically able to ride a bicycle. Bold indicates category value significantly greater or less than expected ( $p<0.05$, adj. stand. Chi-square residual) 
Table 6-5 Social and Demographic Characteristics by Race-Income Groups

\begin{tabular}{|c|c|c|c|c|}
\hline & $\begin{array}{c}\text { Lower-Income } \\
\text { POC }\end{array}$ & $\begin{array}{l}\text { Higher-Income } \\
\text { POC }\end{array}$ & $\begin{array}{l}\text { Lower-Income } \\
\text { White }\end{array}$ & $\begin{array}{l}\text { Higher-Income } \\
\text { White }\end{array}$ \\
\hline \multicolumn{5}{|l|}{ Household Income } \\
\hline Under $\$ 50,000$ & $93 \%$ & $21 \%$ & $93 \%$ & $13 \%$ \\
\hline$\$ 50-\$ 99,000$ & $7 \%$ & $49 \%$ & $7 \%$ & $41 \%$ \\
\hline$\$ 100-\$ 149,000$ & $0 \%$ & $18 \%$ & $0 \%$ & $18 \%$ \\
\hline$\$ 150+$ & $0 \%$ & $12 \%$ & $0 \%$ & $27 \%$ \\
\hline \multicolumn{5}{|c|}{ Do you currently have a . . . ? } \\
\hline Smartphone & $66 \%$ & $92 \%$ & $87 \%$ & $97 \%$ \\
\hline Credit card & $43 \%$ & $88 \%$ & $76 \%$ & $98 \%$ \\
\hline Debit card & $70 \%$ & $92 \%$ & $87 \%$ & $97 \%$ \\
\hline Reliable internet access & $56 \%$ & $87 \%$ & $84 \%$ & $100 \%$ \\
\hline \multicolumn{5}{|l|}{ Housing } \\
\hline Own & $18 \%$ & $59 \%$ & $18 \%$ & $59 \%$ \\
\hline Rent & $74 \%$ & $40 \%$ & $80 \%$ & $40 \%$ \\
\hline Subsidized housing & $36 \%$ & $4 \%$ & $9 \%$ & $0 \%$ \\
\hline \multicolumn{5}{|c|}{ How long have you lived at your current address? } \\
\hline $0-2$ years & $20 \%$ & $28 \%$ & $56 \%$ & $51 \%$ \\
\hline 2.1-5 years & $20 \%$ & $24 \%$ & $24 \%$ & $26 \%$ \\
\hline $6-10$ years & $18 \%$ & $21 \%$ & $16 \%$ & $15 \%$ \\
\hline 11-20 years & $22 \%$ & $18 \%$ & $4 \%$ & $5 \%$ \\
\hline $21+$ years & $20 \%$ & $10 \%$ & $0 \%$ & $3 \%$ \\
\hline \multicolumn{5}{|c|}{ How long have you lived in your current neighborhood? } \\
\hline $0-2$ years & $16 \%$ & $20 \%$ & $48 \%$ & $39 \%$ \\
\hline 2. $1-5$ years & $12 \%$ & $23 \%$ & $26 \%$ & $30 \%$ \\
\hline $6-10$ years & $18 \%$ & $17 \%$ & $19 \%$ & $17 \%$ \\
\hline $11-20$ years & $21 \%$ & $23 \%$ & $5 \%$ & $10 \%$ \\
\hline $21+$ years & $33 \%$ & $17 \%$ & $2 \%$ & $3 \%$ \\
\hline \multicolumn{5}{|l|}{ Age } \\
\hline $18-34$ & $21 \%$ & $28 \%$ & $67 \%$ & $58 \%$ \\
\hline $35-54$ & $45 \%$ & $48 \%$ & $27 \%$ & $36 \%$ \\
\hline $55-64$ & $33 \%$ & $25 \%$ & $7 \%$ & $6 \%$ \\
\hline \multicolumn{5}{|l|}{ Gender } \\
\hline Male & $26 \%$ & $31 \%$ & $32 \%$ & $46 \%$ \\
\hline Female & $74 \%$ & $69 \%$ & $64 \%$ & $53 \%$ \\
\hline \multicolumn{5}{|l|}{ Employment } \\
\hline Employed & $57 \%$ & $94 \%$ & $69 \%$ & $96 \%$ \\
\hline Student & $16 \%$ & $17 \%$ & $45 \%$ & $14 \%$ \\
\hline \multicolumn{5}{|l|}{ Children in Household } \\
\hline Has children & $58 \%$ & $35 \%$ & $37 \%$ & $22 \%$ \\
\hline$n$ & 331 & 212 & 45 & 191 \\
\hline
\end{tabular}

Includes respondents in outreach areas under 65 years and physically able to ride a bicycle. Bold indicates category value significantly greater or less than expected ( $p<0.05$, adj. stand. Chi-square residual) 


\subsection{Statistical analysis of group differences}

The following findings chapters present descriptive findings and our initial analysis of resident responses. For ease of analysis and presentation, we collapsed each categorical response scale into a binary variable (Table 6-6). Descriptive statistics for the full scales are provided in an appendix (Chapter 13).

Table 6-6 Binary Variables Created from Categorical Response Scales

\begin{tabular}{|c|c|c|c|c|c|}
\hline Full Scale & \multicolumn{2}{|c|}{ Binary No/Disagree/Incorrect } & \multicolumn{2}{|c|}{ Binary Yes/Agree/Correct } & Treated as \\
\hline Agreement & Strongly Disagree & Disagree & Agree & Strongly Agree & $\begin{array}{l}\text { Not Sure/ No } \\
\text { Opinion }\end{array}$ \\
\hline Barrier & Not a Barrier & Small Barrier & \multicolumn{2}{|c|}{ Big Barrier } & $\begin{array}{l}\text { Does Not } \\
\text { Apply }\end{array}$ \\
\hline Experience & \multicolumn{2}{|c|}{ No } & \multicolumn{2}{|c|}{ Yes } & Not Sure \\
\hline Intention & Not at All Likely & Not Likely & Somewhat Likely & Very Likely & \\
\hline Knowledge $^{1}$ & $\begin{array}{l}\text { Definitely False } \\
\text { (when True) }\end{array}$ & $\begin{array}{l}\text { Probably False } \\
\text { (when True) }\end{array}$ & $\begin{array}{l}\text { Probably True } \\
\text { (when True) }\end{array}$ & $\begin{array}{l}\text { Definitely True } \\
\text { (when True) }\end{array}$ & \\
\hline Motivation & No More Likely & $\begin{array}{l}\text { Somewhat More } \\
\text { Likely }\end{array}$ & \multicolumn{2}{|c|}{ Much More Likely } & $\begin{array}{l}\text { Does Not } \\
\text { Apply }\end{array}$ \\
\hline
\end{tabular}

${ }^{1}$ Detailed description of how knowledge responses were coded provided in Table 8-7.

For each group difference-gender, race-income, city, and Philadelphia neighborhood—we calculated standardized adjusted chi-square residuals in SPSS. By convention, residuals with absolute values of two or greater indicate an interesting and likely statistically significant $(\mathrm{p}<=0.05)$ difference for a group (Sharpe, 2015). While age is not presented as a specific grouping variable, we did consider age group differences in our statistical analysis and note where significant differences were evident. Notes on statistical significance refer to a 5\% significance level, unless otherwise noted.

To increase our confidence that differences between groups were due to related sociodemographic or location differences, we also estimated binomial logistic regression models that controlled simultaneously for age group (18-34, 35-54, and 55-64), gender, race-income group, and city. We do not present the complete logistic results due to space considerations, but, where results changed significantly with additional control variables, we note that in the text. In general, most significant group differences remained with additional controls. This suggests that the groupings each had an independent impact on responses.

Note that age differences were noted on a number of questions. While not shown in reporting tables, observed differences among age groups are discussed in each of the primary findings chapters under subsections pertaining to demographic differences.

\subsection{Abbreviations used}

In reporting some results, we include a word or phrase in brackets (e.g., [CityName]). The brackets indicate that, on the survey itself, the text in brackets was replaced by the appropriate word or phrase for that city. These are shown in Table 6-7. 
Table 6-7 Interpreting Bracketed Words in Findings

\begin{tabular}{|l|l|l|l|}
\hline \multicolumn{1}{|c|}{ Phrase } & \multicolumn{1}{c|}{ Philadelphia } & \multicolumn{1}{c|}{ Brooklyn / New York City } & \multicolumn{1}{c|}{ Chicago } \\
\hline [CityName] & Philadelphia & New York City & Chicago \\
\hline [BssName] & Indego & Citi Bike & Divvy \\
\hline [Local Partner] & $\begin{array}{l}\text { Bicycle Coalition of } \\
\text { Greater Philadelphia }\end{array}$ & $\begin{array}{l}\text { Bedford Stuyvesant Restoration } \\
\text { Corporation }\end{array}$ & Go Bronzeville \\
\hline [Sponsor] & $\begin{array}{l}\text { Independence Blue Cross } \\
\text { Citi Bank }\end{array}$ & Blue Cross Blue Shield \\
\hline
\end{tabular}




\section{ABOUt their NeighBORHOOd AND BiCyCLING}

Prior to asking questions about bike share, the survey included sections of questions about the respondents' views toward transportation, services and planning in their neighborhood, their views on bicycling in general, and potential barriers they may face when considering whether or not to ride a bicycle.

\subsection{About their neighborhood}

General questions about the respondents’ perceptions of their neighborhood, including transportation options, opportunities for involvement and engagement, and recent changes, are shown in Table 7-1. Percentages shown in the table are the proportion of respondents indicating that they agree (either strongly or somewhat) with each statement. Respondents could also select "no opinion” — such responses, along with skips, are not considered in the reported percentages.

Two questions asked the respondents to state their level of agreement with statements about their current transportation options and ability to get around their neighborhood. Nearly all respondents indicated that they were satisfied with their travel options, and could get places easily enough — with overall agreement in the $87-90 \%$ range.

Six questions asked the respondents to state their level of agreement with statements about their familiarity, experience and perceptions of community services and decision-making. Agreement with these statements varied more. On the low end, only about a third of respondents agreed that they had provided input on decisions affecting their neighborhood, though around half agreed that people like them are considered in those decisions. Over half knew about community and social events in their neighborhood, though only $40 \%$ knew about services provided by community or faith-based organizations. With respect to city services generally, only $40 \%$ felt that city government did a good job serving people like them. On the other hand, nearly three-quarters of respondents felt that the transit agency did a good job serving people like them.

Another group of statements pertained to possible changes in the neighborhood. Nearly nine out of 10 respondents (87\%) agreed that they had noticed changes in their neighborhood in the past year, while $76 \%$ indicated that recent change made the neighborhood more appealing to them. A majority (59\%) agreed that their options for getting around had improved in the past year, though agreement levels varied across race and income groups. Over a third (37\%) of respondents agreed that they may have to leave their neighborhood because it is getting too expensive. These responses showed a number of divergent trends among different demographic groups, as discussed in the following section. 
Table 7-1 Neighborhood Perceptions, by Gender and Race-Income Groups

\begin{tabular}{|c|c|c|c|c|c|c|c|}
\hline \multirow[b]{2}{*}{$\begin{array}{c}\text { Statements about neighborhood and } \\
\text { city } \\
(\% \text { agree })\end{array}$} & \multirow[b]{2}{*}{$\begin{array}{l}\text { All } \\
\text { Able } \\
\text { and } \\
<65\end{array}$} & \multicolumn{2}{|c|}{ By gender ${ }^{2}$} & \multicolumn{4}{|c|}{ By race and income group 3} \\
\hline & & Male & Female & $\begin{array}{l}\text { Lower- } \\
\text { Income } \\
\text { POC }\end{array}$ & $\begin{array}{l}\text { Higher- } \\
\text { Income } \\
\text { POC }\end{array}$ & $\begin{array}{l}\text { Lower- } \\
\text { Income } \\
\text { White }\end{array}$ & $\begin{array}{l}\text { Higher- } \\
\text { Income } \\
\text { White }\end{array}$ \\
\hline $\begin{array}{l}\text { I am satisfied with my options for } \\
\text { getting where I need to go }\end{array}$ & $87 \%$ & $92 \%$ & $85 \%$ & $90 \%$ & $88 \%$ & $87 \%$ & $86 \%$ \\
\hline $\begin{array}{l}\text { I can usually get to and from home and } \\
\text { where I need to go easily enough }\end{array}$ & $90 \%$ & $91 \%$ & $90 \%$ & $90 \%$ & $92 \%$ & $93 \%$ & $91 \%$ \\
\hline $\begin{array}{l}\text { I usually know about community and } \\
\text { social events in my neighborhood }\end{array}$ & $55 \%$ & $56 \%$ & $54 \%$ & $60 \%$ & $52 \%$ & $36 \%$ & $48 \%$ \\
\hline $\begin{array}{l}\text { I know about services provided by } \\
\text { community or faith-based organizations } \\
\text { in my neighborhood }\end{array}$ & $40 \%$ & $40 \%$ & $39 \%$ & $47 \%$ & $38 \%$ & $30 \%$ & $26 \%$ \\
\hline $\begin{array}{l}\text { I have provided input on decisions } \\
\text { affecting my neighborhood }\end{array}$ & $35 \%$ & $38 \%$ & $33 \%$ & $37 \%$ & $33 \%$ & $25 \%$ & $32 \%$ \\
\hline $\begin{array}{l}\text { Concerns of people like me are } \\
\text { considered in decisions affecting my } \\
\text { neighborhood }\end{array}$ & $51 \%$ & $56 \%$ & $47 \%$ & $49 \%$ & $49 \%$ & $43 \%$ & $54 \%$ \\
\hline $\begin{array}{l}\text { My city government does a good job } \\
\text { serving people like me }\end{array}$ & $40 \%$ & $44 \%$ & $37 \%$ & $35 \%$ & $34 \%$ & $53 \%$ & $52 \%$ \\
\hline $\begin{array}{l}\text { The public transit agency does a good } \\
\text { job serving people like me }\end{array}$ & $72 \%$ & $79 \%$ & $68 \%$ & $71 \%$ & $72 \%$ & $79 \%$ & $74 \%$ \\
\hline $\begin{array}{l}\text { I have noticed changes in my } \\
\text { neighborhood in the past } 12 \text { months }\end{array}$ & $87 \%$ & $86 \%$ & $87 \%$ & $85 \%$ & $92 \%$ & $77 \%$ & $89 \%$ \\
\hline $\begin{array}{l}\text { Recent changes make my neighborhood } \\
\text { more appealing to me }\end{array}$ & $76 \%$ & $79 \%$ & $74 \%$ & $74 \%$ & $76 \%$ & $63 \%$ & $82 \%$ \\
\hline $\begin{array}{l}\text { I may have to leave my neighborhood } \\
\text { because it is getting too expensive }\end{array}$ & $37 \%$ & $31 \%$ & $40 \%$ & $45 \%$ & $35 \%$ & $44 \%$ & $21 \%$ \\
\hline $\begin{array}{l}\text { My options for getting around have } \\
\text { gotten better in the past } 12 \text { months }\end{array}$ & $59 \%$ & $61 \%$ & $58 \%$ & $66 \%$ & $60 \%$ & $39 \%$ & $46 \%$ \\
\hline Minimum number of responses ${ }^{1}$ & 718 & 224 & 481 & 271 & 163 & 31 & 144 \\
\hline Maximum number of responses ${ }^{1}$ & 893 & 279 & 595 & 317 & 209 & 45 & 191 \\
\hline
\end{tabular}

Includes respondents in outreach areas under 65 years and physically able to ride a bicycle. People of Color abbreviated POC.

${ }^{1}$ varies by question due to missing and "no opinion"

${ }^{2}$ bold indicates category value significantly greater than expected ( $p<0.05$, adj. stand. Chi-square residual)

${ }^{3}$ bold indicates category value significantly greater or less than expected ( $p<0.05$, adj. stand. Chi-square residual)

\subsubsection{Neighborhood perceptions - demographic differences Differences by race and income}

Lower-income respondents of color were less likely to agree (35\%) and higher-income white respondents more likely to agree (52\%) that city government did a good job serving “people like me.” In contrast to the general city government question, there were no differences based on race and income with respect to transit agency service, where $72 \%$ of all respondents agreed the agency did a good job serving people like them. Lower-income respondents of color were more likely to report knowing about neighborhood events and services.

Regarding neighborhood change, higher-income white respondents were most likely to agree that recent changes made the neighborhood more appealing (82\% agreed compared to $76 \%$ of all respondents). In 
addition, lower-income respondents of color were twice as likely to agree that they might get priced out of the neighborhood compared to the higher-income white group (45\% to $21 \%$ ).

In terms of transportation options, there was some evidence that things were improving for lower-income people of color. Respondents in that group were significantly more likely to agree (66\%) that their options for getting around had improved in the past year compared to respondents in the lower-income white group (39\%) and higher-income white group (46\%).

\section{Differences by gender}

Men were slightly more likely to agree that they were satisfied with their options for getting around (92\% vs. 85\%). Although men were also considerably more likely than women to feel that people like them were considered in neighborhood decisions (56\% to 47\%), the difference was not significant after controlling for race-income group, age, and city. Men were more likely to agree that the transit agency served people like them well, with $79 \%$ agreeing compared to $68 \%$ of women. Women were also more likely than men to feel that they may be priced out of the neighborhood (40\% to $31 \%$ ); however, the difference was not significant when controlling for race-income group, age, and city.

\section{Differences by age}

Though not shown in the findings table, age differences were observed on several of the neighborhood perception questions. Some of these differences may reflect differences in the length of residence, among other factors. Respondents aged 18-34 reported having lived in their neighborhood for an average of five years versus fourteen (35-54) and twenty-two years (54-64) among older respondents. Controlling for other factors (race-income group, gender, and city), those in both the 35-54 and 55-64 age groups reported significantly higher rates of agreement on: satisfaction with transportation options, knowing about neighborhood services, and providing input on neighborhood decisions. Respondents 55-64 were also significantly more likely to agree that they knew about neighborhood events and that they had noticed changes in the past year, compared with the youngest group (18-34).

\subsubsection{Neighborhood perceptions - geographic differences}

Perceptions about neighborhood transportation, engagement and change are shown in Table 7-2 for each of the cities, by study area. Overall, respondents in the study areas were more similar than different with respect to neighborhood perceptions. On several measures of ability to get around, respondents in Philadelphia study areas were more likely to be satisfied with their travel options and to be able to get around easily enough than respondents in study areas in other cities. This would make sense, as these areas were a bit closer to the city center.

Respondents in the Brooklyn study area were a bit less likely than other respondents to know about events and services in their neighborhood. Respondents in the Brooklyn study area were also a bit less optimistic toward their city's transit agency, with only 58\% agreeing that the agency does a good job serving people like them, compared to $72 \%$ across all study areas. Brooklyn residents also were less likely to feel their transportation options had improved in the past year (52\% agreed compared to 59\% for all cities); though still more than half felt their options had improved. Perhaps most notably, respondents in Brooklyn appear to be feeling cost pressures on their neighborhood, with 53\% agreeing that they might have to leave their neighborhood because it is getting too expensive (compared to $37 \%$ across all study areas); this may be a contributing factor to why they are also less likely to view recent changes as making the neighborhood more appealing to them (67\% agreed compared to $76 \%$ across all study areas). Controlling for other factors (race-income group, age, and gender), Bronzeville (Chicago) residents were significantly less likely than those in the other cities to report noticing neighborhood changes in the past year. 
Table 7-2 Neighborhood Perceptions, by City and Neighborhood

\begin{tabular}{|c|c|c|c|c|c|c|c|}
\hline \multirow[b]{2}{*}{$\begin{array}{l}\text { Statements about neighborhood and city } \\
\text { (\% agree) }\end{array}$} & \multirow[b]{2}{*}{$\begin{array}{l}\text { Able } \\
\text { and } \\
\text { Under } \\
65\end{array}$} & \multicolumn{6}{|c|}{ Able and under 65 , by outreach city and area ${ }^{2}$} \\
\hline & & $\begin{array}{l}\text { BKLN } \\
\text { Study } \\
\text { Area }\end{array}$ & $\begin{array}{l}\text { CHI } \\
\text { Study } \\
\text { Area }\end{array}$ & $\begin{array}{l}\text { PHI } \\
\text { Study } \\
\text { Areas } \\
\text { All }\end{array}$ & $\begin{array}{l}\text { PHI } \\
\text { Study } \\
\text { Area } \\
\text { West }\end{array}$ & $\begin{array}{l}\text { PHI } \\
\text { Study } \\
\text { Area } \\
\text { North }\end{array}$ & $\begin{array}{l}\text { PHI } \\
\text { Study } \\
\text { Area } \\
\text { South }\end{array}$ \\
\hline $\begin{array}{l}\text { I am satisfied with my options for getting } \\
\text { where I need to go }\end{array}$ & $87 \%$ & $84 \%$ & $85 \%$ & $90 \%$ & $90 \%$ & $89 \%$ & $91 \%$ \\
\hline $\begin{array}{l}\text { I can usually get to and from home and } \\
\text { where I need to go easily enough }\end{array}$ & $90 \%$ & $85 \%$ & $90 \%$ & $93 \%$ & $93 \%$ & $92 \%$ & $93 \%$ \\
\hline $\begin{array}{l}\text { I usually know about community and } \\
\text { social events in my neighborhood }\end{array}$ & $55 \%$ & $44 \%$ & $56 \%$ & $59 \%$ & $63 \%$ & $54 \%$ & $60 \%$ \\
\hline $\begin{array}{l}\text { I know about services provided by } \\
\text { community or faith-based organizations in } \\
\text { my neighborhood }\end{array}$ & $40 \%$ & $32 \%$ & $40 \%$ & $43 \%$ & $51 \%$ & $46 \%$ & $36 \%$ \\
\hline $\begin{array}{l}\text { I have provided input on decisions } \\
\text { affecting my neighborhood }\end{array}$ & $35 \%$ & $28 \%$ & $32 \%$ & $40 \%$ & $47 \%$ & $35 \%$ & $40 \%$ \\
\hline $\begin{array}{l}\text { Concerns of people like me are } \\
\text { considered in decisions affecting my } \\
\text { neighborhood }\end{array}$ & $51 \%$ & $45 \%$ & $56 \%$ & $50 \%$ & $56 \%$ & $44 \%$ & $52 \%$ \\
\hline $\begin{array}{l}\text { My city government does a good job or } \\
\text { serving people like me }\end{array}$ & $40 \%$ & $41 \%$ & $35 \%$ & $42 \%$ & $40 \%$ & $39 \%$ & $45 \%$ \\
\hline $\begin{array}{l}\text { The public transit agency does a good job } \\
\text { serving people like me }\end{array}$ & $72 \%$ & $58 \%$ & $79 \%$ & $75 \%$ & $75 \%$ & $72 \%$ & $76 \%$ \\
\hline $\begin{array}{l}\text { I have noticed changes in my } \\
\text { neighborhood in the past } 12 \text { months }\end{array}$ & $87 \%$ & $88 \%$ & $84 \%$ & $88 \%$ & $80 \%$ & $90 \%$ & $90 \%$ \\
\hline $\begin{array}{l}\text { Recent changes make my neighborhood } \\
\text { more appealing to me }\end{array}$ & $76 \%$ & $67 \%$ & $79 \%$ & $77 \%$ & $71 \%$ & $82 \%$ & $78 \%$ \\
\hline $\begin{array}{l}\text { I may have to leave my neighborhood } \\
\text { because it is getting too expensive }\end{array}$ & $37 \%$ & $53 \%$ & $40 \%$ & $29 \%$ & $21 \%$ & $39 \%$ & $25 \%$ \\
\hline $\begin{array}{l}\text { My options for getting around have gotten } \\
\text { better in the past } 12 \text { months }\end{array}$ & $59 \%$ & $52 \%$ & $64 \%$ & $59 \%$ & $60 \%$ & $64 \%$ & $54 \%$ \\
\hline Minimum number of responses ${ }^{1}$ & 718 & 173 & 208 & 332 & 92 & 107 & 133 \\
\hline Maximum number of responses ${ }^{1}$ & 893 & 207 & 261 & 429 & 121 & 139 & 170 \\
\hline
\end{tabular}

${ }^{1}$ varies by question due to missing and "no opinion"

${ }^{2}$ bold indicates category value significantly greater or less than expected ( $p<0.05$, adj. stand. Chi-square residual)

\subsection{About bicycling}

General questions about the respondents' perceptions of bicycling are shown in Table 7-3. Percentages shown in the table are the proportion of respondents indicating that they agree (either strongly or somewhat) with each statement. Respondents could also select either "no opinion" or "does not apply" depending on the question — such responses, along with skips, are not considered in the reported percentages.

Several questions focused on broad opinions about bicycling, rather than the individual's bicycling experiences. These included four positive statements about bicycling that may relate to support for public policy, along with two negative statements about bicycling. Overall agreement with the positive statements about bicycling was generally quite high - around 90\% agreed that getting people to ride bikes was good for the environment, would help make the community healthier, that the city should invest in bicycle related projects such as bike lanes, and that riding a bike is a convenient way to get around. Agreement with the negative statements about bicycling was considerably lower, including that people on 
bikes make roads less safe for other (42\% agreed) and that bike lanes make it harder to get around their neighborhood (21\% agreed). However, a number of these showed some important demographic differences, described later in this section.

The remainder of the questions focused on the individual and their experiences with or attitudes toward bicycling. Most respondents indicated that they are familiar with bike lanes in their neighborhood (about 79\%) and there were no differences by the demographic groups. A similar percentage agreed that they see people like themselves riding bikes in their neighborhood, though in this case there were several demographic differences.

Four statements addressed potential personal benefits of bicycling. Getting exercise (at 94\% agreement) and spending less on transportation (at 74\% agreement) were the most popular motivators, with independence and spending time with friends or family agreed to by about half of respondents. A fifth brought up a more negative perspective - despite considerable agreement about these benefits, 78\% still agreed that there were better ways for them to get around.

In terms of recent or expected changes in bicycling behaviors, around a quarter of respondents are bicycling more now than they were a year ago. Just under two-thirds "would like to ride" more than they currently do, but only 57\% plan to ride more in the next year. This fall-off from stated desire to ride more to intention to ride more is consistent across most groups, with certain exceptions noted later in this chapter. 
Table 7-3 Perceptions of Bicycling, by Gender and Race-Income Groups

\begin{tabular}{|c|c|c|c|c|c|c|c|}
\hline \multirow[b]{2}{*}{$\begin{array}{l}\text { Opinions about bicycling in general } \\
\text { (\% agree) }\end{array}$} & \multirow[b]{2}{*}{$\begin{array}{l}\text { All } \\
\text { Able } \\
\text { and } \\
<65\end{array}$} & \multicolumn{2}{|c|}{ By gender ${ }^{2}$} & \multicolumn{4}{|c|}{ By race and income group ${ }^{3}$} \\
\hline & & Male & Female & $\begin{array}{l}\text { Lower- } \\
\text { Income } \\
\text { POC }\end{array}$ & $\begin{array}{l}\text { Higher- } \\
\text { Income } \\
\text { POC }\end{array}$ & $\begin{array}{l}\text { Lower- } \\
\text { Income } \\
\text { White }\end{array}$ & $\begin{array}{l}\text { Higher- } \\
\text { Income } \\
\text { White }\end{array}$ \\
\hline $\begin{array}{l}\text { Getting more people to ride bikes is } \\
\text { good for the environment }\end{array}$ & $92 \%$ & $95 \%$ & $91 \%$ & $90 \%$ & $92 \%$ & $98 \%$ & $98 \%$ \\
\hline $\begin{array}{l}\text { Getting more people to ride bikes will } \\
\text { help make the community healthier }\end{array}$ & $90 \%$ & $93 \%$ & $89 \%$ & $88 \%$ & $90 \%$ & $100 \%$ & $96 \%$ \\
\hline $\begin{array}{l}\text { [CityName] should invest in projects } \\
\text { (such as bike lanes) that make riding } \\
\text { bikes safer and easier }\end{array}$ & $88 \%$ & $90 \%$ & $87 \%$ & $89 \%$ & $79 \%$ & $98 \%$ & $97 \%$ \\
\hline $\begin{array}{l}\text { Riding a bike is a convenient way for } \\
\text { people to get places in [CityName] }\end{array}$ & $89 \%$ & $92 \%$ & $89 \%$ & $90 \%$ & $89 \%$ & $87 \%$ & $93 \%$ \\
\hline $\begin{array}{l}\text { People on bikes make roads less safe } \\
\text { for others }\end{array}$ & $42 \%$ & $39 \%$ & $43 \%$ & $43 \%$ & $51 \%$ & $37 \%$ & $29 \%$ \\
\hline $\begin{array}{l}\text { Bike lanes make it harder to get around } \\
\text { my neighborhood }\end{array}$ & $21 \%$ & $19 \%$ & $22 \%$ & $23 \%$ & $31 \%$ & $8 \%$ & $11 \%$ \\
\hline $\begin{array}{l}\text { I am familiar with the bike lanes in my } \\
\text { neighborhood }\end{array}$ & $79 \%$ & $83 \%$ & $77 \%$ & $80 \%$ & $78 \%$ & $71 \%$ & $80 \%$ \\
\hline $\begin{array}{l}\text { I often see people like me riding bikes } \\
\text { in my neighborhood }\end{array}$ & $77 \%$ & $86 \%$ & $72 \%$ & $76 \%$ & $70 \%$ & $88 \%$ & $88 \%$ \\
\hline $\begin{array}{l}\text { I would like to ride a bicycle (for } \\
\text { transportation) more than I currently do }\end{array}$ & $65 \%$ & $74 \%$ & $61 \%$ & $62 \%$ & $58 \%$ & $79 \%$ & $80 \%$ \\
\hline $\begin{array}{l}\text { There are better ways for me to get } \\
\text { around than by biking }\end{array}$ & $78 \%$ & $69 \%$ & $82 \%$ & $84 \%$ & $84 \%$ & $69 \%$ & $57 \%$ \\
\hline $\begin{array}{l}\text { Riding a bike would make me more } \\
\text { independent in getting around }\end{array}$ & $51 \%$ & $61 \%$ & $46 \%$ & $50 \%$ & $37 \%$ & $73 \%$ & $63 \%$ \\
\hline $\begin{array}{l}\text { Riding a bike would help me spend less } \\
\text { on transportation }\end{array}$ & $74 \%$ & $76 \%$ & $74 \%$ & $77 \%$ & $70 \%$ & $80 \%$ & $77 \%$ \\
\hline $\begin{array}{l}\text { Riding a bike would be a good way for } \\
\text { me to get exercise }\end{array}$ & $94 \%$ & $97 \%$ & $92 \%$ & $92 \%$ & $95 \%$ & $100 \%$ & $97 \%$ \\
\hline $\begin{array}{l}\text { Riding a bike would be a good way for } \\
\text { me to spend time with friends or family }\end{array}$ & $52 \%$ & $58 \%$ & $50 \%$ & $55 \%$ & $48 \%$ & $51 \%$ & $59 \%$ \\
\hline $\begin{array}{l}\text { I'm bicycling more now than I did a year } \\
\text { ago }\end{array}$ & $24 \%$ & $28 \%$ & $21 \%$ & $22 \%$ & $24 \%$ & $26 \%$ & $32 \%$ \\
\hline $\begin{array}{l}\text { I plan to ride a bicycle more often in } \\
\text { the next year }\end{array}$ & $57 \%$ & $66 \%$ & $53 \%$ & $52 \%$ & $59 \%$ & $59 \%$ & $66 \%$ \\
\hline $\begin{array}{l}\text { There is a bike shop that is convenient } \\
\text { for me to go to }\end{array}$ & $63 \%$ & $68 \%$ & $60 \%$ & $58 \%$ & $64 \%$ & $66 \%$ & $71 \%$ \\
\hline Minimum number of responses ${ }^{1}$ & 746 & 248 & 484 & 262 & 176 & 35 & 164 \\
\hline Maximum number of responses ${ }^{1}$ & 869 & 278 & 580 & 314 & 206 & 44 & 189 \\
\hline
\end{tabular}

\subsubsection{Perceptions of bicycling - demographic differences}

Differences by race and income

White respondents were somewhat more likely to agree with the statements on the benefits of bicycling for environment or for community health (with over 96\% agreement). On the question of whether the city 
should invest in projects that "make riding bikes safer and easier," the higher-income respondents of color were less likely to agree than higher-income white respondents (79\% to 97\%). Lower-income respondents of color were in between (at 89\% agreement), but were not statistically significantly different from either.

On the two negative statements about bicycling in general, the higher-income people of color group again responded differently from the higher-income white group. Higher-income respondents of color were more likely to agree that people on bikes make roads less safe for others (51\% agreed compared to 29\% in the higher-income white group), and that bike lanes make it harder to get around the neighborhood (31\% compared to $8 \%-11 \%$ for white respondents, with statistically significant differences regardless of income group). The lower-income people of color group again fell between these extremes and was not significantly different from any of the other groups. Taken together, the questions on investing in bike lanes, bicyclists' making roads less safe, and bike lanes' making travel harder suggest a higher degree of negative sentiment toward bicycling among higher-income respondents of color than among other respondents.

Higher-income respondents of color were less likely to agree that they see people like them bicycling in the neighborhood (70\%), and higher-income white respondents more likely to agree (88\%) than the respondents overall. Higher-income respondents of color were least likely to view bicycling as a means of increased independence, while lower-income respondents of color were the least likely to view biking as a good way to get exercise. Respondents of color (regardless of income) were much more likely to agree that they had better ways to get around than by bike than men (84\% vs. $57-69 \%$ of whites).

Responding about recent and planned changes in bicycling, people of color were somewhat less likely to want to ride more (58\% of those higher-income and $62 \%$ of those lower-income vs. $65 \%$ overall). Lowerincome people of color were less likely to plan to ride more in the next year (52\% vs. $57 \%$ overall). Higher-income white respondents were more likely to state that they would like to ride more (80\%, compared to $65 \%$ of all respondents). Although higher-income white respondents were also more likely to report biking more now than a year ago (32\%, compared to $24 \%$ of all respondents) and to state that they plan to ride more often in the next year (66\%, compared to $57 \%$ of all respondents), neither difference was significant after controlling for gender, age and city.

Figure 7-1 shows the difference of each racial-income demographic group from the overall share for this same set of questions. Displayed this way, some of the demographic differences and similarities become clearer. For example, white respondents, both lower- and higher-income, had generally more positive opinions about bicycling broadly (first six questions), whereas higher-income respondents of color were often more negative than the group as a whole. Regarding the more personal questions, the differences were most pronounced for the statements about seeing people like me riding in my neighborhood, wanting to ride more, there are better ways to get around than biking, and riding a bike would make me more independent. For these questions, white respondents, both lower- and higher-income, were generally more positive, and higher-income respondents of color were less positive than the group as a whole. In some cases, lower-income respondents of color were also more negative. For the other questions focused on the individual (e.g., riding a bike would help me spend less or get exercise), the differences between the groups is smaller. On many of the questions, the small differences observed were not significant. 
Getting more people to ride bikes is good for the environment $(92 \%)$

Getting more people to ride bikes will help make the community healthier (90\%)

[CityName] should invest in projects (such as

bike lanes) that make riding bikes safer and...

People on bikes make roads less safe for others $(42 \%)^{*}$

Bike lanes make it harder to get around my neighborhood (21\%)*

Riding a bike is a convenient way for people to get places in [CityName] $(89 \%)$

I am familiar with the bike lanes in my neighborhood (79\%)

I often see people like me riding bikes in my neighborhood (77\%)

I would like to ride a bicycle (for transportation) more than I currently do (65\%)

There are better ways for me to get around than by biking $(78 \%) *$

Riding a bike would make me more independent in getting around (51\%)

Riding a bike would help me spend less on transportation (74\%)

Riding a bike would be a good way for me to get exercise (94\%)

Riding a bike would be a good way for me to spend time with friends or family (52\%)

I'm bicycling more now than I did a year ago $(24 \%)$

I plan to ride a bicycle more often in the next year (57\%)

There is a bike shop that is convenient for me to go to $(63 \%)$

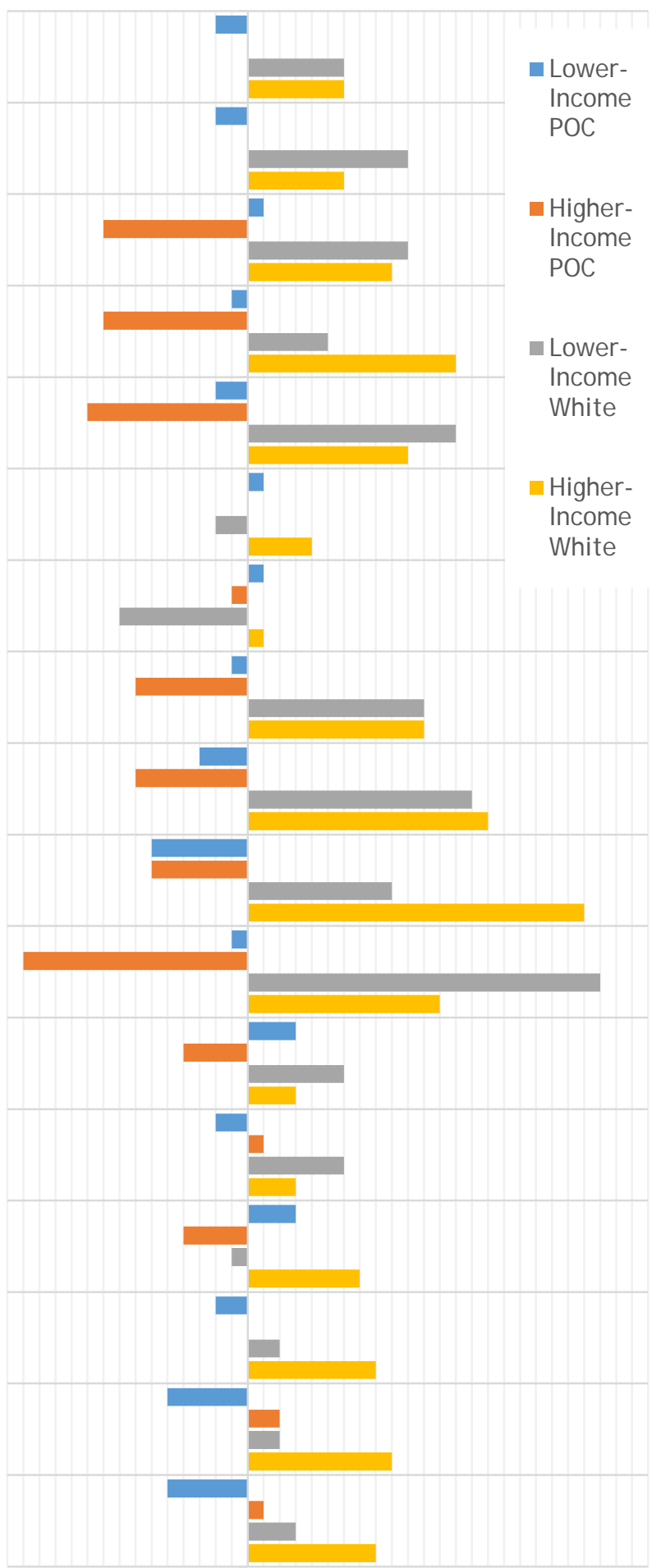

*For starred items difference is inverted. Positive difference denotes more bike positive sentiment, negative difference denotes=more bike negative difference

Figure 7-1 Race and income difference in agreement from average of all areas (shown in parenthesis). 


\section{Differences by gender}

Men were much more likely to agree than women that they see people like them riding in the neighborhood (86\% vs. $72 \%$ ). Men were also much more likely to agree than women on three of the four personal benefits of cycling: more independence, getting exercise, and spending time with friends or family; there was no difference on the statement about bicycling helping them spend less on transportation. Women were much more likely to agree that they had better ways to get around than by bike than men ( $82 \%$ vs. $69 \%)$.

Responding about recent and planned changes in bicycling, men were more likely to state that they would like to ride more (74\% and 61\%). Although men were also more like to report biking more now than a year ago ( $28 \%$ vs. $21 \%$ ) and to state that they plan to ride more often in the next year (66\% vs. 53\%), those differences were not significant after controlling for race-income group, age, and city.

Differences by age

Perceptions of bicycling were largely consistent across age groups for those under 65, with a few exceptions. Respondents aged 35-54 were significantly less likely to agree that bicycling would improve community health, though their rate of agreement was still high overall (87\%). Perhaps due to longer tenure in the neighborhood, those in both older age groups (35-54 and 55-64) were significantly more likely younger residents to report familiarity with local bike lanes. Those aged 18-34 were significantly more likely to agree that bicycling would increase their independence.

\subsubsection{Perceptions of bicycling - geographic differences}

Agreement with statements about bicycling, broken down by survey city and neighborhood, is shown in Table 7-4. Respondents in Chicago had a slightly more negative view toward bicycles than those in other cities, with just under a third feeling that bike lanes make it harder to get around their neighborhoods (compared to 21\% across all cities). Nearly half of respondents in Chicago agreed that people on bikes make roads less safe for others (compared to $42 \%$ across all cities); however, this difference was not significant from other cities after controlling for race-income group, gender, and age. Those in Chicago were also least likely to see people like them riding bikes in their neighborhood, most likely to agree that there are better ways to get around, and least likely to think riding a bike would make them more independent. 
Table 7-4 Perceptions of Bicycling, by City and Neighborhood

\begin{tabular}{|c|c|c|c|c|c|c|c|}
\hline \multirow[b]{2}{*}{$\begin{array}{l}\text { Opinions about bicycling in general } \\
\text { ( } \% \text { agree })\end{array}$} & \multirow[b]{2}{*}{$\begin{array}{l}\text { Able } \\
\text { and } \\
<65\end{array}$} & \multicolumn{6}{|c|}{ Able and under 65, by outreach city and area ${ }^{2}$} \\
\hline & & $\begin{array}{l}\text { BKLN } \\
\text { Study } \\
\text { Area }\end{array}$ & $\begin{array}{l}\text { CHI } \\
\text { Study } \\
\text { Area }\end{array}$ & $\begin{array}{l}\text { PHI } \\
\text { Study } \\
\text { Areas } \\
\text { All }\end{array}$ & $\begin{array}{l}\text { PHI } \\
\text { Study } \\
\text { Area } \\
\text { West }\end{array}$ & $\begin{array}{l}\text { PHI } \\
\text { Study } \\
\text { Area } \\
\text { North }\end{array}$ & $\begin{array}{l}\text { PHI } \\
\text { Study } \\
\text { Area } \\
\text { South }\end{array}$ \\
\hline $\begin{array}{l}\text { Getting more people to ride bikes is } \\
\text { good for the environment }\end{array}$ & $92 \%$ & $90 \%$ & $90 \%$ & $94 \%$ & $98 \%$ & $93 \%$ & $93 \%$ \\
\hline $\begin{array}{l}\text { Getting more people to ride bikes will } \\
\text { help make the community healthier }\end{array}$ & $90 \%$ & $88 \%$ & $89 \%$ & $92 \%$ & $93 \%$ & $90 \%$ & $92 \%$ \\
\hline $\begin{array}{l}\text { [CityName] should invest in projects } \\
\text { (such as bike lanes) that make riding } \\
\text { bikes safer and easier }\end{array}$ & $88 \%$ & $86 \%$ & $80 \%$ & $93 \%$ & $94 \%$ & $92 \%$ & $94 \%$ \\
\hline $\begin{array}{l}\text { People on bikes make roads less safe } \\
\text { for others }\end{array}$ & $42 \%$ & $39 \%$ & $49 \%$ & $39 \%$ & $36 \%$ & $38 \%$ & $43 \%$ \\
\hline $\begin{array}{l}\text { Bike lanes make it harder to get } \\
\text { around my neighborhood }\end{array}$ & $21 \%$ & $21 \%$ & $32 \%$ & $15 \%$ & $11 \%$ & $18 \%$ & $16 \%$ \\
\hline $\begin{array}{l}\text { Riding a bike is a convenient way for } \\
\text { people to get places in [CityName] }\end{array}$ & $89 \%$ & $87 \%$ & $88 \%$ & $92 \%$ & $94 \%$ & $90 \%$ & $92 \%$ \\
\hline $\begin{array}{l}\text { I am familiar with the bike lanes in my } \\
\text { neighborhood }\end{array}$ & $79 \%$ & $72 \%$ & $84 \%$ & $79 \%$ & $85 \%$ & $77 \%$ & $75 \%$ \\
\hline $\begin{array}{l}\text { I often see people like me riding bikes } \\
\text { in my neighborhood }\end{array}$ & $77 \%$ & $77 \%$ & $70 \%$ & $81 \%$ & $74 \%$ & $83 \%$ & $85 \%$ \\
\hline $\begin{array}{l}\text { I would like to ride a bicycle (for } \\
\text { transportation) more than I currently } \\
\text { do }\end{array}$ & $65 \%$ & $64 \%$ & $63 \%$ & $67 \%$ & $72 \%$ & $63 \%$ & $67 \%$ \\
\hline $\begin{array}{l}\text { There are better ways for me to get } \\
\text { around than by biking }\end{array}$ & $78 \%$ & $78 \%$ & $86 \%$ & $73 \%$ & $77 \%$ & $80 \%$ & $65 \%$ \\
\hline $\begin{array}{l}\text { Riding a bike would make me more } \\
\text { independent in getting around }\end{array}$ & $51 \%$ & $54 \%$ & $35 \%$ & $58 \%$ & $56 \%$ & $54 \%$ & $63 \%$ \\
\hline $\begin{array}{l}\text { Riding a bike would help me spend less } \\
\text { on transportation }\end{array}$ & $74 \%$ & $73 \%$ & $72 \%$ & $77 \%$ & $81 \%$ & $69 \%$ & $81 \%$ \\
\hline $\begin{array}{l}\text { Riding a bike would be a good way for } \\
\text { me to get exercise }\end{array}$ & $94 \%$ & $95 \%$ & $94 \%$ & $94 \%$ & $97 \%$ & $91 \%$ & $94 \%$ \\
\hline $\begin{array}{l}\text { Riding a bike would be a good way for } \\
\text { me to spend time with friends or } \\
\text { family }\end{array}$ & $52 \%$ & $53 \%$ & $54 \%$ & $51 \%$ & $50 \%$ & $51 \%$ & $53 \%$ \\
\hline $\begin{array}{l}\text { I'm bicycling more now than I did a } \\
\text { year ago }\end{array}$ & $24 \%$ & $31 \%$ & $21 \%$ & $23 \%$ & $17 \%$ & $16 \%$ & $32 \%$ \\
\hline $\begin{array}{l}\text { I plan to ride a bicycle more often in } \\
\text { the next year }\end{array}$ & $57 \%$ & $53 \%$ & $59 \%$ & $59 \%$ & $65 \%$ & $57 \%$ & $55 \%$ \\
\hline $\begin{array}{l}\text { There is a bike shop that is convenient } \\
\text { for me to go to }\end{array}$ & $63 \%$ & $65 \%$ & $52 \%$ & $69 \%$ & $78 \%$ & $69 \%$ & $62 \%$ \\
\hline Minimum number of responses ${ }^{1}$ & 746 & 163 & 218 & 358 & 96 & 114 & 134 \\
\hline Maximum number of responses ${ }^{1}$ & 869 & 206 & 249 & 418 & 120 & 139 & 167 \\
\hline
\end{tabular}

\subsection{Neighborhood perceptions and bicycling}

The questions about neighborhood perceptions were included in the survey to see how these perceptions may relate to bicycling and bike share. For example, people's level of satisfaction with their daily travel options may influence their support for bicycle infrastructure. In addition, their opinions about bicycling could correlate with their satisfaction with their daily travel options. These relationships are shown in Table 7-5. 
Respondents who were not satisfied with options for getting around often had more negative opinions about bike infrastructure and biking; however, support was still overall very high. For example, large shares of the unsatisfied groups thought riding a bike is a convenient way to get places (78-83\%), though the shares were less than those who were satisfied. Only $25 \%$ of those who were not satisfied with their options thought bike lanes made it harder to get around. Those not satisfied with their options were less likely to agree that there are better ways to get around than bicycling, though the differences were not significant. However, satisfaction with travel options was not correlated with interest in bicycling for transportation more. Finally, of those who agreed that their options for getting around had gotten better in the past year, $29 \%$ said they were bicycling more, compared to $16 \%$ of those who did not think their options had gotten better.

Table 7-5 Satisfaction with Travel Options and Opinions about Bicycling

\begin{tabular}{|c|c|c|c|c|c|c|}
\hline \multirow[t]{2}{*}{$\begin{array}{l}\% \text { that agree with the following } \\
\text { statements... }\end{array}$} & \multicolumn{2}{|c|}{$\begin{array}{l}\text { I am satisfied with my } \\
\text { options for getting } \\
\text { where I need to go }\end{array}$} & \multicolumn{2}{|c|}{$\begin{array}{l}\text { I can usually get to } \\
\text { and from home and } \\
\text { where I need to go } \\
\text { easily enough }\end{array}$} & \multicolumn{2}{|c|}{$\begin{array}{l}\text { My options for getting } \\
\text { around have gotten } \\
\text { better in the past } 12 \\
\text { months }\end{array}$} \\
\hline & Disagree & Agree & Disagree & Agree & Disagree & Agree \\
\hline $\begin{array}{l}\text { [CityName] should invest in } \\
\text { projects (such as bike lanes) } \\
\text { that make riding bikes safer and } \\
\text { easier }\end{array}$ & $86 \%$ & $88 \%$ & $84 \%$ & $88 \%$ & $82 \%$ & $91 \%$ \\
\hline $\begin{array}{l}\text { Bike lanes make it harder to get } \\
\text { around my neighborhood }\end{array}$ & $25 \%$ & $20 \%$ & $28 \%$ & $20 \%$ & $24 \%$ & $19 \%$ \\
\hline $\begin{array}{l}\text { Riding a bike is a convenient way } \\
\text { for people to get places in } \\
\text { [CityName] }\end{array}$ & $78 \%$ & $91 \%$ & $81 \%$ & $90 \%$ & $83 \%$ & $92 \%$ \\
\hline $\begin{array}{l}\text { I am familiar with the bike lanes } \\
\text { in my neighborhood }\end{array}$ & $63 \%$ & $81 \%$ & $54 \%$ & $81 \%$ & $69 \%$ & $85 \%$ \\
\hline $\begin{array}{l}\text { I often see people like me riding } \\
\text { bikes in my neighborhood }\end{array}$ & $59 \%$ & $80 \%$ & $61 \%$ & $79 \%$ & $69 \%$ & $80 \%$ \\
\hline $\begin{array}{l}\text { I would like to ride a bicycle (for } \\
\text { transportation) more than I } \\
\text { currently do }\end{array}$ & $62 \%$ & $66 \%$ & $58 \%$ & $66 \%$ & $62 \%$ & $66 \%$ \\
\hline $\begin{array}{l}\text { There are better ways for me to } \\
\text { get around than by biking }\end{array}$ & $72 \%$ & $79 \%$ & $71 \%$ & $79 \%$ & $76 \%$ & $80 \%$ \\
\hline $\begin{array}{l}\text { Riding a bike would make me } \\
\text { more independent in getting } \\
\text { around }\end{array}$ & $44 \%$ & $51 \%$ & $51 \%$ & $50 \%$ & $43 \%$ & $58 \%$ \\
\hline $\begin{array}{l}\text { Riding a bike would help me } \\
\text { spend less on transportation }\end{array}$ & $73 \%$ & $75 \%$ & $66 \%$ & $76 \%$ & $70 \%$ & $76 \%$ \\
\hline $\begin{array}{l}\text { Riding a bike would be a good } \\
\text { way for me to get exercise }\end{array}$ & $91 \%$ & $94 \%$ & $94 \%$ & $94 \%$ & $91 \%$ & $94 \%$ \\
\hline $\begin{array}{l}\text { Riding a bike would be a good } \\
\text { way for me to spend time with } \\
\text { friends or family }\end{array}$ & $45 \%$ & $53 \%$ & $43 \%$ & $53 \%$ & $44 \%$ & $57 \%$ \\
\hline $\begin{array}{l}\text { I'm bicycling more now than I } \\
\text { did a year ago }\end{array}$ & $22 \%$ & $24 \%$ & $21 \%$ & $24 \%$ & $16 \%$ & $29 \%$ \\
\hline Minimum number of responses ${ }^{1}$ & 101 & 631 & 77 & 656 & 258 & 343 \\
\hline Maximum number of responses ${ }^{1}$ & 112 & 740 & 85 & 770 & 288 & 406 \\
\hline
\end{tabular}

Includes respondents in outreach areas under 65 years and physically able to ride a bicycle.

${ }^{1}$ varies by question due to missing and "no opinion" or "does not apply"

${ }^{2}$ bold indicates category value significantly greater or less than the other group ( $p<0.05$, z-test) 
Some sources have raised concerns about links between bicycle infrastructure and gentrification (e.g. CCC, 2012). To examine this question, Table 7-6 shows responses to questions that may be indicators of concerns related to gentrification and public policy on bicycling for those who disagreed and agreed with whether recent changes in the neighborhood made it more appealing and whether the respondent might need to leave because the neighborhood was getting too expensive. The latter is a more direct measure of one concern of gentrification. Of those who thought they might be priced out of their neighborhood, very large majorities (91\% and 89\%) were supportive of getting more people riding bicycles. In addition, 86\% supported their city's investments in bike projects. While this share was less than those who were not concerned with being priced out (89\%), the high level of agreement does not indicate that the respondents are making a strong negative connection between bicycle infrastructure and gentrification. However, a higher share of those concerned about being priced out did agree that bike lanes make it harder to get around (26\% vs. $19 \%)$.

Table 7-6 Concerns about Neighborhood Changes and Opinions about Bicycling

\begin{tabular}{|c|c|c|c|c|}
\hline \multirow[t]{2}{*}{ \% that agree with the following statements... } & \multicolumn{2}{|c|}{$\begin{array}{l}\text { Recent changes make my } \\
\text { neighborhood more } \\
\text { appealing to me }\end{array}$} & \multicolumn{2}{|c|}{$\begin{array}{l}\text { I may have to leave my } \\
\text { neighborhood because it } \\
\text { is getting too expensive }\end{array}$} \\
\hline & Disagree & Agree & Disagree & Agree \\
\hline $\begin{array}{l}\text { Getting more people to ride bikes is good for the } \\
\text { environment }\end{array}$ & $85 \%$ & $94 \%$ & $93 \%$ & $91 \%$ \\
\hline $\begin{array}{l}\text { Getting more people to ride bikes will help make } \\
\text { the community healthier }\end{array}$ & $81 \%$ & $93 \%$ & $91 \%$ & $89 \%$ \\
\hline $\begin{array}{l}\text { [CityName] should invest in projects (such as bike } \\
\text { lanes) that make riding bikes safer and easier }\end{array}$ & $78 \%$ & $90 \%$ & $89 \%$ & $86 \%$ \\
\hline $\begin{array}{l}\text { Bike lanes make it harder to get around my } \\
\text { neighborhood }\end{array}$ & $22 \%$ & $22 \%$ & $19 \%$ & $26 \%$ \\
\hline $\begin{array}{l}\text { I often see people like me riding bikes in my } \\
\text { neighborhood }\end{array}$ & $71 \%$ & $79 \%$ & $77 \%$ & $76 \%$ \\
\hline Minimum number of responses ${ }^{1}$ & 180 & 548 & 479 & 274 \\
\hline Maximum number of responses ${ }^{1}$ & 189 & 589 & 501 & 293 \\
\hline
\end{tabular}

\subsection{Barriers to bicycling}

Respondents were asked to consider a variety of potential reasons for not bicycling. For each potential barrier, they were instructed to "indicate whether it is something that keeps you from riding a bike (or from biking more).” Response options were not a barrier, small barrier, big barrier, or does not apply. The percentage of respondents selecting "big barrier" for each statement, ordered from highest to lowest percentage of all respondents (able and under 65) stating each is a big barrier, are shown in Table 7-7. Those that selected "does not apply” were not considered in the percentage.

Eight barriers were identified as big for at least $20 \%$ of the respondents. Fear of traffic stands out as a major barrier for nearly half of the respondents, followed by destinations being too far to travel by bike. Several of the barriers that ranked highly for many respondents concerned issues related to personal bike ownership, including not having a bike or related gear (a big barrier for $35 \%$ of all respondents), not having safe places at home or destinations to leave a bike (26\% and 34\% respectively), difficulty of carrying things on a bike (29\%), and the cost of buying a bicycle or related gear being prohibitive (28\%). A large share (27\%) indicated that "riding a bike with my kids is a hassle" is a major barrier. 
Table 7-7 Barriers to Bicycling, by Gender and Race-Income Groups

\begin{tabular}{|c|c|c|c|c|c|c|c|}
\hline \multirow[b]{2}{*}{$\begin{array}{l}\text { Barriers to bicycling more } \\
\text { (\% stating big barrier) }\end{array}$} & \multirow[b]{2}{*}{$\begin{array}{c}\text { All } \\
\text { Able } \\
\text { and } \\
<65\end{array}$} & \multicolumn{2}{|c|}{ By gender ${ }^{2}$} & \multicolumn{4}{|c|}{ By race and income group ${ }^{3}$} \\
\hline & & Male & Female & $\begin{array}{l}\text { Lower- } \\
\text { Income } \\
\text { POC }\end{array}$ & $\begin{array}{l}\text { Higher- } \\
\text { Income } \\
\text { POC }\end{array}$ & $\begin{array}{l}\text { Lower- } \\
\text { Income } \\
\text { White }\end{array}$ & $\begin{array}{l}\text { Higher- } \\
\text { Income } \\
\text { White }\end{array}$ \\
\hline $\begin{array}{l}\text { Traffic makes riding a bike in my } \\
\text { neighborhood feel dangerous }\end{array}$ & $48 \%$ & $35 \%$ & $54 \%$ & $44 \%$ & $50 \%$ & $53 \%$ & $49 \%$ \\
\hline $\begin{array}{l}\text { The places that I need to go are too far } \\
\text { away to reach on a bike }\end{array}$ & $38 \%$ & $29 \%$ & $42 \%$ & $40 \%$ & $44 \%$ & $17 \%$ & $23 \%$ \\
\hline $\begin{array}{l}\text { I don't have a bike or related gear (such } \\
\text { as helmet / lock / lights) }\end{array}$ & $35 \%$ & $28 \%$ & $39 \%$ & $47 \%$ & $25 \%$ & $37 \%$ & $26 \%$ \\
\hline $\begin{array}{l}\text { There might not be a safe place to } \\
\text { leave a bike at the places I go }\end{array}$ & $34 \%$ & $24 \%$ & $38 \%$ & $36 \%$ & $38 \%$ & $30 \%$ & $21 \%$ \\
\hline Carrying things on a bike is too difficult & $29 \%$ & $20 \%$ & $34 \%$ & $34 \%$ & $29 \%$ & $27 \%$ & $17 \%$ \\
\hline $\begin{array}{l}\text { It is too expensive to buy a bike or } \\
\text { related gear }\end{array}$ & $28 \%$ & $20 \%$ & $32 \%$ & $41 \%$ & $17 \%$ & $37 \%$ & $13 \%$ \\
\hline Riding a bike with my kids is a hassle & $27 \%$ & $19 \%$ & $30 \%$ & $30 \%$ & $24 \%$ & $38 \%$ & $30 \%$ \\
\hline $\begin{array}{l}\text { I don't have a safe place to store a bike } \\
\text { at home }\end{array}$ & $26 \%$ & $18 \%$ & $29 \%$ & $32 \%$ & $23 \%$ & $20 \%$ & $18 \%$ \\
\hline Riding a bike could make me sweaty & $19 \%$ & $19 \%$ & $19 \%$ & $17 \%$ & $17 \%$ & $14 \%$ & $22 \%$ \\
\hline $\begin{array}{l}\text { Riding a bike could cause me to be } \\
\text { harassed or a victim of crime }\end{array}$ & $16 \%$ & $12 \%$ & $18 \%$ & $22 \%$ & $17 \%$ & $5 \%$ & $7 \%$ \\
\hline $\begin{array}{l}\text { I don't know a good place for me to get } \\
\text { a bike fixed }\end{array}$ & $14 \%$ & $13 \%$ & $14 \%$ & $23 \%$ & $12 \%$ & $8 \%$ & $4 \%$ \\
\hline $\begin{array}{l}\text { Something could go wrong with a bike } \\
\text { (such as a flat tire) }\end{array}$ & $14 \%$ & $10 \%$ & $16 \%$ & $20 \%$ & $14 \%$ & $7 \%$ & $3 \%$ \\
\hline $\begin{array}{l}\text { My bike is not good for riding around } \\
\text { the city }\end{array}$ & $13 \%$ & $6 \%$ & $17 \%$ & $22 \%$ & $9 \%$ & $8 \%$ & $5 \%$ \\
\hline $\begin{array}{l}\text { The clothes I wear are not appropriate } \\
\text { for biking }\end{array}$ & $13 \%$ & $10 \%$ & $15 \%$ & $15 \%$ & $13 \%$ & $13 \%$ & $11 \%$ \\
\hline $\begin{array}{l}\text { I don't know how to get where I need to } \\
\text { go by bike }\end{array}$ & $11 \%$ & $6 \%$ & $13 \%$ & $15 \%$ & $11 \%$ & $2 \%$ & $6 \%$ \\
\hline $\begin{array}{l}\text { Riding a bike could mess up my hair or } \\
\text { appearance }\end{array}$ & $10 \%$ & $7 \%$ & $11 \%$ & $10 \%$ & $11 \%$ & $12 \%$ & $8 \%$ \\
\hline I am too out of shape to ride a bike & $9 \%$ & $4 \%$ & $11 \%$ & $17 \%$ & $6 \%$ & $6 \%$ & $3 \%$ \\
\hline $\begin{array}{l}\text { Biking might aggravate my personal } \\
\text { health issues }\end{array}$ & $9 \%$ & $7 \%$ & $10 \%$ & $17 \%$ & $5 \%$ & $0 \%$ & $1 \%$ \\
\hline $\begin{array}{l}\text { My friends and family wouldn't want me } \\
\text { to ride a bike }\end{array}$ & $8 \%$ & $4 \%$ & $10 \%$ & $14 \%$ & $5 \%$ & $3 \%$ & $2 \%$ \\
\hline I am too old to ride a bike & $7 \%$ & $5 \%$ & $8 \%$ & $13 \%$ & $4 \%$ & $0 \%$ & $2 \%$ \\
\hline $\begin{array}{l}\text { Riding a bike could make me a target } \\
\text { for police attention }\end{array}$ & $6 \%$ & $7 \%$ & $6 \%$ & $11 \%$ & $6 \%$ & $3 \%$ & $1 \%$ \\
\hline $\begin{array}{l}\text { People might think that I can't afford a } \\
\text { car }\end{array}$ & $4 \%$ & $4 \%$ & $4 \%$ & $10 \%$ & $3 \%$ & $0 \%$ & $0 \%$ \\
\hline $\begin{array}{l}\text { Riding a bike is not viewed as a cool } \\
\text { activity by my friends }\end{array}$ & $4 \%$ & $3 \%$ & $5 \%$ & $10 \%$ & $1 \%$ & $0 \%$ & $0 \%$ \\
\hline Minimum number of responses ${ }^{1}$ & 371 & 107 & 257 & 128 & 70 & 16 & 67 \\
\hline Maximum number of responses ${ }^{1}$ & 762 & 243 & 503 & 256 & 180 & 43 & 177 \\
\hline
\end{tabular}




\subsubsection{Bicycling barriers - demographic differences \\ Differences by race and income}

There are considerable differences in the ranking of barriers among the race and income groups, as shown in Figure 7-2, which groups the barriers into categories.

Traffic safety was the most frequently cited big barrier among all respondents, and there were no significant differences between race and income groups. However, respondents in the lower-income people of color group were much more likely to rate concerns about being the victim of crime or being targeted by police, along with having friends and family members who would not want them to ride a bicycle, as big barriers to bicycling. Higher-income respondents of color were also more likely than white respondents to note these as big barriers, but the difference was not significant.

Barriers in the cost and possessions category were mediated largely by income level, with the lowerincome groups more likely to cite barriers around not having a bike or gear, along with the cost of such equipment.

In terms of logistical concerns around bicycling, differences among the race and income groups fell into two patterns. The two most common barriers in this category were that places were too far to reach by bicycle or that there might not be a safe place to leave a bike at destinations - for these two barriers, respondents of color of either income group were much more likely to note these as big barriers than white respondents. Based on the available data, we do not know if this difference is due to respondents of color actually having farther to travel (e.g. if work destinations were, on average, further from their home locations), or if the perceptions of distances are greater. The barrier relating to the difficulty of carrying things on a bicycle could also be related to perceptions of distance. Other logistical concerns appeared to be influenced by both race and income, including not having a safe place to store a bicycle at home, concern about something going wrong with the bike, and not knowing where to get a bike fixed. For these variables, the lower-income people of color group was considerably more likely to rate the items as big barriers, and the higher-income white group was considerably less likely to do so. Although lower-income respondents of color were more likely to list not knowing how to get places as a barrier, the difference with other race-income groups was not significant after controlling for gender, age, and city.

On a number of the barriers around physical ability, lower-income respondents of color were more likely to rate these as big barriers. These include carrying things on a bike being too difficult, being too out of shape or too old to ride a bicycle, or having personal health issues that could be aggravated by riding a bicycle.

Barriers around image and appearance reveal two distinct trends. On the issue of concern about getting sweaty, not having the right clothes, or having one's hair or appearance messed up, there were no significant differences among groups. However, on several questions about how riding a bicycle might look to other people, including that it might be looked at as not cool, or could convey that they cannot afford a car, lower-income respondents of color were significantly more likely to mark these as big barriers. 

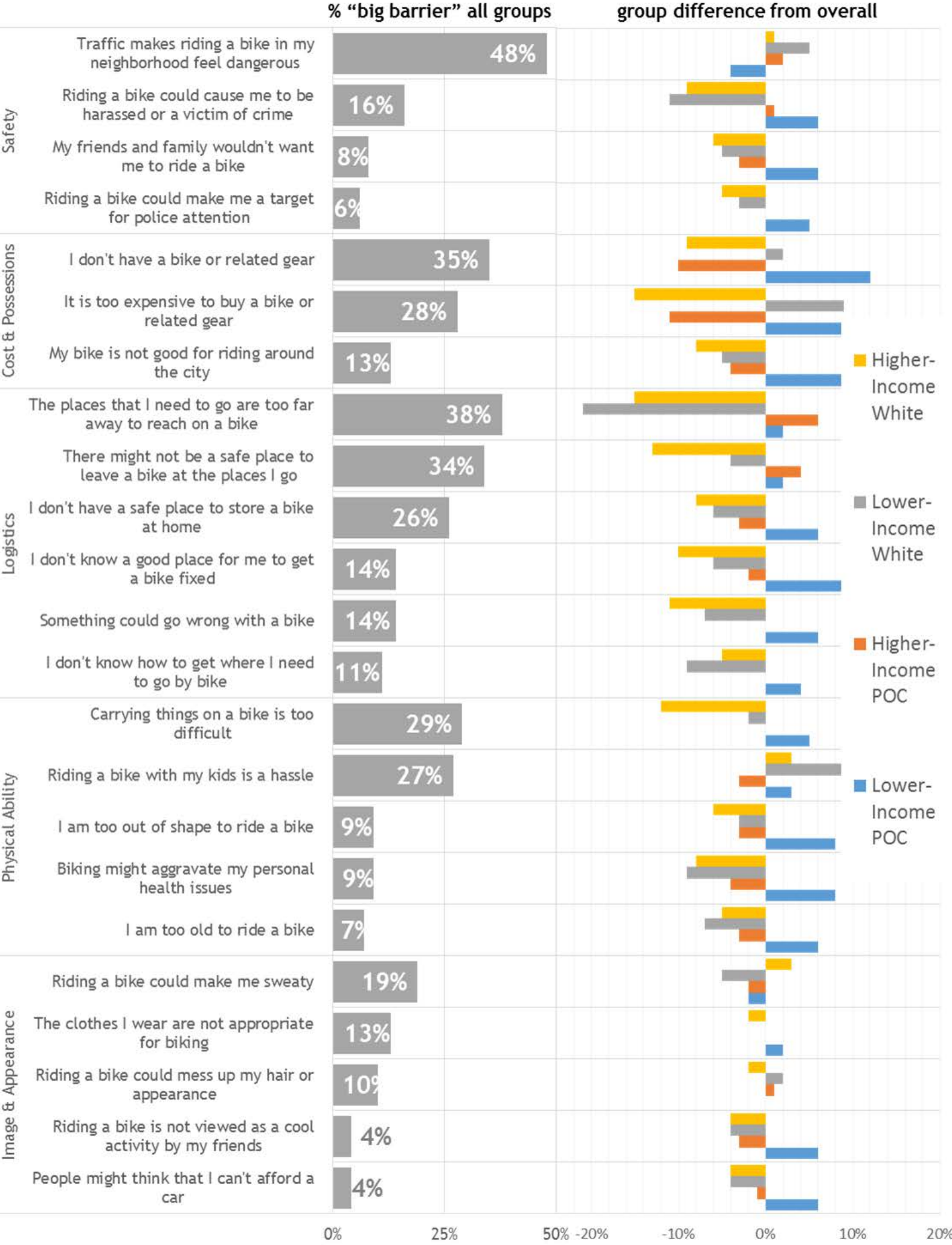

Something could go wrong with a bike

I don't know how to get where I need to go by bike

Carrying things on a bike is too difficult

Riding a bike with my kids is a hassle

I am too out of shape to ride a bike

Biking might aggravate my personal health issues

I am too old to ride a bike

Riding a bike could make me sweaty

The clothes I wear are not appropriate for biking

Riding a bike could mess up my hair or appearance

Riding a bike is not viewed as a cool activity by my friends

People might think that I can't afford a car

$25 \%$

$50 \%-20 \%$

$20 \%$

Figure 7-2 Differences in bicycling barriers by race and income groups 
Figure 7-3 illustrates all of the barriers that exhibited large differences between race-income groups, or those rated as big barriers by at least $10 \%$ of at least one group AND by less than $10 \%$ of another group. Certain barriers that may not apply to many respondents (such as being too old to bike or not having a good bike for city riding) are excluded from the figure for space purposes. The figure highlights that the lower-income people of color group was always among the groups more likely to rate the barriers as big, while the two groups of white respondents were among those less likely to rate the barriers as big. The pattern demonstrates that lower-income respondents of color were more likely to rate a greater number of barriers as big barriers to them bicycling or bicycling more.

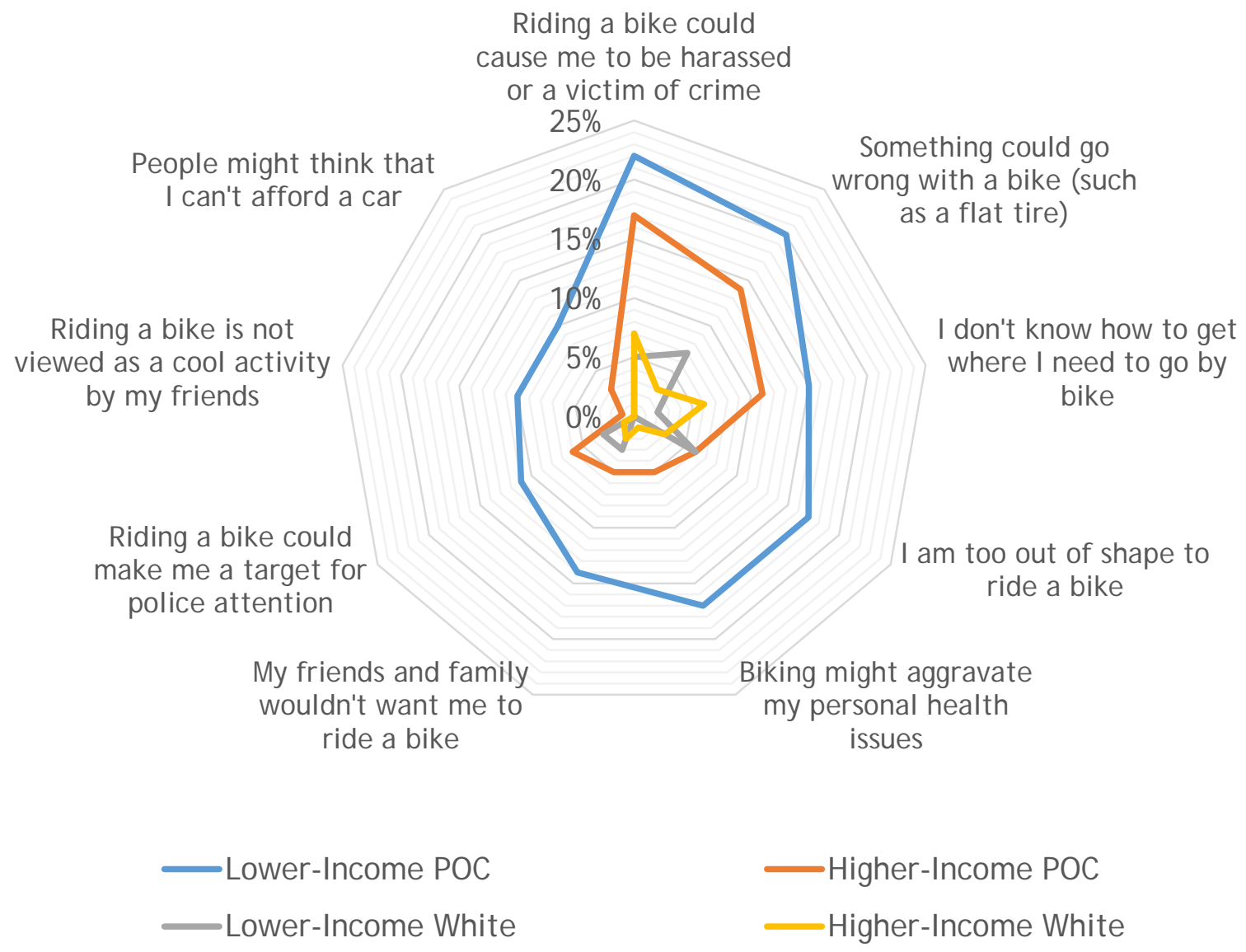

Figure 7-3 Difference between race-income groups on select bicycling barriers, percent stating
"big barrier"

Figure 7-4 shows the average number of items rated as big barriers by members of each of these four groups of respondents. Those in the lower-income people of color group rated 3.6 items as big barriers to bicycling, compared to 2.9 items for the higher-income people of color and lower-income white groups, and 2.2 for the higher-income white group. On average, lower-income respondents of color rated 63\% more items as big barriers to bicycling than higher-income white respondents. Although the difference among the groups is significant and considerable in percentage terms, the difference in the number of barriers in nominal terms (1.4 on average) may be an amount that could be overcome. 


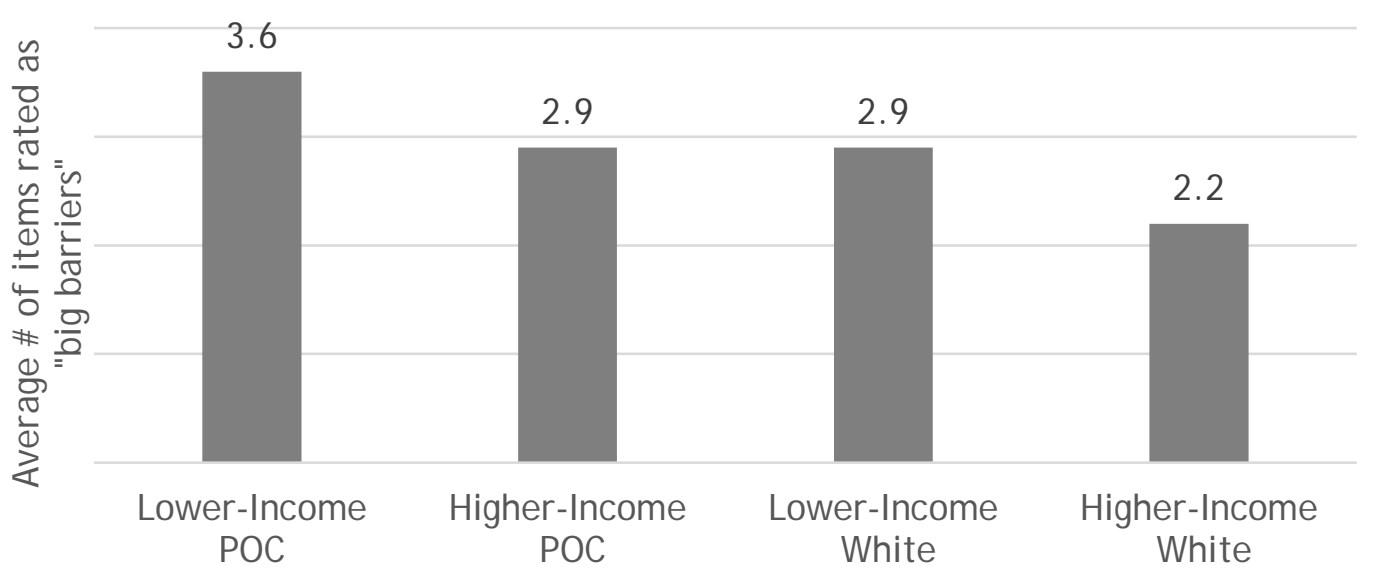

Figure 7-4 Average number of items rated as a "big barrier" to bicycling, by race and income
groups

Differences by gender

For all of the top barriers, women were significantly more likely than men to indicate each was a big barrier, by at least 10 percentage points. Over half of women surveyed stated that feeling unsafe due to traffic was a big barrier; we did not observe any significant difference on that barrier among race and income groups.

Figure 7-5 shows the bicycling barriers broken down by the percentage of men and women who rated each as either a big barrier or small barrier. In every case for which there was a significant difference in the percentage rating each as a big barrier, women were more likely to view the barrier as big.

For each of the cost-related barriers, most barriers around logistical concerns, physical ability and safety, women were more likely than men to rate each as a big barrier. In many cases, the differences were significant. However, after controlling for additional factors (race-income group, age, and city), several gender differences were no longer significant; these included concerns that riding a bike could cause them to be harassed or a victim of crime, concerns about something going wrong with a bike, and the concern that friends and family would not want them to ride a bicycle.

One of the only barriers that men were more likely than women to note as a barrier (big or small) was that riding a bicycle could make them a target for police attention; however, this was not a statistically significant difference.

Barriers related to appearance, including concerns about getting sweaty, or having hair or appearance getting messed up, were not significantly different for women than for men, which may run counter to some assumptions about women’s concerns around bicycling. 


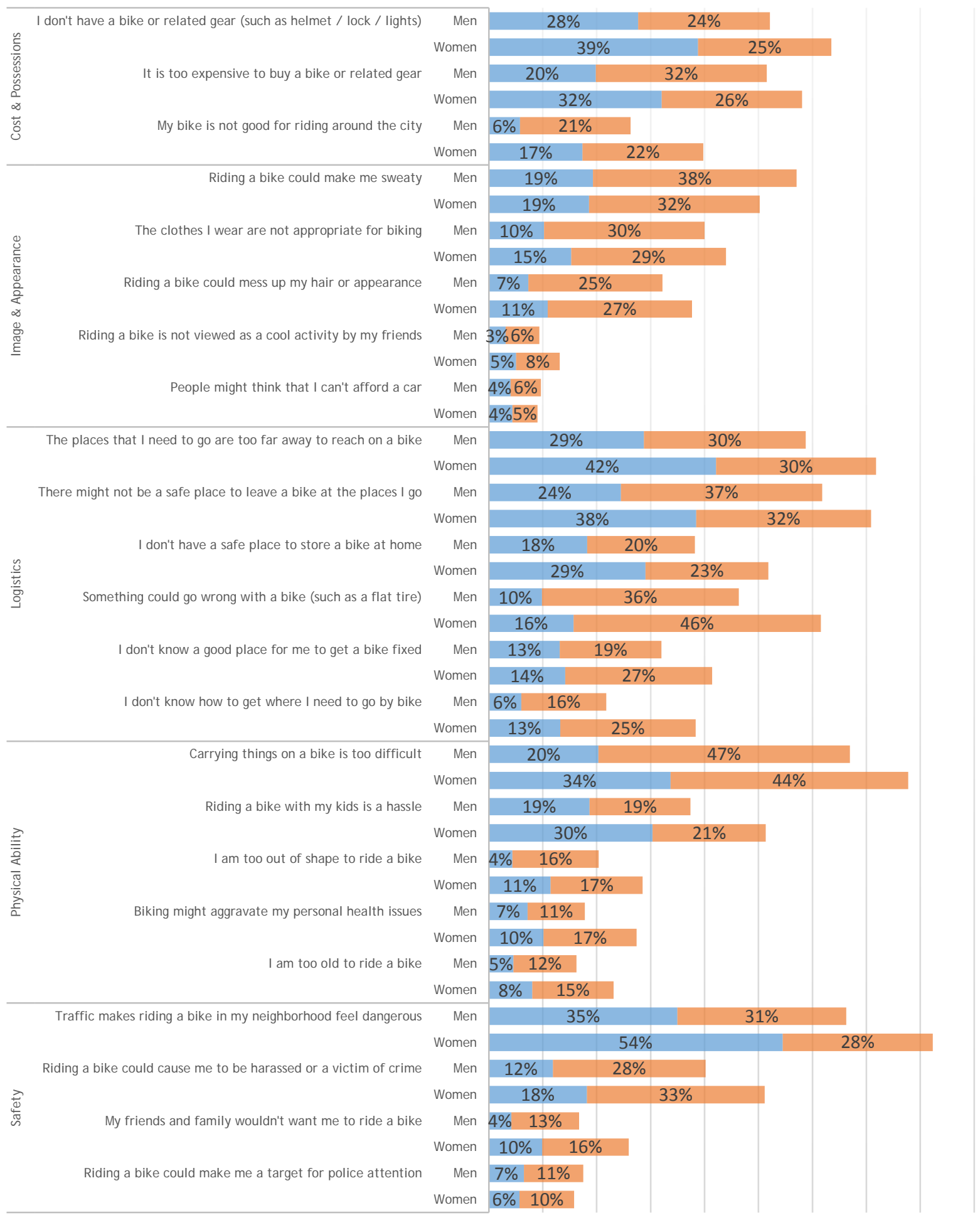

-Big Barrier $\quad$ Small Barrier

Figure 7-5 Gender differences in bicycling barriers 


\section{Differences by age}

The most common major barriers to bicycling showed no significant age differences for those under 65 . Some of the less-frequently cited obstacles, however, did vary by age group, even after controlling for gender, race-income group, and city. This was particularly true for the 55-64 age group. Both respondents aged 35-54 and 55-64 were more likely to state they were too out of shape to ride a bike, though the shares stating this as a big barrier were still fairly low (11\% and $17 \%$, respectively vs. $1.5 \%$ of those 18 34). Those 55-64 were more likely to cite a number of barriers as major ones compared with the 18-34 group: that something could go wrong with a bike ( $27 \%$ vs. $7 \%)$; that friends and family would not want them to ride ( $17 \%$ vs. $3 \%)$; and that they are simply too old to bicycle (18\% vs. $2 \%)$. Clearly, a subset of older adults faces some additional barriers to bicycling in general. These and other issues are explored in more detail in Section 10.2.

Barriers to bicycling related to personal appearance tended to decline with age in some cases. Respondents aged 18-34 were more likely than both those 35-54 and 55-64 to report that their typical clothing not being appropriate for cycling was a big barrier. Concerns about getting sweaty was significantly lower among those 55-64, compared with 18-34 year olds.

\subsubsection{Bicycling barriers - geographic differences}

The percentage of respondents in each of the outreach areas marking each potential barrier as a big barrier is shown in Table 7-8. Overall, respondents in the study areas were more similar than different.

Respondents in Philadelphia were less likely to view barriers in several categories as big barriers to bicycling. These include barriers related to cost, including not having a bike or related gear, or the cost of buying such gear, and barriers related to logistical issues, including destinations' being too far to bicycle, there not being safe places to leave a bike, and not knowing how to get places by bicycle.

Respondents in Brooklyn were more likely to rate several barriers as big barriers, including not having safe places to leave a bicycle at destinations or at home, and the cost of buying a bike or related gear. Traffic safety concerns, while highest in Brooklyn, were not significantly different from other cities after controlling for other factors (race-income group, age, and gender). They were also more likely to see getting sweaty from bicycling and the potential of attracting police attention as big barriers to bicycling.

Those in Chicago were least likely to note traffic safety as a big barrier, but were most likely to rate travel distances as being too far for bicycling (along with not knowing how to get places on a bike). Nearly a quarter of respondents in Chicago noted that concern about getting harassed or being the victim of a crime was big barrier to riding a bike. 
Table 7-8 Barriers to Bicycling, by City and Neighborhood

\begin{tabular}{|c|c|c|c|c|c|c|c|}
\hline \multirow[b]{2}{*}{$\begin{array}{l}\text { Barriers to bicycling more } \\
\text { (\% stating big barrier) }\end{array}$} & \multirow[b]{2}{*}{$\begin{array}{l}\text { Able } \\
\text { and } \\
<65\end{array}$} & \multicolumn{6}{|c|}{ Able and under 65, by outreach city and area ${ }^{2}$} \\
\hline & & $\begin{array}{l}\text { BKLN } \\
\text { Study } \\
\text { Area }\end{array}$ & $\begin{array}{l}\text { CHI } \\
\text { Study } \\
\text { Area }\end{array}$ & $\begin{array}{c}\text { PHI } \\
\text { Study } \\
\text { Areas } \\
\text { All }\end{array}$ & $\begin{array}{c}\text { PHI } \\
\text { Study } \\
\text { Area } \\
\text { West }\end{array}$ & $\begin{array}{c}\text { PHI } \\
\text { Study } \\
\text { Area } \\
\text { North }\end{array}$ & $\begin{array}{c}\text { PHI } \\
\text { Study } \\
\text { Area } \\
\text { South }\end{array}$ \\
\hline $\begin{array}{l}\text { Traffic makes riding a bike in my } \\
\text { neighborhood feel dangerous }\end{array}$ & $48 \%$ & $58 \%$ & $42 \%$ & $48 \%$ & $40 \%$ & $49 \%$ & $52 \%$ \\
\hline $\begin{array}{l}\text { The places that I need to go are too far } \\
\text { away to reach on a bike }\end{array}$ & $38 \%$ & $42 \%$ & $49 \%$ & $28 \%$ & $29 \%$ & $34 \%$ & $23 \%$ \\
\hline $\begin{array}{l}\text { I don't have a bike or related gear (such } \\
\text { as helmet / lock / lights) }\end{array}$ & $35 \%$ & $39 \%$ & $40 \%$ & $30 \%$ & $36 \%$ & $36 \%$ & $21 \%$ \\
\hline $\begin{array}{l}\text { There might not be a safe place to } \\
\text { leave a bike at the places I go }\end{array}$ & $34 \%$ & $41 \%$ & $34 \%$ & $30 \%$ & $28 \%$ & $34 \%$ & $27 \%$ \\
\hline Carrying things on a bike is too difficult & $29 \%$ & $30 \%$ & $33 \%$ & $27 \%$ & $27 \%$ & $28 \%$ & $25 \%$ \\
\hline $\begin{array}{l}\text { It is too expensive to buy a bike or } \\
\text { related gear }\end{array}$ & $28 \%$ & $34 \%$ & $31 \%$ & $23 \%$ & $23 \%$ & $27 \%$ & $20 \%$ \\
\hline Riding a bike with my kids is a hassle & $27 \%$ & $28 \%$ & $30 \%$ & $25 \%$ & $17 \%$ & $22 \%$ & $37 \%$ \\
\hline $\begin{array}{l}\text { I don't have a safe place to store a bike } \\
\text { at home }\end{array}$ & $26 \%$ & $36 \%$ & $27 \%$ & $20 \%$ & $22 \%$ & $21 \%$ & $16 \%$ \\
\hline Riding a bike could make me sweaty & $19 \%$ & $25 \%$ & $16 \%$ & $17 \%$ & $12 \%$ & $16 \%$ & $21 \%$ \\
\hline $\begin{array}{l}\text { Riding a bike could cause me to be } \\
\text { harassed or a victim of crime }\end{array}$ & $16 \%$ & $14 \%$ & $24 \%$ & $12 \%$ & $12 \%$ & $12 \%$ & $13 \%$ \\
\hline $\begin{array}{l}\text { I don't know a good place for me to get } \\
\text { a bike fixed }\end{array}$ & $14 \%$ & $13 \%$ & $17 \%$ & $12 \%$ & $15 \%$ & $11 \%$ & $11 \%$ \\
\hline $\begin{array}{l}\text { Something could go wrong with a bike } \\
\text { (such as a flat tire) }\end{array}$ & $14 \%$ & $14 \%$ & $14 \%$ & $13 \%$ & $11 \%$ & $18 \%$ & $11 \%$ \\
\hline $\begin{array}{l}\text { My bike is not good for riding around } \\
\text { the city }\end{array}$ & $13 \%$ & $17 \%$ & $19 \%$ & $8 \%$ & $10 \%$ & $7 \%$ & $7 \%$ \\
\hline $\begin{array}{l}\text { The clothes I wear are not appropriate } \\
\text { for biking }\end{array}$ & $13 \%$ & $13 \%$ & $17 \%$ & $12 \%$ & $9 \%$ & $11 \%$ & $14 \%$ \\
\hline $\begin{array}{l}\text { I don't know how to get where I need to } \\
\text { go by bike }\end{array}$ & $11 \%$ & $14 \%$ & $16 \%$ & $6 \%$ & $4 \%$ & $6 \%$ & $7 \%$ \\
\hline $\begin{array}{l}\text { Riding a bike could mess up my hair or } \\
\text { appearance }\end{array}$ & $10 \%$ & $11 \%$ & $11 \%$ & $8 \%$ & $7 \%$ & $6 \%$ & $11 \%$ \\
\hline I am too out of shape to ride a bike & $9 \%$ & $10 \%$ & $12 \%$ & $7 \%$ & $11 \%$ & $8 \%$ & $4 \%$ \\
\hline $\begin{array}{l}\text { Biking might aggravate my personal } \\
\text { health issues }\end{array}$ & $9 \%$ & $8 \%$ & $9 \%$ & $10 \%$ & $11 \%$ & $14 \%$ & $5 \%$ \\
\hline $\begin{array}{l}\text { My friends and family wouldn't want me } \\
\text { to ride a bike }\end{array}$ & $8 \%$ & $8 \%$ & $9 \%$ & $7 \%$ & $5 \%$ & $13 \%$ & $4 \%$ \\
\hline I am too old to ride a bike & $7 \%$ & $6 \%$ & $9 \%$ & $6 \%$ & $4 \%$ & $7 \%$ & $6 \%$ \\
\hline $\begin{array}{l}\text { Riding a bike could make me a target } \\
\text { for police attention }\end{array}$ & $6 \%$ & $10 \%$ & $6 \%$ & $4 \%$ & $4 \%$ & $4 \%$ & $5 \%$ \\
\hline $\begin{array}{l}\text { Riding a bike is not viewed as a cool } \\
\text { activity by my friends }\end{array}$ & $4 \%$ & $2 \%$ & $7 \%$ & $4 \%$ & $1 \%$ & $6 \%$ & $4 \%$ \\
\hline $\begin{array}{l}\text { People might think that I can't afford a } \\
\text { car }\end{array}$ & $4 \%$ & $3 \%$ & $7 \%$ & $3 \%$ & $2 \%$ & $6 \%$ & $1 \%$ \\
\hline Minimum number of responses ${ }^{1}$ & 371 & 74 & 118 & 176 & 53 & 67 & 54 \\
\hline Maximum number of responses ${ }^{1}$ & 762 & 173 & 224 & 365 & 106 & 121 & 142 \\
\hline
\end{tabular}

${ }^{1}$ varies by question due to missing and "does not apply"

${ }^{2}$ bold indicates category value significantly greater or less than expected ( $p<0.05$, adj. stand. Chi-square residual) 


\section{EXPERIENCE AND KNOWLEDGE}

A set of survey questions sought to understand how familiar respondents were with the bike share system in their city and neighborhood, where they had gotten information about the system, and what types of encounters or experiences they had related to bike share.

\subsection{Sources of information about bike share}

Before asking questions about bike share, the survey presented respondents with a picture of one of the bike share bikes in their city, and explained that “[BssName] is [CityName]'s public bike share system. People can check out a bike (like the one pictured at right) from any [BssName] station, ride it wherever they want, and return it to another station.” Following this brief description, respondents were asked how much they would say they know about the bike share system.

As shown in Table 8-1, just over a quarter of respondents indicated that they knew quite a bit or a lot, and over half reported knowing "some things" about it. Sixteen percent told us they knew nothing about it. Higher-income white respondents were more likely to report knowing quite a bit or a lot about the system, while lower-income respondents of color were less likely to do so. Lower-income respondents of color were much more likely than other groups to report knowing nothing at all about the local bike share system, and the difference was especially stark compared with the higher-income white group (25\% vs. just 2\%).

Table 8-1 Knowledge about Bike Share, by Gender and Race-Income Groups

\begin{tabular}{|l|c|c|c|c|c|c|c|}
\hline $\begin{array}{c}\text { How much would you say you know } \\
\text { about [BssName]? }\end{array}$ & $\begin{array}{c}\text { All Able } \\
\text { and }<\mathbf{6 5}\end{array}$ & Male & Female & $\begin{array}{c}\text { Lower- } \\
\text { Income } \\
\text { POC }\end{array}$ & $\begin{array}{c}\text { Higher- } \\
\text { Income } \\
\text { POC }\end{array}$ & $\begin{array}{c}\text { Lower- } \\
\text { Income } \\
\text { White }\end{array}$ & $\begin{array}{c}\text { Higher- } \\
\text { Income } \\
\text { White }\end{array}$ \\
\hline Know nothing about it & $16 \%$ & $\mathbf{1 2} \%$ & $18 \%$ & $\mathbf{2 5} \%$ & $11 \%$ & $9 \%$ & $\mathbf{2 \%}$ \\
\hline Know some things about it & $58 \%$ & $56 \%$ & $58 \%$ & $57 \%$ & $61 \%$ & $64 \%$ & $57 \%$ \\
\hline Know quite a bit about it & $18 \%$ & $\mathbf{2 3} \%$ & $15 \%$ & $\mathbf{1 2 \%}$ & $17 \%$ & $18 \%$ & $\mathbf{2 8 \%}$ \\
\hline Know a lot about it & $9 \%$ & $9 \%$ & $8 \%$ & $\mathbf{7 \%}$ & $10 \%$ & $9 \%$ & $\mathbf{1 3 \%}$ \\
\hline $\mathrm{n}$ & 899 & 278 & 602 & 320 & 210 & 45 & 189 \\
\hline
\end{tabular}

Includes respondents in outreach areas under 65 years and physically able to ride a bicycle. People of Color abbreviated POC.

${ }^{1}$ bold indicates category value significantly greater than expected ( $p<0.05$, adj. stand. Chi-square residual)

${ }^{2}$ bold indicates category value significantly greater or less than expected ( $p<0.05$, adj. stand. Chi-square residual)

To get a sense of what types of sources of information people were using to find out about bike share, respondents were provided with a list of potential ways and asked to select those that applied. Results are shown in Table 8-2, which breaks the results down by gender, along with race and income groups. Among all respondents, the bike share station or kiosk was the most common source of information about bike share, selected by half of all respondents. Getting information from friends or family members (at $40 \%$ of respondents), the internet (29\%), ads on buses or bus shelters (25\%), and from television (20\%) rounded out the top five sources of information. On average, respondents indicated that they had gotten information about bike share from 2.5 sources. 
Table 8-2 Sources of Information about Bike Share, by Gender and Race-Income Groups

\begin{tabular}{|c|c|c|c|c|c|c|c|}
\hline \multirow[b]{2}{*}{$\begin{array}{l}\text { Where have you gotten information } \\
\text { about [BssName]? }\end{array}$} & \multirow[b]{2}{*}{$\begin{array}{l}\text { All Able } \\
\text { and }<65\end{array}$} & \multicolumn{2}{|c|}{ By gender ${ }^{1}$} & \multicolumn{4}{|c|}{ By race and income group ${ }^{2}$} \\
\hline & & Male & Female & $\begin{array}{l}\text { Lower- } \\
\text { Income } \\
\text { POC }\end{array}$ & $\begin{array}{c}\text { Higher- } \\
\text { Income } \\
\text { POC }\end{array}$ & $\begin{array}{l}\text { Lower- } \\
\text { Income } \\
\text { White }\end{array}$ & $\begin{array}{c}\text { Higher- } \\
\text { Income } \\
\text { White }\end{array}$ \\
\hline $\begin{array}{l}\text { Have not heard anything about it } \\
\text { before ( } 0 \text { sources selected) }\end{array}$ & $6 \%$ & $5 \%$ & $7 \%$ & $9 \%$ & $6 \%$ & $5 \%$ & $1 \%$ \\
\hline Selecting 1 source & $33 \%$ & $29 \%$ & $34 \%$ & $41 \%$ & $31 \%$ & $32 \%$ & $19 \%$ \\
\hline Selecting 2 or 3 sources & $38 \%$ & $41 \%$ & $37 \%$ & $27 \%$ & $41 \%$ & $48 \%$ & $52 \%$ \\
\hline Selecting 4 or more sources & $23 \%$ & $25 \%$ & $23 \%$ & $23 \%$ & $23 \%$ & $16 \%$ & $28 \%$ \\
\hline \multirow[t]{2}{*}{ Average \# of sources selected } & 2.5 & 2.7 & 2.4 & 2.3 & 2.5 & 2.4 & 3 \\
\hline & \multicolumn{7}{|c|}{$\%$ selecting each source } \\
\hline At a bike share station/ kiosk & $51 \%$ & $59 \%$ & $47 \%$ & $39 \%$ & $53 \%$ & $64 \%$ & $70 \%$ \\
\hline Friends or family & $40 \%$ & $43 \%$ & $38 \%$ & $31 \%$ & $32 \%$ & $43 \%$ & $61 \%$ \\
\hline On the internet & $29 \%$ & $37 \%$ & $25 \%$ & $17 \%$ & $26 \%$ & $39 \%$ & $53 \%$ \\
\hline Ads on buses or bus shelters & $25 \%$ & $26 \%$ & $24 \%$ & $25 \%$ & $28 \%$ & $23 \%$ & $25 \%$ \\
\hline Television & $20 \%$ & $16 \%$ & $21 \%$ & $27 \%$ & $23 \%$ & $9 \%$ & $7 \%$ \\
\hline Newspaper & $17 \%$ & $18 \%$ & $16 \%$ & $18 \%$ & $15 \%$ & $18 \%$ & $17 \%$ \\
\hline On a billboard & $14 \%$ & $12 \%$ & $15 \%$ & $15 \%$ & $14 \%$ & $14 \%$ & $10 \%$ \\
\hline Talked to someone at an event & $12 \%$ & $13 \%$ & $11 \%$ & $11 \%$ & $13 \%$ & $7 \%$ & $14 \%$ \\
\hline Radio & $10 \%$ & $8 \%$ & $11 \%$ & $11 \%$ & $12 \%$ & $0 \%$ & $8 \%$ \\
\hline Got something in the mail & $9 \%$ & $9 \%$ & $9 \%$ & $10 \%$ & $7 \%$ & $2 \%$ & $12 \%$ \\
\hline Other & $8 \%$ & $8 \%$ & $8 \%$ & $9 \%$ & $8 \%$ & $13 \%$ & $6 \%$ \\
\hline Information at work or school & $7 \%$ & $7 \%$ & $6 \%$ & $6 \%$ & $7 \%$ & $7 \%$ & $8 \%$ \\
\hline $\begin{array}{l}\text { Talked to someone from the [Local } \\
\text { Partner] }\end{array}$ & $6 \%$ & $7 \%$ & $5 \%$ & $8 \%$ & $6 \%$ & $5 \%$ & $5 \%$ \\
\hline $\begin{array}{l}\text { At a community center or faith-based } \\
\text { organization }\end{array}$ & $5 \%$ & $4 \%$ & $5 \%$ & $6 \%$ & $4 \%$ & $5 \%$ & $4 \%$ \\
\hline GoKit (Chicago) & $4 \%$ & $5 \%$ & $3 \%$ & $3 \%$ & $7 \%$ & $0 \%$ & $0 \%$ \\
\hline n (Chicago-only question) & 257 & 66 & 187 & 102 & 86 & 3 & 19 \\
\hline n (except Chicago-only question) & 888 & 277 & 591 & 319 & 206 & 45 & 187 \\
\hline
\end{tabular}

Includes respondents in outreach areas under 65 years and physically able to ride a bicycle.

${ }^{1}$ bold indicates category value significantly greater than expected ( $p<0.05$, adj. stand. Chi-square residual)

${ }^{2}$ bold indicates category value significantly greater or less than expected ( $p<0.05$, adj. stand. Chi-square residual)

The considerable difference between the percent of respondents indicating that they "know nothing about” the bike share system (16\% of all respondents, and $25 \%$ of lower-income people of color - see Table 8-1), and the percent who selected zero sources of information about bike share (6\% of all respondents and $9 \%$ of people of color - see Table 8-2) could be due to several causes. There may be people who have heard of bike share (for example they have seen the bikes, or a kiosks, or heard of other people who use it), but still do not think they know anything about it. It is also possible that some respondents mistakenly checked some source of information. 


\subsubsection{Sources of information - demographic differences \\ Differences by race and income}

Figure 8-1 shows the differences of each of four race and income groups from the overall percentage for each source of information - a negative result shows that fewer respondents in that group reported getting bike share information from that source, compared to the respondents as a whole. The higherincome white group was much more likely to report getting information from the bike share station, from friends or family, or on the internet. The higher-income white group also reported receiving information about bike share from an average of three sources, compared to between 2.3 and 2.5 for respondents in other groups. The lower-income people of color group was more likely to get information about bike share from television, or to report not having heard anything about bike share before. On many of the questions, the small differences observed were not significant.

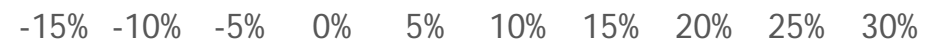

At a bike share station/ kiosk (51\%)

Friends or family $(40 \%)$

On the internet $(29 \%)$

Ads on buses or bus shelters (25\%)

Television (20\%)

Newspaper (17\%)

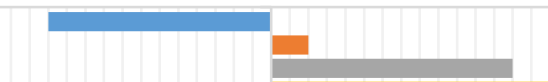

On a billboard (14\%)

Talked to someone at an event (12\%)

Radio (10\%)

Got something in the mail (9\%)

Have not heard anything about it before (6\%)

Information at work or school (7\%)

Talked to someone from the [Local Partner]

At a community center or faith-based organization (5\%)
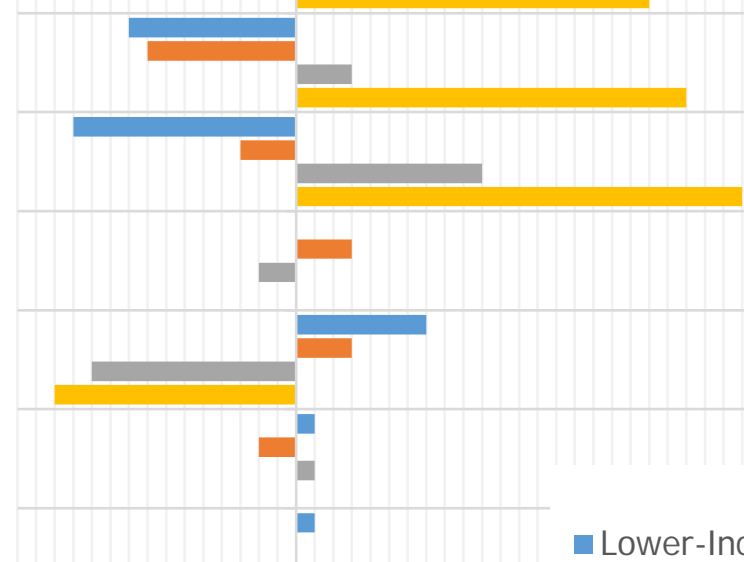

Lower-Income POC
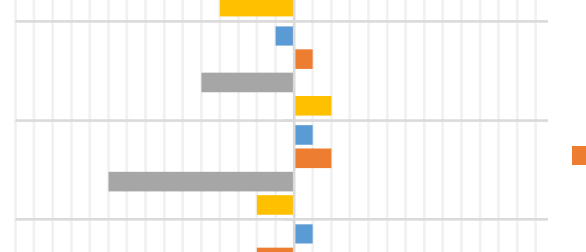

Higher-Income POC
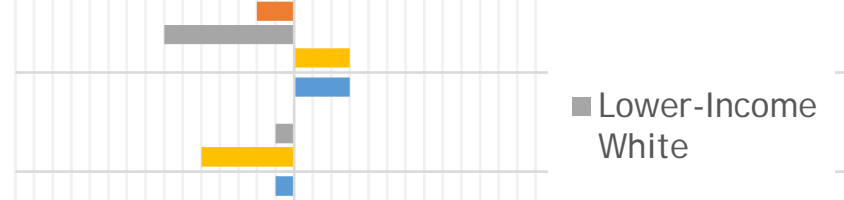

[1 White

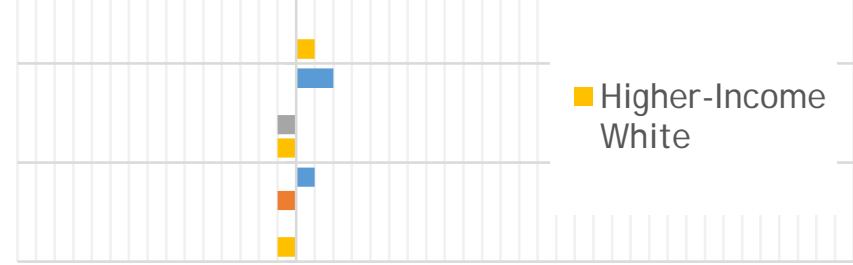

Figure 8-1 Differences in bike share information sources by race and income groups 
Differences by gender

Men were more likely than women to report getting information about bike share from the internet.

Although they were also more likely than women to report getting information from bike share station kiosks, that difference was not significant after controlling for other factors (race-income group, age, and city). Differences between the genders in reported sources of information among other variables were not significant.

Differences by age

Age differences were observed in several aspects of reported bike share information sources. Respondents aged 18-34 were more likely to report getting information from bike share stations/kiosks and from friends and family than respondents $35-54$ or 55-64. Those in the 55-64 age group were also less likely to get information about bike share from the internet. However, those aged 55-64 were more likely to report getting information about bike share from a newspaper.

\subsubsection{Sources of information - geographic differences}

Table 8-3 shows responses to the question about how much the respondents think they know about the bike share system, broken down by city and neighborhood. Table 8-4 shows the sources of information selected by respondents in the different outreach cities and neighborhoods. Respondents in Philadelphia were more likely than those in other cities to note having gotten information about bike share from the bike share stations and via the internet; however, the latter difference was not significant after accounting for other factors (race-income group, age, and gender). Those in Brooklyn were more likely than those in other cities to have gotten information from television or newspapers.

Table 8-3 Knowledge about Bike Share, by City and Neighborhood

\begin{tabular}{|l|c|c|c|c|c|c|c|}
\hline \multirow{2}{*}{$\begin{array}{c}\text { How much would you say you know } \\
\text { about [BssName]? }\end{array}$} & \multicolumn{4}{|c|}{ Able and under 65, by outreach city and area } \\
\hline & $\begin{array}{c}\text { Able } \\
\text { and } \\
<65\end{array}$ & $\begin{array}{c}\text { BKLN } \\
\text { Study } \\
\text { Area }\end{array}$ & $\begin{array}{c}\text { CHI } \\
\text { Study } \\
\text { Area }\end{array}$ & $\begin{array}{c}\text { PHI } \\
\text { Study } \\
\text { Areas } \\
\text { All }\end{array}$ & $\begin{array}{c}\text { PHI } \\
\text { Study } \\
\text { Area } \\
\text { West }\end{array}$ & $\begin{array}{c}\text { PHI } \\
\text { Study } \\
\text { Area } \\
\text { North }\end{array}$ & $\begin{array}{c}\text { PHI } \\
\text { Study } \\
\text { Area } \\
\text { South }\end{array}$ \\
\hline Know nothing about it & $16 \%$ & $17 \%$ & $17 \%$ & $14 \%$ & $15 \%$ & $16 \%$ & $12 \%$ \\
\hline Know some things about it & $58 \%$ & $56 \%$ & $\mathbf{6 4 \%}$ & $55 \%$ & $58 \%$ & $56 \%$ & $52 \%$ \\
\hline Know quite a bit about it & $18 \%$ & $17 \%$ & $\mathbf{1 3} \%$ & $\mathbf{2 2} \%$ & $19 \%$ & $20 \%$ & $25 \%$ \\
\hline Know a lot about it & $9 \%$ & $10 \%$ & $7 \%$ & $10 \%$ & $9 \%$ & $9 \%$ & $11 \%$ \\
\hline$n$ & 899 & 210 & 261 & 428 & 118 & 138 & 172 \\
\hline
\end{tabular}

${ }^{1}$ bold indicates category value significantly greater or less than expected ( $p<0.05$, adj. stand. Chi-square residual) 
Table 8-4 Sources of Information about Bike Share, by City and Neighborhood

\begin{tabular}{|c|c|c|c|c|c|c|c|}
\hline \multirow[b]{2}{*}{$\begin{array}{c}\text { Where have you gotten information } \\
\text { about [BssName]? }\end{array}$} & \multirow[b]{2}{*}{$\begin{array}{l}\text { Able } \\
\text { and } \\
<65\end{array}$} & \multicolumn{6}{|c|}{ Able and under 65 , by outreach city and area ${ }^{1}$} \\
\hline & & $\begin{array}{c}\text { BKLN } \\
\text { Study } \\
\text { Area }\end{array}$ & $\begin{array}{c}\text { CHI } \\
\text { Study } \\
\text { Area }\end{array}$ & $\begin{array}{c}\text { PHI } \\
\text { Study } \\
\text { Areas } \\
\text { All }\end{array}$ & $\begin{array}{c}\text { PHI } \\
\text { Study } \\
\text { Area } \\
\text { West }\end{array}$ & $\begin{array}{c}\text { PHI } \\
\text { Study } \\
\text { Area } \\
\text { North }\end{array}$ & $\begin{array}{c}\text { PHI } \\
\text { Study } \\
\text { Area } \\
\text { South }\end{array}$ \\
\hline $\begin{array}{l}\text { Have not heard anything about it before } \\
\text { ( } 0 \text { sources selected) }\end{array}$ & $6 \%$ & $7 \%$ & $7 \%$ & $6 \%$ & $6 \%$ & $5 \%$ & $6 \%$ \\
\hline Selecting 1 source & $31 \%$ & $30 \%$ & $34 \%$ & $33 \%$ & $35 \%$ & $37 \%$ & $29 \%$ \\
\hline Selecting 2 or 3 sources & $36 \%$ & $35 \%$ & $35 \%$ & $41 \%$ & $38 \%$ & $41 \%$ & $44 \%$ \\
\hline Selecting 4 or more sources & $22 \%$ & $28 \%$ & $24 \%$ & $21 \%$ & $22 \%$ & $18 \%$ & $22 \%$ \\
\hline Average \# of sources selected & 2.5 & 2.7 & 2.5 & 2.5 & 2.5 & 2.3 & 2.6 \\
\hline \multicolumn{8}{|c|}{$\%$ selecting each source } \\
\hline At a bike share station/ kiosk & $51 \%$ & $43 \%$ & $46 \%$ & $57 \%$ & $55 \%$ & $51 \%$ & $64 \%$ \\
\hline Friends or family & $39 \%$ & $45 \%$ & $36 \%$ & $39 \%$ & $35 \%$ & $34 \%$ & $45 \%$ \\
\hline On the internet & $29 \%$ & $31 \%$ & $19 \%$ & $34 \%$ & $32 \%$ & $28 \%$ & $42 \%$ \\
\hline Ads on buses or bus shelters & $25 \%$ & $28 \%$ & $30 \%$ & $21 \%$ & $24 \%$ & $22 \%$ & $18 \%$ \\
\hline Television & $20 \%$ & $26 \%$ & $28 \%$ & $13 \%$ & $12 \%$ & $20 \%$ & $8 \%$ \\
\hline Newspaper & $17 \%$ & $25 \%$ & $15 \%$ & $13 \%$ & $14 \%$ & $12 \%$ & $14 \%$ \\
\hline On a billboard & $14 \%$ & $16 \%$ & $13 \%$ & $13 \%$ & $14 \%$ & $13 \%$ & $12 \%$ \\
\hline Talked to someone at an event & $12 \%$ & $10 \%$ & $10 \%$ & $13 \%$ & $13 \%$ & $13 \%$ & $13 \%$ \\
\hline Radio & $10 \%$ & $14 \%$ & $13 \%$ & $7 \%$ & $5 \%$ & $10 \%$ & $5 \%$ \\
\hline Got something in the mail & $9 \%$ & $11 \%$ & $8 \%$ & $9 \%$ & $13 \%$ & $7 \%$ & $7 \%$ \\
\hline Information at work or school & $7 \%$ & $8 \%$ & $8 \%$ & $5 \%$ & $5 \%$ & $4 \%$ & $7 \%$ \\
\hline $\begin{array}{l}\text { Talked to someone from the [Local } \\
\text { Partner] }\end{array}$ & $6 \%$ & $4 \%$ & $6 \%$ & $7 \%$ & $9 \%$ & $5 \%$ & $7 \%$ \\
\hline $\begin{array}{l}\text { At a community center or faith-based } \\
\text { organization }\end{array}$ & $5 \%$ & $0 \%$ & $5 \%$ & $8 \%$ & $13 \%$ & $5 \%$ & $6 \%$ \\
\hline GoKit (Chicago) & $4 \%$ & & $4 \%$ & & & & \\
\hline Other & $8 \%$ & $7 \%$ & $9 \%$ & $8 \%$ & $4 \%$ & $10 \%$ & $9 \%$ \\
\hline n (Chicago-only question) & 257 & & 254 & & & & \\
\hline n (except Chicago-only question) & 888 & 212 & 256 & 419 & 119 & 134 & 166 \\
\hline
\end{tabular}

${ }^{1}$ bold indicates category value significantly greater or less than expected ( $p<0.05$, adj. stand. Chi-square residual)

\subsection{Experiences with bike share}

One section on the survey asked the respondents whether they had partaken in a variety of activities relating to bike share, including noticing a station in their neighborhood, riding a bike share bike, being a member, and more. Response options for these included yes, no, or not sure. "Not sure” responses are excluded. Responses are shown by gender, race and income in Table 8-5, and by geography in Table 8-6. The vast majority of respondents (95\%) noted that they had seen a bike share station in their neighborhood, and nearly half (46\%) had a friend or family member who had used bike share. About $16 \%$ reported having ever ridden a bike share bike in their city, and $4 \%$ reported being current members or passholders (another 3\% had been members in the past). About one in 10 respondents had spoken to someone who works for the bike share system. The other questions about bike share experiences had 
under $5 \%$ of respondents indicating that they had done the activity: received a coupon for a free ride or day-pass (3\%); gone on an organized bike ride where they learned about the bike share system (2\%); followed the bike share system on social media (4\%); or attended special events related to the bike share system (4\%).

A few questions were forward-looking, asking the respondent if they expected to be a member of the bike share system in 12 months (yes, no or not sure), or how likely they were to seek more information, tell someone about the bike share system, or ride a bike share bike in the next six months. Response options were not at all likely, not likely, somewhat likely, or very likely. Although only $4 \%$ stated they were currently members, $11 \%$ of all respondents indicated that they expected to be members in 12 months. Similarly, although only $16 \%$ had ridden a bike share bike, $42 \%$ said they were likely to ride one in the next six months. Half stated they were likely to tell someone they know about bike share, and 38\% are likely to seek more information about the system. 
Table 8-5 Experiences with Bike Share, by Gender and Race-Income Groups

\begin{tabular}{|c|c|c|c|c|c|c|c|}
\hline \multirow[b]{2}{*}{ About [BssName] and you } & \multirow[b]{2}{*}{$\begin{array}{l}\text { All } \\
\text { Able } \\
\text { and } \\
<65\end{array}$} & \multicolumn{2}{|c|}{ By gender 2} & \multicolumn{4}{|c|}{ By race and income group ${ }^{3}$} \\
\hline & & Male & Female & $\begin{array}{l}\text { Lower- } \\
\text { Income } \\
\text { POC }\end{array}$ & $\begin{array}{l}\text { Higher- } \\
\text { Income } \\
\text { POC }\end{array}$ & $\begin{array}{l}\text { Lower- } \\
\text { Income } \\
\text { White }\end{array}$ & $\begin{array}{l}\text { Higher- } \\
\text { Income } \\
\text { White }\end{array}$ \\
\hline \multicolumn{8}{|c|}{$\%$ responding yes } \\
\hline $\begin{array}{l}\text { Have you noticed a [BssName] station in } \\
\text { your neighborhood? }\end{array}$ & $95 \%$ & $94 \%$ & $95 \%$ & $94 \%$ & $95 \%$ & $98 \%$ & $97 \%$ \\
\hline Have you ridden a [BssName] bike? & $16 \%$ & $20 \%$ & $14 \%$ & $9 \%$ & $18 \%$ & $13 \%$ & $29 \%$ \\
\hline $\begin{array}{l}\text { Are you currently a [BssName] pass } \\
\text { holder? }\end{array}$ & $4 \%$ & $6 \%$ & $3 \%$ & $2 \%$ & $5 \%$ & $2 \%$ & $10 \%$ \\
\hline $\begin{array}{l}\text { If no: Have you ever been a [BssName] } \\
\text { pass holder? }\end{array}$ & $3 \%$ & $3 \%$ & $3 \%$ & $3 \%$ & $3 \%$ & $5 \%$ & $4 \%$ \\
\hline $\begin{array}{l}\text { Did you receive a coupon for a free } \\
\text { [BssName] ride or day-use? }\end{array}$ & $3 \%$ & $4 \%$ & $3 \%$ & $3 \%$ & $4 \%$ & $2 \%$ & $3 \%$ \\
\hline $\begin{array}{l}\text { Have you gone on an organized bike } \\
\text { ride where you learned about } \\
\text { [BssName]? }\end{array}$ & $2 \%$ & $1 \%$ & $3 \%$ & $3 \%$ & $1 \%$ & $2 \%$ & $2 \%$ \\
\hline $\begin{array}{l}\text { Have any of your friends or family used } \\
\text { [BssName]? }\end{array}$ & $46 \%$ & $53 \%$ & $43 \%$ & $35 \%$ & $46 \%$ & $51 \%$ & $70 \%$ \\
\hline $\begin{array}{l}\text { Do you follow [BssName] on Instagram, } \\
\text { Twitter, Facebook, or Email? }\end{array}$ & $4 \%$ & $4 \%$ & $4 \%$ & $5 \%$ & $2 \%$ & $4 \%$ & $7 \%$ \\
\hline $\begin{array}{l}\text { Have you ever talked to someone who } \\
\text { works with [BssName]? }\end{array}$ & $10 \%$ & $10 \%$ & $10 \%$ & $8 \%$ & $10 \%$ & $16 \%$ & $13 \%$ \\
\hline $\begin{array}{l}\text { Have you attended special events } \\
\text { related to [BssName]? }\end{array}$ & $4 \%$ & $2 \%$ & $4 \%$ & $3 \%$ & $4 \%$ & $7 \%$ & $4 \%$ \\
\hline $\begin{array}{l}\text { Do you expect that you will be a } \\
\text { [BssName] pass holder } 12 \text { months from } \\
\text { now? }\end{array}$ & $11 \%$ & $13 \%$ & $11 \%$ & $12 \%$ & $10 \%$ & $13 \%$ & $13 \%$ \\
\hline \multicolumn{8}{|c|}{$\%$ responding likely (somewhat or very) } \\
\hline $\begin{array}{l}\text { Seek more information about using } \\
\text { [BssName]? }\end{array}$ & $38 \%$ & $33 \%$ & $41 \%$ & $44 \%$ & $33 \%$ & $31 \%$ & $33 \%$ \\
\hline $\begin{array}{l}\text { Tell someone you know about } \\
\text { [BssName]? }\end{array}$ & $50 \%$ & $49 \%$ & $50 \%$ & $50 \%$ & $43 \%$ & $62 \%$ & $59 \%$ \\
\hline Ride a [BssName] bike? & $42 \%$ & $42 \%$ & $42 \%$ & $43 \%$ & $43 \%$ & $40 \%$ & $45 \%$ \\
\hline Minimum number of responses ${ }^{1}$ & 856 & 257 & 581 & 320 & 192 & 44 & 170 \\
\hline Maximum number of responses ${ }^{1}$ & 914 & 284 & 610 & 329 & 212 & 45 & 191 \\
\hline
\end{tabular}

\subsubsection{Experiences with bike share - demographic differences}

Differences by race and income

Although respondents in all race-income groups overwhelmingly reported having noticed bike share stations in their neighborhood, white respondents were significantly more likely than respondents of color to report doing so after controlling for age, gender, and city. Compared to lower-income respondents of color, higher-income white respondents were three times as likely to have ridden a bike share bike (29\% to $9 \%$ ), five times as likely to be members (10\% to $2 \%$ ), and twice as likely to have friends or family members who had used bike share (70\% to 35\%) (Table 8-5). However, these groups did not show 
differences on certain forward-looking measures, such as whether they intended to be a bike share member in a year from the survey date (10-13\% across all groups, without significant differences), or whether they would likely ride a bike share bike in the next six months (40-45\% across all groups, without significant differences). Lower-income respondents of color were also more likely than other respondents to indicate that they intend to seek more information about bike share in the next six months. Therefore, it appears that, while higher-income white respondents are currently engaging with bike share at higher rates, this may not be the case in the future.

\section{Differences by gender}

Although men were more likely than women to have ridden a bike share bike (20\% to $14 \%$ ), and to have friends or relatives who had used the bike share system (53\% to 43\%); neither difference was significant after controlling for race-income group, age, and city. On the other hand, women were more likely to state that they would likely seek more information about the bike share system in the next six months (41\% to $33 \%)$.

\section{Differences by age}

Few age differences were noted among the reported experiences with bike share. In fact, the only significant differences in this area were that respondents in the 55-64 age group were less likely to have ridden a bike share bike than younger respondents, and both those 35-54 and 55-64 were less likely to have friends and family that used the bike share system.

\subsubsection{Experiences with bike share - geographic differences}

With some exceptions, experiences with bike share did not differ significantly among the cities and study areas. Respondents in Philadelphia were more likely to report talking to someone who works with the bike share system (13\%, compared to 12\% in Brooklyn and 5\% in Chicago), and to report attending special events related to the bike share systems (5\% compared to $2 \%$ in each of the other cities). Respondents in Brooklyn reported being less likely to tell someone they know about the bike share system or ride a bike share bike than those in the other cities. Membership rates among our sample were remarkably similar across cities (4.2\% to 4.7\%). Philadelphia and Chicago membership rates were within a percentage point of our estimates of the system averages (Chapter 4), while membership among our Brooklyn participants was considerably below the estimated system average rate (8.4\%), but those numbers include Manhattan. 
Table 8-6 Experiences with Bike Share, by City and Neighborhood

\begin{tabular}{|c|c|c|c|c|c|c|c|}
\hline \multirow[b]{2}{*}{ About [BssName] and you } & \multirow[b]{2}{*}{$\begin{array}{l}\text { Able } \\
\text { and } \\
<65\end{array}$} & \multicolumn{6}{|c|}{ Able and under 65 , by outreach city and area2 } \\
\hline & & $\begin{array}{l}\text { BKLN } \\
\text { Study } \\
\text { Area }\end{array}$ & $\begin{array}{l}\text { CHI } \\
\text { Study } \\
\text { Area }\end{array}$ & $\begin{array}{l}\text { PHI } \\
\text { Study } \\
\text { Areas } \\
\text { All }\end{array}$ & $\begin{array}{l}\text { PHI } \\
\text { Study } \\
\text { Area } \\
\text { West }\end{array}$ & $\begin{array}{l}\text { PHI } \\
\text { Study } \\
\text { Area } \\
\text { North }\end{array}$ & $\begin{array}{l}\text { PHI } \\
\text { Study } \\
\text { Area } \\
\text { South }\end{array}$ \\
\hline & \multicolumn{7}{|c|}{$\%$ responding yes } \\
\hline $\begin{array}{l}\text { Have you noticed a [BssName] station in } \\
\text { your neighborhood? }\end{array}$ & $95 \%$ & $96 \%$ & $95 \%$ & $94 \%$ & $94 \%$ & $96 \%$ & $93 \%$ \\
\hline Have you ridden a [BssName] bike? & $16 \%$ & $13 \%$ & $16 \%$ & $18 \%$ & $14 \%$ & $16 \%$ & $22 \%$ \\
\hline $\begin{array}{l}\text { Are you currently a [BssName] pass } \\
\text { holder? }\end{array}$ & $4 \%$ & $5 \%$ & $4 \%$ & $4 \%$ & $2 \%$ & $4 \%$ & $7 \%$ \\
\hline $\begin{array}{l}\text { If not, have you ever been a [BssName] } \\
\text { pass holder? }\end{array}$ & $3 \%$ & $3 \%$ & $2 \%$ & $3 \%$ & $3 \%$ & $4 \%$ & $4 \%$ \\
\hline $\begin{array}{l}\text { Did you receive a coupon for a free } \\
\text { [BssName] ride or day-use? }\end{array}$ & $3 \%$ & $4 \%$ & $4 \%$ & $2 \%$ & $2 \%$ & $1 \%$ & $2 \%$ \\
\hline $\begin{array}{l}\text { Have you gone on an organized bike } \\
\text { ride where you learned about } \\
\text { [BssName]? }\end{array}$ & $2 \%$ & $2 \%$ & $2 \%$ & $3 \%$ & $3 \%$ & $3 \%$ & $2 \%$ \\
\hline $\begin{array}{l}\text { Have any of your friends or family used } \\
\text { [BssName]? }\end{array}$ & $46 \%$ & $49 \%$ & $46 \%$ & $45 \%$ & $45 \%$ & $37 \%$ & $51 \%$ \\
\hline $\begin{array}{l}\text { Do you follow [BssName] on Instagram, } \\
\text { Twitter, Facebook, or Email? }\end{array}$ & $4 \%$ & $3 \%$ & $3 \%$ & $6 \%$ & $6 \%$ & $4 \%$ & $8 \%$ \\
\hline $\begin{array}{l}\text { Have you ever talked to someone who } \\
\text { works with [BssName]? }\end{array}$ & $10 \%$ & $12 \%$ & $5 \%$ & $13 \%$ & $17 \%$ & $7 \%$ & $15 \%$ \\
\hline $\begin{array}{l}\text { Have you attended special events } \\
\text { related to [BssName]? }\end{array}$ & $4 \%$ & $2 \%$ & $2 \%$ & $5 \%$ & $8 \%$ & $5 \%$ & $4 \%$ \\
\hline \multirow[t]{2}{*}{$\begin{array}{l}\text { Do you expect that you will be a } \\
\text { [BssName] pass holder } 12 \text { months from } \\
\text { now? }\end{array}$} & $11 \%$ & $12 \%$ & $8 \%$ & $13 \%$ & $13 \%$ & $12 \%$ & $13 \%$ \\
\hline & \multicolumn{7}{|c|}{$\%$ responding likely (somewhat or very) } \\
\hline $\begin{array}{l}\text { Seek more information about using } \\
\text { [BssName]? }\end{array}$ & $38 \%$ & $34 \%$ & $40 \%$ & $40 \%$ & $47 \%$ & $46 \%$ & $29 \%$ \\
\hline $\begin{array}{l}\text { Tell someone you know about } \\
\text { [BssName]? }\end{array}$ & $50 \%$ & $41 \%$ & $46 \%$ & $56 \%$ & $66 \%$ & $53 \%$ & $52 \%$ \\
\hline Ride a [BssName] bike? & $42 \%$ & $36 \%$ & $43 \%$ & $45 \%$ & $49 \%$ & $51 \%$ & $37 \%$ \\
\hline Minimum number of responses ${ }^{1}$ & 856 & 197 & 247 & 412 & 117 & 137 & 158 \\
\hline Maximum number of responses ${ }^{1}$ & 914 & 215 & 263 & 436 & 122 & 142 & 172 \\
\hline
\end{tabular}

${ }^{1}$ varies by question due to missing

${ }^{2}$ bold indicates category value significantly greater or less than expected ( $p<0.05$, adj. stand. Chi-square residual)

\subsubsection{Sources of information that are most effective}

Although some of the more personal outreach methods are being reported by a relatively few number of respondents, there is some evidence that, for those who do receive this sort of outreach, it may be quite effective. For example, relatively few respondents reported receiving information about bike share via receiving something in the mail (9\%), getting information at work or school (7\%), talking to someone from a local partner organization (6\%), or getting information about bike share at a community center or faith-based organization (5\%). However, as Figure 8-2 suggests, those who did receive these types of 
more personal outreach were considerably more likely to state that they plan to engage in a number of bike share related activities including seeking more information about bike share, riding a bike share bike, and becoming a bike share member.

Of those receiving information about bike share from each source below, \% very likely to engage in bike share activity

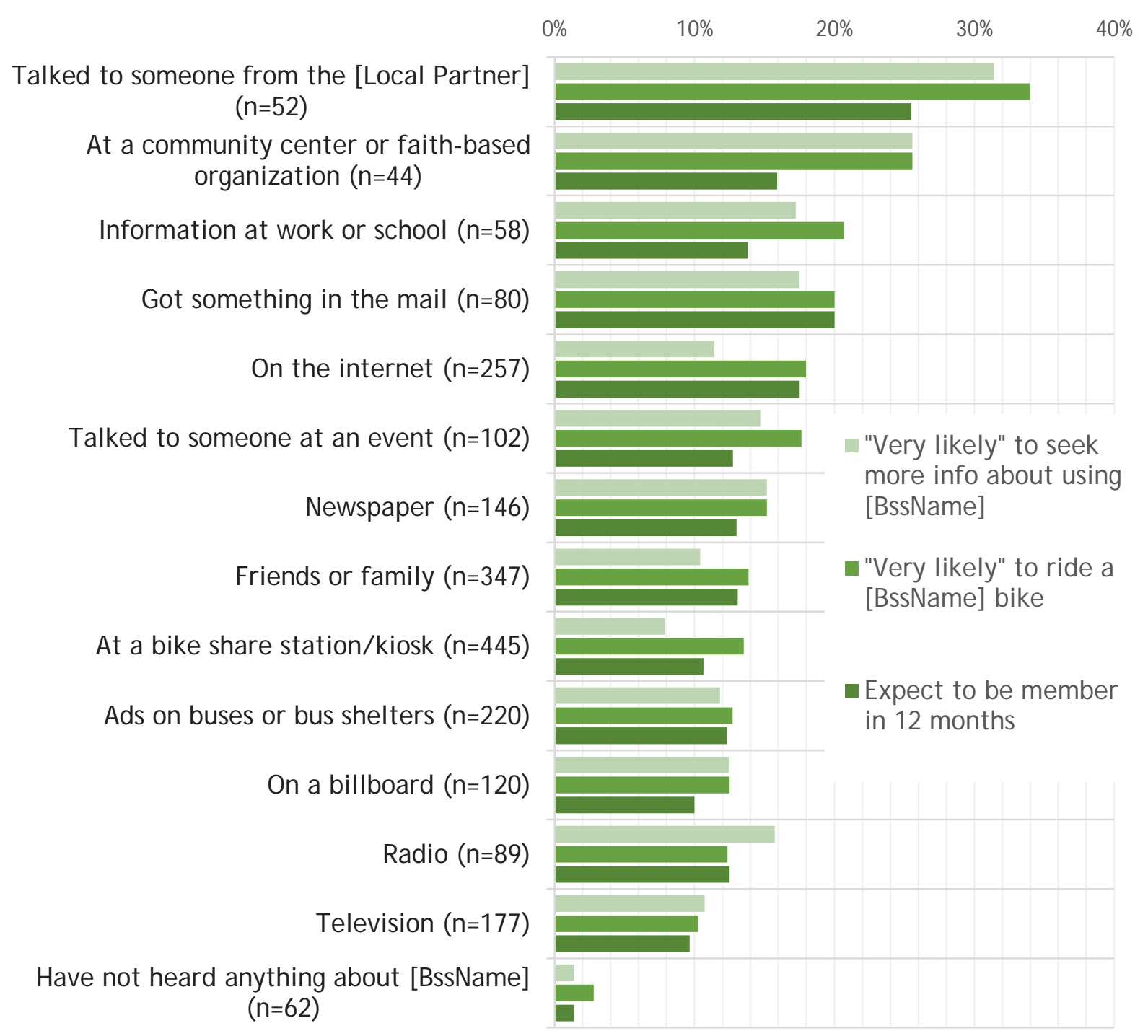

Figure 8-2 Bike share intentions by source of information 


\subsection{Knowledge of bike share}

A set of questions was asked to gauge levels of knowledge about certain details of each of the bike share systems, and to test potential misconceptions. Respondents were asked to rate a series of statements as definitely false, probably false, probably true, definitely true, or no idea. Each of the statements, along with the researchers' report of whether it is true or false, is shown in Table 8-7. In certain cases, statements relating to specific details about the bike share system were different between cities; for example, the statements about the ability to pay monthly, about nonmember cost options, and about member time allowances varied depending on the specific program. Also note that in some cases, statements were true in one city, but false in another, or were not entirely true or entirely false. 
Table 8-7 True-or-False Questions, Correct Responses

\begin{tabular}{|c|c|c|c|}
\hline $\begin{array}{c}\text { Knowledge about bike share system } \\
\text { (\% stating True) }\end{array}$ & $\begin{array}{l}\text { Asked } \\
\text { In }\end{array}$ & $\begin{array}{l}\text { True } \\
\text { or } \\
\text { False }\end{array}$ & Explanation \\
\hline $\begin{array}{l}\text { A debit or credit card is required to use } \\
\text { [BssName] }\end{array}$ & $\begin{array}{l}\text { All } \\
\text { cities }\end{array}$ & $\mathrm{T} / \mathrm{F}$ & $\begin{array}{l}\text { Brooklyn: Mostly True: Debit or credit card } \\
\text { required except for New York City Housing } \\
\text { Authority residents } \\
\text { Chicago: Mostly True - Debit or credit card } \\
\text { required except for Divvy for Everyone members, } \\
\text { Philadelphia: False - Anyone can pay with cash }\end{array}$ \\
\hline $\begin{array}{l}\text { Monthly payment options: } \\
\text { - } \quad \text { People can buy a monthly pass or } \\
\text { membership to use Indego } \\
\text { (Philadelphia) } \\
\text { - People can pay monthly for a } \\
\text { [BssName] membership } \\
\text { (Brooklyn/ Chicago) }\end{array}$ & $\begin{array}{l}\text { All } \\
\text { cities }\end{array}$ & True & $\begin{array}{l}\text { Philadelphia: Users can buy a monthly pass. } \\
\text { Brooklyn/Chicago: Users can make monthly } \\
\text { payments for an annual pass (but cannot buy just } \\
\text { a month pass). }\end{array}$ \\
\hline $\begin{array}{l}\text { A helmet is required to check out a } \\
\text { [BssName] bike }\end{array}$ & $\begin{array}{l}\text { All } \\
\text { cities }\end{array}$ & False & $\begin{array}{l}\text { None of the cities surveyed have mandatory } \\
\text { helmet laws }\end{array}$ \\
\hline $\begin{array}{l}\text { Nonmember / passholder costs: } \\
\text { - If not a passholder, Indego costs } \$ 4 \text { per } \\
30 \text { minutes to use (Philadelphia) } \\
\text { - Nonmembers can buy a 24-hour pass } \\
\text { for } \$[x] \text { (Brooklyn/ Chicago) }\end{array}$ & $\begin{array}{l}\text { All } \\
\text { cities }\end{array}$ & True & $\begin{array}{l}\text { At the time of the survey distribution, the } \\
\text { nonmember costs in the survey question were } \\
\text { accurate. }\end{array}$ \\
\hline $\begin{array}{l}\text { Member time allowance: } \\
\text { - } \quad \text { [BssName] members / passholders can } \\
\text { use a bike longer than nonmembers / } \\
\text { passholders (before extra charges } \\
\text { apply) (Philadelphia/ Brooklyn) } \\
\text { Divvy members and 24-hour pass } \\
\text { holders can check out a bike for } 30 \\
\text { minutes at a time (before extra } \\
\text { charges apply) (Chicago) }\end{array}$ & $\begin{array}{l}\text { All } \\
\text { cities }\end{array}$ & True & The statements were accurate \\
\hline A [BssName] pass / membership costs $\$[x]$ & $\begin{array}{l}\text { All } \\
\text { cities }\end{array}$ & True & $\begin{array}{l}\text { Does not take into account potential discounted } \\
\text { rates }\end{array}$ \\
\hline $\begin{array}{l}\text { A reduced-price pass for [discount } \\
\text { eligibility] is available for [discount price] }\end{array}$ & $\begin{array}{l}\text { All } \\
\text { cities }\end{array}$ & True & $\begin{array}{l}\text { Philadelphia: PA Access card-holders are eligible } \\
\text { for } \$ 5 \text { per month memberships. } \\
\text { Brooklyn: Public housing residents are eligible } \\
\text { for } \$ 5 \text { per month memberships. } \\
\text { Chicago: Based on income, some are eligible for } \\
\$ 5 \text { per year membership (for first year). }\end{array}$ \\
\hline $\begin{array}{l}\text { Only [Sponsor] customers can use } \\
\text { [BssName] }\end{array}$ & $\begin{array}{l}\text { All } \\
\text { cities }\end{array}$ & False & $\begin{array}{l}\text { Bike share use is not limited to customers of } \\
\text { sponsoring companies. }\end{array}$ \\
\hline $\begin{array}{l}\text { You have to have a smartphone to use } \\
\text { [BssName] }\end{array}$ & $\begin{array}{l}\text { All } \\
\text { cities }\end{array}$ & False & $\begin{array}{l}\text { A smartphone is not required to use bike share } \\
\text { (although it helps). }\end{array}$ \\
\hline $\begin{array}{l}\text { If you exceed a time limit, the [BssName] } \\
\text { bicycle will lock }\end{array}$ & $\begin{array}{l}\text { All } \\
\text { cities }\end{array}$ & False & $\begin{array}{l}\text { The bike will not lock, but generally additional } \\
\text { charges accrue (billed to customer account or } \\
\text { credit card). }\end{array}$ \\
\hline $\begin{array}{l}\text { You have to return the bike to the same } \\
\text { station you check it out from }\end{array}$ & $\begin{array}{l}\text { All } \\
\text { cities }\end{array}$ & False & $\begin{array}{l}\text { A bike can be returned to any station with an } \\
\text { available dock. }\end{array}$ \\
\hline
\end{tabular}

Table 8-8 shows the percentage of respondents who provided responses the research team deemed to be correct (for example, the respondent marked either "probably true" or "definitely true" for statements listed as true in Table 8-7) or incorrect (the respondent marked either "probably false" or "definitely 
false” for statements listed as true in Table 8-7); the difference between the sum of the correct and incorrect responses and $100 \%$ is accounted for by those who selected "no idea" for that statement.

On a number of statements about the bike share systems, most respondents knew the correct response and very few answered incorrectly, including statements about the option to pay on a monthly basis (67\% answered correctly vs. 2\% incorrectly), that you don't have to be a sponsor customer (either Citi Bank for Citi Bike, Independence Blue Cross for Indego, or Blue Cross Blue Shield for Divvy - 68\% answered correctly vs. 3\% incorrectly), and that you don't have to return to a bike to the same station you checked it out at (71\% correct vs. $5 \%$ incorrect).

There were several areas of notable misconceptions about the bike share systems. Although anyone in Philadelphia can pay for an Indego pass with cash, fully two-thirds of respondents still indicated that a credit card is required to use the system. Although none of the cities have mandatory helmet laws for bicycle riders, $18 \%$ of respondents thought that a helmet was required to use the bike share system (and only 50\% correctly indicated that the statement was false, with the remainder indicating they did not know the answer). Twelve percent of respondents indicated that they thought that the bike share bike would lock if the user exceeded a time limit, which is not true.

On several questions, the majority of respondents indicated that they had "no idea" about the truth of the statement. These included certain details about the cost of using the system, as a member or nonmember, and the availability of the reduced-price membership or pass option (for which $63 \%$ of respondents indicated that they had "no idea"). 
Table 8-8 Bike Share Knowledge, by Gender and Race-Income Groups

\begin{tabular}{|c|c|c|c|c|c|c|c|}
\hline & \multirow[b]{2}{*}{$\begin{array}{l}\text { All } \\
\text { Able } \\
\text { and } \\
<65\end{array}$} & \multicolumn{2}{|c|}{ By gender 2} & \multicolumn{4}{|c|}{ By race and income group ${ }^{3}$} \\
\hline & & Male & Female & $\begin{array}{l}\text { Lower- } \\
\text { Income } \\
\text { POC }\end{array}$ & $\begin{array}{l}\text { Higher- } \\
\text { Income } \\
\text { POC }\end{array}$ & $\begin{array}{l}\text { Lower- } \\
\text { Income } \\
\text { White }\end{array}$ & $\begin{array}{l}\text { Higher- } \\
\text { Income } \\
\text { White }\end{array}$ \\
\hline \multicolumn{8}{|c|}{$\begin{array}{l}\text { Top row: \% responding with correct answer } \\
\text { Bottom row: \% responding with incorrect answer. Others selected “no idea” }\end{array}$} \\
\hline \multicolumn{8}{|l|}{$\begin{array}{l}\text { A debit or credit card is required to use } \\
\text { [BssName] }\end{array}$} \\
\hline Brooklyn \& Chicago [T] & $\begin{array}{c}76 \% \\
3 \%\end{array}$ & $\begin{array}{c}80 \% \\
2 \%\end{array}$ & $\begin{array}{c}74 \% \\
4 \%\end{array}$ & $\begin{array}{c}70 \% \\
4 \%\end{array}$ & $\begin{array}{c}85 \% \\
2 \%\end{array}$ & $\begin{array}{c}82 \% \\
9 \%\end{array}$ & $\begin{array}{c}84 \% \\
3 \%\end{array}$ \\
\hline Philadelphia [F] & $\begin{array}{l}12 \% \\
67 \%\end{array}$ & $\begin{array}{l}15 \% \\
68 \%\end{array}$ & $\begin{array}{l}11 \% \\
66 \%\end{array}$ & $\begin{array}{l}6 \% \\
67 \%\end{array}$ & $\begin{array}{l}15 \% \\
65 \%\end{array}$ & $\begin{array}{l}15 \% \\
59 \%\end{array}$ & $\begin{array}{l}18 \% \\
70 \%\end{array}$ \\
\hline Monthly pass options [T] & $\begin{array}{l}67 \% \\
2 \%\end{array}$ & $\begin{array}{l}71 \% \\
4 \%\end{array}$ & $\begin{array}{l}65 \% \\
2 \%\end{array}$ & $\begin{array}{l}\mathbf{5 2} \% \\
2 \%\end{array}$ & $\begin{array}{l}71 \% \\
3 \%\end{array}$ & $\begin{array}{c}91 \% \\
0 \%\end{array}$ & $\begin{array}{c}89 \% \\
3 \%\end{array}$ \\
\hline $\begin{array}{l}\text { A helmet is required to check out a } \\
\text { [BssName] bike [F] }\end{array}$ & $\begin{array}{l}50 \% \\
18 \%\end{array}$ & $\begin{array}{l}\mathbf{5 9} \% \\
14 \%\end{array}$ & $\begin{array}{l}46 \% \\
21 \%\end{array}$ & $\begin{array}{l}34 \% \\
28 \%\end{array}$ & $\begin{array}{l}54 \% \\
14 \%\end{array}$ & $\begin{array}{l}62 \% \\
24 \%\end{array}$ & $\begin{array}{l}75 \% \\
9 \%\end{array}$ \\
\hline Non-members/ passholder costs [T] & $\begin{array}{c}44 \% \\
6 \%\end{array}$ & $\begin{array}{c}46 \% \\
5 \%\end{array}$ & $\begin{array}{c}43 \% \\
7 \%\end{array}$ & $\begin{array}{l}\mathbf{3 7} \% \\
7 \%\end{array}$ & $\begin{array}{l}45 \% \\
8 \%\end{array}$ & $\begin{array}{l}58 \% \\
2 \%\end{array}$ & $\begin{array}{c}60 \% \\
4 \%\end{array}$ \\
\hline Member time allowance $[\mathrm{T}]$ & $\begin{array}{c}46 \% \\
7 \%\end{array}$ & $\begin{array}{c}53 \% \\
6 \%\end{array}$ & $\begin{array}{l}43 \% \\
7 \%\end{array}$ & $\begin{array}{c}35 \% \\
9 \%\end{array}$ & $\begin{array}{l}47 \% \\
5 \%\end{array}$ & $\begin{array}{c}58 \% \\
9 \%\end{array}$ & $\begin{array}{c}67 \% \\
7 \%\end{array}$ \\
\hline $\begin{array}{l}\text { A [BssName] pass/ member costs } \$[x] \\
{[\mathrm{T}]}\end{array}$ & $\begin{array}{c}40 \% \\
4 \%\end{array}$ & $\begin{array}{c}44 \% \\
3 \%\end{array}$ & $\begin{array}{l}39 \% \\
5 \%\end{array}$ & $\begin{array}{c}35 \% \\
4 \%\end{array}$ & $\begin{array}{c}41 \% \\
4 \%\end{array}$ & $\begin{array}{c}53 \% \\
4 \%\end{array}$ & $\begin{array}{c}51 \% \\
4 \%\end{array}$ \\
\hline $\begin{array}{l}\text { A reduced price pass for [discount } \\
\text { eligibility] is available for [discount } \\
\text { price] }[\mathrm{T}]\end{array}$ & $\begin{array}{c}31 \% \\
6 \%\end{array}$ & $\begin{array}{l}29 \% \\
7 \%\end{array}$ & $\begin{array}{c}31 \% \\
6 \%\end{array}$ & $\begin{array}{c}\mathbf{2 6 \%} \\
9 \%\end{array}$ & $\begin{array}{l}30 \% \\
7 \%\end{array}$ & $\begin{array}{c}44 \% \\
4 \%\end{array}$ & $\begin{array}{c}40 \% \\
3 \%\end{array}$ \\
\hline $\begin{array}{l}\text { You have to be an [Sponsor] customer } \\
\text { to use [BssName] [F] }\end{array}$ & $\begin{array}{c}68 \% \\
3 \%\end{array}$ & $\begin{array}{c}69 \% \\
4 \%\end{array}$ & $\begin{array}{l}67 \% \\
3 \%\end{array}$ & $\begin{array}{c}53 \% \\
4 \%\end{array}$ & $\begin{array}{l}74 \% \\
3 \%\end{array}$ & $\begin{array}{c}84 \% \\
2 \%\end{array}$ & $\begin{array}{c}91 \% \\
3 \%\end{array}$ \\
\hline $\begin{array}{l}\text { You have to have a smart phone to use } \\
\text { [BssName] [F] }\end{array}$ & $\begin{array}{c}59 \% \\
7 \%\end{array}$ & $\begin{array}{c}65 \% \\
6 \%\end{array}$ & $\begin{array}{l}55 \% \\
7 \%\end{array}$ & $\begin{array}{l}43 \% \\
10 \%\end{array}$ & $\begin{array}{l}57 \% \\
8 \%\end{array}$ & $\begin{array}{c}89 \% \\
0 \%\end{array}$ & $\begin{array}{l}88 \% \\
2 \%\end{array}$ \\
\hline $\begin{array}{l}\text { If you exceed a time limit, the } \\
\text { [BssName] bicycle will lock [F] }\end{array}$ & $\begin{array}{l}45 \% \\
12 \%\end{array}$ & $\begin{array}{c}\mathbf{5 8} \% \\
6 \%\end{array}$ & $\begin{array}{l}39 \% \\
15 \%\end{array}$ & $\begin{array}{l}24 \% \\
21 \%\end{array}$ & $\begin{array}{l}43 \% \\
12 \%\end{array}$ & $\begin{array}{c}67 \% \\
9 \%\end{array}$ & $\begin{array}{c}83 \% \\
2 \%\end{array}$ \\
\hline $\begin{array}{l}\text { You have to return the bike to the same } \\
\text { station you check it out from [F] }\end{array}$ & $\begin{array}{c}71 \% \\
5 \%\end{array}$ & $\begin{array}{c}74 \% \\
3 \%\end{array}$ & $\begin{array}{l}70 \% \\
5 \%\end{array}$ & $\begin{array}{c}\mathbf{5 8} \% \\
7 \%\end{array}$ & $\begin{array}{c}78 \% \\
3 \%\end{array}$ & $\begin{array}{c}91 \% \\
2 \%\end{array}$ & $\begin{array}{c}\mathbf{9 2} \% \\
3 \%\end{array}$ \\
\hline Minimum number of responses ${ }^{1}$ & 893 & 278 & 595 & 319 & 206 & 43 & 189 \\
\hline Maximum number of responses ${ }^{1}$ & 907 & 284 & 604 & 324 & 212 & 45 & 190 \\
\hline
\end{tabular}

\subsubsection{Knowledge of bike share - demographic differences \\ Differences by race and income}

On several of the areas of potential misconceptions, lower-income respondents, and particularly lowerincome people of color, were more likely to hold misconceptions. Lower-income respondents were more likely to incorrectly assume a helmet is required to use bike share (28\% thought this, compared to $18 \%$ of all respondents). Respondents in the lower-income people of color group were most likely to incorrectly assume the bike would lock after a time limit was exceeded, while nearly everyone in the higher-income white group correctly marked this statement as false. 
On several other questions, there was some level of misconception, particularly among the lower-income people of color group, even though overall most respondents knew the right answer. For example, 9\% of respondents in this group incorrectly indicated that the reduced-price membership option didn't exist. Further only $31 \%$ of all respondents, and $26 \%$ of the lower-income people of color, indicated that they knew that the discount was available. In the lower-income people of color group, $10 \%$ incorrectly indicated that a smartphone was required to use the bike share system; and 7\% incorrectly indicated that they had to return to the bike to the same station they checked it out from.

Across a number of the true-false questions, including those for which most respondents indicated that they had "no idea" about the truth of a statement, respondents in the lower-income people of color group were more likely than others to indicate that they didn't know whether the statements were true or not.

\section{Differences by Gender}

On several questions, men were more likely than women to correctly indicate whether a statement was true of false. They were more likely to correctly note that certain statements were false, including statement about needing a helmet, needing a smart phone, and that the bike would lock after a time limit was exceeded. Men were also more likely to correctly indicate that the statement about the member time allowance was true.

\section{Differences by Age}

On many of the true-false questions, younger respondents were more likely to answer correctly, controlling for race-income group, gender, and city. Respondents in the 35-54 and 18-34 were progressively more likely to provide the correct answer, compared to those in the 55-64 age group, for the true-false statements around the monthly pass options, the helmet requirement, the non-member costs, the member time allowance, the member costs, and the need for a smart phone. Those in the 55-64 groups were less likely to provide the correct response to the statements about needing to be a sponsor customer, exceeding the time limit, and returning bikes to the same station. In Brooklyn and Chicago, those 35-54 were less likely to correctly answer whether a credit or debit card was required to use bike share in those cities.

\subsubsection{Knowledge of bike share - geographic differences}

Table 8-9 shows the percentage of respondents in each geographic area who provided responses the research team deemed to be correct or incorrect (see full explanation in prior section).

Respondents in Philadelphia were more likely to respond correctly to the statement about the monthly pass option (75\% did so, comparted to $67 \%$ of all (able and $>65$ ) respondents. This makes sense, as the monthly payment option is a key component of the Indego model and was available from the time the system launched.

After accounting for sociodemographic factors (race-income group, gender, and age), city differences were no longer significant on the statements pertaining to the helmet requirement, member costs, smart phone requirement, exceeding the time limit, and returning the bike to the same station. 
Table 8-9 Bike Share Knowledge, by City and Neighborhood

\begin{tabular}{|c|c|c|c|c|c|c|c|}
\hline & \multirow[b]{2}{*}{$\begin{array}{l}\text { Able } \\
\text { and } \\
<65\end{array}$} & \multicolumn{6}{|c|}{ Able and under 65, by outreach city and area 2} \\
\hline & & $\begin{array}{l}\text { BKLN } \\
\text { Study } \\
\text { Area }\end{array}$ & $\begin{array}{l}\text { CHI } \\
\text { Study } \\
\text { Area }\end{array}$ & $\begin{array}{l}\text { PHI } \\
\text { Study } \\
\text { Areas } \\
\text { All }\end{array}$ & $\begin{array}{l}\text { PHI } \\
\text { Study } \\
\text { Area } \\
\text { West }\end{array}$ & $\begin{array}{l}\text { PHI } \\
\text { Study } \\
\text { Area } \\
\text { North }\end{array}$ & $\begin{array}{l}\text { PHI } \\
\text { Study } \\
\text { Area } \\
\text { South }\end{array}$ \\
\hline \multicolumn{8}{|c|}{$\begin{array}{l}\text { Top row: \% responding with correct answer } \\
\text { Bottom row: \% responding with incorrect answer. Others selected "no idea" }\end{array}$} \\
\hline \multirow{2}{*}{$\begin{array}{l}\text { A debit or credit card is required to } \\
\text { use [BssName] [T/F] }\end{array}$} & $45 \%$ & $77 \%$ & $74 \%$ & $12 \%$ & $12 \%$ & $6 \%$ & $17 \%$ \\
\hline & $34 \%$ & $5 \%$ & $2 \%$ & $67 \%$ & $70 \%$ & $71 \%$ & $62 \%$ \\
\hline \multirow[t]{2}{*}{ Monthly pass options [T] } & $67 \%$ & $64 \%$ & $57 \%$ & $75 \%$ & $76 \%$ & $70 \%$ & $78 \%$ \\
\hline & $2 \%$ & $4 \%$ & $3 \%$ & $1 \%$ & $1 \%$ & $1 \%$ & $1 \%$ \\
\hline \multirow{2}{*}{$\begin{array}{l}\text { A helmet is required to check out a } \\
\text { [BssName] bike [F] }\end{array}$} & $50 \%$ & $46 \%$ & $47 \%$ & $54 \%$ & $50 \%$ & $55 \%$ & $55 \%$ \\
\hline & $18 \%$ & $25 \%$ & $13 \%$ & $18 \%$ & $23 \%$ & $16 \%$ & $17 \%$ \\
\hline \multirow[t]{2}{*}{ Non-members / passholder costs [T] } & $44 \%$ & $43 \%$ & $43 \%$ & $46 \%$ & $45 \%$ & $44 \%$ & $48 \%$ \\
\hline & $6 \%$ & $9 \%$ & $4 \%$ & $7 \%$ & $8 \%$ & $11 \%$ & $4 \%$ \\
\hline \multirow[t]{2}{*}{ Member Time Allowance [T] } & $46 \%$ & $46 \%$ & $46 \%$ & $47 \%$ & $43 \%$ & $46 \%$ & $50 \%$ \\
\hline & $7 \%$ & $5 \%$ & $5 \%$ & $9 \%$ & $13 \%$ & $9 \%$ & $8 \%$ \\
\hline $\begin{array}{l}\text { A [BssName] pass/ member costs } \$[x] \\
{[T]}\end{array}$ & $\begin{array}{c}40 \% \\
4 \%\end{array}$ & $\begin{array}{l}36 \% \\
5 \%\end{array}$ & $\begin{array}{l}38 \% \\
2 \%\end{array}$ & $\begin{array}{c}45 \% \\
6 \%\end{array}$ & $\begin{array}{l}48 \% \\
7 \%\end{array}$ & $\begin{array}{l}42 \% \\
6 \%\end{array}$ & $\begin{array}{l}46 \% \\
5 \%\end{array}$ \\
\hline $\begin{array}{l}\text { A reduced price pass for [discount } \\
\text { eligibility] is available for [discount } \\
\text { price] }[\mathrm{T}]\end{array}$ & $\begin{array}{l}31 \% \\
6 \%\end{array}$ & $\begin{array}{c}28 \% \\
6 \%\end{array}$ & $\begin{array}{l}29 \% \\
7 \%\end{array}$ & $\begin{array}{c}34 \% \\
6 \%\end{array}$ & $\begin{array}{l}39 \% \\
6 \%\end{array}$ & $\begin{array}{l}27 \% \\
10 \%\end{array}$ & $\begin{array}{l}35 \% \\
2 \%\end{array}$ \\
\hline $\begin{array}{l}\text { You have to be an [Sponsor] customer } \\
\text { to use [BssName] [F] }\end{array}$ & $\begin{array}{c}68 \% \\
3 \%\end{array}$ & $\begin{array}{l}69 \% \\
5 \%\end{array}$ & $\begin{array}{l}65 \% \\
3 \%\end{array}$ & $\begin{array}{l}70 \% \\
3 \%\end{array}$ & $\begin{array}{l}69 \% \\
3 \%\end{array}$ & $\begin{array}{l}68 \% \\
2 \%\end{array}$ & $\begin{array}{l}71 \% \\
4 \%\end{array}$ \\
\hline $\begin{array}{l}\text { You have to have a smart phone to } \\
\text { use [BssName] [F] }\end{array}$ & $\begin{array}{c}59 \% \\
7 \%\end{array}$ & $\begin{array}{l}59 \% \\
8 \%\end{array}$ & $\begin{array}{c}52 \% \\
8 \%\end{array}$ & $\begin{array}{c}62 \% \\
6 \%\end{array}$ & $\begin{array}{l}61 \% \\
6 \%\end{array}$ & $\begin{array}{l}58 \% \\
9 \%\end{array}$ & $\begin{array}{l}67 \% \\
4 \%\end{array}$ \\
\hline $\begin{array}{l}\text { If you exceed a time limit, the } \\
\text { [BssName] bicycle will lock [F] }\end{array}$ & $\begin{array}{l}45 \% \\
12 \%\end{array}$ & $\begin{array}{l}46 \% \\
12 \%\end{array}$ & $\begin{array}{l}37 \% \\
14 \%\end{array}$ & $\begin{array}{l}\mathbf{4 9} \% \\
12 \%\end{array}$ & $\begin{array}{l}48 \% \\
15 \%\end{array}$ & $\begin{array}{l}39 \% \\
15 \%\end{array}$ & $\begin{array}{c}58 \% \\
6 \%\end{array}$ \\
\hline $\begin{array}{l}\text { You have to return the bike to the } \\
\text { same station you check it out from } \\
\text { [F] }\end{array}$ & $\begin{array}{c}71 \% \\
5 \%\end{array}$ & $\begin{array}{c}73 \% \\
8 \%\end{array}$ & $\begin{array}{c}\mathbf{6 6 \%} \\
3 \%\end{array}$ & $\begin{array}{c}73 \% \\
5 \%\end{array}$ & $\begin{array}{c}77 \% \\
6 \%\end{array}$ & $\begin{array}{c}70 \% \\
3 \%\end{array}$ & $\begin{array}{c}74 \% \\
6 \%\end{array}$ \\
\hline Minimum number of responses ${ }^{1}$ & 893 & 208 & 247 & 432 & 119 & 140 & 170 \\
\hline Maximum number of responses ${ }^{1}$ & 907 & 212 & 261 & 435 & 120 & 142 & 173 \\
\hline
\end{tabular}

${ }^{1}$ varies by question due to missing

${ }^{2}$ bold indicates category value significantly greater or less than expected ( $p<0.05$, adj. stand. Chi-square residual)

\subsection{Opinions about bike share}

Questions about the respondents' opinions and perceptions of bike share are in shown in Table 8-10. Percentages shown in the table are the proportion of respondents indicating that they agree (either strongly or somewhat) with each statement. Respondents could also select "no opinion” — such responses, along with skips, are not considered in the reported percentages.

Overall, perceptions of the bike share systems and their impact on the city and neighborhood were very positive, with $93 \%$ agreeing that the system was good for the city and $89 \%$ agreeing that it was good for their neighborhood.

Perceptions about the general usefulness of bike share were also quite high, with $73 \%$ agreeing that the system is useful for people like them, and between $77 \%-84 \%$ agreeing that bike share is a good way to 
spend less on transportation, as an alternative to public transportation, and as a way to get to public transportation. Three in four agreed that they see people like them using the bike share system in their neighborhood. About half of respondents agreed that they would like to use the bike share system more than they currently do.

Several questions sought to gauge perceptions around the potential impact of bike share on neighborhood change. Nearly two-thirds (62\%) agreed that having bike share stations would attract new people to move into the neighborhood; however, only $21 \%$ felt having the stations nearby would make the neighborhood a more expensive place to live.

Given that the bike share system itself represents a change in the neighborhood, we also sought to understand how they felt about the process through which the system was implemented. One potential concern we heard in our outreach prior to launching the survey was that bike share stations take up space on streets that had been useful to the community - though only about $21 \%$ of respondents agreed with a statement to that effect. Still, only about $41 \%$ felt that concerns of people like them were addressed in decisions about the bike share system in their neighborhood. However, $71 \%$ felt that there was a focused effort to make the system better for the residents of the neighborhood, and three-quarters felt that, over time, the program was getting better at serving the needs of people like them. 
Table 8-10 Opinions about Bike Share, by Gender and Race-Income Groups

\begin{tabular}{|c|c|c|c|c|c|c|c|}
\hline \multirow[b]{2}{*}{$\begin{array}{l}\text { Opinions about [BssName] } \\
\text { (\% agree) }\end{array}$} & \multirow[b]{2}{*}{$\begin{array}{c}\text { All } \\
\text { Able } \\
\text { and } \\
<65\end{array}$} & \multicolumn{2}{|c|}{ By gender ${ }^{2}$} & \multicolumn{4}{|c|}{ By race and income group ${ }^{3}$} \\
\hline & & Male & Female & $\begin{array}{l}\text { Lower- } \\
\text { Income } \\
\text { POC }\end{array}$ & $\begin{array}{l}\text { Higher- } \\
\text { Income } \\
\text { POC }\end{array}$ & $\begin{array}{l}\text { Lower- } \\
\text { Income } \\
\text { White }\end{array}$ & $\begin{array}{l}\text { Higher- } \\
\text { Income } \\
\text { White }\end{array}$ \\
\hline [BssName] is useful for people like me & $73 \%$ & $75 \%$ & $72 \%$ & $74 \%$ & $67 \%$ & $82 \%$ & $77 \%$ \\
\hline $\begin{array}{l}\text { I would like to use [BssName] more than I } \\
\text { currently do }\end{array}$ & $51 \%$ & $51 \%$ & $52 \%$ & $56 \%$ & $46 \%$ & $44 \%$ & $49 \%$ \\
\hline $\begin{array}{l}\text { Having nearby [BssName] stations will } \\
\text { attract new people to move into the } \\
\text { neighborhood }\end{array}$ & $62 \%$ & $71 \%$ & $57 \%$ & $60 \%$ & $58 \%$ & $49 \%$ & $73 \%$ \\
\hline $\begin{array}{l}\text { Having [BssName] nearby will make it } \\
\text { more expensive to live in the } \\
\text { neighborhood }\end{array}$ & $21 \%$ & $20 \%$ & $22 \%$ & $27 \%$ & $22 \%$ & $27 \%$ & $14 \%$ \\
\hline $\begin{array}{l}\text { Using [BssName] is a good way to spend } \\
\text { less money on transportation }\end{array}$ & $77 \%$ & $78 \%$ & $76 \%$ & $75 \%$ & $82 \%$ & $73 \%$ & $77 \%$ \\
\hline $\begin{array}{l}\text { Using [BssName] is a good alternative to } \\
\text { using public transportation }\end{array}$ & $84 \%$ & $85 \%$ & $84 \%$ & $86 \%$ & $81 \%$ & $88 \%$ & $84 \%$ \\
\hline $\begin{array}{l}\text { [BssName] is a good way to get to public } \\
\text { transportation }\end{array}$ & $78 \%$ & $83 \%$ & $76 \%$ & $77 \%$ & $83 \%$ & $78 \%$ & $78 \%$ \\
\hline $\begin{array}{l}\text { I see people like me using [BssName] in } \\
\text { my neighborhood }\end{array}$ & $75 \%$ & $79 \%$ & $73 \%$ & $75 \%$ & $74 \%$ & $86 \%$ & $75 \%$ \\
\hline $\begin{array}{l}\text { I consider [BssName] to be a part of the } \\
\text { city's public transportation system }\end{array}$ & $71 \%$ & $71 \%$ & $70 \%$ & $77 \%$ & $64 \%$ & $59 \%$ & $69 \%$ \\
\hline $\begin{array}{l}\text { Concerns of people like me were } \\
\text { addressed in decisions about [BssName] } \\
\text { in my neighborhood }\end{array}$ & $42 \%$ & $46 \%$ & $40 \%$ & $46 \%$ & $29 \%$ & $70 \%$ & $49 \%$ \\
\hline $\begin{array}{l}\text { [BssName] stations take up street and } \\
\text { sidewalk space that would be better used } \\
\text { for other things }\end{array}$ & $21 \%$ & $17 \%$ & $22 \%$ & $25 \%$ & $24 \%$ & $14 \%$ & $8 \%$ \\
\hline $\begin{array}{l}\text { There is a focused effort to make } \\
\text { [BssName] better for all residents in my } \\
\text { neighborhood }\end{array}$ & $71 \%$ & $77 \%$ & $68 \%$ & $75 \%$ & $64 \%$ & $81 \%$ & $68 \%$ \\
\hline $\begin{array}{l}\text { Over time, the [BssName] program is } \\
\text { getting better at serving the needs of } \\
\text { people like me }\end{array}$ & $76 \%$ & $80 \%$ & $75 \%$ & $79 \%$ & $65 \%$ & $88 \%$ & $79 \%$ \\
\hline Overall, [BssName] is good for the city & $93 \%$ & $96 \%$ & $91 \%$ & $89 \%$ & $90 \%$ & $100 \%$ & $98 \%$ \\
\hline $\begin{array}{l}\text { Overall, [BssName] is good for my } \\
\text { neighborhood }\end{array}$ & $89 \%$ & $93 \%$ & $88 \%$ & $86 \%$ & $85 \%$ & $95 \%$ & $97 \%$ \\
\hline Minimum number of responses ${ }^{1}$ & 454 & 131 & 314 & 189 & 113 & 10 & 84 \\
\hline Maximum number of responses ${ }^{1}$ & 794 & 253 & 522 & 278 & 189 & 43 & 184 \\
\hline
\end{tabular}

Includes respondents in outreach areas under 65 years and physically able to ride a bicycle.

${ }^{1}$ varies by question due to missing and "no opinion"

${ }^{2}$ bold indicates category value significantly greater than expected ( $p<0.05$, adj. stand. Chi-square residual)

${ }^{3}$ bold indicates category value significantly greater or less than expected ( $p<0.05$, adj. stand. Chi-square residual) 


\subsubsection{Opinions about bike share - differences by demographics Differences by race and income}

Figure 8-3 shows how respondents in the race and income groups differ from the average of the overall respondent pool in terms of the percentage who agreed with each statement. Differences that are more positive toward bike share are to the right of $0 \%$ on the axis, while more negative opinions toward bike share are on the left. On many of the questions, the small differences observed were not significant.

Although respondents in the lower-income people of color group were somewhat less likely than other respondents to agree that bike share is good for the city and for their neighborhood, there were still $89 \%$ and $86 \%$ in that group who agreed with each of those statements, respectively. People in this group were more likely to feel that bike share stations take up space that could better be used for other things, and that having bike share nearby would make it more expensive to live in the neighborhood, with about a quarter of respondents agreeing. On several other statements where this group differed from the overall level of agreement across groups, the difference was actually in a direction that could be considered more positive. For example, more people in this group than any other agreed that the bike share system was part of the city's public transportation system (77\% compared to $71 \%$ overall) and that they would like to ride bike share more than they currently do (56\% compared to $51 \%$ overall); however, the significance of these differences did not hold after controlling for gender, age, and city.

People in the higher-income people of color group differed from overall levels on a few questions. In each case, they were a bit less positive toward some aspect of bike share than other respondents. They were less likely to view bike share as being useful for them (with $67 \%$ agreeing compared to $73 \%$ overall though this difference was not significant after controlling for gender, age, and city), and less likely to view the bike share system as part of the city's public transportation system (with 64\% agreeing compared to $71 \%$ overall). They were also considerably less likely to agree that concerns of people like them were addressed in decision about the bike share system in their neighborhood, with only $29 \%$ of respondents agreeing.

On the other hand, respondents in the higher-income white group were more likely to agree with positive statements, or disagree with negative statements toward bike share. They were more likely agree that bike share would attract people to move to the neighborhood, and that the bike share system was good for the city and neighborhood, and less likely to agree that bike share would make it more expensive to live in their neighborhood or that the stations took up valuable street and sidewalk space. 
[BikeShare] is useful for people like me (73\%)

I would like to use [BikeShare] more than I currently do (51\%)

Having nearby [BikeShare] stations will attract new people to move into the neighborhood $(62 \%)$

Having [BikeShare] nearby will make it more expensive to live in the neighborhood* (21\%)

Using [BikeShare] is a good way to spend less money on transportation $(77 \%)$

Using [BikeShare] is a good alternative to using public transportation (84\%)

[BikeShare] is a good way to get to public transportation $(78 \%)$

I see people like me using [BikeShare] in my neighborhood (75\%)

I consider [BikeShare] to be a part of the city's public transportation system (71\%)

Concerns of people like me were addressed in decisions about [BikeShare] in my neighborhood $(42 \%)$

[BikeShare] stations take up street and sidewalk space that would be better used for other things* (21\%)

There is a focused effort to make [BikeShare] better for all residents in my neighoborhood (71\%)

Over time, the [BikeShare] program is getting better at serving the needs of people like me $(76 \%)$

Overall, [BikeShare] is good for the city (93\%)

Overall, [BikeShare] is good for my neighborhood (89\%)

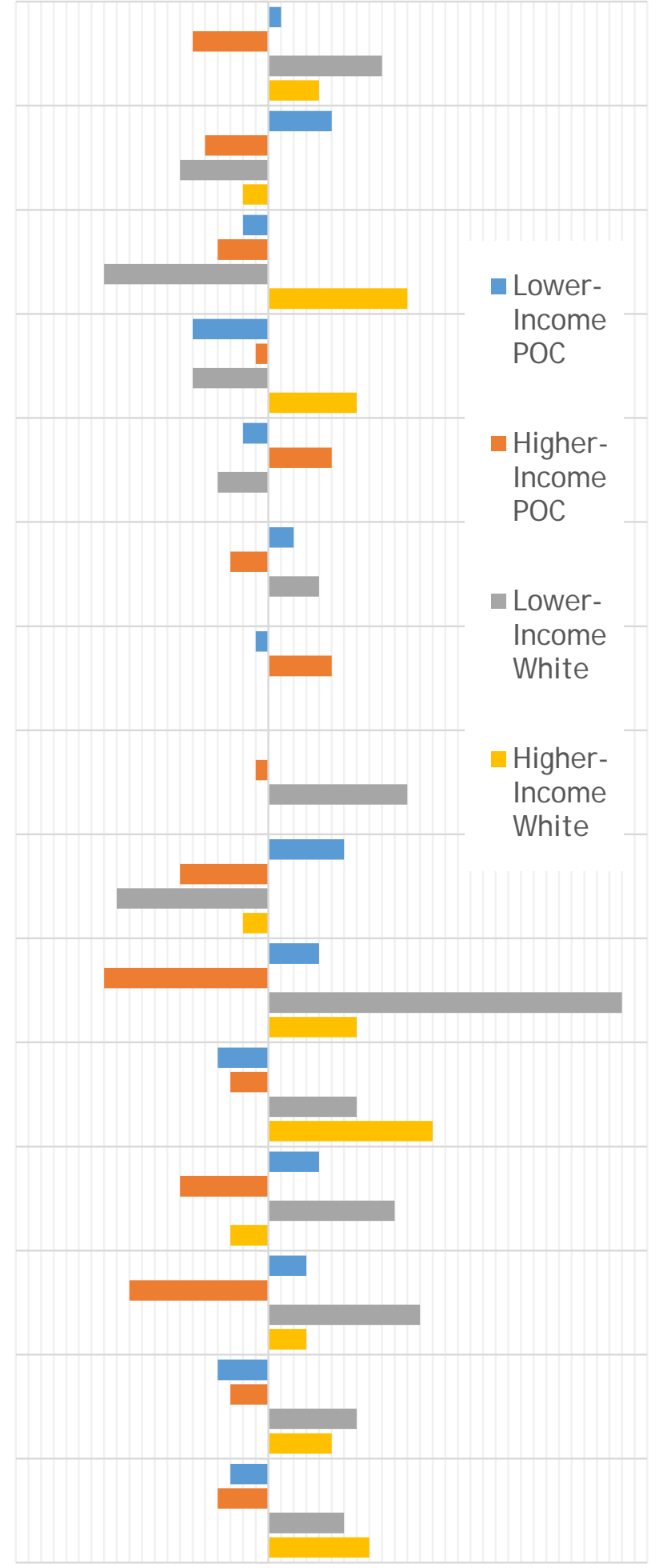

*For starred items difference is inverted. Positive difference denotes more bike positive sentiment, negative difference denotes= more bike negative difference

Figure 8-3 Bike share opinions - demographic differences 


\section{Differences by gender}

On most statements, we did not observe any differences between men and women on perceptions about bike share. On the few statements where we did observe differences, men were more likely than women to take a positive view toward bike share. Men were somewhat more likely than women to view bike share as a good way to get to public transportation (83\% to $76 \%$ ). While men were also more likely to view the system as good for the neighborhood and good for the city, these differences were not significant after accounting for race-income group, age, and city. Men were more likely to agree that the bike share system would attract new people to move to the neighborhood. After controlling for race-income group, age, and city, men were also more likely to state that they saw people like them using the bike share system in their neighborhood.

\section{Differences by age}

Although few age differences were noted, there were several statements on which respondents in the older age groups (35-54 and 55-64) were more likely to take what would be considered a positive view toward bike share, compared with the youngest group (18-34). For example, in older age groups, respondents were less likely to agree that bike share would make it more expensive to live in the neighborhood, and were more likely to agree that bike share is a good way to spend less on transportation. They were also more likely to agree that there was a focused effort to make bike share better for all residents in their neighborhood. Respondents in the 55-64 groups were also most likely to indicate that they think the bike share system is part of the city's transportation system, compared with respondents 18-34.

\subsubsection{Opinions about bike share - geographic differences}

Table 8-11 shows the agreement with the bike share opinion questions broken out by city and neighborhood.

Respondents in Philadelphia were the most likely to agree that the bike share system is useful for people like them (79\% agree, compared to 69\% in Chicago and 66\% in Brooklyn, though the difference with Chicago was not significant when controlling for race-income group, gender, and age), and that they see people like them using bike share (80\%, compared to 73\% in Chicago and 68\% in Brooklyn).

On several measures, respondents in Brooklyn were least likely to view bike share positively - 39\% agreed that having bike share in the neighborhood would make it more expensive to live there (compared to $16 \%$ in the other cities), and 35\% felt that the bike share stations take up space on the street that would be better used for other purposes. Those in Brooklyn were least likely to view the bike share systems as a good way to spend less on transportation or as a part of the city public transportation system. They were also least likely to think there was an effort to make the system better for all residents (59\% agreed, compared to $73 \%-75 \%$ in the other cities), or that the system was getting better at serving the needs of people like them (68\% agreed, but 77\%-79\% agreed in the other cities).

Those in Chicago were most likely to view bike share as a good way to get to public transportation, and as a part of the city's public transportation system. They were also the most likely to agree that the bike share system was good for their neighborhood (at 94\%). 
Table 8-11 Opinions about Bike Share, by City and Neighborhood

\begin{tabular}{|c|c|c|c|c|c|c|c|}
\hline \multirow[b]{2}{*}{$\begin{array}{l}\text { Opinions about [BssName] } \\
\text { (\% agree) }\end{array}$} & \multirow[b]{2}{*}{$\begin{array}{l}\text { Able } \\
\text { and } \\
<65\end{array}$} & \multicolumn{6}{|c|}{ Able and under 65, by outreach city and area ${ }^{2}$} \\
\hline & & $\begin{array}{l}\text { BKLN } \\
\text { Study } \\
\text { Area }\end{array}$ & $\begin{array}{l}\text { CHI } \\
\text { Study } \\
\text { Area }\end{array}$ & $\begin{array}{l}\text { PHI } \\
\text { Study } \\
\text { Areas } \\
\text { All }\end{array}$ & $\begin{array}{c}\text { PHI } \\
\text { Study } \\
\text { Area } \\
\text { West }\end{array}$ & $\begin{array}{l}\text { PHI } \\
\text { Study } \\
\text { Area } \\
\text { North }\end{array}$ & $\begin{array}{c}\text { PHI } \\
\text { Study } \\
\text { Area } \\
\text { South }\end{array}$ \\
\hline [BssName] is useful for people like me & $73 \%$ & $66 \%$ & $69 \%$ & $79 \%$ & $84 \%$ & $76 \%$ & $78 \%$ \\
\hline $\begin{array}{l}\text { I would like to use [BssName] more than } \\
\text { I currently do }\end{array}$ & $51 \%$ & $49 \%$ & $53 \%$ & $52 \%$ & $52 \%$ & $58 \%$ & $47 \%$ \\
\hline $\begin{array}{l}\text { Having nearby [BssName] stations will } \\
\text { attract new people to move into the } \\
\text { neighborhood }\end{array}$ & $62 \%$ & $63 \%$ & $55 \%$ & $66 \%$ & $59 \%$ & $63 \%$ & $73 \%$ \\
\hline $\begin{array}{l}\text { Having [BssName] nearby will make it } \\
\text { more expensive to live in the } \\
\text { neighborhood }\end{array}$ & $21 \%$ & $39 \%$ & $16 \%$ & $16 \%$ & $16 \%$ & $22 \%$ & $12 \%$ \\
\hline $\begin{array}{l}\text { Using [BssName] is a good way to spend } \\
\text { less money on transportation }\end{array}$ & $77 \%$ & $68 \%$ & $79 \%$ & $79 \%$ & $85 \%$ & $76 \%$ & $78 \%$ \\
\hline $\begin{array}{l}\text { Using [BssName] is a good alternative to } \\
\text { using public transportation }\end{array}$ & $84 \%$ & $82 \%$ & $82 \%$ & $86 \%$ & $86 \%$ & $88 \%$ & $85 \%$ \\
\hline $\begin{array}{l}\text { [BssName] is a good way to get to } \\
\text { public transportation }\end{array}$ & $78 \%$ & $81 \%$ & $84 \%$ & $73 \%$ & $74 \%$ & $76 \%$ & $69 \%$ \\
\hline $\begin{array}{l}\text { I see people like me using [BssName] in } \\
\text { my neighborhood }\end{array}$ & $75 \%$ & $68 \%$ & $73 \%$ & $80 \%$ & $76 \%$ & $82 \%$ & $81 \%$ \\
\hline $\begin{array}{l}\text { I consider [BssName] to be a part of the } \\
\text { city's public transportation system }\end{array}$ & $71 \%$ & $62 \%$ & $80 \%$ & $69 \%$ & $69 \%$ & $75 \%$ & $64 \%$ \\
\hline $\begin{array}{l}\text { Concerns of people like me were } \\
\text { addressed in decisions about [BssName] } \\
\text { in my neighborhood }\end{array}$ & $42 \%$ & $47 \%$ & $39 \%$ & $41 \%$ & $48 \%$ & $35 \%$ & $42 \%$ \\
\hline $\begin{array}{l}\text { [BssName] stations take up street and } \\
\text { sidewalk space that would be better } \\
\text { used for other things }\end{array}$ & $21 \%$ & $35 \%$ & $19 \%$ & $14 \%$ & $12 \%$ & $12 \%$ & $18 \%$ \\
\hline $\begin{array}{l}\text { There is a focused effort to make } \\
\text { [BssName] better for all residents in my } \\
\text { neighborhood }\end{array}$ & $71 \%$ & $59 \%$ & $75 \%$ & $73 \%$ & $76 \%$ & $75 \%$ & $70 \%$ \\
\hline $\begin{array}{l}\text { Over time, the [BssName] program is } \\
\text { getting better at serving the needs of } \\
\text { people like me }\end{array}$ & $76 \%$ & $68 \%$ & $77 \%$ & $79 \%$ & $88 \%$ & $78 \%$ & $74 \%$ \\
\hline Overall, [BssName] is good for the city & $93 \%$ & $87 \%$ & $93 \%$ & $94 \%$ & $98 \%$ & $93 \%$ & $92 \%$ \\
\hline $\begin{array}{l}\text { Overall, [BssName] is good for my } \\
\text { neighborhood }\end{array}$ & $89 \%$ & $80 \%$ & $94 \%$ & $91 \%$ & $94 \%$ & $91 \%$ & $90 \%$ \\
\hline Minimum number of responses ${ }^{1}$ & 454 & 105 & 132 & 217 & 64 & 74 & 79 \\
\hline Maximum number of responses ${ }^{1}$ & 794 & 189 & 222 & 383 & 111 & 122 & 152 \\
\hline
\end{tabular}

${ }^{1}$ varies by question due to missing and "no opinion"

2 bold indicates category value significantly greater or less than expected ( $p<0.05$, adj. stand. Chi-square residual)

\subsubsection{Neighborhood perceptions and bike share}

We observed a few differences among our respondents' views toward bike share based on views or concerns they had about their neighborhood in general. For example, respondents who felt they might be priced out of the neighborhood (they agreed with the statement "I may have to leave my neighborhood because it is getting too expensive") tended to be a bit less positive toward bicycling and bike share in general. They were more likely to agree that bike lanes make it hard to get around their neighborhood (32\% to 22\%), were more likely to think bike share will make it more expensive to live in the neighborhood (35\% to 12\%), and were more likely to think bike share stations take up street and sidewalk space better used for other purposes (34\% to 18\%). They were also less likely to feel there is a focused effort to make bike share work for everyone (74\% to 62\%). Although these folks are less likely to think 
bike share is good for the city overall (86\% to 91\%), and good for the neighborhood overall (79\% to 89\%), these are still high support levels.

On the other hand, people who agreed with statements about knowing about events in their neighborhood (they agreed with the statement "I usually know about community and social events in my neighborhood") were more likely to agree that bike share would attract new people to move into the neighborhood (66\% to 57\%), but were less likely to think it would make the neighborhood more expensive (19\% to $25 \%$ ). They were more likely to think bike share is part of the city's public transportation system (76\% to 63\%). They were also much more likely to think the concerns of people like them were considered in planning for bike share (47\% to 35\%), and were much more likely to agree that there is a focused effort to make bike share work for everyone in their neighborhood (76\% to 62\%). 


\section{BIKE ShaRe Motivators AND BARRIERS}

The survey asked several sets of questions to understand factors that might make people more or less likely to use bike share. These included questions about the reasons people would consider using bike share, potential changes that might make them more likely to try bike share, and what barriers exist that keep them from using it (or from using it more).

\subsection{Reasons to try bike share}

Survey respondents were presented with a list of fourteen potential reasons why they use or would consider using the bike share system, and were asked to select all those that apply. There was also a space to write in another reason, or to select "nothing - I wouldn't consider using [the bike share system]." Responses are shown in Table 9-1. On average, respondents selected just over 4 reasons they would consider trying bike share, while nearly one in five (17\%) selected "nothing."

The two most frequently selected options were to get exercise (62\% selected this reason) and for fun (with 53\%). These were the only two reasons selected by over half of respondents. Other recreationaltype reasons selected included riding with family and friends (40\%), and wanting to try biking (29\%). The motivation of helping the environment was chosen by $37 \%$.

Among the more utilitarian reasons were that there were stations near their home, work or school (41\%); bike share is an easy way to get around (38\%); that it saves them money or time compared to other options ( $27 \%$ and $26 \%$ respectively); and that they don't need to rely on transit (20\%). In addition, $23 \%$ selected not needing a bike of their own as a reason to try bike share. Relatively few selected getting to bus or rail stops (14\%), getting to jobs (9\%), or getting to social services (5\%).

We also compared those stating only recreational reasons (exercise, fun, ride with friends/family, want to try biking) for considering bike share with those also (or only) providing more utilitarian reasons (easy way to get around, saves money, saves time, less reliance on transit, access to transit/jobs/social services). Those providing only recreation-related reasons were significantly less likely $(\mathrm{p}<0.05)$ to state intentions to become bike share members, seek more information, tell someone else about bike share, or ride a bike share bike in the near future (the last four items from Table 8-5). The differences held even when controlling for race-income group, gender, age, and city. Those considering bike share only for its recreational value do not appear as motivated to actually participate in the program. 
Table 9-1 Reasons to Try Bike Share, by Gender and Race-Income Groups

\begin{tabular}{|c|c|c|c|c|c|c|c|}
\hline \multirow[b]{2}{*}{$\begin{array}{l}\text { Reasons you would consider using } \\
\text { [BssName] }\end{array}$} & \multirow[b]{2}{*}{$\begin{array}{c}\text { All } \\
\text { Able } \\
\text { and }<65\end{array}$} & \multicolumn{2}{|c|}{ By gender 2} & \multicolumn{4}{|c|}{ By race and income group 3} \\
\hline & & Male & Female & $\begin{array}{l}\text { Lower- } \\
\text { Income } \\
\text { POC }\end{array}$ & $\begin{array}{l}\text { Higher- } \\
\text { Income } \\
\text { POC }\end{array}$ & $\begin{array}{l}\text { Lower- } \\
\text { Income } \\
\text { White }\end{array}$ & $\begin{array}{c}\text { Higher- } \\
\text { Income } \\
\text { White }\end{array}$ \\
\hline None & $17 \%$ & $17 \%$ & $17 \%$ & $17 \%$ & $18 \%$ & $16 \%$ & $13 \%$ \\
\hline 1 or 2 reasons selected & $17 \%$ & $19 \%$ & $16 \%$ & $17 \%$ & $22 \%$ & $18 \%$ & $13 \%$ \\
\hline 3 or 4 reasons selected & $21 \%$ & $22 \%$ & $21 \%$ & $19 \%$ & $21 \%$ & $24 \%$ & $20 \%$ \\
\hline 5 or more reasons selected & $45 \%$ & $43 \%$ & $46 \%$ & $46 \%$ & $40 \%$ & $42 \%$ & $54 \%$ \\
\hline Average \# selected & 4.3 & 4.2 & 4.3 & 4.5 & 3.8 & 4.3 & 4.8 \\
\hline \multicolumn{8}{|c|}{ (\% selected) } \\
\hline To get exercise & $62 \%$ & $55 \%$ & $65 \%$ & $71 \%$ & $59 \%$ & $44 \%$ & $54 \%$ \\
\hline For fun & $53 \%$ & $47 \%$ & $56 \%$ & $57 \%$ & $54 \%$ & $38 \%$ & $51 \%$ \\
\hline $\begin{array}{l}\text { Stations are near my home / work / } \\
\text { school }\end{array}$ & $41 \%$ & $43 \%$ & $40 \%$ & $34 \%$ & $38 \%$ & $49 \%$ & $58 \%$ \\
\hline To ride with friends/ family & $40 \%$ & $38 \%$ & $41 \%$ & $48 \%$ & $39 \%$ & $33 \%$ & $35 \%$ \\
\hline It's an easy way to get around & $38 \%$ & $43 \%$ & $36 \%$ & $38 \%$ & $32 \%$ & $42 \%$ & $48 \%$ \\
\hline To help the environment & $37 \%$ & $35 \%$ & $39 \%$ & $39 \%$ & $35 \%$ & $38 \%$ & $37 \%$ \\
\hline Want to try biking & $29 \%$ & $22 \%$ & $32 \%$ & $37 \%$ & $26 \%$ & $27 \%$ & $18 \%$ \\
\hline $\begin{array}{l}\text { Saves me money compared to other } \\
\text { transportation options }\end{array}$ & $27 \%$ & $31 \%$ & $26 \%$ & $34 \%$ & $20 \%$ & $31 \%$ & $29 \%$ \\
\hline $\begin{array}{l}\text { Saves me time compared to other } \\
\text { transportation options }\end{array}$ & $26 \%$ & $31 \%$ & $23 \%$ & $22 \%$ & $16 \%$ & $33 \%$ & $43 \%$ \\
\hline Don't need a bike of my own & $23 \%$ & $19 \%$ & $26 \%$ & $20 \%$ & $24 \%$ & $31 \%$ & $33 \%$ \\
\hline Don't want to rely on transit & $20 \%$ & $22 \%$ & $18 \%$ & $16 \%$ & $15 \%$ & $22 \%$ & $32 \%$ \\
\hline To get to bus or rail stops & $14 \%$ & $16 \%$ & $13 \%$ & $13 \%$ & $12 \%$ & $13 \%$ & $20 \%$ \\
\hline To get to jobs more easily & $9 \%$ & $13 \%$ & $8 \%$ & $11 \%$ & $5 \%$ & $16 \%$ & $12 \%$ \\
\hline To get to social services & $5 \%$ & $7 \%$ & $4 \%$ & $7 \%$ & $2 \%$ & $7 \%$ & $4 \%$ \\
\hline Other & $4 \%$ & $3 \%$ & $5 \%$ & $2 \%$ & $3 \%$ & $2 \%$ & $7 \%$ \\
\hline Minimum number of responses ${ }^{1}$ & 885 & 277 & 588 & 321 & 203 & 45 & 187 \\
\hline Maximum number of responses ${ }^{1}$ & 886 & 277 & 589 & 322 & 203 & 45 & 187 \\
\hline
\end{tabular}

\subsubsection{Reasons to try bike share - demographic differences}

Differences by race and income

In general, higher-income respondents of color selected fewer reasons (3.8 on average), while higherincome white respondents selected more reasons (4.8 on average). Higher-income white respondents were also significantly less likely to have stated that there are no reasons they would consider using bike share (after controlling for gender, age and city). Figure 9-1 illustrates some of the differences in percentage of respondents selecting each type of potential reason for trying bike share by race and income groups.

Many of the reasons to try bike share that fall on the more recreational end of the spectrum, including for exercise, for fun, to ride with friends and family, and giving bicycling a try, were among the more frequently cited reasons for all respondents. Each of these reasons was also more likely to be selected by 
lower-income respondents of color, although the difference was not significant in the case for riding for fun. Getting exercise was the most popular reason for respondents of color (both lower- and higherincome), and the second-highest reason for white respondents (both lower- and higher-income).

Conversely, many of the utilitarian reasons for bicycling were more likely to be selected by respondents in the higher-income white group. Reasons with a significant difference include stations' being near their home, work or school; it being an easy way to get around; saving time compared to other transportation options; not needing a bike of their own; not needing to rely on transit; and getting to bus or rail stops. The most popular reason for both white lower- and higher-income groups was because stations were near their home, work, or school. On some of the questions, for some of the groups, the small differences observed from the overall average were not significant. 


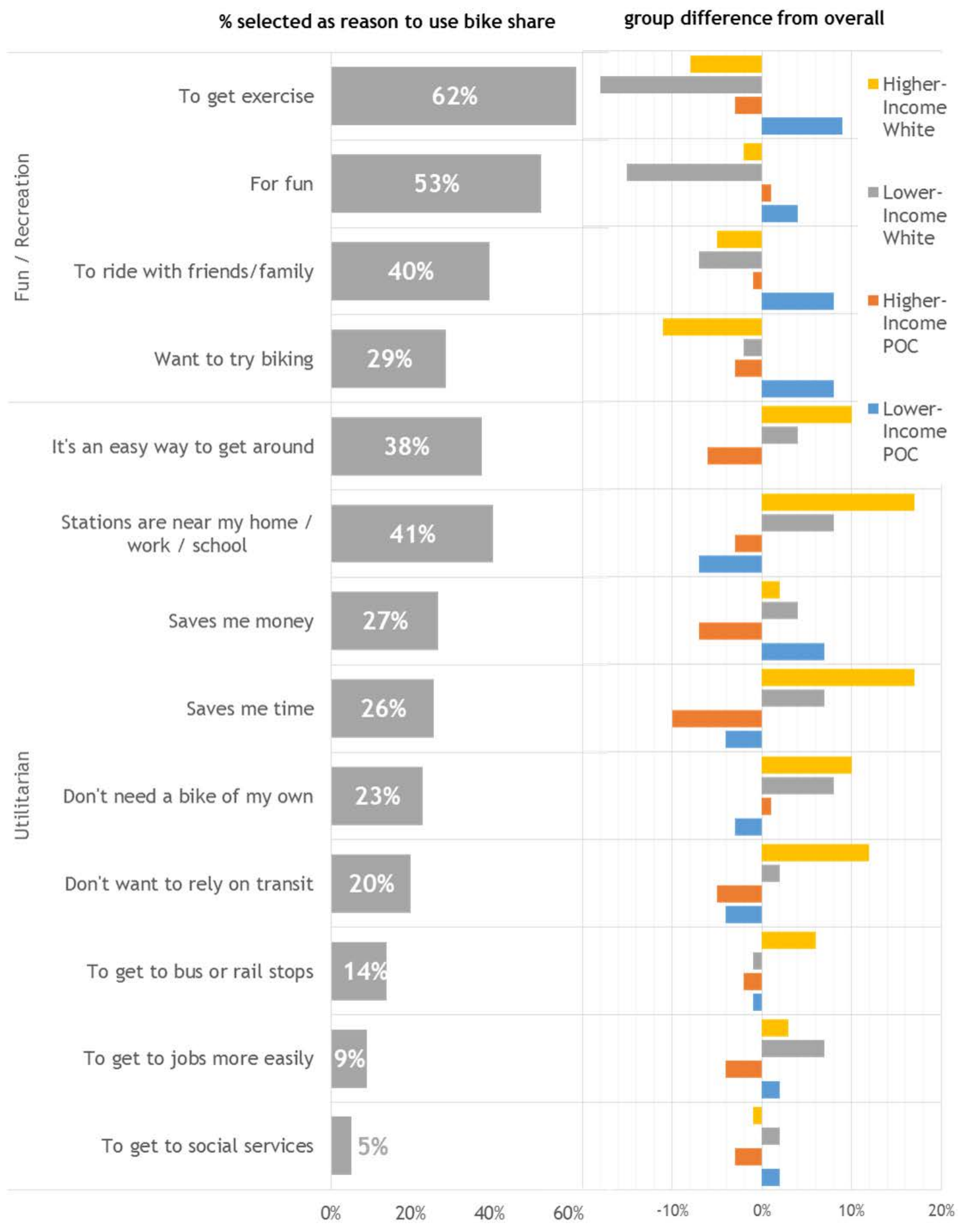

Figure 9-1 Recreational and utilitarian reasons for trying bike share, differences by race-income groups 


\section{Differences by gender}

Women were more likely than men to list some of the recreational items as reasons they would consider using bike share (or using it more): getting exercise (65\% vs. 55\%), fun (56\% vs. $47 \%$ ), and just wanting to try biking (32\% vs. $22 \%$ ). Men were a bit more likely to list saving time compared to other options (31\% to $23 \%$ ), along with several of the less frequently selected reasons such as getting to jobs (13\% to $8 \%$ ) and getting to social services ( $7 \%$ to $4 \%$ ). Women were more likely to be motivated by not having a bike of their own (which makes sense, as only a quarter of female survey respondents reported owning a bicycle, compared to $48 \%$ for men).

Differences by age

Age groups demonstrated a few differences in terms of reasons they would consider trying bike share. Respondents in the older age groups (35-54 and 55-64) were progressively less likely to select riding with friends and family as reason to try bike share (compared to those in the 18-34 age group). Viewing bike share as an easy way to get around was more likely to be cited by those in the 55-64 group, while just wanting to try biking was more likely to be cited by those in the 18-34 age group. Finally, those in the 3554 group were less likely to select not needing a bike of their own as a reason to try bike share.

\subsubsection{Reasons to try bike share - geographic differences}

Table 9-2 shows the percentage of respondents in each outreach study area that selected each of the potential reasons for using bike share. Respondents in Chicago were a bit more likely to be attracted to the recreational reasons for using bike share than those in Brooklyn and Philadelphia (although the differences on the "to get exercise" reason were not significant after controlling for sociodemographic factors). Respondents in Chicago were also less likely to view bike share as a useful alternative to transit in terms of saving time or being more reliable. Those in Brooklyn were more likely than other respondents to view bike share as potentially providing time savings and increased reliability compared to transit. 
Table 9-2 Reasons to Try Bike Share, by City and Neighborhood

\begin{tabular}{|c|c|c|c|c|c|c|c|}
\hline \multirow[b]{2}{*}{$\begin{array}{c}\text { Reasons you would consider using } \\
\text { [BssName] }\end{array}$} & \multirow[b]{2}{*}{$\begin{array}{c}\text { Able } \\
\text { and } \\
<65\end{array}$} & \multicolumn{6}{|c|}{ Able and under 65 , by outreach city and area ${ }^{1}$} \\
\hline & & $\begin{array}{c}\text { BKLN } \\
\text { Study } \\
\text { Area }\end{array}$ & $\begin{array}{c}\text { CHI } \\
\text { Study } \\
\text { Area }\end{array}$ & $\begin{array}{c}\text { PHI } \\
\text { Study } \\
\text { Areas All }\end{array}$ & $\begin{array}{c}\text { PHI } \\
\text { Study } \\
\text { Area } \\
\text { West }\end{array}$ & $\begin{array}{c}\text { PHI } \\
\text { Study } \\
\text { Area } \\
\text { North }\end{array}$ & $\begin{array}{c}\text { PHI } \\
\text { Study } \\
\text { Area } \\
\text { South }\end{array}$ \\
\hline None & $17 \%$ & $17 \%$ & $15 \%$ & $19 \%$ & $20 \%$ & $14 \%$ & $21 \%$ \\
\hline 1 or 2 reasons selected & $17 \%$ & $17 \%$ & $19 \%$ & $16 \%$ & $18 \%$ & $13 \%$ & $17 \%$ \\
\hline 3 or 4 reasons selected & $21 \%$ & $15 \%$ & $23 \%$ & $23 \%$ & $22 \%$ & $29 \%$ & $18 \%$ \\
\hline 5 or more reasons selected & $45 \%$ & $50 \%$ & $43 \%$ & $43 \%$ & $40 \%$ & $44 \%$ & $45 \%$ \\
\hline Average \# selected & 4.3 & 4.6 & 4.3 & 4.2 & 3.9 & 4.5 & 4.1 \\
\hline \multicolumn{8}{|c|}{ (\% selected) } \\
\hline To get exercise & $62 \%$ & $62 \%$ & $67 \%$ & $58 \%$ & $60 \%$ & $70 \%$ & $47 \%$ \\
\hline For fun & $53 \%$ & $55 \%$ & $60 \%$ & $48 \%$ & $51 \%$ & $51 \%$ & $42 \%$ \\
\hline $\begin{array}{l}\text { Stations are near my home / work / } \\
\text { school }\end{array}$ & $41 \%$ & $39 \%$ & $36 \%$ & $45 \%$ & $43 \%$ & $47 \%$ & $44 \%$ \\
\hline To ride with friends/ family & $40 \%$ & $36 \%$ & $49 \%$ & $36 \%$ & $33 \%$ & $39 \%$ & $34 \%$ \\
\hline It's an easy way to get around & $38 \%$ & $41 \%$ & $32 \%$ & $41 \%$ & $37 \%$ & $39 \%$ & $45 \%$ \\
\hline To help the environment & $37 \%$ & $41 \%$ & $38 \%$ & $36 \%$ & $36 \%$ & $39 \%$ & $32 \%$ \\
\hline Want to try biking & $29 \%$ & $26 \%$ & $32 \%$ & $28 \%$ & $26 \%$ & $33 \%$ & $26 \%$ \\
\hline $\begin{array}{l}\text { Saves me money compared to other } \\
\text { transportation options }\end{array}$ & $27 \%$ & $30 \%$ & $24 \%$ & $28 \%$ & $23 \%$ & $28 \%$ & $32 \%$ \\
\hline $\begin{array}{l}\text { Saves me time compared to other } \\
\text { transportation options }\end{array}$ & $26 \%$ & $34 \%$ & $16 \%$ & $27 \%$ & $17 \%$ & $30 \%$ & $32 \%$ \\
\hline Don't need a bike of my own & $23 \%$ & $24 \%$ & $24 \%$ & $23 \%$ & $20 \%$ & $25 \%$ & $23 \%$ \\
\hline Don't want to rely on transit & $20 \%$ & $29 \%$ & $11 \%$ & $20 \%$ & $22 \%$ & $18 \%$ & $21 \%$ \\
\hline To get to bus or rail stops & $14 \%$ & $16 \%$ & $20 \%$ & $10 \%$ & $8 \%$ & $11 \%$ & $9 \%$ \\
\hline To get to jobs more easily & $9 \%$ & $14 \%$ & $7 \%$ & $9 \%$ & $5 \%$ & $7 \%$ & $13 \%$ \\
\hline To get to social services & $5 \%$ & $5 \%$ & $5 \%$ & $4 \%$ & $3 \%$ & $7 \%$ & $2 \%$ \\
\hline Other & $4 \%$ & $2 \%$ & $4 \%$ & $5 \%$ & $4 \%$ & $2 \%$ & $8 \%$ \\
\hline Number of responses & 886 & 201 & 257 & 428 & 120 & 140 & 168 \\
\hline
\end{tabular}

${ }^{1}$ bold indicates category value significantly greater or less than expected ( $p<0.05$, adj. stand. Chi-square residual)

\subsubsection{Multiple reasons and current or planned bike share behavior}

We looked at several indications of whether or not people do currently or plan to use bike share based on the number of the reasons they provided for why they would consider using bike share, as shown in Figure 9-2. Those people who listed five or more reasons were much more likely to have ridden a bike share bike in the past (26\%, compared to $3 \%$ for those who listed zero reasons to try bike share), to be very likely to ride in the next six months (23\%, compared to $2 \%$ ), to be a current member ( $8 \%$, compared to $1 \%$ ), to expect to be a member in 12 months (21\%, compared to $0 \%$ ), and to agree that they would like to use bike share more than they currently do (23\%, compared to $2 \%$ ). 


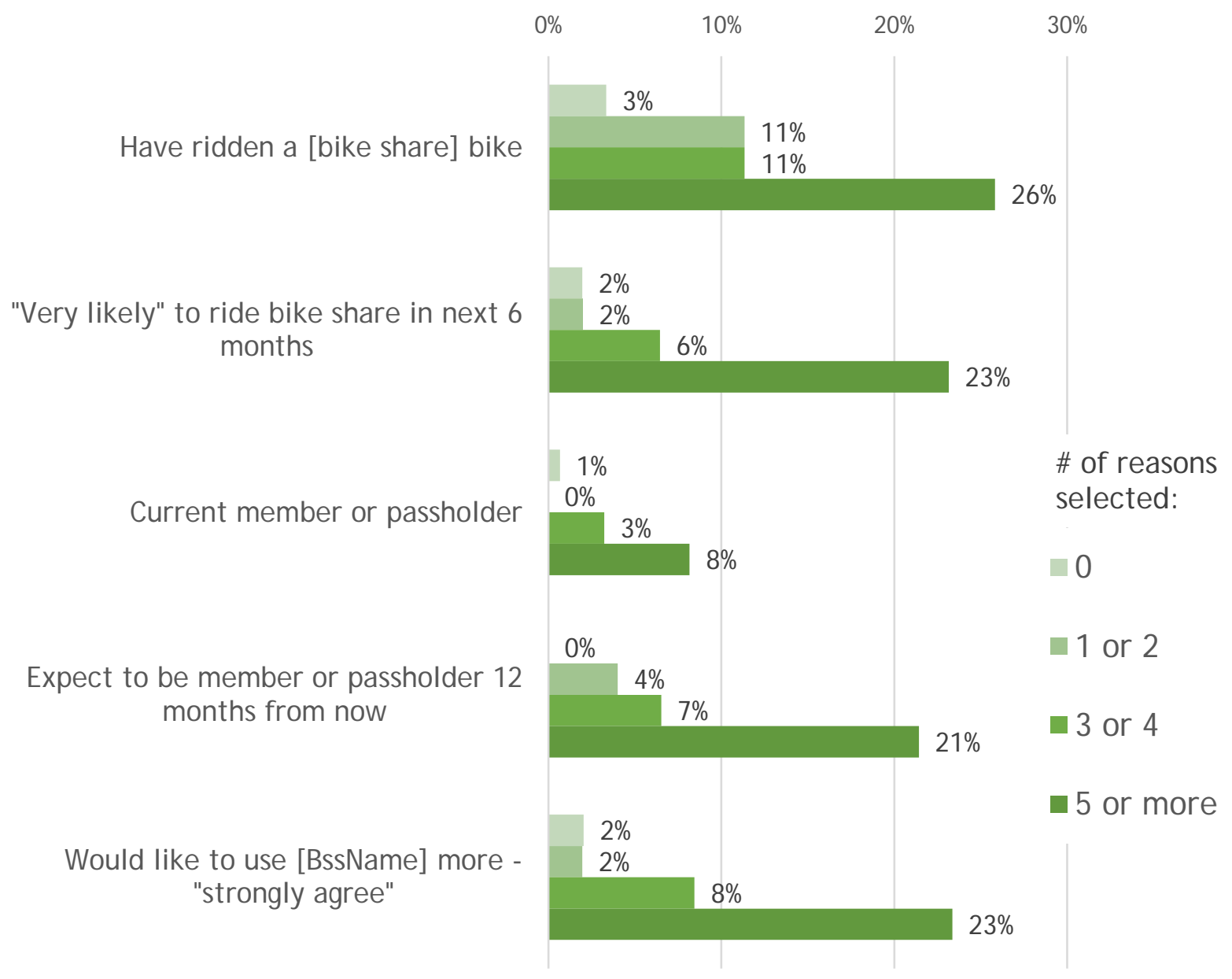

Figure 9-2 Number of reasons selected, and current/planned bike share behavior

\subsection{Efficacy of potential program changes}

A set of questions asked respondents to indicate whether certain changes to the bike share system would make them more likely to use bike share. Respondents had the options: no more likely, somewhat more likely, much more likely, or does not apply. Table 9-3 shows the percentage of respondents selecting somewhat or much more likely for each change — those who selected does not apply were excluded when calculating the percentages shown.

Discounted memberships, free transfers with public transit, and more short term options were the changes most frequently cited as making respondents more likely to use bike share (each with around 71\%-73\% stating they would be somewhat more or much more likely to use bike share. Of these, free transfers between public transportation and bike share was the most likely to be selected as making people "much more likely" to try bike share, with $47 \%$ — discounted and short term membership each had around $40 \%$ stating these would make them much more likely. 
More bike share stations, either near destinations (at 68\%) or simply close together (at 59\%) were identified by more than half of the respondents. Among those saying the lack of stations near their destinations was a big barrier to their using bike share, $86 \%$ said alleviating this issue would likely get them to ride bike share. Access to free or low-cost helmets or gear was selected by $59 \%$ of respondents. Several payment-related changes also received nearly half of the respondents stating they would make them more likely to use bike share - these include signing up or buying passes in stores rather than online (47\%) and an easier way to pay with cash (46\%).

Help finding safe ways to get around was selecting by over half of the respondents (58\%). Respondents who noted that "traffic makes riding a bike in my neighborhood feel dangerous" as a big barrier were considerably more likely than those who stated this was not a barrier or was a small barrier to state that help finding safe ways to get around would make them more likely to use the bike share system.

Having more friends or family be able to use bike share with them was selected by 52\%, and having bike share riders be more diverse was selected by 33\%.

Table 9-3 Efficacy of Potential Program Changes, by Gender and Race-Income Groups

\begin{tabular}{|c|c|c|c|c|c|c|c|}
\hline \multirow[b]{2}{*}{$\begin{array}{l}\text { Would the following changes make } \\
\text { you more likely to use [BssName] } \\
\text { (\% somewhat or much more likely) }\end{array}$} & \multirow[b]{2}{*}{$\begin{array}{c}\text { All } \\
\text { Able } \\
\text { and } \\
<65\end{array}$} & \multicolumn{2}{|c|}{ By gender ${ }^{2}$} & \multicolumn{4}{|c|}{ By race and income group ${ }^{3}$} \\
\hline & & Male & Female & $\begin{array}{l}\text { Lower- } \\
\text { Income } \\
\text { POC }\end{array}$ & $\begin{array}{l}\text { Higher- } \\
\text { Income } \\
\text { POC }\end{array}$ & $\begin{array}{l}\text { Lower- } \\
\text { Income } \\
\text { White }\end{array}$ & $\begin{array}{l}\text { Higher- } \\
\text { Income } \\
\text { White }\end{array}$ \\
\hline $\begin{array}{l}\text { Discounted membership or use } \\
\text { options }\end{array}$ & $73 \%$ & $70 \%$ & $75 \%$ & $80 \%$ & $65 \%$ & $82 \%$ & $70 \%$ \\
\hline $\begin{array}{l}\text { Free transfers between public } \\
\text { transportation and [BssName] }\end{array}$ & $72 \%$ & $69 \%$ & $73 \%$ & $77 \%$ & $66 \%$ & $93 \%$ & $66 \%$ \\
\hline $\begin{array}{l}\text { More short-term membership or pass } \\
\text { options }\end{array}$ & $71 \%$ & $66 \%$ & $73 \%$ & $80 \%$ & $65 \%$ & $75 \%$ & $64 \%$ \\
\hline $\begin{array}{l}\text { Access to free or low-cost helmets } \\
\text { and other gear }\end{array}$ & $59 \%$ & $49 \%$ & $64 \%$ & $72 \%$ & $54 \%$ & $72 \%$ & $45 \%$ \\
\hline $\begin{array}{l}\text { Option to sign up or buy passes at a } \\
\text { store instead of online }\end{array}$ & $47 \%$ & $40 \%$ & $51 \%$ & $70 \%$ & $40 \%$ & $35 \%$ & $20 \%$ \\
\hline Easier way to pay with cash & $46 \%$ & $39 \%$ & $49 \%$ & $67 \%$ & $34 \%$ & $44 \%$ & $24 \%$ \\
\hline $\begin{array}{l}\text { More [BssName] stations where I } \\
\text { want to go }\end{array}$ & $68 \%$ & $69 \%$ & $68 \%$ & $72 \%$ & $59 \%$ & $79 \%$ & $73 \%$ \\
\hline $\begin{array}{l}\text { More [BssName] stations close } \\
\text { together }\end{array}$ & $59 \%$ & $59 \%$ & $58 \%$ & $64 \%$ & $53 \%$ & $62 \%$ & $59 \%$ \\
\hline $\begin{array}{l}\text { Help finding safe ways to get where I } \\
\text { need to go }\end{array}$ & $58 \%$ & $47 \%$ & $63 \%$ & $70 \%$ & $52 \%$ & $55 \%$ & $46 \%$ \\
\hline $\begin{array}{l}\text { If more of my friends or family could } \\
\text { use [BssName] with me }\end{array}$ & $52 \%$ & $47 \%$ & $54 \%$ & $69 \%$ & $52 \%$ & $39 \%$ & $32 \%$ \\
\hline Organized rides for people like me & $49 \%$ & $39 \%$ & $53 \%$ & $71 \%$ & $50 \%$ & $28 \%$ & $19 \%$ \\
\hline If [BssName] users were more diverse & $33 \%$ & $28 \%$ & $35 \%$ & $57 \%$ & $32 \%$ & $25 \%$ & $9 \%$ \\
\hline Minimum number of responses ${ }^{1}$ & 606 & 206 & 386 & 186 & 152 & 36 & 159 \\
\hline Maximum number of responses ${ }^{1}$ & 753 & 243 & 493 & 255 & 180 & 44 & 172 \\
\hline
\end{tabular}

Includes respondents in outreach areas under 65 years and physically able to ride a bicycle.

${ }^{1}$ varies by question due to missing and "does not apply"

2 bold indicates category value significantly greater than expected ( $p<0.05$, adj. stand. Chi-square residual)

${ }^{3}$ bold indicates category value significantly greater or less than expected ( $p<0.05$, adj. stand. Chi-square residual) 
The survey also provided an open-ended question that asked respondents to describe one thing that would make them more likely to use the bike share system. Open-ended responses were coded based on themes. Reduced costs were the most frequently cited motivating change in the open-ended responses, being mentioned by $16 \%$ of respondents. Several respondents suggested that, in considering whether to use bike share or transit for a trip, they would consider the value proposition of bike share in comparison to a transit ride, particularly for one-ride payment options (such as Indego's \$4 for 30 minute ride option). One wrote: "Sometimes I just need to ride 1 mile to pick something up - then ride right back. But I'd have to pay \$4 to get up there - check it into a station - then pay another \$4 five minutes later when I need to head back;" concluding that there should be a "way to 'park' the bike for a short time when you need to pick up food or run small errands around the city." Note that some systems do have a mechanism for riders to "hold" a ride, which allows them to lock up the bike but keep the trip active, so that they can complete a trip with stops - none of the systems in the surveyed cities have this option. Another told us that one thing that would make them more likely would be if bike share "cost the same or less than riding” on transit.

Having more conveniently placed station locations (such as nearer their home or work) was cited by $9 \%$ of respondents. One respondent noted that they live "on the edge of the service area and the stations are located in areas already well served by public transit. If I could pick up and drop off bikes in the nearby neighborhoods with fewer public transit options, I'd consider giving it a try, but as it stands the only reason I might ever use it now is if I'm in the mood to take a bike ride for leisure.”

Improvements to the bikes themselves, including being lighter and easier to pedal, were cited by $7 \%$. One person told us they would like a " 3 wheel bike for seniors," while another felt that "smoother riding bikes" that were less heavy would make them more likely to try bike share. Several noted better cargo capacity, or "cargo-type bikes near grocery stores” would be welcome.

Improvement to safety, including both safety from traffic and personal safety, was cited by $7 \%$. A number noted that they would like improvement to bike lanes and facilities, such as "bike lanes TOTALLY separate from cars," and that they would ride if "it wasn't dangerous to ride in traffic.” Another hinted at personal safety, with one noted that they would like "lighted [bike share] stations" for 24-hour safety, and another stated that one thing that would make them more likely use bike share would be "feeling safer in my community (due to violence, etc.) to where I'd want to expose myself on a bike in the neighborhood.”

Getting more information about bike share was cited by 5\%, including one person who wrote that "I already had a goal to start biking for better health, I just need more insight and information” about the bike share system. Another thought that a "dedicated bike share app with time ticker and bike station finder" would make them more likely to use bike share. Note that some of the systems in the surveyed cities do include ride time-keeping capability, which highlights that the challenge may be as much about getting the existing resources in front of people as about creating new resources.

Longer time limits was cited by $5 \%$, including one who felt the time limits were inconvenient and asked "you have to check in every 30 minutes? I think that takes up a lot of time, and prolongs arriving at your destination." Another, who would ride for recreation, told us that "If I wanted to really use it instead of purchasing a bike, I would want longer time blocks (1-4 hours) to use it to go for longer rides or places where that is not a [bike share] station.”

Related to improving the bike experience, several respondents hinted at amenities that might be found in a gym-type setting, with one stating that they "wonder about cleanliness" and "knowing the last time the bike was cleaned," and another thought that "water/Gatorade machines at select stations for folks to refresh for long distances” would make them more likely to ride. 


\subsubsection{Program change efficacy - demographic differences \\ Differences by race and income}

There are some interesting differences in responses by race and income groups. In some cases, income appears to drive higher support for a particular change, in other cases race, and sometimes a combination of the two. These differences can be seen in Figure 9-3 as well as Table 9-3.

Regardless of race, lower-income respondents were usually more likely to indicate that these changes would make them more likely to use bike share. A few of the changes appeared to be particularly appealing to lower-income respondents, including the discounted memberships, free transfers with public transportation, and access to free or low-cost helmets and other gear. Most of the changes related to price and pass options were favored more by both lower-income respondent groups, with two exceptions. Being able to buy passes in a store instead of online was favored by $70 \%$ of lower-income respondents of color, but only $35 \%$ of lower-income white respondents. An easier way to pay with cash was chosen by $67 \%$ of lower-income respondents of color, but only $44 \%$ of lower-income white respondents.

Some controlling of variables did help us understand some of the relationships. Differences between demographic groups regarding free transfers between public transportation and bike share disappeared when controlling for transit use (some or most trips in the past week). Three-quarters of all transit users stated this would influence them to use bike share. Among respondents of color saying they would use bike share to just try biking, access to free or reduced-cost helmets and gear would be a large influence to get them riding bike share ( $80 \%$ stated it would be likely to get them to ride bike share). While it would seem access to a credit card would explain some of the relationship between those wanting to be able to buy passes from a store or in cash, it was more closely linked to those who reported not wanting to use a credit card. Three-quarters of respondents of color who do not want to use a credit card would be influenced by a cash option. Seventy-two percent of lower-income respondents of color without a credit card (the largest group without a credit card in our sample) would like to see a cash option. A similar proportion of lower-income respondents of color who prefer not to use a credit card would be influenced to try bike share if they could buy passes from a store instead of online.

For lower-income respondents of color, a wider variety of types of program changes appeared to be more appealing. Every change was chosen by over half of these respondents, whereas some changes received positive responses from one-third or fewer of the respondents in the other race and income groups.

Improvements related to station placement were chosen by at least half of all respondent groups. However, higher-income respondents of color seemed less motivated by station placement, either by having more stations where they needed to go or by having stations closer together.

Respondents of color, both lower- and higher-income, were more interested in changes that involve socializing with other people. Organized rides were of particular interest to respondents of color, at rates two to three times that of the lower- and higher-income white respondents. Similarly, "if more of my friends and family could use bike share" was more popular among both people of color groups compared to both white groups.

On some of the questions, for some of the groups, the small differences observed from the overall average were not significant. 


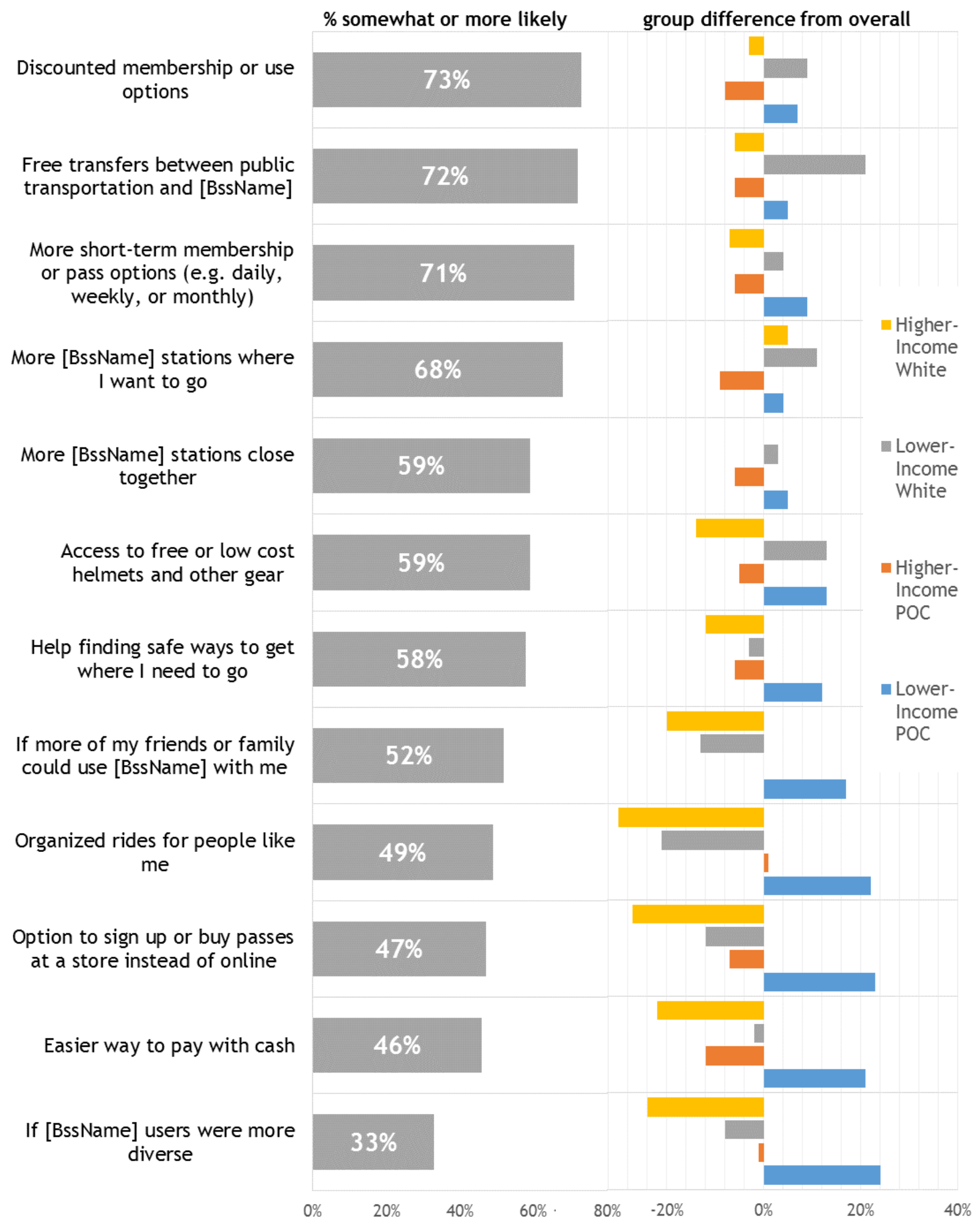

Figure 9-3 Efficacy of potential program changes, race and income differences 
Differences by gender

A number of program changes were more appealing to women than men (Figure 9-4). These included having access to free or low-cost helmets or gear (64\% of women said the change would make them more likely to try bike share, compared to $49 \%$ of men), and help finding safe biking routes (63\% to $47 \%$ ). On several other questions, observed gender differences were not significant after controlling for race-income group, age, and city; these included having more short-term membership or pass options, options to sign up at a store instead of online, an easier way to pay with cash, and organized rides for people like them. 
Free transfers between public transportation and [bike share]

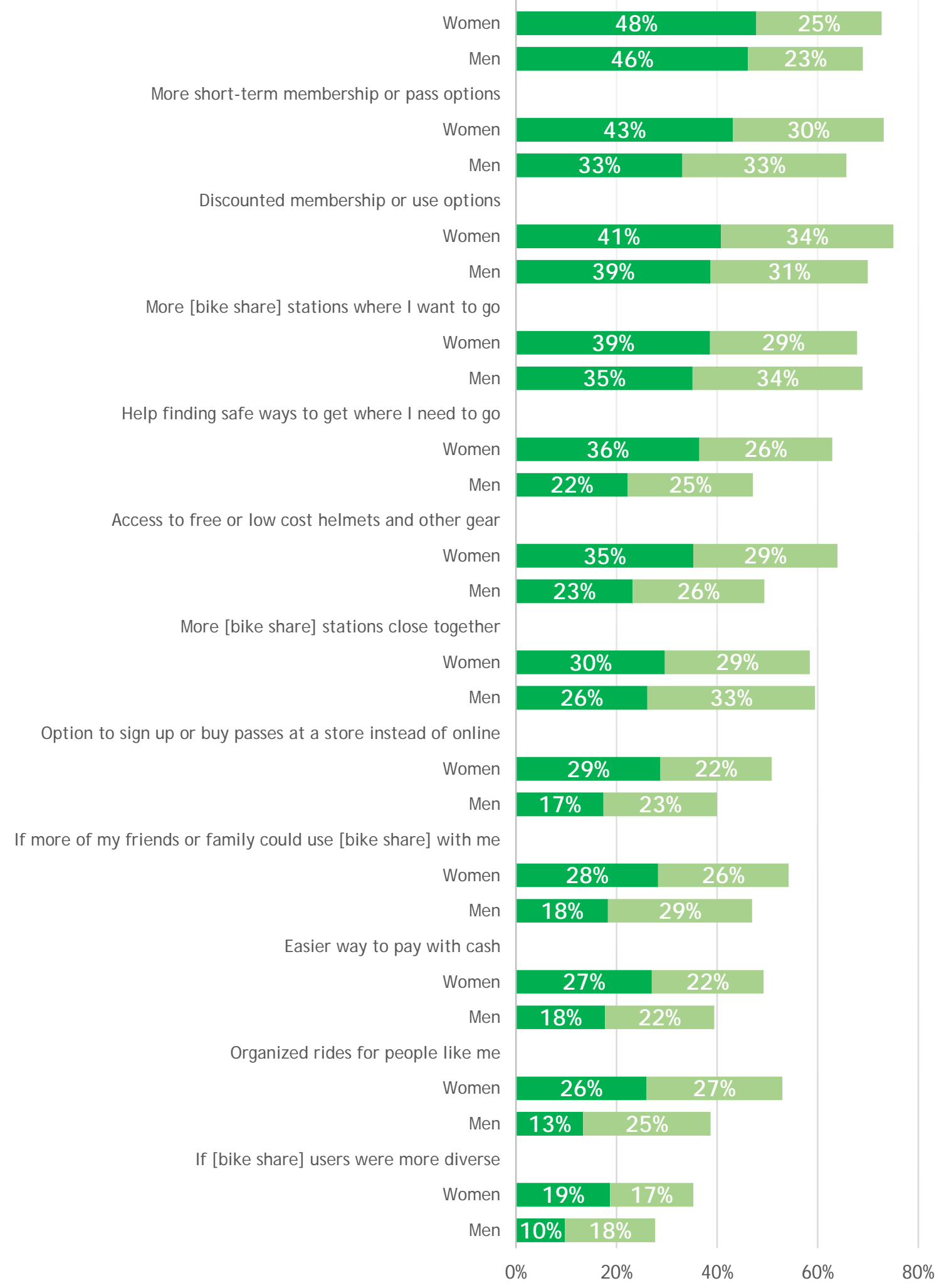

Figure 9-4 Efficacy of potential program changes, by gender 


\section{Differences by age}

On several of the potential program changes, older respondents were less likely to state that the changes would make them more likely to use bike share. Those indicating that discounted membership or use options, free transfers with public transportation, and more bike share stations where they want to go would make them more likely to use bike share each decreased with each successive older age group (35$54,55-64)$ relative to the youngest (18-34). Those in the 55-64 age group were also less likely to state that more short-term membership or pass options would make them more likely to use bike share, relative to 18-34 year olds.

\subsubsection{Program change efficacy - geographic differences}

There was a considerable amount of consistency across the different cities. Half of the 12 changes were rated similarly across all three cities, including most of the most frequently selected changes - an exception is the idea of free transfers between public transportation and bike share, which was more likely to be selected by respondents in Brooklyn (at 79\%) and less likely to be selected by those in Philadelphia (at 68\%).

Table 9-4 Efficacy of Potential Program Changes, by City and Neighborhood

\begin{tabular}{|c|c|c|c|c|c|c|c|}
\hline \multirow[b]{2}{*}{$\begin{array}{c}\text { Changes that might make you more } \\
\text { likely to use [BssName] } \\
\text { (\% more likely) }\end{array}$} & \multirow[b]{2}{*}{$\begin{array}{l}\text { Able } \\
\text { and } \\
<65\end{array}$} & \multicolumn{6}{|c|}{ Able and under 65 , by outreach city and area ${ }^{2}$} \\
\hline & & $\begin{array}{l}\text { BKLN } \\
\text { Study } \\
\text { Area }\end{array}$ & $\begin{array}{l}\text { CHI } \\
\text { Study } \\
\text { Area }\end{array}$ & $\begin{array}{l}\text { PHI } \\
\text { Study } \\
\text { Areas } \\
\text { All }\end{array}$ & $\begin{array}{l}\text { PHI } \\
\text { Study } \\
\text { Area } \\
\text { West }\end{array}$ & $\begin{array}{l}\text { PHI } \\
\text { Study } \\
\text { Area } \\
\text { North }\end{array}$ & $\begin{array}{l}\text { PHI } \\
\text { Study } \\
\text { Area } \\
\text { South }\end{array}$ \\
\hline Discounted membership or use options & $73 \%$ & $77 \%$ & $73 \%$ & $71 \%$ & $74 \%$ & $75 \%$ & $65 \%$ \\
\hline $\begin{array}{l}\text { Free transfers between public } \\
\text { transportation and [BssName] }\end{array}$ & $72 \%$ & $79 \%$ & $73 \%$ & $68 \%$ & $71 \%$ & $69 \%$ & $65 \%$ \\
\hline $\begin{array}{l}\text { More short-term membership or pass } \\
\text { options (e.g. daily, weekly, or monthly) }\end{array}$ & $71 \%$ & $71 \%$ & $71 \%$ & $70 \%$ & $77 \%$ & $74 \%$ & $61 \%$ \\
\hline $\begin{array}{l}\text { More [BssName] stations where I want } \\
\text { to go }\end{array}$ & $68 \%$ & $73 \%$ & $65 \%$ & $68 \%$ & $71 \%$ & $70 \%$ & $64 \%$ \\
\hline $\begin{array}{l}\text { Access to free or low cost helmets and } \\
\text { other gear }\end{array}$ & $59 \%$ & $64 \%$ & $57 \%$ & $58 \%$ & $59 \%$ & $63 \%$ & $55 \%$ \\
\hline More [BssName] stations close together & $59 \%$ & $64 \%$ & $58 \%$ & $57 \%$ & $56 \%$ & $57 \%$ & $57 \%$ \\
\hline $\begin{array}{l}\text { Help finding safe ways to get where I } \\
\text { need to go }\end{array}$ & $58 \%$ & $65 \%$ & $57 \%$ & $54 \%$ & $57 \%$ & $61 \%$ & $47 \%$ \\
\hline $\begin{array}{l}\text { If more of my friends or family could } \\
\text { use [BssName] with me }\end{array}$ & $52 \%$ & $55 \%$ & $59 \%$ & $46 \%$ & $50 \%$ & $51 \%$ & $38 \%$ \\
\hline Organized rides for people like me & $49 \%$ & $51 \%$ & $56 \%$ & $43 \%$ & $47 \%$ & $49 \%$ & $36 \%$ \\
\hline $\begin{array}{l}\text { Option to sign up or buy passes at a } \\
\text { store instead of online }\end{array}$ & $47 \%$ & $45 \%$ & $56 \%$ & $44 \%$ & $43 \%$ & $53 \%$ & $35 \%$ \\
\hline Easier way to pay with cash & $46 \%$ & $45 \%$ & $50 \%$ & $45 \%$ & $46 \%$ & $53 \%$ & $37 \%$ \\
\hline If [BssName] users were more diverse & $33 \%$ & $41 \%$ & $39 \%$ & $26 \%$ & $25 \%$ & $33 \%$ & $19 \%$ \\
\hline Minimum number of responses ${ }^{1}$ & 606 & 147 & 169 & 290 & 80 & 96 & 114 \\
\hline Maximum number of responses ${ }^{1}$ & 753 & 175 & 214 & 364 & 102 & 122 & 142 \\
\hline
\end{tabular}




\subsection{Barriers to using bike share}

Respondents were asked consider a variety of potential reasons for not using bike share. For each potential barrier, people were instructed to consider "how much of a barrier" each would be. Response options include not a barrier, small barrier, big barrier, or does not apply. The percentage of respondents selecting "big barrier" for each selection, ordered from highest to lowest percentage of all respondents (able and under 65) who stated each is a big barrier, are shown in Table 9-5. Those who selected "does not apply" were not considered in the percentage.

Figure 9-5 shows the breakdown of respondents who selected big barrier, small barrier, or no barrier for each of the barriers, grouped into thematic categories. Cost-related barriers were the most cited overall, with membership or use costs being too high and concern about having to pay for the bike if anything should happen to it as the two most cited barriers in that category. Not wanting to use a credit card and not having a smartphone were less frequently cited. Even for lower-income people of color with a credit card, $28 \%$ still did not want to use a credit card for bike share.

The next group of barriers, related to access and logistics, were somewhat less likely to be big barriers, but more likely to be listed as small barriers. Concerns about not knowing if there would be a bike available or a free spot to drop off a bike, or where a station to drop off a bike would be were the top barriers in this category, followed by there not being stations near the places people want to go. Only $10 \%$ indicated that not having stations near their home was a big barrier to using bike share. This reflects, in part, the fact that all respondents were selected based on living within at maximum a quarter-mile of a bike share station.

The third barrier group is related to knowledge and experience. Just over one in five respondents said that not knowing enough about how to use bike share was a big barrier, and $8 \%$ indicated as a big barrier that various aspects of bike share were too complicated - including checking out and returning bikes, or signing up for the system. Fourteen percent said that concern about the bikes' not adjusting to fit them was a big barrier. We grouped information sources by ads/news, information type sources (internet and stations/kiosks), and personal touch sources (talked to someone from BSS or community partner, went on organized bike ride, went to an event about BSS, talked to someone at an event). Regardless of type of source, between $25 \%$ and $27 \%$ of lower-income respondents of color still reported not knowing enough as a big barrier. Among lower-income respondents of color stating that signing up for bike share is too complicated, $43 \%$ did not have reliable internet access and $37 \%$ had a high school education or less.

Several other barriers were categorized into a "social” group. These included people who said that they just prefer to ride their own bike (cited by $37 \%$ as a big barrier for not using bike share), and not being able to use bike share with their children (cited by 22\%). Eight percent listed not wanting to support the bike share program as a big barrier, and $6 \%$ listed not wanting to be seen on a bike share bike as a big barrier.

The survey also provided an open-ended question that asked respondents to tell us the most important barrier keeping them from using bike share. Open-ended responses were coded based on themes. After having their own bike (cited by $17 \%$ of respondents), the cost of bike share was the most frequently cited most important barriers, with $14 \%$ of people saying this. Concerns about traffic safety were next with $11 \%$ indicating this was the most important barrier. Other frequently cited barriers included inconvenient station locations (8\%), using other transportation modes (5\%), not being able to ride (4\%), not having enough information (4\%), health conditions that prevent them from riding (4\%), concerns about the bikes 
themselves (3\%), not having or want to use credit or debit cards (3\%), and not want to ride long distances (3\%). Twelve percent told us that nothing would get them to ride bike share.

Table 9-5 Bike Share Barriers, by Gender and Race-Income Groups

\begin{tabular}{|c|c|c|c|c|c|c|c|}
\hline \multirow[b]{2}{*}{$\begin{array}{l}\text { Reasons for not using [BssName] more } \\
\text { (\% stating big barrier) }\end{array}$} & \multirow[b]{2}{*}{$\begin{array}{l}\text { All } \\
\text { Able } \\
\text { and } \\
<65\end{array}$} & \multicolumn{2}{|c|}{ By gender ${ }^{2}$} & \multicolumn{4}{|c|}{ By race and income group ${ }^{3}$} \\
\hline & & Male & Female & $\begin{array}{l}\text { Lower- } \\
\text { Income } \\
\text { POC }\end{array}$ & $\begin{array}{l}\text { Higher- } \\
\text { Income } \\
\text { POC }\end{array}$ & $\begin{array}{l}\text { Lower- } \\
\text { Income } \\
\text { White }\end{array}$ & $\begin{array}{l}\text { Higher- } \\
\text { Income } \\
\text { White }\end{array}$ \\
\hline I just prefer to ride my own bike & $37 \%$ & $43 \%$ & $33 \%$ & $27 \%$ & $36 \%$ & $43 \%$ & $45 \%$ \\
\hline Membership or use costs are too high & $37 \%$ & $33 \%$ & $39 \%$ & $48 \%$ & $33 \%$ & $40 \%$ & $18 \%$ \\
\hline $\begin{array}{l}\text { I worry that I'll have to pay for the bike } \\
\text { if anything happens to it }\end{array}$ & $34 \%$ & $26 \%$ & $38 \%$ & $52 \%$ & $31 \%$ & $17 \%$ & $10 \%$ \\
\hline $\begin{array}{l}\text { I don't want to use a credit card to use } \\
\text { bike share }\end{array}$ & $23 \%$ & $17 \%$ & $26 \%$ & $37 \%$ & $21 \%$ & $12 \%$ & $4 \%$ \\
\hline $\begin{array}{l}\text { I worry that there might not be an } \\
\text { available bike at a station to check out, } \\
\text { or a free space at a station when } \\
\text { returning a bike }\end{array}$ & $23 \%$ & $21 \%$ & $24 \%$ & $24 \%$ & $23 \%$ & $26 \%$ & $18 \%$ \\
\hline I can't use [BssName] with my child(ren) & $22 \%$ & $14 \%$ & $27 \%$ & $25 \%$ & $28 \%$ & $28 \%$ & $14 \%$ \\
\hline I don't know enough about how to use it & $21 \%$ & $16 \%$ & $23 \%$ & $34 \%$ & $19 \%$ & $8 \%$ & $7 \%$ \\
\hline $\begin{array}{l}\text { I don't know where other stations are to } \\
\text { drop off a bike }\end{array}$ & $17 \%$ & $15 \%$ & $18 \%$ & $21 \%$ & $15 \%$ & $20 \%$ & $14 \%$ \\
\hline $\begin{array}{l}\text { There aren't [BssName] stations near } \\
\text { where I want to go }\end{array}$ & $15 \%$ & $14 \%$ & $15 \%$ & $19 \%$ & $14 \%$ & $18 \%$ & $11 \%$ \\
\hline $\begin{array}{l}\text { I worry that the [BssName] bikes } \\
\text { wouldn't adjust to fit me }\end{array}$ & $14 \%$ & $16 \%$ & $14 \%$ & $23 \%$ & $15 \%$ & $7 \%$ & $3 \%$ \\
\hline I don't have a smart-phone & $13 \%$ & $11 \%$ & $14 \%$ & $24 \%$ & $5 \%$ & $7 \%$ & $1 \%$ \\
\hline $\begin{array}{l}\text { There aren't [BssName] stations near } \\
\text { my home }\end{array}$ & $10 \%$ & $10 \%$ & $10 \%$ & $11 \%$ & $9 \%$ & $5 \%$ & $10 \%$ \\
\hline $\begin{array}{l}\text { I just don't want to support the } \\
\text { [BssName] program }\end{array}$ & $8 \%$ & $7 \%$ & $9 \%$ & $14 \%$ & $10 \%$ & $0 \%$ & $1 \%$ \\
\hline $\begin{array}{l}\text { Checking out and returning [BssName] } \\
\text { bikes is too complicated }\end{array}$ & $8 \%$ & $6 \%$ & $9 \%$ & $14 \%$ & $7 \%$ & $0 \%$ & $2 \%$ \\
\hline $\begin{array}{l}\text { Signing up for [BssName] is too } \\
\text { complicated }\end{array}$ & $8 \%$ & $6 \%$ & $9 \%$ & $13 \%$ & $7 \%$ & $3 \%$ & $1 \%$ \\
\hline $\begin{array}{l}\text { I don't want to be seen on a [BssName] } \\
\text { bike }\end{array}$ & $6 \%$ & $6 \%$ & $6 \%$ & $9 \%$ & $4 \%$ & $8 \%$ & $4 \%$ \\
\hline Minimum number of responses ${ }^{1}$ & 458 & 145 & 299 & 150 & 94 & 25 & 110 \\
\hline Maximum number of responses ${ }^{1}$ & 719 & 233 & 469 & 237 & 164 & 42 & 175 \\
\hline
\end{tabular}




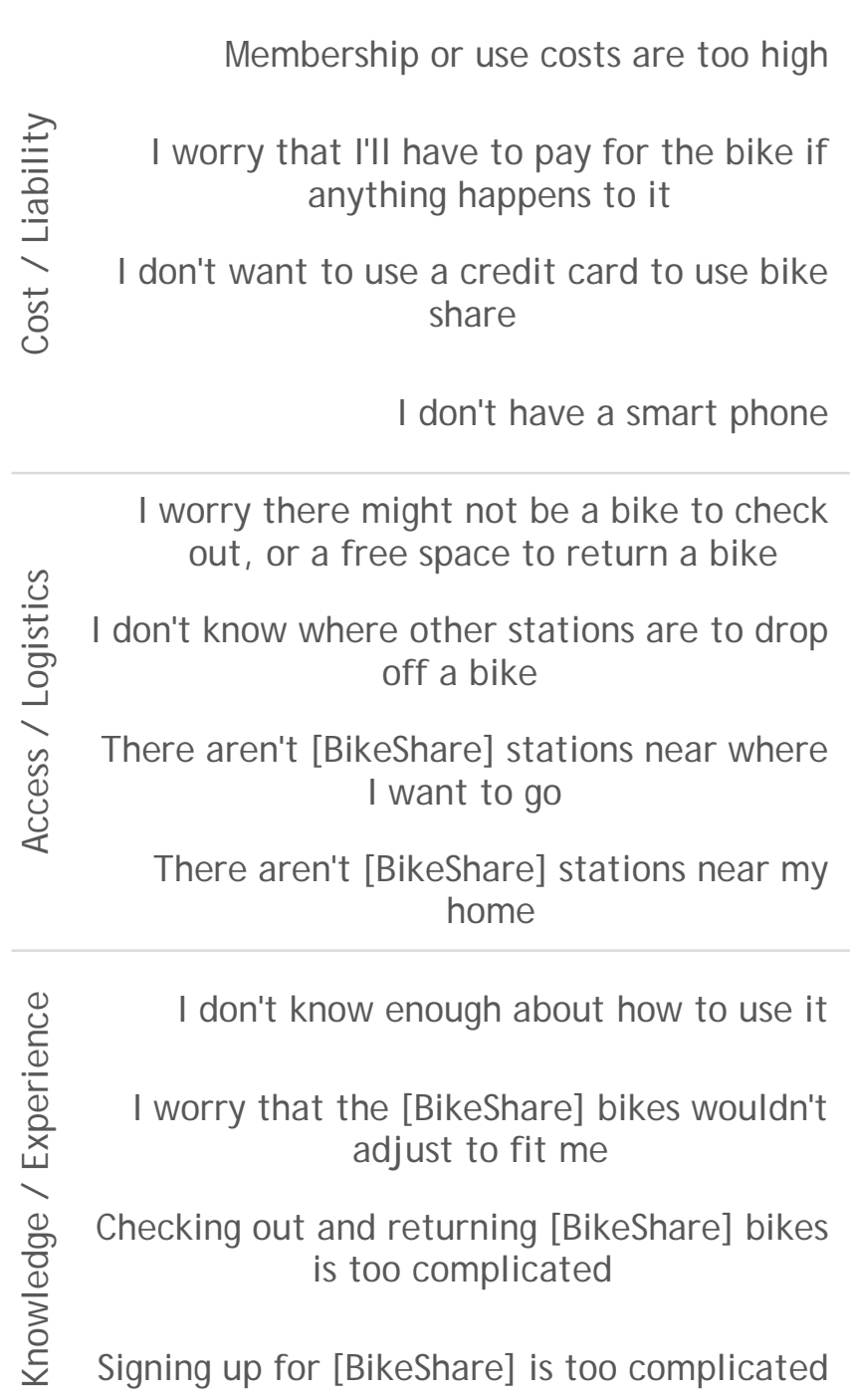

I just prefer to ride my own bike

I can't use [BikeShare] with my child(ren)

$\overline{\frac{\pi}{8}}$

I just don't want to support the [BikeShare] program

I don't want to be seen on a [Bikeshare] bike

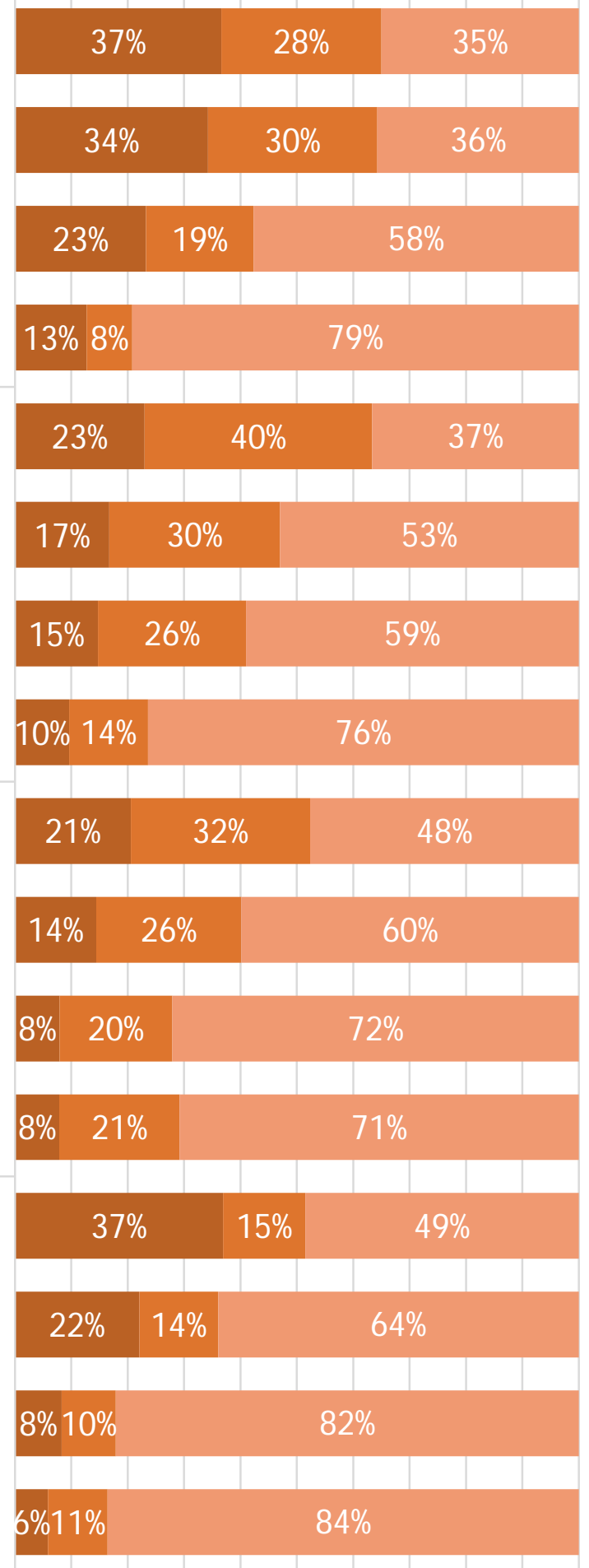

- Big barrier $\square$ Small barrier $\quad$ Not a barrier

\section{Figure 9-5 Bike share barrier breakdown}




\subsubsection{Bike share barriers - demographic differences \\ Differences by race and income}

There are several differences in barriers by race and income. Figure 9-6 shows the overall percentage of respondents noting each barrier was a big barrier, and the degree to which respondents in each of four race and income groups differed from the overall average.

On the cost-related barrier questions, differences emerged by both income and race. Lower-income respondents were more likely to list each as a big barrier, and respondents of color were more likely to list them as a big barrier. In many cases, the differences were significant. The barriers of having to pay for the bike if anything happens to it and not wanting to use a credit card suggest a concern around being on the hook for unexpected costs that appears to be considerable for respondents of color (and particularly those who are lower-income), and nearly negligible for higher-income white respondents. We received some rich information on open-ended questions from lower-income respondents of color on why they would not want to pay with a credit or debit card. For those with only a debit card, "just making sure [they] have the funds [in the account] at the time of purchase" was a barrier, while another told us that "if something happens to the bike, I can't afford to replace or pay for it.” Even for those not citing their ability to pay, use of a credit or debit card was still a barrier. One person told us that "I don't like using debit or credit cards, just in case if I were to get mugged and jumped for the bike then I would be charged . . . I would rather get a cheap bike stolen from me.” Another said that, even though they had a personal credit and debit card, they "don't need or want headaches with billing and extra fees in [their] life." Not having a smartphone was cited by $24 \%$ of lower-income respondents of color, much higher than any other group.

On the access and logistics questions, there were few differences by race or income. Lower-income respondents of color were a bit more likely to list not knowing where there are other stations to drop off a bike as a big barrier; however, this difference (at $21 \%$ in this group to $17 \%$ overall) was not significant after controlling for gender, age, and city. The general parity among groups in this category may have to do with the fact that all respondents surveyed, regardless of race and income group, lived within a short distance of a bike share station — hence, similar responses on these access questions would make sense.

For barriers around knowledge and experience, lower-income respondents of color were significantly more likely to state each of these barriers as big barriers. Compared to higher-income white respondents, these differences become stark: $34 \%$ to $7 \%$ on not knowing enough about how to use bike share as a big barrier, $23 \%$ to $3 \%$ on worrying that the bikes might not adjust to fit, $14 \%$ to $2 \%$ on concerns about aspects of the sign-up being too complicated and $13 \%$ to $1 \%$ on concerns about the check-out process being too complicated. On open ended responses, several lower-income respondents of color indicated that not having adequate information about the system or available discounts was keeping them from using bike share. One person told us that they "need information on the [discount program] because I would love to ride as opposed to walking." Another stated that that biggest barrier for them was that the "don't know about it - [I] just see them in my neighborhood, but how do I use it - it seems expensive." For these people, not knowing the details of the available discounts or how to use the system is preventing them from using bike share.

The barriers categorized as social barriers are a bit more mixed in terms of differences among these groups. Higher-income white respondents were most likely to cite a preference for using their own bike, while lower-income respondents of color were least likely to cite this. For lower-income respondents of color, if they owned a bike but did not ride it in the past week, their preference toward their own bike mostly disappears (dropping from $26 \%$ to $8 \%$ ). However, the preference toward their own bike did not erode much for the other groups even if they did not ride in the past week, suggesting something else is 
going on. The inability to use bike share with children was least likely to be cited by higher-income white respondents, but there was no difference among the other groups. People of color were more likely to list not wanting to support the bike share program as a big barrier (14\% of lower-income and $10 \%$ of higherincome respondents of color listed this as a big barrier, compared to $1 \%$ or less of white respondents). Not wanting to be seen on a bike share bike was cited as a big barrier by $8 \%-9 \%$ of lower-income respondents, and by $4 \%$ of higher-income respondents, regardless of race; however, this difference was not significant after controlling for gender, age, and city. 


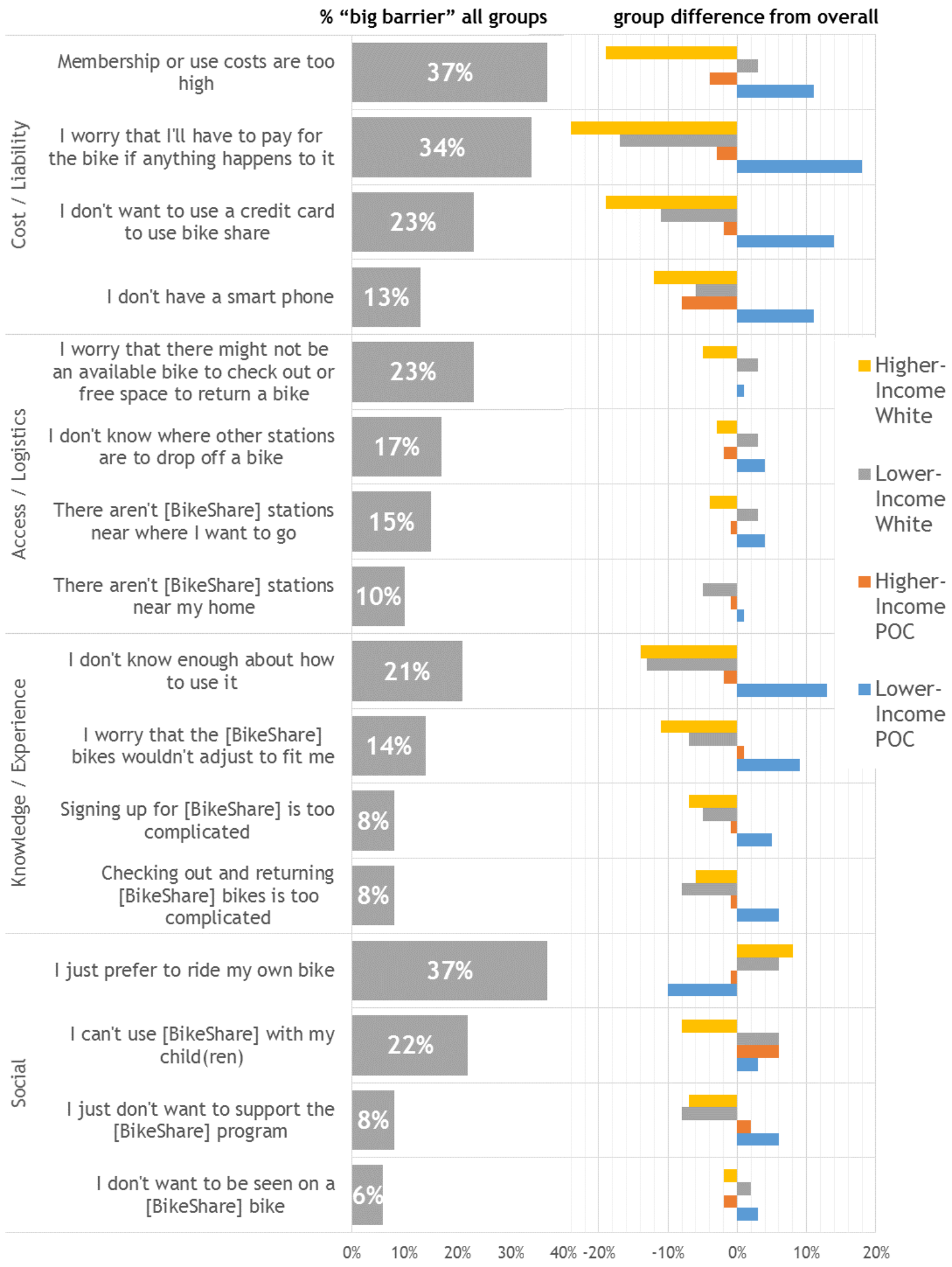

Figure 9-6 Race and income differences for bike share barriers 
Figure 9-7 shows the average number of items rated as big barriers to using bike share by members of each of these four groups of respondents. As with the barriers to bicycling, those in the lower-income people of color group rated more barriers as big, at an average of 2.5 items per respondent, compared to 1.8 for the higher-income people of color group, 2.0 for the lower-income white group, and 1.4 for the higher-income white group.

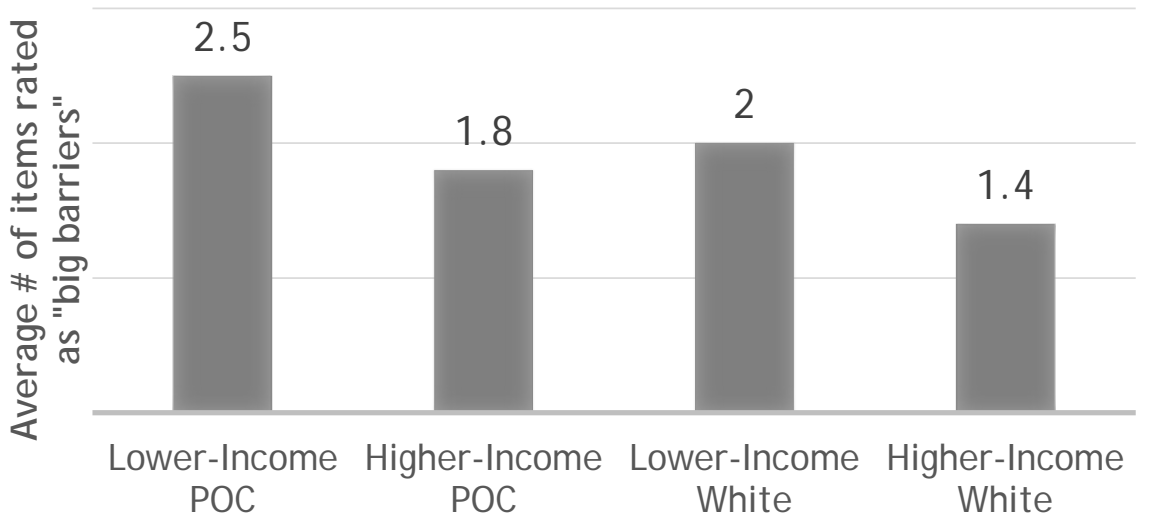

Figure 9-7 Average number of items rated as a "big barrier" to bike share, by race and income groups

Differences by gender

Although women were more likely than men to view liability-related cost concerns, including what would happen if the bike were lost or damaged, and not wanting to use a credit card, as big barriers, these differences were not significant after controlling for other factors (race-income group, age, and city). On many of the other barriers, there were not statistical differences between men and women. Among the few for which we observed a difference were concerns around not being able to use bike share with their children (a big barrier for $27 \%$ of women compared to $14 \%$ of men), concerns about not knowing enough about how to use bike share (a big barrier for $23 \%$ compared to $16 \%$ of men), and preferring to ride their own bike (43\% to 33\%), although the latter two differences were not significant after controlling for other factors. Finally, after controlling for other factors (race-income group, age, city), women were significantly less likely than men to state that concerns about the bike adjusting to fit them would be a big barrier.

Differences by age

Controlling for race-income group, age, and city, older respondents were more likely to state that not having a smart phone was a big barrier to using bike share, and were less likely to state that not being able to use the bike share system with their children was a big barrier. Older respondents were also more likely to state that not wanting to use a credit card was a big barrier to using bike share. 


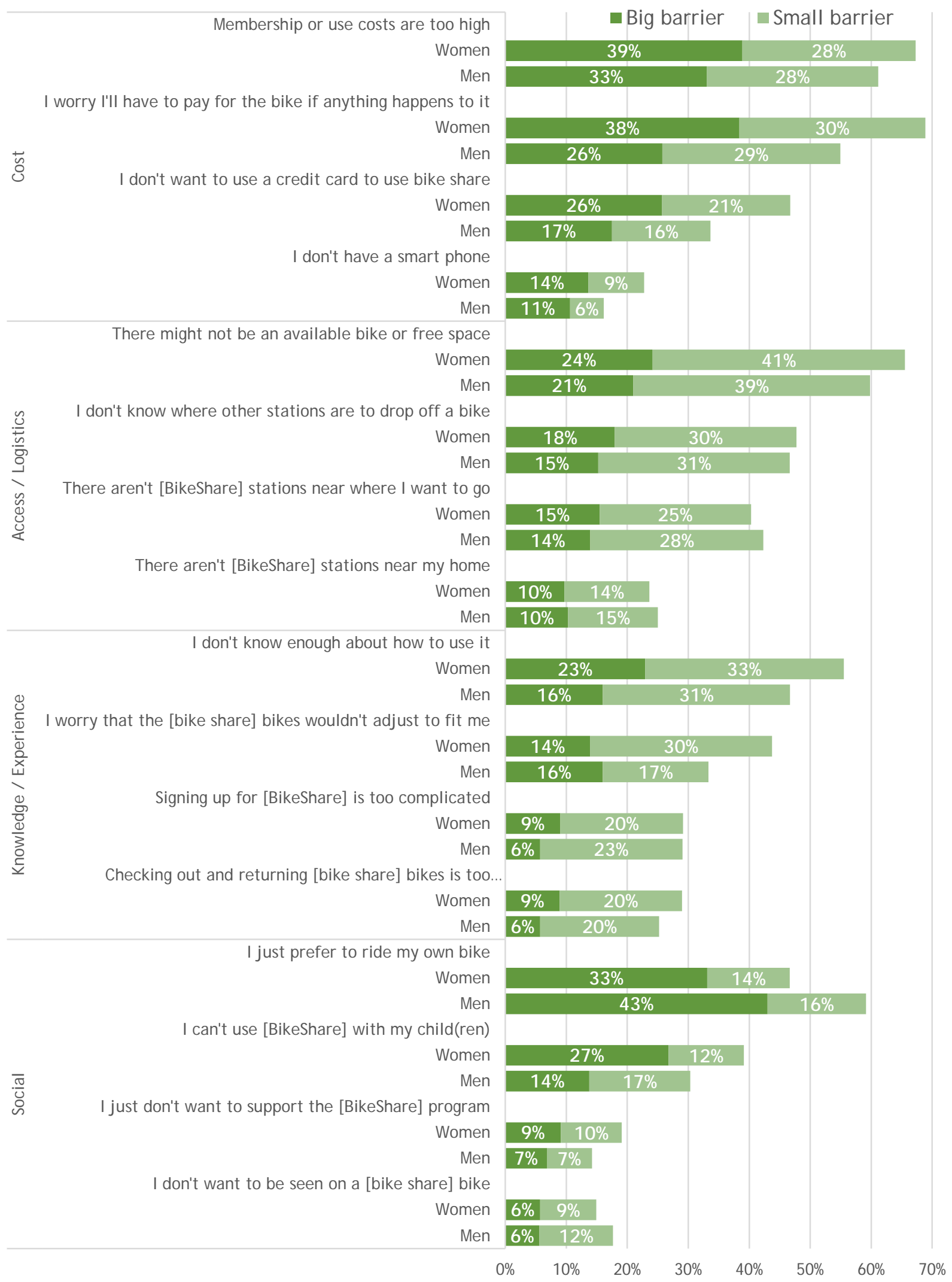

Figure 9-8 Barriers to using bike share, by gender 


\subsubsection{Bike share barriers - geographic differences}

There were several differences in barriers among the three cities. Cost-related barriers were often less of a barrier for the Philadelphia respondents, though there was some inconsistency among the three study areas within the city. Philadelphia respondents were also least likely to cite some of the logistical and knowledge barriers, including not knowing how to use the system, or that the system for signing up or checking out bikes was too complicated.

Brooklyn respondents were more likely to cite station-related barriers, including not having stations where they want to go and not knowing where other stations were. This may reflect the fact that the Brooklyn stations are on the edge of the Citi Bike system, so that it is not possible to use the bikes to travel in certain directions. Brooklyn respondents were also most likely to indicate that they didn't want to be seen on a bike share bike or that they did not want to support the system; these were cited as big barriers for $12 \%$ and $15 \%$ of the Brooklyn respondents, respectively. They were also most likely to say that they just preferred using their own bike.

Chicago respondents were more concerned about having to pay for the bike if anything happened, but this difference was not significant after controlling for race-income group, gender, and age. They also cited lack of knowledge as a big barrier more often. 
Table 9-6 Bike Share Barriers, by City and Neighborhood

\begin{tabular}{|c|c|c|c|c|c|c|c|}
\hline \multirow[b]{2}{*}{$\begin{array}{c}\text { Reasons for not using [bike share] } \\
\text { more } \\
\text { (\% stating big barrier) }\end{array}$} & \multirow[b]{2}{*}{$\begin{array}{l}\text { Able } \\
\text { and } \\
<65\end{array}$} & \multicolumn{6}{|c|}{ Able and under 65, by outreach city and area 2} \\
\hline & & $\begin{array}{l}\text { BKLN } \\
\text { Study } \\
\text { Area }\end{array}$ & $\begin{array}{l}\text { CHI } \\
\text { Study } \\
\text { Area }\end{array}$ & $\begin{array}{l}\text { PHI } \\
\text { Study } \\
\text { Areas } \\
\text { All }\end{array}$ & $\begin{array}{l}\text { PHI } \\
\text { Study } \\
\text { Area } \\
\text { West }\end{array}$ & $\begin{array}{l}\text { PHI } \\
\text { Study } \\
\text { Area } \\
\text { North }\end{array}$ & $\begin{array}{l}\text { PHI } \\
\text { Study } \\
\text { Area } \\
\text { South }\end{array}$ \\
\hline Membership or use costs are too high & $37 \%$ & $48 \%$ & $41 \%$ & $29 \%$ & $28 \%$ & $38 \%$ & $21 \%$ \\
\hline $\begin{array}{l}\text { I worry that I'll have to pay for the bike } \\
\text { if anything happens to it }\end{array}$ & $34 \%$ & $35 \%$ & $44 \%$ & $28 \%$ & $35 \%$ & $31 \%$ & $20 \%$ \\
\hline $\begin{array}{l}\text { I don't want to use a credit card to use } \\
\text { bike share }\end{array}$ & $23 \%$ & $26 \%$ & $27 \%$ & $20 \%$ & $21 \%$ & $26 \%$ & $13 \%$ \\
\hline I don't have a smart phone & $13 \%$ & $15 \%$ & $15 \%$ & $11 \%$ & $10 \%$ & $13 \%$ & $9 \%$ \\
\hline $\begin{array}{l}\text { I worry that there might not be an } \\
\text { available bike at a station to check out, } \\
\text { or a free space at a station when } \\
\text { returning a bike }\end{array}$ & $23 \%$ & $28 \%$ & $26 \%$ & $19 \%$ & $23 \%$ & $21 \%$ & $14 \%$ \\
\hline $\begin{array}{l}\text { There aren't [BssName] stations near } \\
\text { where I want to go }\end{array}$ & $15 \%$ & $22 \%$ & $11 \%$ & $13 \%$ & $17 \%$ & $11 \%$ & $13 \%$ \\
\hline $\begin{array}{l}\text { There aren't [BssName] stations near } \\
\text { my home }\end{array}$ & $10 \%$ & $12 \%$ & $12 \%$ & $7 \%$ & $7 \%$ & $2 \%$ & $11 \%$ \\
\hline $\begin{array}{l}\text { I don't know where other stations are to } \\
\text { drop off a bike }\end{array}$ & $17 \%$ & $24 \%$ & $19 \%$ & $12 \%$ & $10 \%$ & $14 \%$ & $12 \%$ \\
\hline I don't know enough about how to use it & $21 \%$ & $23 \%$ & $27 \%$ & $16 \%$ & $19 \%$ & $20 \%$ & $9 \%$ \\
\hline $\begin{array}{l}\text { I worry that the [BssName] bikes } \\
\text { wouldn't adjust to fit me }\end{array}$ & $14 \%$ & $17 \%$ & $18 \%$ & $12 \%$ & $16 \%$ & $12 \%$ & $8 \%$ \\
\hline $\begin{array}{l}\text { Signing up for [BssName] is too } \\
\text { complicated }\end{array}$ & $8 \%$ & $13 \%$ & $10 \%$ & $4 \%$ & $1 \%$ & $5 \%$ & $6 \%$ \\
\hline $\begin{array}{l}\text { Checking out and returning [BssName] } \\
\text { bikes is too complicated }\end{array}$ & $8 \%$ & $12 \%$ & $12 \%$ & $4 \%$ & $2 \%$ & $5 \%$ & $4 \%$ \\
\hline $\begin{array}{l}\text { I don't want to be seen on a [BssName] } \\
\text { bike }\end{array}$ & $6 \%$ & $12 \%$ & $4 \%$ & $4 \%$ & $4 \%$ & $4 \%$ & $5 \%$ \\
\hline $\begin{array}{l}\text { I can't use [BssName] with my } \\
\text { child(ren) }\end{array}$ & $22 \%$ & $24 \%$ & $26 \%$ & $19 \%$ & $20 \%$ & $15 \%$ & $22 \%$ \\
\hline $\begin{array}{l}\text { I just don't want to support the } \\
\text { [BssName] program }\end{array}$ & $8 \%$ & $15 \%$ & $9 \%$ & $5 \%$ & $1 \%$ & $5 \%$ & $7 \%$ \\
\hline I just prefer to ride my own bike & $37 \%$ & $46 \%$ & $29 \%$ & $37 \%$ & $33 \%$ & $23 \%$ & $49 \%$ \\
\hline Minimum number of responses ${ }^{1}$ & 458 & 105 & 127 & 226 & 59 & 73 & 85 \\
\hline Maximum number of responses ${ }^{1}$ & 719 & 164 & 209 & 346 & 98 & 118 & 131 \\
\hline
\end{tabular}

\subsubsection{Efficacy of program changes in addressing specific barriers}

We sought to understand if certain potential program changes were more effective for people who noted big barriers that might be addressed by those changes. For example, for people who indicated that "bike share membership or use costs were too high" was a big barrier, did changes related to reducing cost barriers (such as "providing discounted membership or use options") make them much more likely to use bike share (Table 9-7)? Note that in comparison to Table 9-3, this table just looks at those stating the change would make them "much more likely" to use bike share (and does not include those who would be somewhat more likely to use bike share with each change). 
A number of changes appear to be particularly effective for respondents who said that "bike share membership or use costs are too higher" constituted a big barrier compared to respondents who said this was a small barrier or not a barrier. Half or more of the respondents who noted this as a big barrier indicated that that would be much more likely to use bike share if there were discounted membership or use options, free transfers with public transportation, and more options for short-term membership or passes. People who said this was a small barrier or not a barrier were less likely to be swayed by these changes.

Around a third of those who noted that worrying about having to pay for the bike was a big barrier indicated that an easier way to pay with cash would make them much more likely to use bike share. For those for whom not wanting to use a credit card was a big barrier, $43 \%-44 \%$ indicated that easier ways to pay with cash and the option to sign up or buy passes at a store instead of online would make them much more likely to use bike share. Among those who indicated these barriers were small (or not barriers), only $15 \%-18 \%$ felt these changes would make them much more likely to use bike share.

Among people who indicated that not having bike share stations near their desired destinations was a big barrier, between $52 \%$ and $60 \%$ indicated that free transfers with public transportation, more stations close together, and more stations where they want to go would make them much more likely to use bike share, considerably more than among people who didn't list this as a big barrier. The numbers were comparable for those who noted that not having bike share stations near their home was a big barrier.

"Organized rides for people like me" and having more friends or family able to use bike share with them were changes that were more appealing to people who listed as a big barrier "I don't know enough about how to use" bike share, and that signing up is too complicated (about a third of those who listed these as big barriers indicated the above changes would make them much more likely to use bike share). For those who said that concerns that the bike would not adjust to fit them, organized rides for people like them were much more effective than for those who listed this as a small barrier (or not a barrier).

For people who indicated that riding a bike could make them a target for police attention, or cause them to be harassed or a victim of crime, we looked at the effect of organized rides, having friends or family ride with them, more diversity in bike share users, and help finding safe ways to get where they need to go. People for whom concern about police attention was a big barrier were more likely to state that each of these changes would make them much more likely to use bike share (31\% to $47 \%$ said so, compared to $10 \%-25 \%$ for those who didn't note police attention as a big barrier). For those concerned that riding a bike could cause them to be harassed or the victim of a crime, each of these changes except organized rides was more appealing than they were for those who didn't list harassment or crime as a big barrier. 
Table 9-7 Efficacy of Program Changes, by Perceived Barrier

\begin{tabular}{|c|c|c|}
\hline \multirow{2}{*}{$\begin{array}{l}\text { Barriers, and potential changes } \\
\text { Barrier: Membership or use costs are too high }\end{array}$} & \multicolumn{2}{|c|}{$\begin{array}{c}\text { Percent indicating each change would } \\
\text { make them "much more likely" to use bike } \\
\text { share, among those who said the barriers } \\
\text { was: }\end{array}$} \\
\hline & Big Barrier $(n=248)$ & Small/ not a barrier \\
\hline Discounted membership or use options & $55 \%$ & $30 \%$ \\
\hline Free transfers between public transportation and bike share & $57 \%$ & $38 \%$ \\
\hline More short term membership or pass options & $50 \%$ & $30 \%$ \\
\hline $\begin{array}{l}\text { Barrier: I worry that I'II have to pay for the bike if anything } \\
\text { happens to it }\end{array}$ & Big Barrier $(n=241)$ & Small/ not a barrier \\
\hline Easier way to pay with cash & $32 \%$ & $16 \%$ \\
\hline Barrier: I don't want to use a credit card to use bike share & Big Barrier $(n=160)$ & Small/ not a barrier \\
\hline Easier way to pay with cash & $44 \%$ & $15 \%$ \\
\hline Option to sign up or buy passes at a store instead of online & $43 \%$ & $18 \%$ \\
\hline $\begin{array}{l}\text { Barrier: There aren't [BssName] stations near where I want to } \\
\text { go }\end{array}$ & Big Barrier $(n=90)$ & Small/ not a barrier \\
\hline Free transfers between public transportation and [bike share] & $59 \%$ & $41 \%$ \\
\hline More [bike share] stations close together & $52 \%$ & $20 \%$ \\
\hline More [bike share] stations where I want to go & $60 \%$ & $30 \%$ \\
\hline Barrier: I don't know enough about how to use [BssName] & Big Barrier $(n=141)$ & Small/ not a barrier \\
\hline Organized rides for people like me & $33 \%$ & $15 \%$ \\
\hline If more of my friends or family could use [BssName] with me & $35 \%$ & $19 \%$ \\
\hline Barrier: I worry the [BssName] bikes won't adj ust to fit me & Big Barrier $(n=97)$ & Small/ not a barrier \\
\hline Organized rides for people like me & $31 \%$ & $16 \%$ \\
\hline Barrier: Signing up for [BssName] is too complicated & Big Barrier $(n=49)$ & Small/ not a barrier \\
\hline Organized rides for people like me & $33 \%$ & $17 \%$ \\
\hline If more of my friends or family could use [BssName] with me & $35 \%$ & $20 \%$ \\
\hline $\begin{array}{l}\text { Barrier: Riding a bike could make me a target for police } \\
\text { attention }\end{array}$ & Big Barrier $(n=36)$ & Small/ not a barrier \\
\hline Organized rides for people like me & $31 \%$ & $18 \%$ \\
\hline If more of my friends or family could use bike share with me & $39 \%$ & $19 \%$ \\
\hline If bike share users were more diverse & $33 \%$ & $10 \%$ \\
\hline Help finding safe ways to get where I need to go & $47 \%$ & $25 \%$ \\
\hline $\begin{array}{l}\text { Barrier: Riding a bike could cause me to be harassed or a victim } \\
\text { of crime }\end{array}$ & Big Barrier $(n=107)$ & Small/ not a barrier \\
\hline Organized rides for people like me & $22 \%$ & $18 \%$ \\
\hline If more of my friends or family could use bike share with me & $32 \%$ & $18 \%$ \\
\hline If bike share users were more diverse & $20 \%$ & $10 \%$ \\
\hline Help finding safe ways to get where I need to go & $37 \%$ & $24 \%$ \\
\hline
\end{tabular}




\section{FURTHER ANALYSIS}

This chapter of the report transitions from looking at the general study target population, and focuses analysis in on specific subgroups or topics of inquiry. As explained in chapter 6 , the analysis to this point was limited to responses from people in the BBSP outreach areas in order to understand the views and experiences of people living in areas targeted for BBSP equity efforts. Further it was limited to those who stated that they were physically able to ride a bicycle and were under 65 years of age. This was done because those not able to ride a standard bicycle are not likely to participate in the current bike share system and because older adults’ responses from were often very different from younger adults'.

First, we examine differences between responses from the control study areas and the study areas targeted for BBSP outreach, to help understand the effects of the outreach efforts. Next, we explore subgroups within the larger sample. Increasing bike share use among people not physically able to ride a standard bicycle and among older adults will likely require approaches different from those that work with the respondents analyzed in prior chapters. The analysis of older adults focuses on older adults of color because of the small number of older white adults in our survey sample. Next, we examined respondents who are able to ride and under 65, but who indicated that they were not interested in riding a bicycle for transportation. In addition, we look more closely at respondents who have children living in their household, as well as any observed differences between Hispanic and Black respondents.

\subsection{Outreach areas compared to control areas}

In addition to the BBSP outreach areas, the project team also surveyed residents of two comparison neighborhoods - one each in Chicago and Brooklyn. These control areas were nearby the outreach areas that also received bike share stations, but were not the focus of BBSP outreach. Although the outreach might be expected to have a relatively minor impact upon the average resident of the outreach neighborhood (particularly since the survey didn't attempt to identify people who had shown prior interest in bike share), the control areas were included to see if differences could be observed. Information about the demographics of the respondents in the control neighborhoods were shown in Table 5-3 and Table 5-4 in Sections 5.2 and 5.3. Respondents in the Chicago control neighborhood are very similar to those in the outreach neighborhood, though poverty rates are slightly higher. On the other hand, the Brooklyn control neighborhood respondents matched well on income, but were more likely to be Hispanic and less likely to be Black. They were also younger.

As with the analysis in the other main findings chapters, the data presented here are limited to respondents who are under 65 years of age and physically able to ride a bicycle. We compared the outreach and control areas in terms of how they received information about bike share, experiences they have had with bike share, opinions about bike share, and knowledge about bike share. We also looked at reasons for trying bike share, changes that might make them more likely to use bike share, and barriers to bicycling or using bike share. 
In terms of how people receive information about bike share (Table 10-1) few significant differences were observed. On the question of whether they had gotten information from the BBSP project partner in the city, respondents in the outreach area of Chicago were three times more likely to have gotten information from Go Bronzeville than those in the control area (6\% to $2 \%$ ), while in Brooklyn, respondents in the outreach areas were four times more likely to have received information from BSRC (4\% to 1\%); given the geographic focus of these organizations, these differences make sense.

Table 10-1 Sources of Bike Share Information for Outreach and Control Areas

\begin{tabular}{|c|c|c|c|c|}
\hline \multirow[b]{2}{*}{ Where have you gotten information about [BssName]? } & \multicolumn{2}{|c|}{ Chicago $^{1}$} & \multicolumn{2}{|c|}{ Brooklyn ${ }^{1}$} \\
\hline & $\begin{array}{c}\text { BBSP } \\
\text { Outreach } \\
\text { Area }\end{array}$ & $\begin{array}{c}\text { Control } \\
\text { Area }\end{array}$ & $\begin{array}{c}\text { BBSP } \\
\text { Outreach } \\
\text { Area }\end{array}$ & $\begin{array}{c}\text { Control } \\
\text { Area }\end{array}$ \\
\hline Have not heard anything about it ( 0 sources selected) & $7 \%$ & $8 \%$ & $7 \%$ & $4 \%$ \\
\hline Average \# of sources selected & 2.5 & 2.4 & 2.7 & 2.7 \\
\hline \multicolumn{5}{|c|}{$\%$ selecting each source } \\
\hline At a bike share station/ kiosk & $46 \%$ & $36 \%$ & $43 \%$ & $47 \%$ \\
\hline Talked to someone at an event & $10 \%$ & $9 \%$ & $10 \%$ & $14 \%$ \\
\hline Got something in the mail & $8 \%$ & $6 \%$ & $11 \%$ & $6 \%$ \\
\hline Ads on buses or bus shelters & $30 \%$ & $33 \%$ & $28 \%$ & $23 \%$ \\
\hline Talked to someone from the [Local Partner] & $6 \%$ & $2 \%$ & $4 \%$ & $1 \%$ \\
\hline On a billboard & $13 \%$ & $20 \%$ & $16 \%$ & $12 \%$ \\
\hline Information at work or school & $8 \%$ & $10 \%$ & $8 \%$ & $8 \%$ \\
\hline Radio & $13 \%$ & $16 \%$ & $14 \%$ & $11 \%$ \\
\hline Television & $28 \%$ & $26 \%$ & $26 \%$ & $23 \%$ \\
\hline Newspaper & $15 \%$ & $19 \%$ & $25 \%$ & $25 \%$ \\
\hline On the internet & $19 \%$ & $18 \%$ & $31 \%$ & $42 \%$ \\
\hline Friends or family & $36 \%$ & $34 \%$ & $45 \%$ & $47 \%$ \\
\hline At a community center or faith-based organization & $5 \%$ & $5 \%$ & $0 \%$ & $6 \%$ \\
\hline GoKit (Chicago) & $4 \%$ & $0 \%$ & $\mathrm{n} / \mathrm{a}$ & $\mathrm{n} / \mathrm{a}$ \\
\hline $\mathrm{n}$ & 254 & 97 & 207 & 115 \\
\hline
\end{tabular}

Note: Includes respondents $<65$ years old, and physically able to ride a bicycle

${ }^{1}$ Bold indicates category value significantly greater than expected ( $p<0.05$, adj. stand. Chi-square residual) 
On questions about experiences with bike share (Table 10-2), respondents in Chicago's outreach area were a bit more likely to report certain experiences such as having ridden a Divvy bike (16\% compared to $5 \%$ in the control area), and to have friends or family who have used Divvy (46\% compared to 34\%). In Brooklyn, respondents in the control area were more likely than respondents in Bedford-Stuyvesant to have ridden a Citi Bike (22\% versus 11\%), currently be a Citi Bike member (11\% to 5\%), follow Citi Bike on social media ( $8 \%$ to $2 \%$ ), have talked to someone who works with Citi Bike (17\% to 11\%), and have attended special events related to Citi Bike (7\% to 2\%).

Table 10-2 Experiences with Bike Share for Outreach and Control Areas

About [BssName] and you (\% Yes or Likely)

Have you noticed a [BssName] station in your neighborhood?

Have you ridden a [BssName] bike?

Are you currently a [BssName] pass holder?

If no: Have you ever been a [BssName] pass holder?

Did you receive a coupon for a free [BssName] ride or day-use?

Have you gone on an organized bike ride where you learned about [BssName]?

Have any of your friends or family used [BssName]?

Do you follow [BssName] on Instagram, Twitter,

Facebook, or Email?

Have you ever talked to someone who works with

[BssName]?

Have you attended special events related to [BssName]?

Do you expect that you will be a [BssName] pass holder

12 months from now?

Seek more information about using [BssName]

Tell someone you know about [BssName]

Ride a [BssName] bike?

Minimum number of responses ${ }^{1}$

Maximum number of responses ${ }^{1}$

\begin{tabular}{|c|c|c|c|}
\hline \multicolumn{2}{|c|}{ Chicago $^{1}$} & \multicolumn{2}{|c|}{ Brooklyn $^{1}$} \\
\hline $\begin{array}{c}\text { BBSP } \\
\text { Outreach } \\
\text { Area }\end{array}$ & $\begin{array}{c}\text { Control } \\
\text { Area }\end{array}$ & $\begin{array}{c}\text { BBSP } \\
\text { Outreach } \\
\text { Area }\end{array}$ & $\begin{array}{c}\text { Control } \\
\text { Area }\end{array}$ \\
\hline $95 \%$ & $91 \%$ & $96 \%$ & $98 \%$ \\
\hline $16 \%$ & $5 \%$ & $13 \%$ & $22 \%$ \\
\hline $4 \%$ & $1 \%$ & $5 \%$ & $11 \%$ \\
\hline $2 \%$ & $1 \%$ & $3 \%$ & $2 \%$ \\
\hline $4 \%$ & $1 \%$ & $4 \%$ & $7 \%$ \\
\hline $2 \%$ & $4 \%$ & $2 \%$ & $1 \%$ \\
\hline $46 \%$ & $34 \%$ & $49 \%$ & $58 \%$ \\
\hline $3 \%$ & $2 \%$ & $2 \%$ & $8 \%$ \\
\hline $5 \%$ & $8 \%$ & $11 \%$ & $17 \%$ \\
\hline $2 \%$ & $2 \%$ & $2 \%$ & $7 \%$ \\
\hline $8 \%$ & $6 \%$ & $12 \%$ & $18 \%$ \\
\hline $40 \%$ & $40 \%$ & $33 \%$ & $31 \%$ \\
\hline $46 \%$ & $48 \%$ & $41 \%$ & $43 \%$ \\
\hline $43 \%$ & $46 \%$ & $35 \%$ & $38 \%$ \\
\hline 247 & 101 & 196 & 106 \\
\hline 263 & 106 & 214 & 120 \\
\hline
\end{tabular}

${ }^{1}$ varies by question due to missing

Note: Includes respondents $<65$ years old, and physically able to ride a bicycle

${ }^{1}$ Bold indicates category value significantly greater than expected ( $p<0.05$, adj. stand. Chi-square residual) 
Table 10-3 shows the percentage of respondents agreeing with various statements about bike share, while Table 10-4 shows the percentage who provided correct responses to various true-false questions. Perhaps most notably, there were very few differences observed. Respondents in the Brooklyn control area were more likely to view bike share as a good way to spend less money on transportation. Respondents in Chicago's outreach area were more likely to correctly note that bike share wasn't limited to customers of Blue Cross Blue Shield (the system sponsor) and to know that the bike wouldn't lock after a certain time limit. No other significant differences were observed on these questions.

\section{Table 10-3 Opinions about Bike Share, Outreach and Control Areas}

\begin{tabular}{|c|c|c|c|c|}
\hline $\begin{array}{l}\text { Opinions about [BssName] } \\
\text { (\% Agree) }\end{array}$ & $\begin{array}{c}\text { BBSP } \\
\text { Outreach } \\
\text { Area }\end{array}$ & $\begin{array}{l}\text { Control } \\
\text { Area }\end{array}$ & $\begin{array}{c}\text { BBSP } \\
\text { Outreac } \\
\text { h Area }\end{array}$ & $\begin{array}{l}\text { Control } \\
\text { Area }\end{array}$ \\
\hline [BssName] is useful for people like me & $69 \%$ & $73 \%$ & $66 \%$ & $75 \%$ \\
\hline I would like to use [BssName] more than I currently do & $53 \%$ & $46 \%$ & $49 \%$ & $53 \%$ \\
\hline $\begin{array}{l}\text { Having nearby [BssName] stations will attract new people to } \\
\text { move into the neighborhood }\end{array}$ & $55 \%$ & $48 \%$ & $63 \%$ & $66 \%$ \\
\hline $\begin{array}{l}\text { Having [BssName] nearby will make it more expensive to live in } \\
\text { the neighborhood }\end{array}$ & $16 \%$ & $9 \%$ & $39 \%$ & $41 \%$ \\
\hline $\begin{array}{l}\text { Using [BssName] is a good way to spend less money on } \\
\text { transportation }\end{array}$ & $79 \%$ & $75 \%$ & $68 \%$ & $85 \%$ \\
\hline $\begin{array}{l}\text { Using [BssName] is a good alternative to using public } \\
\text { transportation }\end{array}$ & $82 \%$ & $83 \%$ & $82 \%$ & $87 \%$ \\
\hline [BssName] is a good way to get to public transportation & $84 \%$ & $88 \%$ & $81 \%$ & $80 \%$ \\
\hline I see people like me using [BssName] in my neighborhood & $73 \%$ & $67 \%$ & $68 \%$ & $77 \%$ \\
\hline $\begin{array}{l}\text { I consider [BssName] to be a part of the city's public } \\
\text { transportation system }\end{array}$ & $80 \%$ & $80 \%$ & $62 \%$ & $68 \%$ \\
\hline $\begin{array}{l}\text { Concerns of people like me were addressed in decisions about } \\
\text { [BssName] in my neighborhood }\end{array}$ & $39 \%$ & $28 \%$ & $47 \%$ & $41 \%$ \\
\hline $\begin{array}{l}\text { [BssName] stations take up street and sidewalk space that } \\
\text { would be better used for other things }\end{array}$ & $19 \%$ & $16 \%$ & $35 \%$ & $35 \%$ \\
\hline $\begin{array}{l}\text { There is a focused effort to make [BssName] better for all } \\
\text { residents in my neighborhood }\end{array}$ & $75 \%$ & $73 \%$ & $59 \%$ & $64 \%$ \\
\hline $\begin{array}{l}\text { Over time, the [BssName] program is getting better at serving } \\
\text { the needs of people like me }\end{array}$ & $77 \%$ & $79 \%$ & $68 \%$ & $75 \%$ \\
\hline Overall, [BssName] is good for the city & $93 \%$ & $93 \%$ & $87 \%$ & $88 \%$ \\
\hline Overall, [BssName] is good for my neighborhood & $94 \%$ & $87 \%$ & $80 \%$ & $81 \%$ \\
\hline Minimum number of responses ${ }^{1}$ & 132 & 53 & 105 & 51 \\
\hline Maximum number of responses ${ }^{1}$ & 222 & 89 & 189 & 103 \\
\hline
\end{tabular}

${ }^{1}$ varies by question due to missing and "no opinion"

Note: Includes respondents $<65$ years old, and physically able to ride a bicycle

${ }^{1}$ Bold indicates category value significantly greater than expected ( $p<0.05$, adj. stand. Chi-square residual) 
Table 10-4 Knowledge about the Bike Share System, by Outreach and Control Areas

\begin{tabular}{|c|c|c|c|c|}
\hline \multirow[b]{2}{*}{$\begin{array}{l}\text { Percent of respondents responding with correct response } \\
\text { on T/F statement }\end{array}$} & \multicolumn{2}{|c|}{ Chicago $^{1}$} & \multicolumn{2}{|c|}{ Brooklyn ${ }^{1}$} \\
\hline & $\begin{array}{c}\text { BBSP } \\
\text { Outreach } \\
\text { Area }\end{array}$ & $\begin{array}{l}\text { Control } \\
\text { Area }\end{array}$ & $\begin{array}{c}\text { BBSP } \\
\text { Outreach } \\
\text { Area }\end{array}$ & $\begin{array}{l}\text { Control } \\
\text { Area }\end{array}$ \\
\hline A debit or credit card is required to use [BssShare] & $74 \%$ & $69 \%$ & $77 \%$ & $75 \%$ \\
\hline People can buy a monthly pass to use [BssShare] & $56 \%$ & $52 \%$ & $64 \%$ & $63 \%$ \\
\hline A helmet is required to check out a [BssShare] bike & $47 \%$ & $39 \%$ & $46 \%$ & $50 \%$ \\
\hline Nonmembers can buy a 24-hour pass for $\$[\mathrm{x}][\mathrm{NYC} \mathrm{CHI}$ only] & $43 \%$ & $39 \%$ & $43 \%$ & $53 \%$ \\
\hline $\begin{array}{l}\text { Members can use bikes longer than nonmembers (NYC) or } \\
\text { Members/ Day Pass holders can use for } 30 \text { minutes (CHI) }\end{array}$ & $46 \%$ & $36 \%$ & $46 \%$ & $45 \%$ \\
\hline A [BssShare] pass/ membership costs $\$[x]$ & $38 \%$ & $30 \%$ & $36 \%$ & $41 \%$ \\
\hline $\begin{array}{l}\text { A reduced price pass for [discount eligibility] is available for } \\
\text { [discount price] }\end{array}$ & $29 \%$ & $27 \%$ & $28 \%$ & $29 \%$ \\
\hline You have to be an [Sponsor] customer to use [BssShare] & $65 \%$ & $52 \%$ & $69 \%$ & $63 \%$ \\
\hline You have to have a smartphone to use [BssShare] & $52 \%$ & $40 \%$ & $59 \%$ & $61 \%$ \\
\hline If you exceed a time limit, the [BssShare] bicycle will lock & $37 \%$ & $23 \%$ & $46 \%$ & $44 \%$ \\
\hline $\begin{array}{l}\text { You have to return the bike to the same station you check it } \\
\text { out from }\end{array}$ & $66 \%$ & $56 \%$ & $73 \%$ & $72 \%$ \\
\hline $\begin{array}{l}\text { CitiBank customers can receive a } 10 \% \text { discount on Citi Bike } \\
\text { memberships }\end{array}$ & & & $40 \%$ & $43 \%$ \\
\hline Minimum number of responses ${ }^{1}$ & 212 & 102 & 208 & 118 \\
\hline Maximum number of responses ${ }^{1}$ & 262 & 120 & 212 & 120 \\
\hline
\end{tabular}

${ }^{1}$ varies by question due to missing

Note: Includes respondents $<65$ years old, and physically able to ride a bicycle

${ }^{1}$ Bold indicates category value significantly greater than expected ( $p<0.05$, adj. stand. Chi-square residual) 
In terms of what reasons respondents selected for why they would consider using bike share (Table 10-5), those in the outreach areas selected more reasons to try bike share than those in the control areas (4.3 reasons selected on average in the Chicago outreach area compared to 4 in the control area, and 4.6 compared to 4.4 in Brooklyn); however these were not significant differences. In fact, the only significant difference observed was that those in the Chicago control area were more likely to view getting exercise as a reason to try bike share ( $79 \%$ to $67 \%)$.

Table 10-5 Reasons to Try Bike Share, by Outreach and Control Areas

\begin{tabular}{|c|c|c|c|c|}
\hline \multirow{2}{*}{ Reasons you would consider using [BssName] } & & \\
\hline & $\begin{array}{c}\text { BBSP } \\
\text { Outreach } \\
\text { Area }\end{array}$ & $\begin{array}{c}\text { Control } \\
\text { Area }\end{array}$ & $\begin{array}{c}\text { BBSP } \\
\text { Outreach } \\
\text { Area }\end{array}$ & $\begin{array}{c}\text { Control } \\
\text { Area }\end{array}$ \\
\hline None & $15 \%$ & $14 \%$ & $17 \%$ & $17 \%$ \\
\hline Average \# selected & 4.3 & 4 & 4.6 & 4.4 \\
\hline \multicolumn{5}{|c|}{$\%$ selected } \\
\hline Want to try biking & $32 \%$ & $30 \%$ & $26 \%$ & $28 \%$ \\
\hline Saves me money compared to other transportation options & $24 \%$ & $23 \%$ & $30 \%$ & $32 \%$ \\
\hline Saves me time compared to other transportation options & $16 \%$ & $10 \%$ & $34 \%$ & $33 \%$ \\
\hline To get exercise & $67 \%$ & $79 \%$ & $62 \%$ & $58 \%$ \\
\hline For fun & $60 \%$ & $63 \%$ & $55 \%$ & $49 \%$ \\
\hline To get to bus or rail stops & $20 \%$ & $17 \%$ & $16 \%$ & $21 \%$ \\
\hline Don't want to rely on transit & $11 \%$ & $9 \%$ & $29 \%$ & $25 \%$ \\
\hline It's an easy way to get around & $32 \%$ & $30 \%$ & $41 \%$ & $35 \%$ \\
\hline To ride with friends/ family & $49 \%$ & $52 \%$ & $36 \%$ & $32 \%$ \\
\hline Stations are near my home / work / school & $36 \%$ & $30 \%$ & $39 \%$ & $41 \%$ \\
\hline To help the environment & $38 \%$ & $33 \%$ & $41 \%$ & $39 \%$ \\
\hline Don't need a bike of my own & $24 \%$ & $18 \%$ & $24 \%$ & $29 \%$ \\
\hline To get to jobs more easily & $7 \%$ & $5 \%$ & $14 \%$ & $10 \%$ \\
\hline To get to social services & $5 \%$ & $5 \%$ & $5 \%$ & $4 \%$ \\
\hline Other & $4 \%$ & $3 \%$ & $2 \%$ & $6 \%$ \\
\hline $\mathrm{n}$ & 257 & 103 & 201 & 117 \\
\hline
\end{tabular}

Note: Includes respondents $<65$ years old, and physically able to ride a bicycle

${ }^{1}$ Bold indicates category value significantly greater than expected ( $p<0.05$, adj. stand. Chi-square residual) 
Table 10-6 shows how these groups rated potential changes in terms of whether they would make the respondent more likely to use bike share. In Chicago, those in the control area were more likely to rate receiving help finding safe ways to get where they need to go as something that would make them more likely to use bike share. In Brooklyn, people in the outreach area were more likely to rate organized rides for people like them as something that would make them more likely to use bike share.

\section{Table 10-6 Efficacy of Potential Changes, by Outreach and Control Areas}

\begin{tabular}{|c|c|c|c|c|}
\hline \multirow[b]{2}{*}{$\begin{array}{l}\text { Would the following changes make you more likely to use } \\
\text { [BssName]? } \\
\text { (\% somewhat or much more likely) }\end{array}$} & \multicolumn{2}{|c|}{ Chicago $^{2}$} & \multicolumn{2}{|c|}{ Brooklyn $^{2}$} \\
\hline & $\begin{array}{l}\text { BBSP } \\
\text { Outreach } \\
\text { Area }\end{array}$ & $\begin{array}{c}\text { Control } \\
\text { Area }\end{array}$ & $\begin{array}{l}\text { BBSP } \\
\text { Outreach } \\
\text { Area }\end{array}$ & $\begin{array}{c}\text { Control } \\
\text { Area }\end{array}$ \\
\hline Discounted membership or use options & $73 \%$ & $80 \%$ & $77 \%$ & $81 \%$ \\
\hline More short-term membership or pass options & $71 \%$ & $75 \%$ & $71 \%$ & $73 \%$ \\
\hline Easier way to pay with cash & $50 \%$ & $63 \%$ & $45 \%$ & $38 \%$ \\
\hline Option to sign up or buy passes at a store instead of online & $56 \%$ & $66 \%$ & $45 \%$ & $45 \%$ \\
\hline Access to free or low cost helmets and other gear & $57 \%$ & $61 \%$ & $64 \%$ & $66 \%$ \\
\hline Organized rides for people like me & $56 \%$ & $64 \%$ & $51 \%$ & $37 \%$ \\
\hline If more of my friends or family could use [BssShare] with me & $59 \%$ & $61 \%$ & $55 \%$ & $53 \%$ \\
\hline If [BssShare] users were more diverse & $39 \%$ & $52 \%$ & $41 \%$ & $29 \%$ \\
\hline Help finding safe ways to get where I need to go & $57 \%$ & $73 \%$ & $65 \%$ & $68 \%$ \\
\hline Free transfers between public transportation and [BssName] & $73 \%$ & $78 \%$ & $79 \%$ & $79 \%$ \\
\hline More [BssShare] stations close together & $58 \%$ & $64 \%$ & $64 \%$ & $64 \%$ \\
\hline More [BssShare] stations where I want to go & $65 \%$ & $70 \%$ & $73 \%$ & $76 \%$ \\
\hline Minimum number of responses ${ }^{1}$ & 169 & 64 & 147 & 75 \\
\hline Maximum number of responses ${ }^{1}$ & 214 & 83 & 175 & 98 \\
\hline
\end{tabular}

The percentages of respondents who rated various barriers to bicycling as big barriers are shown in Table 10-7. Respondents in the south side Chicago control neighborhood were more likely to note a number of potential barriers as big barriers, including that places are too far to go by bike (nearly three-quarters said so, compared to half in the outreach area), and that traffic makes riding a bicycle feel dangerous (60\% rated this a big barrier, compared to $42 \%$ in the outreach area). People in the Chicago control area were also much more likely to rate something going wrong with a bike (such as a flat tire) as a big barrier (41\% versus $14 \%$ ), that riding could make them a target for police attention ( $21 \%$ to $6 \%$ ), that riding could cause them to be harassed or a victim of crime (40\% to 24\%). Comparatively, the Brooklyn outreach and control neighborhoods had very few differences, and only one was significant (people in BedfordStuyvesant were more likely to note that riding with their children was a hassle). 
Table 10-7 Barriers to Bicycling, by Outreach and Control Areas

\begin{tabular}{|c|c|c|c|c|}
\hline $\begin{array}{l}\text { Barrier to bicycling more } \\
\text { (\% stating big barrier) }\end{array}$ & $\begin{array}{c}\text { BBSP } \\
\text { Outreach } \\
\text { Area }\end{array}$ & $\begin{array}{l}\text { Control } \\
\text { Area }\end{array}$ & $\begin{array}{c}\text { BBSP } \\
\text { Outreach } \\
\text { Area }\end{array}$ & $\begin{array}{c}\text { Control } \\
\text { Area }\end{array}$ \\
\hline I don't have a bike or related gear (such as helmet / lock / lights) & $40 \%$ & $42 \%$ & $39 \%$ & $35 \%$ \\
\hline It is too expensive to buy a bike or related gear & $31 \%$ & $39 \%$ & $35 \%$ & $27 \%$ \\
\hline I don't know a good place for me to get a bike fixed & $17 \%$ & $31 \%$ & $13 \%$ & $16 \%$ \\
\hline I don't have a safe place to store a bike at home & $27 \%$ & $33 \%$ & $36 \%$ & $38 \%$ \\
\hline There might not be a safe place to leave a bike at the places I go & $34 \%$ & $46 \%$ & $41 \%$ & $46 \%$ \\
\hline The places that I need to go are too far away to reach on a bike & $49 \%$ & $74 \%$ & $43 \%$ & $40 \%$ \\
\hline I don't know how to get where I need to go by bike & $16 \%$ & $17 \%$ & $14 \%$ & $14 \%$ \\
\hline Traffic makes riding a bike in my neighborhood feel dangerous & $42 \%$ & $60 \%$ & $58 \%$ & $55 \%$ \\
\hline My bike is not good for riding around the city & $19 \%$ & $30 \%$ & $17 \%$ & $21 \%$ \\
\hline I am too old to ride a bike & $9 \%$ & $18 \%$ & $6 \%$ & $6 \%$ \\
\hline I am too out of shape to ride a bike & $12 \%$ & $16 \%$ & $10 \%$ & $6 \%$ \\
\hline Biking might aggravate my personal health issues & $9 \%$ & $18 \%$ & $8 \%$ & $5 \%$ \\
\hline Carrying things on a bike is too difficult & $33 \%$ & $44 \%$ & $30 \%$ & $34 \%$ \\
\hline Riding a bike with my kids is a hassle & $30 \%$ & $32 \%$ & $28 \%$ & $12 \%$ \\
\hline Something could go wrong with a bike (such as a flat tire) & $14 \%$ & $41 \%$ & $14 \%$ & $13 \%$ \\
\hline My friends and family wouldn't want me to ride a bike & $9 \%$ & $23 \%$ & $8 \%$ & $8 \%$ \\
\hline Riding a bike is not viewed as a cool activity by my friends & $7 \%$ & $13 \%$ & $2 \%$ & $6 \%$ \\
\hline People might think that I can't afford a car & $7 \%$ & $18 \%$ & $3 \%$ & $5 \%$ \\
\hline Riding a bike could make me a target for police attention & $6 \%$ & $21 \%$ & $10 \%$ & $10 \%$ \\
\hline Riding a bike could cause me to be harassed or a victim of crime & $24 \%$ & $40 \%$ & $14 \%$ & $17 \%$ \\
\hline Riding a bike could mess up my hair or appearance & $11 \%$ & $14 \%$ & $11 \%$ & $8 \%$ \\
\hline The clothes I wear are not appropriate for biking & $17 \%$ & $17 \%$ & $14 \%$ & $8 \%$ \\
\hline Riding a bike could make me sweaty & $16 \%$ & $22 \%$ & $25 \%$ & $20 \%$ \\
\hline Minimum number of responses ${ }^{1}$ & 118 & 43 & 74 & 42 \\
\hline Maximum number of responses ${ }^{1}$ & 224 & 96 & 172 & 101 \\
\hline
\end{tabular}

Note: Includes respondents $<65$ years old, and physically able to ride a bicycle

${ }^{1}$ varies by question due to missing and "does not apply"

${ }^{2}$ Bold indicates category value significantly greater than expected $(p<0.05$, adj. stand. Chi-square residual) 
Barriers to using bike share are shown in Table 10-8. People in Chicago's control area were more likely to cite not wanting to use a credit card (47\% noted this as a big barrier, compared to $27 \%$ in the Bronzeville outreach area), and not having a smartphone (27\% versus 15\%). In Brooklyn, respondents in the outreach area were more likely to note not having a smartphone as a big barrier (15\% versus 5\%), to view bike share sign-up and checking out bikes as too complicated, and to not want to support the program (15\% to $4 \%)$.

\section{Table 10-8 Barriers to Using Bike Share, by Outreach and Control Areas}

\section{Barrier to bicycling [BssName] more (\% stating big barrier)}

I worry that I'II have to pay for the bike if anything happens to it

I don't know enough about how to use it

Membership or use costs are too high

I worry that there might not be an available bike at a station to check out, or a free space at a station when returning a bike

I worry that the [BssShare] bikes wouldn't adjust to fit me I don't want to use a credit card to use bike share I don't have a smartphone

There aren't [BssShare] stations near where I want to go

There aren't [BssShare] stations near my home

I don't know where other stations are to drop off a bike

I don't want to be seen on a [BssShare] bike

Signing up for [BssShare] is too complicated

Checking out and returning [BssName] bikes is too complicated

I can't use [BssShare] with my child(ren)

I just don't want to support the [BssShare] program

I just prefer to ride my own bike

Minimum number of responses ${ }^{1}$

Maximum number of responses ${ }^{1}$

\begin{tabular}{|c|c|c|c|}
\hline \multicolumn{2}{|c|}{ Chicago $^{2}$} & \multicolumn{2}{|c|}{ Brooklyn ${ }^{2}$} \\
\hline $\begin{array}{l}\text { BBSP } \\
\text { Outreach } \\
\text { Area }\end{array}$ & $\begin{array}{c}\text { Control } \\
\text { Area }\end{array}$ & $\begin{array}{c}\text { BBSP } \\
\text { Outreach } \\
\text { Area }\end{array}$ & $\begin{array}{c}\text { Control } \\
\text { Area }\end{array}$ \\
\hline $44 \%$ & $45 \%$ & $36 \%$ & $32 \%$ \\
\hline $27 \%$ & $39 \%$ & $23 \%$ & $20 \%$ \\
\hline $41 \%$ & $39 \%$ & $48 \%$ & $43 \%$ \\
\hline $26 \%$ & $31 \%$ & $28 \%$ & $28 \%$ \\
\hline $18 \%$ & $12 \%$ & $17 \%$ & $16 \%$ \\
\hline $27 \%$ & $47 \%$ & $26 \%$ & $16 \%$ \\
\hline $15 \%$ & $27 \%$ & $15 \%$ & $5 \%$ \\
\hline $11 \%$ & $17 \%$ & $22 \%$ & $17 \%$ \\
\hline $12 \%$ & $15 \%$ & $12 \%$ & $7 \%$ \\
\hline $19 \%$ & $19 \%$ & $24 \%$ & $19 \%$ \\
\hline $4 \%$ & $5 \%$ & $12 \%$ & $5 \%$ \\
\hline $10 \%$ & $13 \%$ & $13 \%$ & $5 \%$ \\
\hline $12 \%$ & $13 \%$ & $12 \%$ & $4 \%$ \\
\hline $26 \%$ & $30 \%$ & $24 \%$ & $18 \%$ \\
\hline $9 \%$ & $13 \%$ & $15 \%$ & $4 \%$ \\
\hline $29 \%$ & $25 \%$ & $46 \%$ & $30 \%$ \\
\hline 127 & 50 & 104 & 56 \\
\hline 209 & 85 & 163 & 93 \\
\hline
\end{tabular}

Note: Includes respondents $<65$ years old, and physically able to ride a bicycle

${ }^{1}$ varies by question due to missing and "does not apply"

${ }^{2}$ Bold indicates category value significantly greater than expected ( $p<0.05$, adj. stand. Chi-square residual)

\subsubsection{Discussion}

We did not observe many differences between the outreach and control areas, and many of those that were observed may be largely due to geographic differences (for example, barriers related to places' being too far to travel in Chicago's south side control neighborhood may be due to its being farther from downtown than Bronzeville), and demographic differences (for example, respondents in the Brooklyn control were a bit more likely to be Hispanic or white than those in the outreach neighborhood). 
One challenge with our survey is that it is just one point in time, and does not provide a dynamic picture of bike share use over time. However, other indicators do provide some data points that could point toward BBSP outreach efforts having an effect. For example, as Figure 10-1 shows, stations in BedfordStuyvesant appear to be showing greater increases in use than other nearby stations. On average, the number of bike share trips from the 24 stations in the outreach area went up 59\%, compared to $46 \%$ at the seven stations in our control neighborhood. For this analysis, we compared trips made in September through December 2016 with the same months in 2015. We selected these dates because the same numbers of stations were available at both points in time, so any changes are not likely attributable to growth in the system. We were not able to detect similar differences in the Chicago outreach and control neighborhoods. There may be other factors explaining this, including some station re-locations.

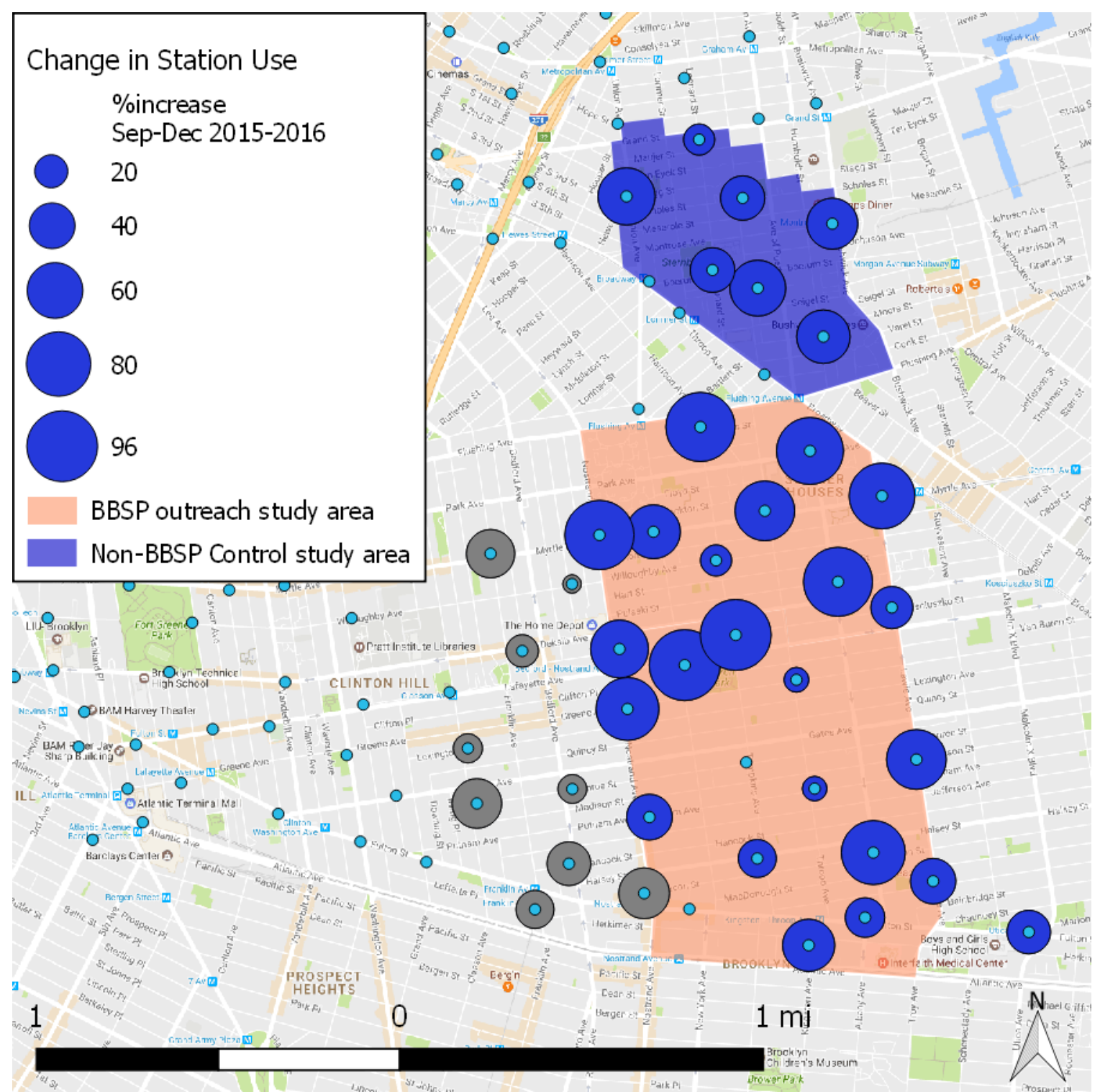

Figure 10-1 Increases in Citi Bike use by area for existing (gray) and expansion (blue) stations (data: Citi Bike, Google Maps) 


\subsection{Older adults and those physically unable to ride}

The main body of this report addresses the view of those younger than 65 years old and physically able to ride a bike. We have separated out older adults because of their different uses of and abilities surrounding bicycling. They are more likely to be retired, thus removing their need to commute anywhere. They are also much more likely to state that they are physically unable to ride a bike. Note that the determination of "physically unable to ride a bike" is self-reported and may not be a true indication of a physical disability.

Older adults and populations with physical limitations are understudied groups within bicycling and bike share. According to Bopp, Der Ananian and Campbell (2014), older adults are less likely to actively commute than younger populations. However, when it comes to physical activity, older adults have been shown to participate more if the activity is "moderate in intensity, simple and convenient to engage in, relatively inexpensive, and noncompetitive,” (King, 2001). Several studies have also shown a preference among older adults for independent activities (King, 2001), for which bicycling could be suitable. For older adults who do bike, safe bike infrastructure and convenient access to businesses and parks are crucial to their getting on a bike (Strath, Isaacs and Greenwald, 2007).

When it comes to physical disabilities and riding a bicycle, the literature is scarce. Bike share systems have high hurdles to meet the needs of all populations among the "physically unable" due to the varying array of ways people may be physically unable to ride a bike. Some people may feel they are physically unable but actually are capable of riding a bike; marketing and classes could alter that perception (Clark and Curl, 2016). Electric bikes may address the needs of some, but not all, of the physically unable community, while trikes could serve a different sub-set (Clark and Curl, 2016). Finding the right solution is dependent upon the place and the population.

\subsubsection{Methods}

This section of the report uses a slightly different method of analysis than the previous sections. We continue to use $300 \%$ of the poverty line as a cutoff for identifying lower- and higher-income populations. For identifying older adults, we use two age groups: 55-64 (“younger older adults” henceforth) and 65 and older ("older older adults" henceforth). Because of sample-size issues, we have excluded white populations from the analysis. This was primarily because their small sample was unevenly distributed by income, which could lead to large changes in the outcome of this analysis. Evidence of this is shown in Table 10-9. For the age groups, we further group them by income (less than $300 \%$ of poverty and $300 \%+$ poverty) and physical ability to ride a bike. To understand the interaction of income and ability, we consider the income of all older adults (55+), grouped by their stated physical ability to ride a bike. We later analyze only older adults who currently ride a bike or have expressed an interest in riding a bike more in the future and group them by the last time they rode a bike. This "bike-willing" category is based on the respondents' answers to the questions that reveal to us whether they currently ride a bike or plan to in the future. They are labeled as "bike-willing" if they rode a bike for at least some trips in the last week, ride a bike more than they did in the last year, plan to ride more in the next year, rode a bike in the last year, have ridden a bike share bike, or plan to ride a bike share bike in the next 6 months. 
Table 10-9 Demographics of the Older Adult Population

\begin{tabular}{|c|c|c|c|c|}
\hline & \multicolumn{2}{|c|}{ All } & \multicolumn{2}{|c|}{ People of Color Only } \\
\hline & 55 to 64 years & 65 and older & 55-64 years & 65 and older \\
\hline Respondents & 303 & 299 & 269 & 263 \\
\hline \multicolumn{5}{|l|}{ Race and Ethnicity } \\
\hline ...People of color & $89 \%$ & $88 \%$ & - & - \\
\hline ...Non-Hispanic white & $6 \%$ & $7 \%$ & - & - \\
\hline \multicolumn{5}{|l|}{ Gender } \\
\hline ...female & $69 \%$ & $64 \%$ & $70 \%$ & $65 \%$ \\
\hline \multicolumn{5}{|c|}{ Poverty (\% Federal guideline for household size) } \\
\hline ...Less than $150 \%$ & $41 \%$ & $43 \%$ & $44 \%$ & $45 \%$ \\
\hline$\ldots 150-300 \%$ & $29 \%$ & $35 \%$ & $31 \%$ & $38 \%$ \\
\hline ...more than $300 \%$ & $30 \%$ & $22 \%$ & $26 \%$ & $18 \%$ \\
\hline \multicolumn{5}{|l|}{ Employed } \\
\hline ...part or full-time & $43 \%$ & $11 \%$ & $42 \%$ & $9 \%$ \\
\hline ...retired & $24 \%$ & $69 \%$ & $25 \%$ & $69 \%$ \\
\hline \multicolumn{5}{|l|}{ Education (highest level) } \\
\hline ...Less than High School & $8 \%$ & $16 \%$ & $9 \%$ & $17 \%$ \\
\hline ...High School Diploma/ GED & $27 \%$ & $29 \%$ & $29 \%$ & $32 \%$ \\
\hline ...Some college/ Associate's & $39 \%$ & $31 \%$ & $40 \%$ & $30 \%$ \\
\hline ...Bachelor's degree or higher & $22 \%$ & $22 \%$ & $19 \%$ & $19 \%$ \\
\hline \multicolumn{5}{|l|}{ Housing Tenure } \\
\hline ...renter & $60 \%$ & $62 \%$ & $63 \%$ & $64 \%$ \\
\hline \multicolumn{5}{|l|}{ Car Ownership } \\
\hline ...No vehicle available & $58 \%$ & $63 \%$ & $60 \%$ & $65 \%$ \\
\hline \multicolumn{5}{|l|}{ Biking Ability } \\
\hline ...not physically able & $20 \%$ & $33 \%$ & $21 \%$ & $34 \%$ \\
\hline
\end{tabular}




\subsubsection{Findings: Older adults of color, their neighborhood and bicycling}

A large majority of all older adults are satisfied with their options of getting where they need to go (88\%). An even larger percentage is aware of changes in their neighborhood in the past 12 months (90\%). Although three-quarters of all older adults approve of the changes, older adults without the physical ability to ride a bike are the least accepting of the changes (see Table 10-10). This suggests that the changes that are occurring are not accommodating populations with physical limitations. Additionally, ability was a substantial indicator of whether people felt their transportation options were getting better. Only $45 \%$ of younger older adults physically unable to ride a bike thought their transportation options were getting better, compared with $65 \%$ for all groups. Lower-income populations physically unable to ride a bike were less likely to see their transportation options getting better ( $56 \%$ vs. $71 \%$ ), but the difference disappeared for higher-income populations.

Table 10-10 Opinions about Neighborhood and City by Age and Physical Ability to Ride a Bike

\begin{tabular}{|c|c|c|c|c|c|}
\hline \multirow[b]{2}{*}{ Statements about neighborhood and city (\% agree $)^{2}$} & \multicolumn{2}{|c|}{$55-64$} & \multicolumn{2}{|c|}{$65+$} & \multirow[b]{2}{*}{ All } \\
\hline & Able & Unable & Able & Unable & \\
\hline I am satisfied with my options for getting where I need to go & $88 \%$ & $74 \%$ & $91 \%$ & $85 \%$ & $87 \%$ \\
\hline $\begin{array}{l}\text { I usually know about community and social events in my } \\
\text { neighborhood }\end{array}$ & $68 \%$ & $54 \%$ & $79 \%$ & $56 \%$ & $68 \%$ \\
\hline $\begin{array}{l}\text { I know about services provided by community or faith-based } \\
\text { organizations in my neighborhood }\end{array}$ & $52 \%$ & $41 \%$ & $71 \%$ & $53 \%$ & $57 \%$ \\
\hline $\begin{array}{l}\text { I have noticed changes in my neighborhood in the past } 12 \\
\text { months }\end{array}$ & $90 \%$ & $89 \%$ & $90 \%$ & $87 \%$ & $89 \%$ \\
\hline Recent changes make my neighborhood more appealing to me & $76 \%$ & $52 \%$ & $78 \%$ & $63 \%$ & $71 \%$ \\
\hline $\begin{array}{l}\text { I may have to leave my neighborhood because it is getting to } \\
\text { expensive }\end{array}$ & $42 \%$ & $48 \%$ & $34 \%$ & $38 \%$ & $39 \%$ \\
\hline I have provided input on decisions affecting my neighborhood & $47 \%$ & $48 \%$ & $\mathbf{5 7 \%}$ & $51 \%$ & $49 \%$ \\
\hline $\begin{array}{l}\text { Concerns of people like me are considered in decisions } \\
\text { affecting my neighborhood }\end{array}$ & $52 \%$ & $45 \%$ & $56 \%$ & $42 \%$ & $50 \%$ \\
\hline My city government does a good job of serving people like me & $37 \%$ & $34 \%$ & $52 \%$ & $43 \%$ & $42 \%$ \\
\hline $\begin{array}{l}\text { I can usually go to and from home and where I need to go } \\
\text { easily enough }\end{array}$ & $89 \%$ & $70 \%$ & $92 \%$ & $90 \%$ & $88 \%$ \\
\hline $\begin{array}{l}\text { My options for getting around have gotten better in the past } \\
12 \text { months }\end{array}$ & $70 \%$ & $45 \%$ & $69 \%$ & $63 \%$ & $65 \%$ \\
\hline $\begin{array}{l}\text { The public transit agency does a good job of serving people } \\
\text { like me }\end{array}$ & $75 \%$ & $61 \%$ & $83 \%$ & $69 \%$ & $75 \%$ \\
\hline Minimum number of responses ${ }^{1}$ & 193 & 50 & 133 & 74 & 483 \\
\hline Maximum number of responses ${ }^{1}$ & 228 & 64 & 177 & 103 & 572 \\
\hline
\end{tabular}


Table 10-11 shows the percentage of each group agreeing with general opinions of bicycling. Overall, older adults feel that there are better options to getting around than by bicycle (88\%). As expected, older adults who are physically able to bike were much more likely to approve of biking in general and see it as something useful for them. Lower-income older adults were more positive about bicycling regardless of age or ability. Younger older adults were also more positive. Older adults unable to physically ride a bike are slightly less positive. This is particularly the case on items unrelated to whether they are able to use a bike, such as that the presence of bike lanes makes it harder to get around the neighborhood (39\% of physically unable older older adults agree, vs. $28 \%$ for all older adults) or the environmental and community health benefits of bicycling (72\% and $75 \%$ agree, respectively, vs. $83 \%$ and $83 \%$ for all older adults). Physically unable older adults do not, in general, see bikes as much of an option for them.

While income did show some significant differences, the low number of responses among higher-income physically unable populations did not give us confidence in the results.

\section{Table 10-11 Opinions about Bicycling by Age and Physical Ability to Ride a Bike}

\begin{tabular}{|c|c|c|c|c|c|}
\hline \multirow[b]{2}{*}{ Bike Opinions (\% agree) $)^{2}$} & \multicolumn{2}{|c|}{$55-64$} & \multicolumn{2}{|c|}{$65+$} & \multirow[b]{2}{*}{ All } \\
\hline & Able & Unable & Able & Unable & \\
\hline Getting more people to ride bikes is good for the environment & $87 \%$ & $71 \%$ & $87 \%$ & $72 \%$ & $83 \%$ \\
\hline $\begin{array}{l}\text { Getting more people to ride bikes will help make the community } \\
\text { healthier }\end{array}$ & $87 \%$ & $80 \%$ & $82 \%$ & $75 \%$ & $83 \%$ \\
\hline $\begin{array}{l}\text { [CityName] should invest in projects (such as bike lanes) that } \\
\text { make riding bikes safer and easier }\end{array}$ & $84 \%$ & $83 \%$ & $87 \%$ & $75 \%$ & $83 \%$ \\
\hline People on bikes make roads less safe for others & $44 \%$ & $50 \%$ & $49 \%$ & $59 \%$ & $49 \%$ \\
\hline Bike lanes make it harder to get around my neighborhood & $20 \%$ & $35 \%$ & $31 \%$ & $39 \%$ & $28 \%$ \\
\hline $\begin{array}{l}\text { Riding a bike is a convenient way for people to get places in } \\
\text { [CityName] }\end{array}$ & $88 \%$ & $87 \%$ & $89 \%$ & $78 \%$ & $87 \%$ \\
\hline I am familiar with the bike lanes in my neighborhood & $89 \%$ & $74 \%$ & $88 \%$ & $72 \%$ & $84 \%$ \\
\hline I often see people like me riding bikes in my neighborhood & $72 \%$ & $55 \%$ & $73 \%$ & $57 \%$ & $68 \%$ \\
\hline $\begin{array}{l}\text { I would like to ride a bicycle (for transportation) more than I } \\
\text { currently do }\end{array}$ & $60 \%$ & $11 \%$ & $39 \%$ & $12 \%$ & $41 \%$ \\
\hline There are better ways for me to get around than by biking & $86 \%$ & $87 \%$ & $90 \%$ & $92 \%$ & $88 \%$ \\
\hline $\begin{array}{l}\text { Riding a bike would make me more independent in getting } \\
\text { around }\end{array}$ & $45 \%$ & $27 \%$ & $40 \%$ & $8 \%$ & $36 \%$ \\
\hline Riding a bike would help me spend less on transportation & $73 \%$ & $58 \%$ & $58 \%$ & $19 \%$ & $59 \%$ \\
\hline Riding a bike would be a good way for me to get exercise & $93 \%$ & $77 \%$ & $90 \%$ & $49 \%$ & $84 \%$ \\
\hline $\begin{array}{l}\text { Riding a bike would be a good way for me to spend time with } \\
\text { friends or family }\end{array}$ & $49 \%$ & $36 \%$ & $43 \%$ & $14 \%$ & $5 \%$ \\
\hline I'm bicycling more now than I did a year ago & $15 \%$ & $8 \%$ & $13 \%$ & $3 \%$ & $12 \%$ \\
\hline I plan to ride a bicycle more often in the next year & $50 \%$ & $3 \%$ & $41 \%$ & $6 \%$ & $36 \%$ \\
\hline There is a bike shop that is convenient for me to go to & $\mathbf{5 7 \%}$ & $29 \%$ & $\mathbf{5 9 \%}$ & $24 \%$ & $50 \%$ \\
\hline Minimum number of responses ${ }^{1}$ & 183 & 39 & 111 & 65 & 396 \\
\hline Maximum number of responses ${ }^{1}$ & 221 & 57 & 159 & 95 & 531 \\
\hline
\end{tabular}


As with the younger population analyzed earlier in the report, distance to destinations and traffic are the top concerns that most older adults feel keep them from riding a bike more (Table 10-12). Surprisingly, "too old" was only the sixth most frequently cited barrier for all older adults. Older older adults appear to have more concerns around their age, concerns their friends and family would not like their riding a bike, and the ability to carry things on a bike. These appear to be related to ability. Concerns about physical appearance or police attention did not make the top ten barriers to bicycling for older adults.

Those older adults physically unable to ride a bike consistently rated many more items as big barriers. The barriers they rated as a group to be biggest were most related to their health (too old and could aggravate health issues) and potential frailty (ability to carry things with a bike, places are too far away to reach on bike, and friends and family would not want me riding a bike). These barriers were rated high enough to push traffic concerns down to 4 and 5 depending on age group.

Table 10-12 Rankings of Top Ten Barriers to Bicycling for Older Adults by Age and Physical Ability to Ride a Bike

\begin{tabular}{|c|c|c|c|c|c|}
\hline \multirow{2}{*}{$\begin{array}{l}\text { Rankings of Barriers to bicycling more } \\
\text { (\% Stating Big Barrier) }\end{array}$} & \multicolumn{2}{|c|}{$55-64$} & \multicolumn{2}{|c|}{$65+$} & \multirow[t]{2}{*}{ All } \\
\hline & Able & Unable & Able & Unable & \\
\hline $\begin{array}{l}\text { Traffic makes riding a bike in my neighborhood feel } \\
\text { dangerous }\end{array}$ & $1(48 \%)$ & $4(68 \%)$ & $2(50 \%)$ & $5(76 \%)$ & $2(54 \%)$ \\
\hline I don't have a bike or bike-related gear & $3(45 \%)$ & $9(50 \%)$ & $5(37 \%)$ & $9(68 \%)$ & $4(45 \%)$ \\
\hline $\begin{array}{l}\text { The places that I need to go are too far away to reach } \\
\text { on a bike }\end{array}$ & $2(47 \%)$ & $2(73 \%)$ & $1(52 \%)$ & $3(82 \%)$ & $1(54 \%)$ \\
\hline It is too expensive to buy a bike or bike-related gear & $4(40 \%)$ & - & - & - & $8(38 \%)$ \\
\hline $\begin{array}{l}\text { There might not be a safe place to leave a bike at the } \\
\text { places I go }\end{array}$ & $5(39 \%)$ & $6(60 \%)$ & $4(44 \%)$ & - & $5(44 \%)$ \\
\hline Carrying things on a bike is too difficult & $6(39 \%)$ & $5(63 \%)$ & $3(47 \%)$ & $1(85 \%)$ & $3(49 \%)$ \\
\hline Something could go wrong with a bike (such as flat tire) & $9(31 \%)$ & $10(48 \%)$ & - & $10(64 \%)$ & $10(35 \%)$ \\
\hline Riding a bike with my kids is a hassle & $7(36 \%)$ & - & - & $8(73 \%)$ & $7(38 \%)$ \\
\hline I am too old to ride a bike & - & $7(59 \%)$ & $6(36 \%)$ & $2(82 \%)$ & $6(40 \%)$ \\
\hline I don't have a safe place to store a bike at home & $8(32 \%)$ & - & $9(31 \%)$ & - & $13(33 \%)$ \\
\hline My friends and family would not want me to ride a bike & - & $3(69 \%)$ & $7(34 \%)$ & $6(75 \%)$ & $9(35 \%)$ \\
\hline Biking might aggravate my personal health issues & - & $1(75 \%)$ & - & $4(80 \%)$ & $12(34 \%)$ \\
\hline I am too out of shape to ride a bike & - & - & - & $7(74 \%)$ & $15(29 \%)$ \\
\hline $\begin{array}{l}\text { Riding a bike could cause me to be harassed or a victim } \\
\text { of crime }\end{array}$ & - & $8(56 \%)$ & $10(31 \%)$ & - & $11(34 \%)$ \\
\hline My bike is not good for riding around the city & $10(30 \%)$ & - & $8(33 \%)$ & - & $14(33 \%)$ \\
\hline Minimum number of responses ${ }^{1}$ & 69 & 12 & 33 & 11 & 127 \\
\hline Maximum number of responses ${ }^{1}$ & 161 & 36 & 105 & 50 & 332 \\
\hline
\end{tabular}


There were 245 older adults who said they plan to ride more in the next 12 months. Of those, one-third had biked in the last year, $26 \%$ had biked one to five years ago, and $42 \%$ last biked more than five years ago. Looking just at these respondents, barriers to bicycling were substantially different for older adults who have biked within the last five years and those who have not (See Table 10-13). The No. 1 barrier for both those who have biked within the last year and those that have biked within the last one to five years was "places are too far away to reach on a bike.” Those who had not ridden a bike in the last five years rated many more items as big barriers, leading to much higher percentages stating a big barrier than the other groups. Nearly $60 \%$ of older adults who have not ridden a bike in the last five years stated they do not have a bike or bike-related gear (their No.1 barrier).

Table 10-13 Barriers to Bicycling for Older Adults Planning to Bike More in the Future by the Last Time They Rode a Bike

\begin{tabular}{|c|c|c|c|}
\hline \multirow[b]{2}{*}{ Barriers to bicycling more (\% Stating Big Barrier) } & \multicolumn{3}{|c|}{ Last Biked } \\
\hline & $\begin{array}{l}\text { Last } 12 \\
\text { months }\end{array}$ & $\begin{array}{l}\text { one to } \\
\text { five } \\
\text { years }\end{array}$ & $5+$ years \\
\hline The places that I need to go are too far away to reach on a bike & $1(44 \%)$ & $1(39 \%)$ & $2(59 \%)$ \\
\hline Traffic makes riding a bike in my neighborhood feel dangerous & $2(35 \%)$ & $2(37 \%)$ & $4(56 \%)$ \\
\hline I don't have a bike or bike-related gear & $5(23 \%)$ & $3(35 \%)$ & $1(59 \%)$ \\
\hline There might not be a safe place to leave a bike at the places I go & $3(34 \%)$ & $6(28 \%)$ & $3(58 \%)$ \\
\hline It is too expensive to buy a bike or bike-related gear & $4(25 \%)$ & $8(25 \%)$ & $6(49 \%)$ \\
\hline Carrying things on a bike is too difficult & $7(21 \%)$ & $4(29 \%)$ & $5(50 \%)$ \\
\hline I don't have a safe place to store a bike at home & $8(19 \%)$ & $5(28 \%)$ & $12(36 \%)$ \\
\hline Min number of responses ${ }^{1}$ & 53 & 49 & 64 \\
\hline Max number of responses ${ }^{1}$ & 68 & 54 & 84 \\
\hline
\end{tabular}

${ }^{1}$ varies by question due to missing and "does not apply" 


\subsubsection{Findings: Older adults of color and bike sharing}

When it comes to bike share, older adults tend to have generally supportive feelings. Large majorities see bike share as being good for the city and their neighborhood (Table 10-14). Slightly lower, but still very high percentages of older adults see that there's a focused effort to make bike share better for all people and that it is getting better for people like them.

However, older adults also see some problems. Older older adults tend to see bike share as something that is not for them. This is especially the case once ability is considered. Older adults physically unable to ride a bike tended to have less positive opinions.

Older adults, overall, see the ability of bike share to bring new people to the neighborhood and to make the neighborhood more expensive as less an issue than the under-65 and able population explored in the main analysis in section 8.4. However, the physically unable population generally has less approval for the changes they are seeing in their neighborhood and take particular issue with stations' taking up street and sidewalk space.

Table 10-14 Opinions about Bike Share By Age Groups and Physical Ability to Ride A Bike

\section{Bike Share Opinions (\% agree) $)^{2}$}

[BssName] is useful for people like me

I would like to use [BssName] more than I currently do

Having nearby [BssName] stations will attract new people to move into the neighborhood

Having [BssName] nearby will make it more expensive to live in the neighborhood

Using [BssName] is a good way to spend less money on transportation

Using [BssName] is a good alternative to using public transportation

[BssName] is a good way to get to public transportation I see people like me using [BssName] in my neighborhood

I consider [BssName] to be a part of the city's public transportation system

Concerns of people like me were addressed in decisions about [BssName] in my neighborhood

[BssName] stations take up street and sidewalk space that would be better used for other things

There is a focused effort to make [BssName] better for all residents in my neighborhood

Over time, the [BssName] program is getting better at serving the needs of people like me

Overall, [BssName] is good for the city

Overall, [BssName] is good for my neighborhood

Minimum number of responses ${ }^{1}$

Maximum number of responses ${ }^{1}$

\begin{tabular}{|c|c|c|c|c|}
\hline \multicolumn{2}{|c|}{$\mathbf{5 5 - 6 4}$} & \multicolumn{2}{|c|}{$\mathbf{6 5 +}$} & \multicolumn{1}{|c|}{} \\
\hline Able & Unable & Able & Unable & All \\
\hline $\mathbf{7 5} \%$ & $\mathbf{6 1 \%}$ & $52 \%$ & $\mathbf{2 7} \%$ & $57 \%$ \\
\hline $\mathbf{5 0} \%$ & $22 \%$ & $31 \%$ & $\mathbf{1 3} \%$ & $36 \%$ \\
\hline $54 \%$ & $48 \%$ & $48 \%$ & $42 \%$ & $50 \%$ \\
\hline $16 \%$ & $19 \%$ & $21 \%$ & $13 \%$ & $17 \%$ \\
\hline $78 \%$ & $\mathbf{9 2} \%$ & $75 \%$ & $73 \%$ & $78 \%$ \\
\hline $82 \%$ & $\mathbf{9 1} \%$ & $77 \%$ & $70 \%$ & $80 \%$ \\
\hline $\mathbf{8 2} \%$ & $82 \%$ & $70 \%$ & $\mathbf{6 4} \%$ & $76 \%$ \\
\hline $\mathbf{7 8 \%}$ & $63 \%$ & $63 \%$ & $\mathbf{4 0} \%$ & $67 \%$ \\
\hline $\mathbf{8 0} \%$ & $65 \%$ & $73 \%$ & $66 \%$ & $74 \%$ \\
\hline $\mathbf{4 6} \%$ & $24 \%$ & $43 \%$ & $\mathbf{1 9} \%$ & $38 \%$ \\
\hline $\mathbf{2 2} \%$ & $\mathbf{4 2} \%$ & $23 \%$ & $\mathbf{4 0} \%$ & $27 \%$ \\
\hline $80 \%$ & $69 \%$ & $80 \%$ & $\mathbf{6 2} \%$ & $76 \%$ \\
\hline $78 \%$ & $65 \%$ & $79 \%$ & $\mathbf{4 6} \%$ & $73 \%$ \\
\hline $90 \%$ & $85 \%$ & $91 \%$ & $\mathbf{7 5} \%$ & $88 \%$ \\
\hline $88 \%$ & $82 \%$ & $90 \%$ & $\mathbf{6 5} \%$ & $85 \%$ \\
\hline 118 & 20 & 73 & 37 & 253 \\
\hline 178 & 37 & 123 & 54 & 375 \\
\hline & & & & \\
\hline
\end{tabular}

${ }^{1}$ varies by question due to missing and "no opinion"

2 bold indicates category value significantly greater or less than expected ( $p \varangle 0.05$, adj. stand Chi-Square residual) 
Among the group of older adults willing to bike, they felt bike share was a useful thing for them (76\%) and a greater percentage of them than any of the above groups want to use bike share more (65\%). Slightly less than two-thirds are in the 55-64 and able category, which explains some of their tendencies toward strong support of bike share. The boost in percentage of those who want to use bike share more does suggest this group is more willing to not just support bike share's existence but also use it.

For barriers to using bike share, the analysis only focuses on the bike-willing older adults. We believe that this group would be the one with the most potential to utilize bike share based on the above analysis.

There were less dramatic differences by when older adults last rode a bike for what they saw as barriers to using bike share than for barriers to bicycling in general (See Table 10-15). Again, those who had not ridden a bike in the last five years cited many more items as big barriers. Many of the top barriers to bike share use that were cited by the focus population in the main report were shared by those in the older adult group, such as cost issues (worrying about paying for the bike if something happens to it, membership costs and not wanting to use a credit card). For those who have ridden a bike within the last year and one to five years ago, $29 \%$ and $26 \%$, respectively, stated they would rather ride their own bike. While this was a similar percentage to the group who had not ridden in the last five years, their high ranking of this item suggests many would be hesitant to look toward bike share to meet their biking needs.

\section{Table 10-15 Barriers to Using Bike Share for Older Adults Stating They Plan to Bike More in the Next 12 Months by When They Last Rode a Bike}

\begin{tabular}{|c|c|c|c|}
\hline \multirow[b]{2}{*}{ Barriers to Using Bike Share (\%) } & \multicolumn{3}{|c|}{ Last Biked } \\
\hline & $\begin{array}{l}\text { Last } 12 \\
\text { months }\end{array}$ & $\begin{array}{c}\text { one to } \\
\text { five } \\
\text { years }\end{array}$ & $5+$ years \\
\hline I worry that I'II have to pay for the bike if anything happens to it & $1(48 \%)$ & $1(46 \%)$ & $1(57 \%)$ \\
\hline Membership or use costs are too high & $2(42 \%)$ & $5(26 \%)$ & $3(44 \%)$ \\
\hline I don't want to use a credit card to use bike share & $4(31 \%)$ & $2(37 \%)$ & $4(42 \%)$ \\
\hline I don't have a smartphone & $8(24 \%)$ & $3(28 \%)$ & $2(46 \%)$ \\
\hline I don't know enough about how to use it & $6(26 \%)$ & $6(26 \%)$ & $5(36 \%)$ \\
\hline I worry that there might not be an available bike at a station to check out & $3(33 \%)$ & $9(16 \%)$ & $6(36 \%)$ \\
\hline I just prefer to ride my own bike & $5(29 \%)$ & $4(26 \%)$ & $10(26 \%)$ \\
\hline Min number of responses ${ }^{1}$ & 48 & 27 & 31 \\
\hline Max number of responses ${ }^{1}$ & 57 & 47 & 75 \\
\hline
\end{tabular}

For testing the efficacy of potential program changes, we continued to focus on the willing to bike group. This time we grouped them further by whether they stated they were unlikely or likely to ride a bike share bike in the next 6 months. This was done because while, generally, this group was supportive of bike share, this question explicitly asks them whether they see themselves using it in the near future.

Table 10-16 shows the percentage of the willing to bike group who state they would be much more likely to use bike share for each statement on a potential program change. As expected, those stating they were likely to ride a bike share bike in the near future were much more likely to have a strong opinion on what would and would not get them to ride bike share. Their highest desires are related to costs (more membership options, 44\%; discounted memberships, 39\%). This was similar to the desires of the younger, bike-willing, people of color group that stated they were likely to ride bike share in the near 
future. However, the top desire of all groups — except older adults likely to ride a bike share bike — was free transfers between bike share and public transportation. Unlikely-to-ride older adults also want to see an option to sign up and purchase passes at stores rather than online. Considering the number of people in this group who stated a lack of smartphone as a big barrier to using bike share, this was not surprising.

Table 10-16 Efficacy of Potential Program Changes on Populations Willing to Bike by Age Group and Stated Likelihood of Riding a Bike Share Bike in the Current System

\begin{tabular}{|c|c|c|c|c|}
\hline \multirow[b]{3}{*}{$\begin{array}{c}\text { Efficacy of Potential Program Changes } \\
\text { (\% Stating Change Would Make Them Much More } \\
\text { Likely to Use [BssName]) })^{2}\end{array}$} & \multicolumn{2}{|c|}{ Older Adults } & \multicolumn{2}{|c|}{ NonOlder Adults } \\
\hline & \multicolumn{4}{|c|}{$\begin{array}{l}\text { Unlikely or likely to ride a bike share bike in the } \\
\text { next } 6 \text { months }\end{array}$} \\
\hline & Unlikely & Likely & Unlikely & Likely \\
\hline More short-term membership or pass options & $20 \%$ & $44 \%$ & $23 \%$ & $53 \%$ \\
\hline Discounted membership or use options & $18 \%$ & $39 \%$ & $26 \%$ & $53 \%$ \\
\hline Help finding safe ways to get where I need to go & $17 \%$ & $38 \%$ & $16 \%$ & $40 \%$ \\
\hline $\begin{array}{l}\text { Option to sign up or buy passes at a store instead of } \\
\text { online }\end{array}$ & $23 \%$ & $37 \%$ & $15 \%$ & $35 \%$ \\
\hline Access to free or low cost helmets and other gear & $20 \%$ & $36 \%$ & $16 \%$ & $41 \%$ \\
\hline $\begin{array}{l}\text { If more of my friends or family could use [BssName] with } \\
\text { me }\end{array}$ & $17 \%$ & $36 \%$ & $13 \%$ & $37 \%$ \\
\hline More [BssName] stations where I want to go & $20 \%$ & $33 \%$ & $15 \%$ & $39 \%$ \\
\hline Organized rides for people like me & $19 \%$ & $32 \%$ & $11 \%$ & $32 \%$ \\
\hline More [BssName] stations close together & $18 \%$ & $32 \%$ & $11 \%$ & $33 \%$ \\
\hline $\begin{array}{l}\text { Free transfers between public transportation and } \\
\text { [BssName] }\end{array}$ & $23 \%$ & $31 \%$ & $31 \%$ & $55 \%$ \\
\hline Easier way to pay with cash & $16 \%$ & $28 \%$ & $16 \%$ & $32 \%$ \\
\hline If [BssName] users were more diverse & $10 \%$ & $18 \%$ & $11 \%$ & $17 \%$ \\
\hline Min number of responses ${ }^{1}$ & 92 & 138 & 152 & 238 \\
\hline Max number of responses ${ }^{1}$ & 96 & 141 & 154 & 244 \\
\hline
\end{tabular}

${ }^{1}$ varies by question due to missing and "does not apply"

${ }^{2}$ bold indicates category value significantly greater or less than expected ( $p \varangle 0.05$, adj. stand Chi-Square residual) 
Older adults willing to bike do not have any different reasons for why they would use bike share than their younger counterparts. There are also few differences in rankings on reasons between those likely and unlikely to use bike share, the main one being a high percentage of those unlikely to ride bike share selecting "nothing." (See Table 10-17). For all groups, exercise, fun and riding with friends/family top the list while commuting falls near the bottom of the list.

Table 10-17 Reasons to Try Bike Share for Populations Willing to Bike by Age Group and Stated Likelihood of Riding Bike Share in the Next 6 Months

\begin{tabular}{|c|c|c|c|c|}
\hline \multirow[b]{3}{*}{ Reasons to Try [BssName] $\left(\%\right.$ Yes) ${ }^{1}$} & \multicolumn{2}{|c|}{ Older Adults } & \multicolumn{2}{|c|}{ NonOlder Adults } \\
\hline & \multicolumn{4}{|c|}{$\begin{array}{l}\text { Unlikely or likely to ride a bike share bike in the } \\
\text { next } 6 \text { months }\end{array}$} \\
\hline & Unlikely & Likely & Unlikely & Likely \\
\hline To get exercise & $66 \%$ & $93 \%$ & $57 \%$ & $81 \%$ \\
\hline For fun & $50 \%$ & $80 \%$ & $49 \%$ & $69 \%$ \\
\hline To ride with friends/ family & $42 \%$ & $60 \%$ & $35 \%$ & $61 \%$ \\
\hline To help the environment & $38 \%$ & $56 \%$ & $28 \%$ & $47 \%$ \\
\hline It's an easy way to get around & $29 \%$ & $53 \%$ & $21 \%$ & $47 \%$ \\
\hline Stations are near my home/work/ school & $29 \%$ & $50 \%$ & $22 \%$ & $51 \%$ \\
\hline Want to try biking & $24 \%$ & $48 \%$ & $15 \%$ & $45 \%$ \\
\hline $\begin{array}{l}\text { Saves me money compared to other transportation } \\
\text { options }\end{array}$ & $20 \%$ & $32 \%$ & $20 \%$ & $39 \%$ \\
\hline Don't need a bike of my own & $15 \%$ & $30 \%$ & $17 \%$ & $29 \%$ \\
\hline $\begin{array}{l}\text { Saves me time compared to other transportation } \\
\text { options }\end{array}$ & $13 \%$ & $22 \%$ & $13 \%$ & $29 \%$ \\
\hline To get to a bus or rail stop & $12 \%$ & $18 \%$ & $9 \%$ & $20 \%$ \\
\hline Don't want to rely on transit & $11 \%$ & $14 \%$ & $13 \%$ & $22 \%$ \\
\hline To get to social services & $9 \%$ & $13 \%$ & $2 \%$ & $8 \%$ \\
\hline To get to jobs easily & $8 \%$ & $11 \%$ & $4 \%$ & $11 \%$ \\
\hline Nothing - I wouldn't consider using [BssName] & $20 \%$ & $7 \%$ & $24 \%$ & $3 \%$ \\
\hline $\mathrm{n}$ & 93 & 139 & 150 & 246 \\
\hline
\end{tabular}

\subsubsection{Younger, physically unable respondents}

This brief section covers the 97 respondents who stated they were younger than 55 years old and physically unable to ride a bike. Given the small sample size, we are constrained in the analyses that we can conduct, but we try to give as comprehensive a view as we can as to how they may differ from the physically unable group 55 years old and older. Of those who provided responses, 88\% were of lower income (68\% were classified as less than $150 \%$ of the poverty level) and $96 \%$ were people of color. For the remaining analysis, we restrict our analysis to just the lower-income respondents of color. While this further lessens the sample size to 51 respondents, this helps control for potential spuriousness related to inclusion of white and higher-income populations.

Younger physically unable people expressed a stronger agreement toward the statement of wanting to ride a bike more in the future (32\% vs. $12 \%$ for older adults). They also feel that riding a bike would make them much more independent (42\% vs. 14\% for older adults). One-third of respondents under age 55 who are physically unable to ride a bike stated they would like to use bike share more than they currently do. 
On their opinions around bike share, like the older-adult unable population, younger unable people largely felt they did not have a say in decisions around the bike share program (71\%). More than half also believed that bike share stations take up street and sidewalk space. Half of all people physically unable to ride a bike believe that bike share is getting better at serving the needs of people like them. Considering that these results are limited to populations earning less than $300 \%$ of the poverty level, this may be due to changes to the programs around low-income populations.

\subsubsection{Discussion}

Just as with any equity strategy, the intersections of concerns of any one person create complicated storylines. This makes it difficult to determine what aspect of a program is most important to any one person or group of people. We discovered through the analysis of the survey results for older adults and populations physically unable to ride a bike that their stories are incredibly complex. While program changes around discounts may allow a bike share program to capture some of the population, many people have layers of concerns that need to be addressed before they will consider using bike share. We saw some evidence that higher-income older adults were possibly seeing the efforts to improve equity in the system as something that was not accommodating their needs. Similarly, people physically unable to ride a bike were not seeing efforts to improve the system for people like them.

From the questions we asked, it is difficult to determine what the physical ailments are that led respondents to classify themselves as physically unable to ride a bike. The wide range of possibilities within this group makes it difficult to determine how much of an impediment their physical ailments are to their riding a bike. This started to reveal itself within the younger and physically unable group. Considering the percentages of this group that wants to ride a bike more and ride bike share more, their physical ailments may not be as much of a barrier as they are for older adults. For populations stating they are physically unable to ride a bike, e bike share organizations should reach out to local disability groups and residents to consider possible solutions.

The willing-to-bike group presents some interesting strategies for bike share organizations. Over a third of the older-adult population in this group earned less than $150 \%$ of the poverty level and another $27 \%$ are added in the $150 \%-300 \%$ poverty level group. Thus, their concerns largely overlap with issues around income. Older adults who have not biked in the last five years listed a lack of bike and bike-related gear as their top barrier. A bike share bike could address that problem, with some outreach efforts. However, the barriers of traffic and the places they want to go being too far away are very large barriers and would likely need to be addressed to get these people over the hump. Overall, $3 \%$ of all older adults in our study stated they have ridden a bike share bike, and over $25 \%$ stated that it is likely they will ride a bike share bike in the next 6 months. How many of those will actually end up riding a bike share bike is unknown, but the potential is there.

\section{3 Those not interested in riding}

The resident survey sample provided an opportunity to understand some of the opinions, perceptions and concerns of a group whose voice is often not included in understanding bicycling or bike share - people of color who do not ride a bicycle and are not interested in doing so. Even if they do not use bike share, they may view it as having an impact on their city, neighborhood, friends or family.

To get at these individuals, we wanted to break respondents into people who had ridden a bicycle at some point in the recent past, and those who had not, and those who expressed interest in biking more compared with those who did not. Among respondents of color, those who indicated that they had ridden a bicycle within the past five years were divided into one group $(n=443)$. Those who had not ridden a 
bicycle in the past five years ( $\mathrm{n}=451)$ were divided into two groups based on whether they agreed with the statement "I would like to ride a bicycle (for transportation) more than I currently do" (n=124) or disagreed (i.e. are not interested in riding more, $n=327$ ). We also limited the respondents for this analysis to those under age 65 (and in the case of the barriers discussion, those who are physically able to ride a bicycle).

Table 10-18 shows the percentage of respondents in each of these groups who agree with statements about their neighborhood, city, and transportation. Those in the "not interested" group were a bit less likely to think changes were making the neighborhood more appealing, that their transportation options had improved in the past 12 months, or that their concerns were considered in decisions affecting their neighborhood. However, across most other questions in this section, the "not interested" respondents were largely in agreement with those who had ridden a bicycle, or those who expressed interest in riding.

Table 10-18 Perceptions of Neighborhood and Transportation, by Interest in Bicycling, Respondents of Color

\begin{tabular}{|c|c|c|c|c|}
\hline $\begin{array}{l}\text { Statements about neighborhood and city } \\
\text { (\% Agree) }\end{array}$ & $\begin{array}{c}\text { Ridden } \\
\text { in past } \\
\text { five } \\
\text { years }\end{array}$ & $\begin{array}{c}\text { Not } \\
\text { ridden } \\
\text { past five } \\
\text { years; Not } \\
\text { Interested }\end{array}$ & $\begin{array}{l}\text { Not ridden } \\
\text { past five } \\
\text { years; } \\
\text { possibly } \\
\text { interested }\end{array}$ & $\begin{array}{c}\text { Total } \\
\text { (these } \\
\text { groups) }\end{array}$ \\
\hline I am satisfied with my options for getting where I need to go & $88 \%$ & $83 \%$ & $80 \%$ & $85 \%$ \\
\hline $\begin{array}{l}\text { I usually know about community and social events in my } \\
\text { neighborhood }\end{array}$ & $57 \%$ & $55 \%$ & $55 \%$ & $56 \%$ \\
\hline $\begin{array}{l}\text { I know about services provided by community or faith based } \\
\text { organizations in my neighborhood }\end{array}$ & $46 \%$ & $41 \%$ & $45 \%$ & $44 \%$ \\
\hline $\begin{array}{l}\text { I have noticed changes in my neighborhood in the past } 12 \\
\text { months }\end{array}$ & $88 \%$ & $85 \%$ & $82 \%$ & $86 \%$ \\
\hline $\begin{array}{l}\text { Recent changes make my neighborhood more appealing to } \\
\text { me }\end{array}$ & $75 \%$ & $63 \%$ & $69 \%$ & $70 \%$ \\
\hline $\begin{array}{l}\text { I may have to leave my neighborhood because it is getting } \\
\text { too expensive }\end{array}$ & $40 \%$ & $43 \%$ & $48 \%$ & $42 \%$ \\
\hline I have provided input on decisions affecting my neighborhood & $41 \%$ & $34 \%$ & $40 \%$ & $39 \%$ \\
\hline $\begin{array}{l}\text { Concerns of people like me are considered in decisions } \\
\text { affecting my neighborhood }\end{array}$ & $55 \%$ & $44 \%$ & $47 \%$ & $50 \%$ \\
\hline $\begin{array}{l}\text { My city government does a good job of serving people like } \\
\text { me }\end{array}$ & $40 \%$ & $32 \%$ & $29 \%$ & $36 \%$ \\
\hline $\begin{array}{l}\text { I can usually get to and from home and where I need to go } \\
\text { easily enough }\end{array}$ & $90 \%$ & $86 \%$ & $87 \%$ & $88 \%$ \\
\hline $\begin{array}{l}\text { My options for getting around have gotten better in the past } \\
12 \text { months }\end{array}$ & $67 \%$ & $56 \%$ & $60 \%$ & $62 \%$ \\
\hline $\begin{array}{l}\text { The public transit agency does a good job serving people like } \\
\text { me }\end{array}$ & $75 \%$ & $65 \%$ & $63 \%$ & $70 \%$ \\
\hline Minimum number of responses ${ }^{1}$ & 369 & 258 & 99 & 730 \\
\hline Maximum number of responses ${ }^{1}$ & 433 & 314 & 120 & 865 \\
\hline
\end{tabular}


Table 10-19 shows the percentage of respondents in each of these groups that agree with statements about bicycling in general, while Table 10-20 shows the level of agreement with statements about bike share. Two trends emerge.

First, across numerous statements about bicycling and about bike share, those in the "not interested" group were more likely to express somewhat more negative views toward bicycling and bike share. One notable statement is that "riding a bike would make me more independent in getting around" — only 22\% of the not interested group agreed with that statement, while $68 \%$ of the possibly interested group agreed (significantly more than even those who had ridden a bicycle in the past five years). Less than a quarter in this group felt that concerns of people like them were addressed in decisions about the bike share system in their neighborhood

The second notable trend that emerges is that, on many statements, those who are not interested in bicycling more, while they are not as positive as other respondents, still hold many positive views toward bicycling and bike share: Over three-quarters agree that getting people on bikes is good for the environment (77\%), is good for making the community healthier (78\%), is a convenient way for people to get places (82\%), and that the city should invest in bike projects (77\%). They even report agreeing with a number of ways bicycling could help them personally, including being a good way to get exercise (82\%), and helping them spend less on transportation (58\%). Half of these respondents felt that the bike share system was useful for people like them, and most agreed that it was a good way to spend less on transportation (73\%) and a good alternative to public transportation (74\%). Despite having somewhat less positive views on the subject, $82 \%$ in the not interested group felt the bike share system was good for the city, and 74\% felt it was good for their neighborhood. 
Table 10-19 Opinions on Bicycling, by Interest in Bicycling, Respondents of Color

\begin{tabular}{|c|c|c|c|c|}
\hline $\begin{array}{l}\text { Opinions about bicycling in general } \\
\text { ( } \% \text { agree })\end{array}$ & $\begin{array}{c}\text { Ridden } \\
\text { in past } \\
\text { five } \\
\text { years }\end{array}$ & $\begin{array}{c}\text { Not } \\
\text { ridden } \\
\text { past five } \\
\text { years; Not } \\
\text { Interested }\end{array}$ & $\begin{array}{l}\text { Not ridden } \\
\text { past five } \\
\text { years; } \\
\text { possibly } \\
\text { interested }\end{array}$ & $\begin{array}{c}\text { Total } \\
\text { (these } \\
\text { groups) }\end{array}$ \\
\hline $\begin{array}{l}\text { Getting more people to ride bikes is good for the } \\
\text { environment }\end{array}$ & $95 \%$ & $77 \%$ & $93 \%$ & $89 \%$ \\
\hline $\begin{array}{l}\text { Getting more people to ride bikes will help make the } \\
\text { community healthier }\end{array}$ & $93 \%$ & $78 \%$ & $95 \%$ & $88 \%$ \\
\hline $\begin{array}{l}\text { [CityName] should invest in projects (such as bike lanes) that } \\
\text { make riding bikes safer and easier }\end{array}$ & $88 \%$ & $77 \%$ & $93 \%$ & $85 \%$ \\
\hline People on bikes make roads less safe for others & $41 \%$ & $55 \%$ & $48 \%$ & $47 \%$ \\
\hline Bike lanes make it harder to get around my neighborhood & $22 \%$ & $35 \%$ & $25 \%$ & $27 \%$ \\
\hline $\begin{array}{l}\text { Riding a bike is a convenient way for people to get places in } \\
\text { [CityName] }\end{array}$ & $90 \%$ & $82 \%$ & $92 \%$ & $87 \%$ \\
\hline I am familiar with the bike lanes in my neighborhood & $81 \%$ & $74 \%$ & $80 \%$ & $79 \%$ \\
\hline I often see people like me riding bikes in my neighborhood & $79 \%$ & $61 \%$ & $71 \%$ & $72 \%$ \\
\hline There are better ways for me to get around than by biking & $81 \%$ & $90 \%$ & $86 \%$ & $85 \%$ \\
\hline $\begin{array}{l}\text { Riding a bike would make me more independent in getting } \\
\text { around }\end{array}$ & $51 \%$ & $22 \%$ & $68 \%$ & $45 \%$ \\
\hline Riding a bike would help me spend less on transportation & $79 \%$ & $58 \%$ & $83 \%$ & $73 \%$ \\
\hline Riding a bike would be a good way for me to get exercise & $96 \%$ & $82 \%$ & $94 \%$ & $91 \%$ \\
\hline $\begin{array}{l}\text { Riding a bike would be a good way for me to spend time with } \\
\text { friends or family }\end{array}$ & $59 \%$ & $30 \%$ & $61 \%$ & $50 \%$ \\
\hline I'm bicycling more now than I did a year ago & $28 \%$ & $3 \%$ & $14 \%$ & $18 \%$ \\
\hline I plan to ride a bicycle more often in the next year & $71 \%$ & $16 \%$ & $52 \%$ & $51 \%$ \\
\hline There is a bike shop that is convenient for me to go to & $65 \%$ & $42 \%$ & $49 \%$ & $56 \%$ \\
\hline Minimum number of responses ${ }^{1}$ & 375 & 210 & 97 & 682 \\
\hline Maximum number of responses ${ }^{1}$ & 427 & 287 & 121 & 825 \\
\hline
\end{tabular}

${ }^{1}$ varies by question due to missing and "no opinion" or "does not apply"

Bolded percentages indicate significant difference (at 0.5\%ANOVA with Tukey post-hoc test). If one of three groups is bolded, it is different from both other groups; if two are bolded, they are different from each other; if all three are bolded, they are all different from one another. Excludes those over 65 and white respondents. 
Table 10-20 Opinions about Bike Share, by Interest in Bicycling, Respondents of Color

\begin{tabular}{|c|c|c|c|c|}
\hline $\begin{array}{l}\text { Opinions about [BssName] } \\
\text { (\% agree) }\end{array}$ & $\begin{array}{c}\text { Ridden } \\
\text { in past } \\
\text { five } \\
\text { years }\end{array}$ & $\begin{array}{c}\text { Not } \\
\text { ridden } \\
\text { past five } \\
\text { years; Not } \\
\text { Interested }\end{array}$ & $\begin{array}{l}\text { Not ridden } \\
\text { past five } \\
\text { years; } \\
\text { possibly } \\
\text { interested }\end{array}$ & $\begin{array}{c}\text { Total } \\
\text { (these } \\
\text { groups) }\end{array}$ \\
\hline [BssName] is useful for people like me & $75 \%$ & $50 \%$ & $77 \%$ & $67 \%$ \\
\hline I would like to use [BssName] more than I currently do & $58 \%$ & $25 \%$ & $70 \%$ & $49 \%$ \\
\hline $\begin{array}{l}\text { Having nearby [BssName] stations will attract new people to } \\
\text { move into the neighborhood }\end{array}$ & $63 \%$ & $47 \%$ & $63 \%$ & $58 \%$ \\
\hline $\begin{array}{l}\text { Having [BssName] nearby will make it more expensive to live in } \\
\text { the neighborhood }\end{array}$ & $19 \%$ & $29 \%$ & $24 \%$ & $23 \%$ \\
\hline $\begin{array}{l}\text { Using [BssName] is a good way to spend less money on } \\
\text { transportation }\end{array}$ & $77 \%$ & $73 \%$ & $88 \%$ & $78 \%$ \\
\hline $\begin{array}{l}\text { Using [BssName] is a good alternative to using public } \\
\text { transportation }\end{array}$ & $86 \%$ & $74 \%$ & $92 \%$ & $83 \%$ \\
\hline [BssName] is a good way to get to public transportation & $82 \%$ & $71 \%$ & $82 \%$ & $78 \%$ \\
\hline I see people like me using [BssName] in my neighborhood & $80 \%$ & $59 \%$ & $72 \%$ & $72 \%$ \\
\hline $\begin{array}{l}\text { I consider [BssName] to be a part of the city's public } \\
\text { transportation system }\end{array}$ & $74 \%$ & $65 \%$ & $83 \%$ & $73 \%$ \\
\hline $\begin{array}{l}\text { Concerns of people like me were addressed in decisions about } \\
\text { [BssName] in my neighborhood }\end{array}$ & $43 \%$ & $23 \%$ & $46 \%$ & $36 \%$ \\
\hline $\begin{array}{l}\text { [BssName] stations take up street and sidewalk space that } \\
\text { would be better used for other things }\end{array}$ & $21 \%$ & $39 \%$ & $24 \%$ & $27 \%$ \\
\hline $\begin{array}{l}\text { There is a focused effort to make [BssName] better for all } \\
\text { residents in my neighborhood }\end{array}$ & $74 \%$ & $65 \%$ & $74 \%$ & $71 \%$ \\
\hline $\begin{array}{l}\text { Over time, the [BssName] program is getting better at serving } \\
\text { the needs of people like me }\end{array}$ & $80 \%$ & $59 \%$ & $76 \%$ & $74 \%$ \\
\hline Overall, [BssName] is good for the city & $92 \%$ & $82 \%$ & $90 \%$ & $88 \%$ \\
\hline Overall, [BssName] is good for my neighborhood & $89 \%$ & $74 \%$ & $88 \%$ & $84 \%$ \\
\hline Minimum number of responses ${ }^{1}$ & 235 & 128 & 74 & 469 \\
\hline Maximum number of responses ${ }^{1}$ & 383 & 239 & 108 & 730 \\
\hline
\end{tabular}


In comparing these groups in regard to barriers to bicycling and bike share, we removed those who indicated they were not physically able to ride a bicycle. Table 10-21 shows the percentage of respondents in each group who stated each barrier to bicycling was a big barrier. The percentage of respondents in the not interested group who felt that traffic safety concerns were a big barrier to bicycling was a surprising $72 \%$, compared to $54 \%$ among those who were interested, and $39 \%$ among those who had actually ridden in the past five years. Carrying things on a bike was another top barrier for the not interested group, with 51\% reporting this as a big barrier.

Table 10-21 Barriers to Bicycling, by Interest in Bicycling, Respondents of Color

\begin{tabular}{|c|c|c|c|c|}
\hline $\begin{array}{l}\text { Barriers to bicycling more } \\
\text { (\% stating big barrier) }\end{array}$ & $\begin{array}{c}\text { Ridden } \\
\text { in past } \\
\text { five } \\
\text { years }\end{array}$ & $\begin{array}{l}\text { Not ridden } \\
\text { past five } \\
\text { years, Not } \\
\text { Interested }\end{array}$ & $\begin{array}{c}\text { Not ridden } \\
\text { past five } \\
\text { years, } \\
\text { possibly } \\
\text { interested }\end{array}$ & Total \\
\hline $\begin{array}{l}\text { I don't have a bike or related gear (such as helmet / lock / } \\
\text { lights) }\end{array}$ & $31 \%$ & $49 \%$ & $52 \%$ & $39 \%$ \\
\hline It is too expensive to buy a bike or related gear & $25 \%$ & $39 \%$ & $51 \%$ & $33 \%$ \\
\hline I don't know a good place for me to get a bike fixed & $15 \%$ & $22 \%$ & $37 \%$ & $20 \%$ \\
\hline I don't have a safe place to store a bike at home & $25 \%$ & $36 \%$ & $39 \%$ & $30 \%$ \\
\hline $\begin{array}{l}\text { There might not be a safe place to leave a bike at the places I } \\
\text { go }\end{array}$ & $37 \%$ & $44 \%$ & $51 \%$ & $41 \%$ \\
\hline The places that I need to go are too far away to reach on a bike & $40 \%$ & $62 \%$ & $56 \%$ & $48 \%$ \\
\hline I don't know how to get where I need to go by bike & $9 \%$ & $26 \%$ & $19 \%$ & $15 \%$ \\
\hline Traffic makes riding a bike in my neighborhood feel dangerous & $39 \%$ & $72 \%$ & $54 \%$ & $50 \%$ \\
\hline My bike is not good for riding around the city & $15 \%$ & $31 \%$ & $28 \%$ & $19 \%$ \\
\hline I am too old to ride a bike & $5 \%$ & $21 \%$ & $14 \%$ & $10 \%$ \\
\hline I am too out of shape to ride a bike & $7 \%$ & $20 \%$ & $18 \%$ & $13 \%$ \\
\hline Biking might aggravate my personal health issues & $8 \%$ & $22 \%$ & $16 \%$ & $13 \%$ \\
\hline Carrying things on a bike is too difficult & $28 \%$ & $51 \%$ & $36 \%$ & $35 \%$ \\
\hline Riding a bike with my kids is a hassle & $23 \%$ & $32 \%$ & $34 \%$ & $26 \%$ \\
\hline Something could go wrong with a bike (such as a flat tire) & $14 \%$ & $33 \%$ & $36 \%$ & $22 \%$ \\
\hline My friends and family wouldn't want me to ride a bike & $8 \%$ & $20 \%$ & $17 \%$ & $12 \%$ \\
\hline Riding a bike is not viewed as a cool activity by my friends & $5 \%$ & $10 \%$ & $11 \%$ & $7 \%$ \\
\hline People might think that I can't afford a car & $6 \%$ & $11 \%$ & $11 \%$ & $8 \%$ \\
\hline Riding a bike could make me a target for police attention & $8 \%$ & $12 \%$ & $16 \%$ & $10 \%$ \\
\hline Riding a bike could cause me to be harassed or a victim of crime & $18 \%$ & $30 \%$ & $30 \%$ & $23 \%$ \\
\hline Riding a bike could mess up my hair or appearance & $8 \%$ & $15 \%$ & $12 \%$ & $11 \%$ \\
\hline The clothes I wear are not appropriate for biking & $12 \%$ & $21 \%$ & $10 \%$ & $14 \%$ \\
\hline Riding a bike could make me sweaty & $16 \%$ & $24 \%$ & $17 \%$ & $18 \%$ \\
\hline Minimum number of responses ${ }^{1}$ & 204 & 54 & 40 & 315 \\
\hline Maximum number of responses ${ }^{1}$ & 366 & 164 & 91 & 619 \\
\hline
\end{tabular}


Table 10-22 shows the percentage of respondents in each group indicating that each bike share barrier was a big barrier. Among bike share barriers, the not interested group was more likely to list concerns about the bike adjusting to fit them, using a credit card, not having a smartphone, and not wanting to support the program. Interestingly, the possibly interested group differed from those who had ridden in the past five years on only two bike share barriers - they were more likely to be concerned about liability should something happen to the bicycle, and were more likely to say they lack adequate knowledge about how to use the bike share system.

Table 10-22 Barriers to using Bike Share, by Interest in Bicycling, Respondents of Color

\begin{tabular}{|c|c|c|c|c|}
\hline $\begin{array}{l}\text { Reasons for not using [BssName] more } \\
\text { (\% stating big barrier) }\end{array}$ & $\begin{array}{c}\text { Ridden } \\
\text { in past } \\
\text { five } \\
\text { years }\end{array}$ & $\begin{array}{c}\text { Not } \\
\text { ridden } \\
\text { past five } \\
\text { years, Not } \\
\text { Interested }\end{array}$ & $\begin{array}{c}\text { Not ridden } \\
\text { past five } \\
\text { years, } \\
\text { possibly } \\
\text { interested }\end{array}$ & Total \\
\hline I worry that I'II have to pay for the bike if anything happens to it & $38 \%$ & $48 \%$ & $62 \%$ & $44 \%$ \\
\hline I don't know enough about how to use it & $22 \%$ & $35 \%$ & $42 \%$ & $28 \%$ \\
\hline Membership or use costs are too high & $40 \%$ & $44 \%$ & $48 \%$ & $43 \%$ \\
\hline $\begin{array}{l}\text { I worry that there might not be an available bike at a station to } \\
\text { check out, or a free space at a station when returning a bike }\end{array}$ & $23 \%$ & $29 \%$ & $32 \%$ & $26 \%$ \\
\hline I worry that the [BssName] bikes wouldn't adjust to fit me & $14 \%$ & $27 \%$ & $24 \%$ & $19 \%$ \\
\hline I don't want to use a credit card to use bike share & $27 \%$ & $44 \%$ & $35 \%$ & $33 \%$ \\
\hline I don't have a smartphone & $13 \%$ & $27 \%$ & $25 \%$ & $18 \%$ \\
\hline There aren't [BssName] stations near where I want to go & $16 \%$ & $17 \%$ & $19 \%$ & $17 \%$ \\
\hline There aren't [BssName] stations near my home & $9 \%$ & $13 \%$ & $15 \%$ & $11 \%$ \\
\hline I don't know where other stations are to drop off a bike & $15 \%$ & $21 \%$ & $25 \%$ & $18 \%$ \\
\hline I don't want to be seen on a [BssName] bike & $4 \%$ & $7 \%$ & $11 \%$ & $6 \%$ \\
\hline Signing up for [BssName] is too complicated & $8 \%$ & $13 \%$ & $13 \%$ & $10 \%$ \\
\hline Checking out and returning [BssName] bikes is too complicated & $9 \%$ & $13 \%$ & $13 \%$ & $11 \%$ \\
\hline I can't use [BssName] with my child(ren) & $24 \%$ & $34 \%$ & $24 \%$ & $26 \%$ \\
\hline I just don't want to support the [BssName] program & $7 \%$ & $22 \%$ & $11 \%$ & $11 \%$ \\
\hline I just prefer to ride my own bike & $31 \%$ & $25 \%$ & $20 \%$ & $28 \%$ \\
\hline Minimum number of responses ${ }^{1}$ & 223 & 72 & 45 & 361 \\
\hline Maximum number of responses ${ }^{1}$ & 334 & 157 & 81 & 572 \\
\hline
\end{tabular}




\section{4 Households with children}

Some of the research on bicycling indicates that having children in the household may affect adults' bicycling. For example, rates of bicycling go down after having a child (Rau and Manton, 2016, Scheiner 2014), particularly for women and after having more than one child (Scheiner, 2015). Some evidence suggests that adults with children in the household were more likely to take leisure, as opposed to utility, bicycle trips (Ryley, 2006). Moreover, the questions on our survey related to riding with children did reveal some demographic differences. Therefore, we looked more closely at differences between respondents without children and those with one or two or more children. Among respondents under 65 years of age and physically able to ride a bicycle, 364 households had at least one related child; 608 had no children. We did not have adequate information for 170 households.

Respondents with two or more children were sometimes less positive about bicycling (Table 10-23). For example, they were more likely to state that bike lanes make it harder to get around their neighborhood ( $28 \%$ vs. $18 \%$ of respondents without children). They were less likely to want to ride a bicycle for more of their transportation, though 55\% did want to do so. Their opinions about bike share did not differ much from respondents without children (Table 10-24), except that a slightly lower share (87\%) felt that overall their city’s bike share system was good for the city. 
Table 10-23 About Bicycling, by Number of Children

\begin{tabular}{|c|c|c|c|c|}
\hline $\begin{array}{l}\text { Opinions about bicycling } \\
\text { (\% agree with each statement) }\end{array}$ & $\begin{array}{l}\text { No } \\
\text { Children }\end{array}$ & 1 Child & $\begin{array}{l}2 \text { or more } \\
\text { children }\end{array}$ & Total \\
\hline Getting more people to ride bikes is good for the environment* & $94 \%$ & $89 \%$ & $88 \%$ & $92 \%$ \\
\hline $\begin{array}{l}\text { Getting more people to ride bikes will help make the community } \\
\text { healthier }\end{array}$ & $92 \%$ & $86 \%$ & $84 \%$ & $90 \%$ \\
\hline $\begin{array}{l}\text { [CityName] should invest in projects (such as bike lanes) that make } \\
\text { riding bikes safer and easier* }\end{array}$ & $90 \%$ & $83 \%$ & $84 \%$ & $87 \%$ \\
\hline People on bikes make roads less safe for others & $40 \%$ & $46 \%$ & $42 \%$ & $42 \%$ \\
\hline Bike lanes make it harder to get around my neighborhood & $18 \%$ & $23 \%$ & $28 \%$ & $21 \%$ \\
\hline $\begin{array}{l}\text { Riding a bike is a convenient way for people to get places in } \\
\text { [CityName] }\end{array}$ & $90 \%$ & $93 \%$ & $84 \%$ & $89 \%$ \\
\hline I am familiar with the bike lanes in my neighborhood & $79 \%$ & $80 \%$ & $75 \%$ & $78 \%$ \\
\hline I often see people like me riding bikes in my neighborhood & $77 \%$ & $79 \%$ & $74 \%$ & $77 \%$ \\
\hline $\begin{array}{l}\text { I would like to ride a bicycle (for transportation) more than I } \\
\text { currently do. }\end{array}$ & $68 \%$ & $60 \%$ & $55 \%$ & $64 \%$ \\
\hline There are better ways for me to get around than by biking & $75 \%$ & $85 \%$ & $79 \%$ & $78 \%$ \\
\hline Riding a bike would make me more independent in getting around & $55 \%$ & $40 \%$ & $46 \%$ & $50 \%$ \\
\hline Riding a bike would help me spend less on transportation & $74 \%$ & $75 \%$ & $70 \%$ & $74 \%$ \\
\hline Riding a bike would be a good way for me to get exercise & $95 \%$ & $95 \%$ & $92 \%$ & $94 \%$ \\
\hline $\begin{array}{l}\text { Riding a bike would be a good way for me to spend time with } \\
\text { friends or family* }\end{array}$ & $50 \%$ & $59 \%$ & $57 \%$ & $53 \%$ \\
\hline I'm bicycling more now than I did a year ago* & $26 \%$ & $17 \%$ & $18 \%$ & $23 \%$ \\
\hline I plan to ride a bicycle more often in the next year & $58 \%$ & $60 \%$ & $53 \%$ & $57 \%$ \\
\hline There is a bike shop that is convenient for me to go to & $63 \%$ & $62 \%$ & $57 \%$ & $62 \%$ \\
\hline Minimum number of responses ${ }^{1}$ & 498 & 132 & 158 & 788 \\
\hline Maximum number of responses ${ }^{1}$ & 577 & 167 & 187 & 928 \\
\hline
\end{tabular}

${ }^{1}$ varies by question due to missing and "no opinion"

Bolded percentages indicate significant difference (at 0.5\%ANOVA with Tukey post-hoc test). If one of three groups is bolded, it is different from both other groups; if two are bolded, they are different from each other; if all three are bolded, they are all different from one another. Starred statements showed a significant difference between the no-children households and the combined households with children. 
Table 10-24 Opinions about Bike Share, by Number of Children

\begin{tabular}{|c|c|c|c|c|}
\hline $\begin{array}{l}\text { Opinions about bike share } \\
\text { (\% agree with each statement) }\end{array}$ & $\begin{array}{l}\text { No } \\
\text { Children }\end{array}$ & 1 Child & $\begin{array}{l}2 \text { or more } \\
\text { children }\end{array}$ & Total \\
\hline [BssName] is useful for people like me & $75 \%$ & $69 \%$ & $73 \%$ & $74 \%$ \\
\hline I would like to use [BssName] more than I currently do & $47 \%$ & $50 \%$ & $58 \%$ & $50 \%$ \\
\hline $\begin{array}{l}\text { Having nearby [BssName] stations will attract new people to } \\
\text { move into the neighborhood }\end{array}$ & $63 \%$ & $58 \%$ & $56 \%$ & $61 \%$ \\
\hline $\begin{array}{l}\text { Having [BssName] nearby will make it more expensive to live in } \\
\text { the neighborhood }\end{array}$ & $24 \%$ & $20 \%$ & $24 \%$ & $23 \%$ \\
\hline $\begin{array}{l}\text { Using [BssName] is a good way to spend less money on } \\
\text { transportation }\end{array}$ & $77 \%$ & $77 \%$ & $75 \%$ & $77 \%$ \\
\hline $\begin{array}{l}\text { Using [BssName] is a good alternative to using public } \\
\text { transportation }\end{array}$ & $83 \%$ & $86 \%$ & $84 \%$ & $83 \%$ \\
\hline [BssName] is a good way to get to public transportation & $81 \%$ & $77 \%$ & $77 \%$ & $79 \%$ \\
\hline I see people like me using [BssName] in my neighborhood & $74 \%$ & $76 \%$ & $75 \%$ & $75 \%$ \\
\hline $\begin{array}{l}\text { I consider [BssName] to be a part of the city's public } \\
\text { transportation system }\end{array}$ & $70 \%$ & $70 \%$ & $71 \%$ & $70 \%$ \\
\hline $\begin{array}{l}\text { Concerns of people like me were addressed in decisions about } \\
\text { [BssName] in my neighborhood }\end{array}$ & $41 \%$ & $38 \%$ & $40 \%$ & $40 \%$ \\
\hline $\begin{array}{l}\text { [BssName] stations take up street and sidewalk space that would } \\
\text { be better used for other things }\end{array}$ & $19 \%$ & $21 \%$ & $28 \%$ & $21 \%$ \\
\hline $\begin{array}{l}\text { There is a focused effort to make [BssName] better for all } \\
\text { residents in my neighborhood }\end{array}$ & $68 \%$ & $74 \%$ & $69 \%$ & $70 \%$ \\
\hline $\begin{array}{l}\text { Over time, the [BssName] program is getting better at serving } \\
\text { the needs of people like me }\end{array}$ & $75 \%$ & $79 \%$ & $76 \%$ & $76 \%$ \\
\hline Overall, [BssName] is good for the city & $94 \%$ & $90 \%$ & $87 \%$ & $92 \%$ \\
\hline Overall, [BssName] is good for my neighborhood & $89 \%$ & $89 \%$ & $82 \%$ & $88 \%$ \\
\hline Minimum number of responses ${ }^{1}$ & 282 & 94 & 96 & 472 \\
\hline Maximum number of responses ${ }^{1}$ & 532 & 153 & 160 & 845 \\
\hline
\end{tabular}

${ }^{1}$ varies by question due to missing and "no opinion"

Bolded percentages indicate significant difference (at 0.5\%ANOVA with Tukey post-hoc test). If one of three groups is bolded, it is different from both other groups; if two are bolded, they are different from each other; if all three are bolded, they are all different from one another. 
Perhaps surprisingly, the barriers to bicycling did not differ much between respondents with no children and those with children (Table 10-25). One exception was that people with two or more children were more likely to say that the expense of buying a bike or related gear was a big barrier. Similarly, there were no differences in barriers to using bike share (Table 10-26).

Table 10-25 Barriers to Bicycling, by Number of Children

\begin{tabular}{|c|c|c|c|c|}
\hline $\begin{array}{c}\text { Bicycling Barriers } \\
\text { (\% indicating item is a "big barrier") }\end{array}$ & $\begin{array}{l}\text { No } \\
\text { Children }\end{array}$ & 1 Child & $\begin{array}{l}2 \text { or more } \\
\text { children }\end{array}$ & Total \\
\hline $\begin{array}{l}\text { I don't have a bike or related gear (such as helmet / lock / } \\
\text { lights) }\end{array}$ & $34 \%$ & $43 \%$ & $39 \%$ & $37 \%$ \\
\hline It is too expensive to buy a bike or related gear & $26 \%$ & $33 \%$ & $37 \%$ & $29 \%$ \\
\hline I don't know a good place for me to get a bike fixed & $14 \%$ & $16 \%$ & $21 \%$ & $16 \%$ \\
\hline I don't have a safe place to store a bike at home & $27 \%$ & $34 \%$ & $24 \%$ & $27 \%$ \\
\hline $\begin{array}{l}\text { There might not be a safe place to leave a bike at the places I } \\
\text { go }\end{array}$ & $33 \%$ & $39 \%$ & $38 \%$ & $35 \%$ \\
\hline $\begin{array}{l}\text { The places that I need to go are too far away to reach on a } \\
\text { bike* }\end{array}$ & $37 \%$ & $45 \%$ & $48 \%$ & $41 \%$ \\
\hline I don't know how to get where I need to go by bike & $12 \%$ & $9 \%$ & $13 \%$ & $12 \%$ \\
\hline Traffic makes riding a bike in my neighborhood feel dangerous & $50 \%$ & $52 \%$ & $48 \%$ & $50 \%$ \\
\hline My bike is not good for riding around the city & $15 \%$ & $14 \%$ & $12 \%$ & $14 \%$ \\
\hline I am too old to ride a bike & $8 \%$ & $8 \%$ & $7 \%$ & $8 \%$ \\
\hline I am too out of shape to ride a bike & $8 \%$ & $11 \%$ & $12 \%$ & $9 \%$ \\
\hline Biking might aggravate my personal health issues & $7 \%$ & $11 \%$ & $10 \%$ & $8 \%$ \\
\hline Carrying things on a bike is too difficult & $30 \%$ & $34 \%$ & $34 \%$ & $31 \%$ \\
\hline Riding a bike with my kids is a hassle & $17 \%$ & $32 \%$ & $33 \%$ & $27 \%$ \\
\hline Something could go wrong with a bike (such as a flat tire) & $14 \%$ & $16 \%$ & $20 \%$ & $16 \%$ \\
\hline My friends and family wouldn't want me to ride a bike & $8 \%$ & $8 \%$ & $14 \%$ & $9 \%$ \\
\hline Riding a bike is not viewed as a cool activity by my friends & $4 \%$ & $4 \%$ & $8 \%$ & $5 \%$ \\
\hline People might think that I can't afford a car & $5 \%$ & $5 \%$ & $6 \%$ & $5 \%$ \\
\hline Riding a bike could make me a target for police attention & $7 \%$ & $8 \%$ & $12 \%$ & $8 \%$ \\
\hline $\begin{array}{l}\text { Riding a bike could cause me to be harassed or a victim of } \\
\text { crime }\end{array}$ & $17 \%$ & $21 \%$ & $18 \%$ & $18 \%$ \\
\hline Riding a bike could mess up my hair or appearance & $9 \%$ & $12 \%$ & $8 \%$ & $10 \%$ \\
\hline The clothes I wear are not appropriate for biking & $12 \%$ & $16 \%$ & $11 \%$ & $13 \%$ \\
\hline Riding a bike could make me sweaty & $20 \%$ & $19 \%$ & $17 \%$ & $19 \%$ \\
\hline Minimum number of responses ${ }^{1}$ & 155 & 70 & 90 & 400 \\
\hline Maximum number of responses ${ }^{1}$ & 520 & 140 & 161 & 821 \\
\hline
\end{tabular}


Table 10-26 Barriers to Bike Share, by Number of Children

\begin{tabular}{|c|c|c|c|c|}
\hline $\begin{array}{l}\text { Bike Share Barriers } \\
\text { (\% indicating item is a "big barrier") }\end{array}$ & $\begin{array}{l}\text { No } \\
\text { Children }\end{array}$ & 1 Child & $\begin{array}{l}2 \text { or more } \\
\text { children }\end{array}$ & Total \\
\hline $\begin{array}{l}\text { I worry that I'Il have to pay for the bike if anything happens to } \\
\text { it }\end{array}$ & $31 \%$ & $37 \%$ & $43 \%$ & $34 \%$ \\
\hline I don't know enough about how to use it & $18 \%$ & $29 \%$ & $28 \%$ & $22 \%$ \\
\hline Membership or use costs are too high & $38 \%$ & $40 \%$ & $40 \%$ & $38 \%$ \\
\hline $\begin{array}{l}\text { I worry that there might not be an available bike at a station to } \\
\text { check out, or a free space at a station when returning a bike }\end{array}$ & $22 \%$ & $24 \%$ & $26 \%$ & $23 \%$ \\
\hline I worry that the [BssName] bikes wouldn't adj ust to fit me* & $11 \%$ & $19 \%$ & $17 \%$ & $14 \%$ \\
\hline I don't want to use a credit card to use bike share & $19 \%$ & $36 \%$ & $34 \%$ & $25 \%$ \\
\hline I don't have a smartphone & $12 \%$ & $13 \%$ & $14 \%$ & $13 \%$ \\
\hline There aren't [BssName] stations near where I want to go & $15 \%$ & $16 \%$ & $14 \%$ & $15 \%$ \\
\hline There aren't [BssName] stations near my home & $9 \%$ & $13 \%$ & $11 \%$ & $10 \%$ \\
\hline I don't know where other stations are to drop off a bike & $17 \%$ & $21 \%$ & $17 \%$ & $18 \%$ \\
\hline I don't want to be seen on a [BssName] bike & $6 \%$ & $4 \%$ & $5 \%$ & $6 \%$ \\
\hline Signing up for [BssName] is too complicated & $7 \%$ & $9 \%$ & $10 \%$ & $8 \%$ \\
\hline Checking out and returning [BssName] bikes is too complicated & $7 \%$ & $6 \%$ & $11 \%$ & $8 \%$ \\
\hline I can't use [BssName] with my child(ren) & $10 \%$ & $35 \%$ & $41 \%$ & $24 \%$ \\
\hline I just don't want to support the [BssName] program & $6 \%$ & $9 \%$ & $13 \%$ & $8 \%$ \\
\hline I just prefer to ride my own bike & $41 \%$ & $30 \%$ & $22 \%$ & $36 \%$ \\
\hline Minimum number of responses ${ }^{1}$ & 249 & 92 & 112 & 489 \\
\hline Maximum number of responses ${ }^{1}$ & 484 & 136 & 156 & 776 \\
\hline
\end{tabular}

${ }^{1}$ varies by question due to missing and "does not apply"

Bolded percentages indicate significant difference (at 0.5\%ANOVA with Tukey post-hoc test). If one of three groups is bolded, it is different from both other groups; if two are bolded, they are different from each other; if all three are bolded, they are all different from one another. Starred statements showed a significant differences between the no-children households and the combined households with children.

\subsection{Hispanic and Black respondents}

The main findings chapters of this report grouped respondents of color, both to maintain adequate group sizes for statistical analysis, and also because past research has shown that people of color were not participating in bike share at the same rates as white residents. We did want to examine the degree to which subgroups within the people of color analysis grouping differed, and particularly where Hispanic and Black respondents may differ (or be consistent). The lower- and higher-income groupings of white respondents in the main findings chapter can be consulted for comparison.

In past studies, there is evidence that Hispanic individuals were more likely to have ridden a bicycle in the past year (PeopleForBikes 2015). In terms of reasons for bicycling and barriers to bicycling, Brown and Sinclair (2016) found that many motivators and barriers were similar for Hispanic and Black individuals, with Hispanic respondents naming family, fun and fitness as top reasons to bike, and Black respondents naming exercise, fun and leisure. Hoe (2015b) found that, among people who had used bike share, Black and Hispanic respondents were much more likely to report using it for recreation (57\% and 80\% respectively, compared to $29 \%$ for white respondents). Brown and Sinclair (2016) also noted that in terms of concerns about personal safety, Black respondents were more likely to be concerned over being stopped by police, while Hispanic respondents were more likely to fear being victims of crime. In terms 
of bike share specifically, one study of five North American cities found that both Hispanic and Black individuals were significantly underrepresented among bike share users compared to their share of the population (Shaheen et al., 2014b). A study in Washington, D.C., compared bike share users to cyclists throughout the region, and found that, compared to their proportion among cyclists, African-Americans were underrepresented among bike share users, and that Hispanics were overrepresented among bike share users (Buck et al., 2013).

For this analysis, we started with respondents under age 65 and physically able to ride a bicycle, and include respondents in both the outreach areas covered in the main report findings and respondents in the control areas of Brooklyn and Chicago. Looking at responses to race and ethnicity demographic questions, we pulled those who indicated that they considered themselves to be Hispanic and not Black ( $n=76)$, Hispanic and Black ( $n=15)$, and Black but not Hispanic $(n=610)$. The Hispanic and Black subgroup is very small, limiting potential findings. The breakdown of these respondents by city and stated income (combined into three income categories) is shown in Table 10-27. The majority of Hispanic respondents in the sample came from the Brooklyn surveys, while half the Black (not Hispanic) respondents came from the Chicago surveys. However, the income category breakdowns of the three groups were very similar.

Table 10-27 Hispanic and Black Respondents, by City and Income Category

\begin{tabular}{|c|c|c|c|c|}
\hline & $\begin{array}{l}\text { Hispanic, not } \\
\text { Black }\end{array}$ & Hispanic, Black & $\begin{array}{c}\text { Black, not } \\
\text { Hispanic }\end{array}$ & Total \\
\hline \multicolumn{5}{|l|}{ City } \\
\hline Philadelphia & $17 \%$ & $20 \%$ & $32 \%$ & $30 \%$ \\
\hline Chicago & $5 \%$ & $27 \%$ & $49 \%$ & $43 \%$ \\
\hline Brooklyn & $78 \%$ & $53 \%$ & $20 \%$ & $27 \%$ \\
\hline$n$ & 76 & 15 & 610 & 701 \\
\hline \multicolumn{5}{|l|}{ Income } \\
\hline $0-35 \mathrm{k}$ & $54 \%$ & $53 \%$ & $55 \%$ & $55 \%$ \\
\hline $35-75 \mathrm{k}$ & $23 \%$ & $20 \%$ & $29 \%$ & $28 \%$ \\
\hline $75 k+$ & $23 \%$ & $27 \%$ & $16 \%$ & $17 \%$ \\
\hline$n$ & 70 & 15 & 564 & 649 \\
\hline
\end{tabular}

Note: Includes respondents under 65 years old and physically able to ride a bicycle. 
In terms of sources of information about bike share (Table 10-28), Black respondents were more likely to have not heard anything about bike share (at $8 \%$, compared to $0-1 \%$ for the Hispanic respondents). However, across most other sources of information, there were not significant differences among the groups. The one exception was that Hispanic respondents were more likely than Black respondents to have gotten information about bike share from the internet (37\% to 18\%).

\section{Table 10-28 Sources of Bike Share Information, Hispanic and Black Respondents}

\begin{tabular}{|c|c|c|c|}
\hline Where have you gotten information about [BssName]? & $\begin{array}{l}\text { Hispanic, } \\
\text { not Black }\end{array}$ & $\begin{array}{l}\text { Hispanic, } \\
\text { Black }\end{array}$ & $\begin{array}{c}\text { Black, not } \\
\text { Hispanic }\end{array}$ \\
\hline Have not heard anything about it ( 0 sources selected) & $1 \%$ & $0 \%$ & $8 \%$ \\
\hline Average \# of sources selected & 2.6 & 2.7 & 2.4 \\
\hline \multicolumn{4}{|c|}{$\%$ selecting each source } \\
\hline At a bike share station/ kiosk & $7 \%$ & $0 \%$ & $11 \%$ \\
\hline Talked to someone at an event & $15 \%$ & $13 \%$ & $11 \%$ \\
\hline Got something in the mail & $7 \%$ & $13 \%$ & $10 \%$ \\
\hline Ads on buses or bus shelters & $23 \%$ & $40 \%$ & $28 \%$ \\
\hline Talked to someone from the [Local Partner] & $3 \%$ & $7 \%$ & $6 \%$ \\
\hline On a billboard & $16 \%$ & $7 \%$ & $16 \%$ \\
\hline Information at work or school & $7 \%$ & $7 \%$ & $7 \%$ \\
\hline Radio & $14 \%$ & $27 \%$ & $13 \%$ \\
\hline Television & $22 \%$ & $47 \%$ & $28 \%$ \\
\hline Newspaper & $25 \%$ & $20 \%$ & $17 \%$ \\
\hline On the internet & $37 \%$ & $27 \%$ & $18 \%$ \\
\hline Friends or family & $37 \%$ & $20 \%$ & $32 \%$ \\
\hline At a community center or faith-based organization & $4 \%$ & $0 \%$ & $6 \%$ \\
\hline $\mathrm{n}$ & 73 & 15 & 577 \\
\hline
\end{tabular}

Note: Includes respondents $<65$ years old, and physically able to ride a bicycle; Bold indicates category value significantly greater than expected $(p<0.05$, adj. stand. Chi-square residual) 
Comparing different types of experience and interactions people have had with the bike share system in their city (Table 10-29) there were again few significant differences between Hispanic and Black respondents. The one area that showed a significant difference was that Hispanic respondents were more likely to have friends or family who have used bike share (49\% compared to $37 \%$ of Black respondents).

Table 10-29 Experiences with Bike Share, Hispanic and Black Respondents

\begin{tabular}{|c|c|c|c|}
\hline $\begin{array}{l}\text { About [BssName] and you } \\
\text { (\% Yes or Likely) }\end{array}$ & $\begin{array}{l}\text { Hispanic, } \\
\text { not Black }\end{array}$ & $\begin{array}{l}\text { Hispanic, } \\
\text { Black }\end{array}$ & $\begin{array}{l}\text { Black, not } \\
\text { Hispanic }\end{array}$ \\
\hline \multicolumn{4}{|l|}{$\%$ responding yes } \\
\hline Have you noticed a [BssName] station in your neighborhood? & $97 \%$ & $93 \%$ & $94 \%$ \\
\hline Have you ridden a [BssName] bike? & $9 \%$ & $20 \%$ & $11 \%$ \\
\hline Are you currently a [BssName] pass holder? & $3 \%$ & $0 \%$ & $3 \%$ \\
\hline If no: Have you ever been a [BssName] pass holder? & $1 \%$ & $0 \%$ & $2 \%$ \\
\hline Did you receive a coupon for a free [BssName] ride or day-use? & $1 \%$ & $13 \%$ & $3 \%$ \\
\hline $\begin{array}{l}\text { Have you gone on an organized bike ride where you learned about } \\
\text { [BssName]? }\end{array}$ & $1 \%$ & $7 \%$ & $3 \%$ \\
\hline Have any of your friends or family used [BssName]? & $49 \%$ & $27 \%$ & $37 \%$ \\
\hline Do you follow [BssName] on Instagram, Twitter, Facebook, or Email? & $4 \%$ & $0 \%$ & $4 \%$ \\
\hline Have you ever talked to someone who works with [BssName]? & $13 \%$ & $20 \%$ & $9 \%$ \\
\hline Have you attended special events related to [BssName]? & $7 \%$ & $0 \%$ & $4 \%$ \\
\hline $\begin{array}{l}\text { Do you expect that you will be a [BssName] pass holder } 12 \text { months from } \\
\text { now? }\end{array}$ & $11 \%$ & $7 \%$ & $12 \%$ \\
\hline \multicolumn{4}{|c|}{$\%$ responding likely (somewhat or very) } \\
\hline Seek more information about using [BssName] & $38 \%$ & $20 \%$ & $41 \%$ \\
\hline Tell someone you know about [BssName] & $55 \%$ & $33 \%$ & $47 \%$ \\
\hline Ride a [BssName] bike? & $39 \%$ & $40 \%$ & $44 \%$ \\
\hline Minimum number of responses ${ }^{1}$ & 70 & 15 & 577 \\
\hline Maximum number of responses ${ }^{1}$ & 76 & 15 & 608 \\
\hline
\end{tabular}

${ }^{1}$ varies by question due to missing

Note: Includes respondents $<65$ years old, and physically able to ride a bicycle; Bold indicates category value significantly greater than expected $(p<0.05$, adj. stand. Chi-square residual) 
Respondents' agreement with a variety of opinion statements about the bike share system is shown in Table 10-30. Hispanic respondents in the survey were a bit more likely to think that having bike share around would attract new people to the neighborhood, and that bike share would make it more expensive to live in the neighborhood. When looking just at respondents from Brooklyn (where most of the Hispanic respondents in the survey were from), Hispanic respondents were still a bit more likely to view bike share as potentially attracting new people to the neighborhood and making it more expensive to live there; however, the differences were no longer statistically significant.

Table 10-30 Opinions about Bike Share, Hispanic and Black Respondents

\begin{tabular}{|c|c|c|c|}
\hline $\begin{array}{l}\text { Opinions about [BssName] } \\
\text { (\% Agree) }\end{array}$ & $\begin{array}{l}\text { Hispanic, } \\
\text { not Black }\end{array}$ & $\begin{array}{l}\text { Hispanic, } \\
\text { Black }\end{array}$ & $\begin{array}{l}\text { Black, not } \\
\text { Hispanic }\end{array}$ \\
\hline [BssName] is useful for people like me & $78 \%$ & $54 \%$ & $70 \%$ \\
\hline I would like to use [BssName] more than I currently do & $59 \%$ & $38 \%$ & $51 \%$ \\
\hline $\begin{array}{l}\text { Having nearby [BssName] stations will attract new people to move into } \\
\text { the neighborhood }\end{array}$ & $73 \%$ & $67 \%$ & $56 \%$ \\
\hline $\begin{array}{l}\text { Having [BssName] nearby will make it more expensive to live in the } \\
\text { neighborhood }\end{array}$ & $37 \%$ & $40 \%$ & $22 \%$ \\
\hline Using [BssName] is a good way to spend less money on transportation & $79 \%$ & $73 \%$ & $77 \%$ \\
\hline Using [BssName] is a good alternative to using public transportation & $83 \%$ & $71 \%$ & $84 \%$ \\
\hline [BssName] is a good way to get to public transportation & $76 \%$ & $71 \%$ & $81 \%$ \\
\hline I see people like me using [BssName] in my neighborhood & $77 \%$ & $50 \%$ & $73 \%$ \\
\hline $\begin{array}{l}\text { I consider [BssName] to be a part of the city's public transportation } \\
\text { system }\end{array}$ & $66 \%$ & $60 \%$ & $75 \%$ \\
\hline $\begin{array}{l}\text { Concerns of people like me were addressed in decisions about } \\
\text { [BssName] in my neighborhood }\end{array}$ & $36 \%$ & $29 \%$ & $39 \%$ \\
\hline $\begin{array}{l}\text { [BssName] stations take up street and sidewalk space that would be } \\
\text { better used for other things }\end{array}$ & $32 \%$ & $29 \%$ & $25 \%$ \\
\hline $\begin{array}{l}\text { There is a focused effort to make [BssName] better for all residents in } \\
\text { my neighborhood }\end{array}$ & $70 \%$ & $50 \%$ & $73 \%$ \\
\hline $\begin{array}{l}\text { Over time, the [BssName] program is getting better at serving the } \\
\text { needs of people like me }\end{array}$ & $76 \%$ & $50 \%$ & $75 \%$ \\
\hline Overall, [BssName] is good for the city & $88 \%$ & $92 \%$ & $90 \%$ \\
\hline Overall, [BssName] is good for my neighborhood & $79 \%$ & $92 \%$ & $86 \%$ \\
\hline Minimum number of responses ${ }^{1}$ & 33 & 6 & 332 \\
\hline Maximum number of responses ${ }^{1}$ & 69 & 15 & 514 \\
\hline
\end{tabular}

${ }^{1}$ varies by question due to missing and "no opinion"

Note: Includes respondents $<65$ years old, and physically able to ride a bicycle; Bold indicates category value significantly greater than expected ( $p<0.05$, adj. stand. Chi-square residual) 
Responses to reasons to try bike share are shown in Table 10-31. Both Hispanic and Black respondents were most likely to cite exercise and fun as reasons to try using bike share, which is consistent with the Brown and Sinclair (2015) findings about reasons for bicycling in general. Hispanic respondents were more likely than Black respondents to list not wanting to rely on transit and getting to jobs more easily as possible reasons for trying bike share. No other significant differences on other potential reasons for using bike share were observed.

Table 10-31 Reasons to Try Bike Share, Hispanic and Black Respondents

\begin{tabular}{|c|c|c|c|}
\hline Reasons you would consider using [BssName] & $\begin{array}{l}\text { Hispanic, } \\
\text { not Black }\end{array}$ & $\begin{array}{l}\text { Hispanic, } \\
\text { Black }\end{array}$ & $\begin{array}{c}\text { Black, not } \\
\text { Hispanic }\end{array}$ \\
\hline None & $18 \%$ & $27 \%$ & $17 \%$ \\
\hline Average \# selected & 4.5 & 3.7 & 4.1 \\
\hline \multicolumn{4}{|c|}{$\%$ Selected } \\
\hline Want to try biking & $42 \%$ & $33 \%$ & $32 \%$ \\
\hline Saves me money compared to other transportation options & $27 \%$ & $33 \%$ & $26 \%$ \\
\hline Saves me time compared to other transportation options & $24 \%$ & $13 \%$ & $18 \%$ \\
\hline To get exercise & $62 \%$ & $53 \%$ & $69 \%$ \\
\hline For fun & $58 \%$ & $47 \%$ & $57 \%$ \\
\hline To get to bus or rail stops & $16 \%$ & $13 \%$ & $12 \%$ \\
\hline Don't want to rely on transit & $24 \%$ & $13 \%$ & $14 \%$ \\
\hline It's an easy way to get around & $36 \%$ & $33 \%$ & $33 \%$ \\
\hline To ride with friends/ family & $39 \%$ & $40 \%$ & $45 \%$ \\
\hline Stations are near my home / work / school & $32 \%$ & $20 \%$ & $34 \%$ \\
\hline To help the environment & $43 \%$ & $33 \%$ & $36 \%$ \\
\hline Don't need a bike of my own & $18 \%$ & $20 \%$ & $21 \%$ \\
\hline To get to jobs more easily & $16 \%$ & $13 \%$ & $7 \%$ \\
\hline To get to social services & $7 \%$ & $7 \%$ & $5 \%$ \\
\hline Other & $5 \%$ & $0 \%$ & $2 \%$ \\
\hline n & 74 & 15 & 588 \\
\hline
\end{tabular}

Note: Includes respondents $<65$ years old, and physically able to ride a bicycle; Bold indicates category value significantly greater than expected ( $p<0.05$, adj. stand. Chi-square residual) 
Table 10-32 shows the percentage of respondents in each group who responded correctly to each of a set of true-false questions. Hispanic respondents were more likely to correctly know that bike share users do not have to return a bike to same station they check it out from, while Black respondents were least likely to correctly know whether a credit card was required to use the system.

Table 10-32 Knowledge about the Bike Share system, Hispanic and Black Respondents

\begin{tabular}{|c|c|c|c|}
\hline $\begin{array}{c}\text { Percent of respondents responding with correct response on T/F } \\
\text { statement }\end{array}$ & $\begin{array}{l}\text { Hispanic, } \\
\text { not Black }\end{array}$ & $\begin{array}{l}\text { Hispanic, } \\
\text { Black }\end{array}$ & $\begin{array}{l}\text { Black, not } \\
\text { Hispanic }\end{array}$ \\
\hline A debit or credit card is required to use [BssName] & $64 \%$ & $80 \%$ & $52 \%$ \\
\hline People can buy a monthly pass to use [BssName] & $64 \%$ & $67 \%$ & $55 \%$ \\
\hline A helmet is required to check out a [BssName] bike & $43 \%$ & $33 \%$ & $39 \%$ \\
\hline $\begin{array}{l}\text { Nonmembers' cost is } 24-\text { hour pass for } \$[x] \text { [NYC CHI only] } \$ 4 \text { per } 30 \\
\text { minutes to use }[\mathrm{PHL} \text { only] }\end{array}$ & $41 \%$ & $47 \%$ & $38 \%$ \\
\hline $\begin{array}{l}\text { Members can use longer than nonmembers (Phil, NYC) or Members/ Day } \\
\text { Pass holders can use for } 30 \text { minutes }(\mathrm{CHI})\end{array}$ & $41 \%$ & $47 \%$ & $38 \%$ \\
\hline A [BssName] pass/ membership costs $\$[x]$ & $36 \%$ & $43 \%$ & $35 \%$ \\
\hline $\begin{array}{l}\text { A reduced price pass for [discount eligibility] is available for [discount } \\
\text { price] }\end{array}$ & $28 \%$ & $20 \%$ & $27 \%$ \\
\hline You have to be a [Sponsor] customer to use [BssName] & $61 \%$ & $87 \%$ & $58 \%$ \\
\hline You have to have a smartphone to use [BssName] & $57 \%$ & $47 \%$ & $46 \%$ \\
\hline If you exceed a time limit, the [BssName] bicycle will lock & $38 \%$ & $27 \%$ & $28 \%$ \\
\hline You have to return the bike to the same station you check it out from & $75 \%$ & $73 \%$ & $60 \%$ \\
\hline Minimum number of responses ${ }^{1}$ & 74 & 14 & 598 \\
\hline Maximum number of responses ${ }^{1}$ & 75 & 15 & 604 \\
\hline
\end{tabular}

${ }^{1}$ varies by question due to missing

Note: Includes respondents $<65$ years old, and physically able to ride a bicycle; Bold indicates category value significantly greater than expected ( $p<0.05$, adj. stand. Chi-square residual) 
We did not observe many differences between Hispanic and Black respondents on barriers to bicycling (Table 10-33). Hispanic respondents were more likely to state that not having a good place to store a bike at home was a big barrier (44\%, compared to $28 \%$ for Black respondents); however, this difference once not significant when controlling for city. Black respondents were also less likely to list not having a safe place to leave a bike at destinations as a big barrier. Although Brown and Sinclair's focus group suggested that Black individuals were more likely to be concerned over being stopped by police and Hispanic individuals were more concerned about being victims of crime, we did not see significant differences between these groups on the percentage listing concerns about being a target of police attention or being a victim of harassment or crime.

Table 10-33 Barriers to Bicycling, Hispanic and Black Respondents

\begin{tabular}{|c|c|c|c|}
\hline $\begin{array}{l}\text { Barrier to bicycling more } \\
\text { (\% stating big barrier) }\end{array}$ & $\begin{array}{l}\text { Hispanic, } \\
\text { not Black }\end{array}$ & $\begin{array}{l}\text { Hispanic, } \\
\text { Black }\end{array}$ & $\begin{array}{l}\text { Black, not } \\
\text { Hispanic }\end{array}$ \\
\hline I don't have a bike or related gear (such as helmet / lock / lights) & $32 \%$ & $54 \%$ & $40 \%$ \\
\hline It is too expensive to buy a bike or related gear & $35 \%$ & $38 \%$ & $34 \%$ \\
\hline I don't know a good place for me to get a bike fixed & $20 \%$ & $45 \%$ & $20 \%$ \\
\hline I don't have a safe place to store a bike at home & $44 \%$ & $45 \%$ & $28 \%$ \\
\hline There might not be a safe place to leave a bike at the places I go & $52 \%$ & $62 \%$ & $38 \%$ \\
\hline The places that I need to go are too far away to reach on a bike & $53 \%$ & $58 \%$ & $49 \%$ \\
\hline I don't know how to get where I need to go by bike & $12 \%$ & $50 \%$ & $14 \%$ \\
\hline Traffic makes riding a bike in my neighborhood feel dangerous & $53 \%$ & $71 \%$ & $49 \%$ \\
\hline My bike is not good for riding around the city & $21 \%$ & $0 \%$ & $20 \%$ \\
\hline I am too old to ride a bike & $7 \%$ & $0 \%$ & $12 \%$ \\
\hline I am too out of shape to ride a bike & $14 \%$ & $0 \%$ & $13 \%$ \\
\hline Biking might aggravate my personal health issues & $9 \%$ & $0 \%$ & $15 \%$ \\
\hline Carrying things on a bike is too difficult & $34 \%$ & $43 \%$ & $37 \%$ \\
\hline Riding a bike with my kids is a hassle & $22 \%$ & $17 \%$ & $27 \%$ \\
\hline Something could go wrong with a bike (such as a flat tire) & $19 \%$ & $9 \%$ & $23 \%$ \\
\hline My friends and family wouldn't want me to ride a bike & $10 \%$ & $11 \%$ & $14 \%$ \\
\hline Riding a bike is not viewed as a cool activity by my friends & $10 \%$ & $0 \%$ & $8 \%$ \\
\hline People might think that I can't afford a car & $5 \%$ & $11 \%$ & $9 \%$ \\
\hline Riding a bike could make me a target for police attention & $14 \%$ & $11 \%$ & $10 \%$ \\
\hline Riding a bike could cause me to be harassed or a victim of crime & $18 \%$ & $25 \%$ & $24 \%$ \\
\hline Riding a bike could mess up my hair or appearance & $7 \%$ & $8 \%$ & $11 \%$ \\
\hline The clothes I wear are not appropriate for biking & $10 \%$ & $23 \%$ & $15 \%$ \\
\hline Riding a bike could make me sweaty & $26 \%$ & $23 \%$ & $18 \%$ \\
\hline Minimum number of responses ${ }^{1}$ & 27 & 6 & 244 \\
\hline Maximum number of responses ${ }^{1}$ & 59 & 14 & 489 \\
\hline
\end{tabular}

${ }^{1}$ varies by question due to missing and "does not apply"

Note: Includes respondents $<65$ years old, and physically able to ride a bicycle; Bold indicates category value significantly greater than expected ( $p<0.05$, adj. stand. Chi-square residual) 
There were also few differences between Hispanic and Black respondents on barriers to bike share (Table 10-34). Only one difference was significant: Hispanic respondents were much less likely to note that not having a smartphone was a big barrier ( $8 \%$, compared to $21 \%$ for Black respondents).

Table 10-34 Barriers to Using Bike Share, Hispanic and Black Respondents

\begin{tabular}{|c|c|c|c|}
\hline $\begin{array}{l}\text { Barrier to bicycling [BssName] more } \\
\text { ( } \% \text { stating big barrier) }\end{array}$ & $\begin{array}{l}\text { Hispanic, } \\
\text { not Black }\end{array}$ & $\begin{array}{l}\text { Hispanic, } \\
\text { Black }\end{array}$ & $\begin{array}{l}\text { Black, not } \\
\text { Hispanic }\end{array}$ \\
\hline I worry that I'II have to pay for the bike if anything happens to it & $39 \%$ & $42 \%$ & $45 \%$ \\
\hline I don't know enough about how to use it & $27 \%$ & $9 \%$ & $29 \%$ \\
\hline Membership or use costs are too high & $47 \%$ & $40 \%$ & $41 \%$ \\
\hline $\begin{array}{l}\text { I worry that there might not be an available bike at a station to check } \\
\text { out, or a free space at a station when returning a bike }\end{array}$ & $24 \%$ & $45 \%$ & $26 \%$ \\
\hline I worry that the [BssName] bikes wouldn't adj ust to fit me & $21 \%$ & $10 \%$ & $19 \%$ \\
\hline I don't want to use a credit card to use bike share & $31 \%$ & $27 \%$ & $34 \%$ \\
\hline I don't have a smartphone & $8 \%$ & $11 \%$ & $21 \%$ \\
\hline There aren't [BssName] stations near where I want to go & $19 \%$ & $18 \%$ & $16 \%$ \\
\hline There aren't [BssName] stations near my home & $14 \%$ & $0 \%$ & $10 \%$ \\
\hline I don't know where other stations are to drop off a bike & $20 \%$ & $17 \%$ & $18 \%$ \\
\hline I don't want to be seen on a [BssName] bike & $5 \%$ & $0 \%$ & $6 \%$ \\
\hline Signing up for [BssName] is too complicated & $7 \%$ & $0 \%$ & $11 \%$ \\
\hline Checking out and returning [BssName] bikes is too complicated & $7 \%$ & $0 \%$ & $11 \%$ \\
\hline I can't use [BssName] with my child(ren) & $21 \%$ & $25 \%$ & $27 \%$ \\
\hline I just don't want to support the [BssName] program & $5 \%$ & $14 \%$ & $12 \%$ \\
\hline I just prefer to ride my own bike & $26 \%$ & $29 \%$ & $28 \%$ \\
\hline Minimum number of responses ${ }^{1}$ & 29 & 7 & 283 \\
\hline Maximum number of responses ${ }^{1}$ & 54 & 12 & 459 \\
\hline
\end{tabular}

${ }^{1}$ varies by question due to missing and "does not apply"

Note: Includes respondents $<65$ years old, and physically able to ride a bicycle; Bold indicates category value significantly greater than expected ( $p<0.05$, adj. stand. Chi-square residual) 
Table 10-35 shows the percentage of respondents in each group indicating that various changes would make them more likely to use the bike share system. The only significant difference observed was that Hispanic respondents were more likely to indicate that more bike share stations where they want to go would make them more likely to use bike share (78\% indicated this would make them more likely to use bike share, compared to $65 \%$ for Black respondents).

\section{Table 10-35 Efficacy of Potential Changes, Hispanic and Black Respondents}

\begin{tabular}{|c|c|c|c|}
\hline $\begin{array}{l}\text { Would the following changes make you more likely to use [BssName]? } \\
\text { ( } \% \text { somewhat or much more likely) }\end{array}$ & $\begin{array}{l}\text { Hispanic, } \\
\text { not Black }\end{array}$ & $\begin{array}{l}\text { Hispanic, } \\
\text { Black }\end{array}$ & $\begin{array}{l}\text { Black, not } \\
\text { Hispanic }\end{array}$ \\
\hline Discounted membership or use options & $77 \%$ & $83 \%$ & $76 \%$ \\
\hline More short-term membership or pass options & $75 \%$ & $85 \%$ & $74 \%$ \\
\hline Easier way to pay with cash & $58 \%$ & $46 \%$ & $57 \%$ \\
\hline Option to sign up or buy passes at a store instead of online & $56 \%$ & $62 \%$ & $61 \%$ \\
\hline Access to free or low cost helmets and other gear & $64 \%$ & $58 \%$ & $65 \%$ \\
\hline Organized rides for people like me & $55 \%$ & $67 \%$ & $65 \%$ \\
\hline If more of my friends or family could use [BssName] with me & $64 \%$ & $50 \%$ & $63 \%$ \\
\hline If [BssName] users were more diverse & $44 \%$ & $55 \%$ & $46 \%$ \\
\hline Help finding safe ways to get where I need to go & $66 \%$ & $77 \%$ & $64 \%$ \\
\hline Free transfers between public transportation and [BssName] & $81 \%$ & $85 \%$ & $72 \%$ \\
\hline More [BssName] stations close together & $65 \%$ & $45 \%$ & $60 \%$ \\
\hline More [BssName] stations where I want to go & $78 \%$ & $75 \%$ & $65 \%$ \\
\hline Minimum number of responses ${ }^{1}$ & 41 & 11 & 369 \\
\hline Maximum number of responses ${ }^{1}$ & 64 & 13 & 470 \\
\hline
\end{tabular}

${ }^{1}$ varies by question due to missing and "does not apply"

Note: Includes respondents $<65$ years old, and physically able to ride a bicycle; Bold indicates category value significantly greater than expected ( $p<0.05$, adj. stand. Chi-square residual)

\subsection{Discussion}

Overall, we found more similarities than differences among Hispanic and Black respondents in the survey neighborhoods in terms of how they view bicycling and bike share. 


\section{CONCLUSIONS}

Public bike share systems in the U.S. have been criticized for not serving the diverse populations of cities, particularly lower-income residents and people of color. Existing research has shown that people of color, along with lower-income, female, older and less-educated groups are under-represented among bike share users (Rixey, 2013, Shaheen et al., 2014, Shaheen et al., 2015, Virginia Tech, 2012). Lack of bike share stations in neighborhoods with people of color and lower incomes is one factor (Ursaki \& Aultman-Hall, 2015), but does not completely explain the disparities. The Better Bike Share Partnership (BBSP) aimed to address this problem through focused efforts and investments in several cities.

Our research aimed to better understand the barriers to and opportunities for expanding the use of bike share in traditionally underserved neighborhoods, with a focus on people of color and lower-income individuals, and to examine the effectiveness of the BBSP efforts. This report (one of three from this research project) focuses on data collected from a survey of residents in neighborhoods in Philadelphia, Brooklyn, and Chicago that were targeted for BBSP outreach efforts. The neighborhoods included in the study are majority-minority (79-94\% people of color) and lower-income (36-61\% of households under $150 \%$ of the poverty level).

The conclusions that follow are organized around our original research questions. ${ }^{8}$ They are drawn primarily from the analysis of data from adults in outreach areas who are under 65 years old and stated they were physically able to ride a bicycle. Of those respondents who provided income and race information ( $\mathrm{n}=779), 42 \%$ are lower-income (defined as $300 \%$ of poverty or below) people of color, $27 \%$ are higher-income (above $300 \%$ of poverty) people of color, $6 \%$ are lower-income and white (not Hispanic), and 25\% are higher-income and white. These four demographic categories were the basis for our equity-focused analysis, with the last category (higher-income and white) representing the more typical bike share users currently in U.S. cities (Shaheen et al., 2014).

Overall, the research approach — surveying residents in three cities - allowed us to answer our research questions and provide valuable insights into how bike share could become more equitable. Before presenting the more detailed conclusions, we draw two general conclusions related to the research approach and analysis.

First, there are far more similarities among the three cities' resident responses than differences. This indicates that the findings are likely generalizable to other cities, particularly to people of color and lower-income populations. Of course, there are always geographic differences that will affect bicycling and bike share use. In addition, our sample of people of color was predominantly Black and nonHispanic, though we found very few differences in responses between the Hispanic and Black respondents. Still, our sample does not allow us to draw conclusions about other specific races or ethnicities. This is an area ripe for additional research.

Second, we found that race and income often influence responses to bicycling and bike share in different ways. Differences in behavior and opinions sometimes correlated with income, sometimes with race, and sometimes with race and income combined. These complexities must be considered when developing programs and policies to address equity problems with bike share. Note, however, that our sample of white, lower-income respondents was small, and we cannot draw strong conclusions for that demographic group.

\footnotetext{
${ }^{8}$ Some overlapping questions have been combined.
} 


\section{1 How does bike share work for specific underserved and understudied populations?}

Currently, bike share is not a common transportation option for lower-income residents in these communities. Overall, $4 \%$ of our survey respondents were members of their city's bike share program at the time of the survey, with significant differences depending on race and income. Only $2 \%$ of the lowerincome residents (white or people of color) were members, compared to $5 \%$ of higher-income people of color and $10 \%$ of higher-income white residents. The rates for lower-income respondents are less than half that of estimated system-wide membership rates in our study cities.

Higher shares of the residents have ridden a bike share bike in their city: $9 \%$ of lower-income people of color; $18 \%$ of higher-income people of color; $13 \%$ of lower-income white residents; and $29 \%$ of higherincome white residents. Comparing membership rates with ridership rates indicates that people of color and lower-income residents may be more likely to be casual users of the system, rather than regular members. This is consistent with other research (Buck et al., 2013; Shaheen, Christensen and Viegas de Lima, 2015; Virginia Tech University, 2012).

All of the people surveyed lived within about one-quarter mile of a bike share station. Therefore, differences in membership and use based on race and income cannot be explained simply by station siting. This is also consistent with other research (Hoe, 2015b; Rixey, 2013).

\section{2 How might needs and use patterns differ from other user groups?}

People of color and lower-income residents in the survey had additional demographic characteristics that would lead to different transportation needs. For example, only $57 \%$ of the lower-income respondents of color were employed, compared to $94 \%$ of higher-income people of color and $96 \%$ of higher-income white residents. Nearly half (45\%) of the lower-income white residents surveyed were students. Respondents of color were generally older, with only $21 \%$ (lower-income) and 28\% (higher-income) in the 18-34 age group, compared to 58\% of the higher-income white residents. The lower-income respondents of color were most likely to have children at home - 58\% compared to 35\% of higher-income people of color and $22 \%$ of higher-income white residents.

Given the small share of respondents who use bike share regularly, this survey did not ask about how residents used bike share if they did use it. That is the focus of the user survey component of this research project. Those findings will appear a separate report (anticipated in summer 2017).

\section{3 Are there specific barriers among people of color and lower-income residents?}

People of color and lower-income residents cited more barriers to bicycling generally and using bike share than higher-income white residents. The extent of the barriers sometimes differed by race and/or income, though some barriers were universal.

The city efforts to locate bike share stations in these neighborhoods has largely removed one of the most significant barriers to equitable bike share cited in the research — station siting. Nearly all (95\%) of the residents had noticed a bike share station in their neighborhood. Only $10 \%$ indicated that not having bike share stations near their home was a big barrier to using bike share - one of the least common barriers among those included on the survey. Having bike share stations near destinations is a slightly greater barrier. Overall, 15\% of residents cited this as a big barrier, with no significant differences by race and income group. Another access and logistical issue - being concerned that there would be no 
bikes or open docks available at a station — was a big barrier for $23 \%$ of residents, but without differences related to race or income.

The survey revealed important cost- and liability-related barriers to using bike share. High costs of membership were a big barrier for nearly half (48\%) of lower-income respondents of color, compared to $33 \%$ of higher-income people of color and only $18 \%$ of higher-income white residents. In addition, 52\% of lower-income respondents of color worried that they would have to pay for the bike if anything happened to it and cited that as a big barrier to using bike share. This compared to $31 \%$ of higher-income people of color and $10 \%$ of higher-income white residents. These figures reveal that concerns about price and being charged for theft or damage to the bike are related to income, but also and race.

Many respondents, not just lower-income residents, felt that needing to use a credit or debit card, or a smartphone, was a barrier to using bike share (even when credit cards or smartphone were not required). Lower-income respondents of color are much less likely to have a credit or debit card (43\% and $70 \%$ respectively), a smartphone (66\%), or reliable internet access (56\%). These rates are significantly lower than all other respondents. Over one-third of lower-income respondents of color (37\%) cited not wanting to use a credit card as a big barrier for using bike share, compared with $21 \%$ of higherincome people of color and $4 \%$ of higher-income white residents. Therefore, even though higher-income people of color had credit cards at nearly the same rate as higher-income white residents (88\% and 98\%, respectively), their use was a bigger barrier for them. On the other hand, not having a smartphone was a big barrier for $24 \%$ of lower-income respondents of color, but only $1 \%-7 \%$ of the other respondent groups. Smartphones are not required to use the system, but can make it easier to find stations and know whether bikes are available.

Another set of barriers relates to knowledge - or, more importantly, lack of knowledge or incorrect knowledge. Most noticeably, 34\% of lower-income respondents of color said that not knowing enough about how to use bike share was a big barrier to using it, compared to $19 \%$ of higher-income people of color and $7 \%$ of higher-income white residents.

There were several areas of notable misconceptions about the bike share systems. Although none of the cities have mandatory helmet laws for bicycle riders, $18 \%$ of respondents thought that a helmet was required to use the bike share system. Lower-income respondents were more likely to incorrectly assume a helmet is required to use bike share. Over one-in-five (21\%) of lower-income respondents of color mistakenly thought that the bike share bike would lock if the user exceeded a time limit, compared with only $2 \%$ of higher-income white respondents. On several questions, the majority of respondents indicated that they had "no idea" about the truth of the statement. These included certain details about the cost of using the system (56\% responded "no idea") and the availability of the reduced-price membership or pass option (63\% responded "no idea"). Across these and a number of other questions, respondents in the lower-income people of color group were more likely to indicate that they didn't know whether the statements were true or not. Finally, even when cash options are available, most residents thought that using bike share requires a credit card, and lower-income people of color were least likely to know cash was an option.

The biggest barrier to bicycling generally is concern about traffic safety, regardless of race or income. Nearly half (48\%) of residents cited this as a big barrier to riding a bike in their neighborhood. For other barriers to bicycling, important differences were noted across race and income groups. Respondents of color were much more likely to cite travel distances as being too far to go by bicycle (40$44 \%$, compared to $17-23 \%$ of white respondents). It is unclear whether the places they travel are actually 
farther away, or if it reflects a difference in perceptions of bikeable distance. Income does not appear to play a major role here.

For people of color, personal safety is also a concern. Race is an important factor in whether respondents feel their personal safety could be compromised, either as a victim of crime or as a target for police attention. For people of color, being lower-income further exacerbated the concerns. For example, $22 \%$ of lower-income respondents of color stated that a big barrier to riding was that doing so could cause them to be harassed or a victim of crime. This compared to $17 \%$ of higher-income people of color and $7 \%$ of higher-income white residents. While a smaller share (11\%) of lower-income respondents of color cited being a target for police attention as a big barrier to bicycling, this was still higher than for higherincome people of color (6\%) and higher-income white residents (1\%).

Other common perceptions of barriers to bicycling, such as comfort issues and social stigmas, do not appear to be major. For example, only $10 \%$ of residents cited messed-up hair or appearance as a big barrier to bicycling, with no differences by race or income. However, while only $4 \%$ of all residents stated that people thinking that they could not afford a car was a big barrier to riding a bicycle (generally, not just a bike share bike), $10 \%$ of lower-income respondents of color cited this as a big barrier. On the other hand, a high share of residents (75\%) agreed that they see people like them using bike share, and this share was the same for respondents of color (lower- and higher-income) as higher-income white residents.

\section{4 Are there specific opportunities for increasing bike share use among people of color and lower-income residents?}

Lower-income residents have fewer mobility options. Less than half (49\%) of lower-income respondents of color had a driver's license, compared with over $90 \%$ of the higher-income respondents. These respondents made most of their trips on transit, in addition to walking. Only 30\% of them had a car available for use and only $17 \%$ had a working bicycle.

Bike share may address many of the major barriers to bicycling for these residents. Some of the most common barriers to bicycling cited by lower-income people of color included not having a bike or related gear (47\%); not having a safe place to leave a bike at their destination (36\%); the expense of buying a bike or related gear (41\%); not having a safe place to store a bike at home (32\%); not knowing a place to get a bike fixed (23\%); and worries about something going wrong with a bike, such as a flat tire (20\%). Nearly all of these barriers were more significant for lower-income respondents of color than the other respondents, and many were among the top ten barriers to bicycling. They are all barriers that can be addressed with bike share.

There is strong interest among residents in these neighborhoods in using bike share more in the future. Over half (56\%) of lower-income respondents of color agreed that they would like to use bike share more than they currently do. Moreover, $44 \%$ of this group indicated that they were likely to seek more information about using bike share, over 10 percentage points higher than the other demographic groups. In addition, $11 \%$ of all residents expected to become a member in the next 12 months, with no differences among race and income groups.

Recreational reasons for using bike share are more broadly cited, particularly for lower-income people of color, but may be less motivating without some accompanying utilitarian motivation. Getting exercise was cited by $71 \%$ of lower-income respondents of color as a reason they would consider using bike share, a rate much higher than other respondent groups. Being able to ride with friends and family was cited by $48 \%$ of lower-income respondents of color, again higher than other demographic groups. Respondents of color were also less likely to list a number of utilitarian items as reasons they 
might try bike share, including saving them time compared to other transportation options, and not wanting to rely on transit.

However, respondents who only listed recreation items as reasons they would consider using bike share were less likely to indicate that they intended to ride a bike share bike or to become bike share members in the future. Either making bike share more attractive for recreational use or making a better case for bike share's transportation utility among people who currently only see recreational value might improve outreach results. Examples to explore might include extended check-outs (perhaps on weekends or offpeak hours), pricing options better suited to occasional users, or more information on how to reach common destinations by bike share.

Residents generally have positive attitudes about bicycling and bike share. A large majority of all residents (73\%) agreed that the city's bike share system "is useful for people like me.” Agreement among lower-income respondents of color was equally high (74\%). Residents see bicycling as a good way for them to get exercise (over $90 \%$ of all demographic groups), to spend less on transportation (over $70 \%$ of all demographic groups), and to spend time with friends or family (about half of respondents of color). These positive statements about bicycling generally appear to apply to bike share as well, particularly for lower-income respondents of color. As noted above, some common negative social and comfort perceptions of bicycling do not appear to be major barriers to encouraging more bike share use in these neighborhoods.

\subsection{Which interventions are most effective in increasing awareness and use of bike share?}

Residents, particularly lower-income people of color, responded positively to the possible changes to increase bike share use. Because price was the biggest barrier for many residents, discounted memberships, free transfers with public transit, and more short-term membership or pass options were the most appealing changes. There were several changes for which large shares of lower-income people of color stated that the change would make them somewhat or much more likely to use bike share and at significantly higher rates than respondents generally: discounted memberships (80\%); free transfers to/from public transit (77\%); more short-term membership or pass options (80\%); access to free or low cost helmets or other gear (72\%); options to sign up or buy passes at a store instead of online (70\%); an easier way to pay with cash (67\%); if more of my friends or family could ride with me (69\%); and organized rides for people like me (71\%).

Given the multiple barriers related to lack of knowledge and/or misconceptions about bike share, marketing, education, and outreach efforts are key to increasing use. Sixteen percent of all residents surveyed, and 25\% of lower-income people of color, told us that they knew "nothing" about the bike share system. Still, 94\% of respondents told us that they had heard about the system in some way prior to the survey. However, lower-income respondents of color received information from fewer sources. The most common source of information was the bike share station itself, cited by $51 \%$ of all respondents, but only 39\% of lower-income respondents of color. These residents were very unlikely to get information from the internet ( $17 \%$ vs. $26 \%$ of higher-income people of color and $53 \%$ of higher-income white residents). They were more likely than some groups to get information from television.

More personal sources of information may be more effective. While fewer residents received information from more personal sources, such as talking with someone from the bike share outreach program or at a community center or faith-based organization, these sources were correlated with higher rates of intent in using bike share in the future. Residents who received information via more passive 
modes, such as the bike share station, bus shelter ads, billboards, television, and radio had lower rates of intention to use bike share.

Sources of information also need to address the concerns and interests of the target market. The survey identified many of the possible motivations for lower-income people of color (such as getting exercise or saving money on transportation), along with some of the missing or incorrect information (such as needing a credit card, having discount options available, needing to wear a helmet, etc.). These findings may be useful in developing more effective informational materials.

\section{6 Are the promotion and outreach efforts reaching target populations?}

Most residents had received some information about the bike share system. However, as noted above, many of the residents in the target populations lack some key information or have misconceptions that need to be corrected.

There is evidence that residents are recognizing the efforts to plan a more equitable bike share system. A large majority (71\%) agreed that "there is a focused effort to make [the bike share system] better for all residents in my neighborhood" and 76\% agreed that "over time, the [bike share system] program is getting better at serving the needs of people like me.” Agreement was similarly high among lower-income people of color ( $75 \%$ and $79 \%$, respectively), but lower among higher-income people of color (64\% and 65\%, respectively). On the other hand, only $42 \%$ of residents felt that "concerns of people like me were addressed in decisions about [the bike share system] in my neighborhood.” Agreement with this statement was lowest among higher-income people of color (only $29 \%$ vs. $46 \%$ of lower-income respondents of color). There were no differences among the cities on this question.

Residents recognize the broader benefits of bike share for their neighborhood and city. Nearly all respondents agreed that the bike share system was good for the city (93\%) and their neighborhood (89\%), though agreement was slightly lower among lower-income people of color (89\% and 86\%, respectively). Similarly high shares agreed that bike share is a good alternative to public transit. The survey revealed some concerns about rising costs related to both bike share and neighborhood change, but only among a relatively small share of residents. For example, $27 \%$ of lower-income respondents of color agreed that "having [the bike share system] nearby will make it more expensive to live in the neighborhood." Only $14 \%$ of higher-income white residents agreed with this statement.

\subsection{How effective are the various efforts employed to increase the equity of bike share systems?}

Comparisons among the three cities reveal some possible differences in strategy effectiveness. For example, residents in Philadelphia were most likely to agree that the bike share system was "useful for people like me.” Of the three systems, equity was a major consideration from the inception of that city's system, with stations being sited in these diverse neighborhoods from the start. In contrast, residents of the Bed-Stuy neighborhood of Brooklyn often had less-positive attitudes toward the bike share system than the other cities, though sentiments were still generally positive. Philadelphia residents were also:

- More likely to have attended a special event related to bike share (5\% vs. 2\% for the other cities),

- Less likely to state that membership or use costs were too high (29\% vs. $48 \%$ for Brooklyn and $41 \%$ for Chicago),

- Less likely to say that signing up is too complicated and therefore a barrier (4\% vs $12 \%$ for the other cities), and

- Less likely to indicate that lack of knowledge was a barrier (16\% vs $23-27 \%$ ). 
The responses to these items may be related to the outreach efforts in that city, which included a cash payment option, monthly passes, and a low-cost walk-up option, as well as extensive outreach efforts (see section 3.2.2 on page 26 for more details).

Comparisons between the neighborhoods targeted by the BBSP outreach and the study's control neighborhoods reveal some possible differences in strategy effectiveness. Overall, we did not observe many significant differences between the outreach areas and our control neighborhoods that would indicate that the outreach efforts were effective. This was particularly true for the Brooklyn neighborhood, and likely due to differences in geography and demographics. However, there were some differences in Chicago that are consistent with the outreach efforts' being effective:

- Respondents in the outreach area of Chicago were three times as likely to have gotten information from Go Bronzeville as those in the control area (6\% to $2 \%$ )

- Respondents in Chicago's outreach area were more likely to report certain experiences such as having ridden a Divvy bike (16\% compared to 5\% in the control area), and to have friends or family who have used Divvy (46\% compared to 34\%).

- Respondents in Chicago's outreach area were more likely to correctly note that bike share wasn't limited to customers of Blue Cross Blue Shield (the system sponsor) and to know that the bike wouldn't lock after a certain time limit.

- Those in Chicago's control area were more likely to cite not wanting to use a credit card (47\% noted this as a big barrier, compared to $27 \%$ in the Bronzeville outreach area), and not having a smartphone (27\% versus $15 \%)$.

Differences in ridership growth in Brooklyn suggest that the outreach efforts there may be effective. While we did not detect differences in the survey responses that support the effectiveness of the outreach efforts, we did observe larger growth in ridership at stations in the outreach area compared with the control neighborhood.

\section{8 Other key findings}

Although outside the scope of the original research questions, the study provided a valuable opportunity to explore certain other questions about experiences with and views toward bicycling and bike share.

\subsubsection{Gender differences}

Many of the gender differences observed for barriers to bike share were not significant after controlling for other factors, however, a number of differences in more general barriers to bicycling remained. After controlling for race and income group, age, and city, the only bike share barrier that women were more likely than men to cite as a big barrier was not being able to use bike share with their children (27\% to $14 \%$ ). However, for an array of more general barriers to bicycling, women were significantly more likely to rate barriers as big, often by as many as 10-15 percentage points. Women were also less likely to agree that they see people like them riding bikes in their neighborhood (72\% to $86 \%$ ) or to want to ride a bike more than they currently do (61\% to $74 \%)$, and were significantly less likely to think bicycling more would make them more independent (46\% to $61 \%$ ).

However, women were more likely to state being likely to seek more information about bike share in the next six months (41\% to 33\%). Women were also more likely than men to say that exercise, fun, and just wanting to try biking were reasons they would consider using bike share. Thus, it appears that women may be as interested in bike share as men, particularly for recreation, and that the barriers existing for women are more related to bicycling in general, not specifically to bike share. 


\subsubsection{Older adults}

Among older adults of color, bicycling and bike share were viewed as positive contributions to the neighborhood, and many are interested trying bicycling and bike share. Older people of color had very positive views towards bicycling in general, with over $80 \%$ agreeing that getting people to ride bikes is good for the environment, that their city should invest in making bicycling safer and easier, and that bicycling is a convenient way to get places. In fact, among those physically able to ride, $60 \%$ of adults 55 64 and $39 \%$ of those $65+$ said they would like to ride a bike for transportation purposes more than they currently are, and over $90 \%$ of each group said it would be a good way to get exercise. For those who had not biked in over five years, the top barrier was not having a bike or related gear - a barrier that bike share could address. Older people of color viewed bike share positively as well, with 85-88\% saying it was good for the neighborhood and city. Among those physically able to ride a bicycle, half of those 5564 and 31\% of those $65+$ said they would like to ride bike share more than they currently do.

\section{8. 3 People not physically able to ride a standard bicycle}

A considerable portion of adults stated that they are physically unable to ride a bicycle, but would like to do so. Among people of color under age 55 who reported being physically unable to ride a bicycle, a third said they would like to ride a bike more in the future, and a similar percentage said they would like to use bike share more than they currently do. However, nearly three-quarters of these respondents told us that they did not think concerns of people like them were addressed in decisions around bike share in their community.

\subsection{Views on biking and bike share among those not interested in biking}

People of color who are not interested in riding a bicycle did not view bicycling as an activity that would make them more independent in getting around; however, they still viewed bicycling as good for their community. We looked at people of color who indicated they were not interested in riding a bicycle more. Among those who had not ridden within the past five years, a major difference between those who were interested in riding more and those who were not was that the interested group was much more likely to view bicycling as something that could make them more independent in getting around (68\% agreed, compared to $22 \%$ of the not interested). Those not interested in riding were also much more likely to state that traffic made riding a bike in their neighborhood feel dangerous ( $72 \%$ agreed, compared to $54 \%$ of the possible interested, and $39 \%$ of those who had ridden in the past five years). However, even those not interested in riding more generally viewed bicycling as something cities should be investing to make safer and easier, and that could help the environment and make the community healthier (77-78\% agreed on each). 


\section{References And ReLEVANT Resources}

Ahillen, M., Mateo-Babiano, D., and Corcoran, J. (2015). The Dynamics of Bike-Sharing in Washington, D.C. and Brisbane, Australia: Implications for Policy and Planning. International Journal of Sustainable Transportation, DOI: 10.1080/15568318.2014.966933.

Alberts, Brian, Jamie Palumbo, and Eric Pierce. (2012). Vehicle 4 Change: Health Implications of the Capital Bikeshare Program. The George Washington University. December.

http://mobilitylab.org/wp-

content/uploads/2013/05/2013_CapitalBikeshare_HealthSurvey_Report.pdf (accessed April 13, 2017).

Bachand-Marleau, J., B. Lee, and A. El-Geneidy (2012). Better Understanding of Factors Influencing Likelihood of Using Shared Bicycle Systems and Frequency of Use. Transportation Research Record: Journal of the Transportation Research Board 2314: 66-71. Nov. 2011. Web. 26 Feb. 2016.

Brown, C.T., and J. Sinclair (2017). Removing Barriers to Bicycle Use in Black and Hispanic Communities. Presented at the Transportation Research Board Annual Meeting, January 10, 2017.

Bopp, M., Der Ananian, C., and Campbell, M.E. (2014). Differences in Active Commuting among Younger and Older Adults. Journal of Aging and Physical Activity, 22(2), 199-211.

Buck, D. (2012). Encouraging Equitable Access to Public Bikesharing Systems. Master's Thesis, Virginia Tech, 2012.

Buck, D., R. Buehler, P. Happ, B. Rawls, P. Chung, and N. Borecki. Are Bikeshare Users Different from Regular Cyclists? A First Look at Short-Term Users, Annual Members, and Area Cyclists in the Washington, D.C., Region. Transportation Research Record: Journal of the Transportation Research Board 2387 (2013): 112-119.

Carney, M. (2012). Bike-Sharing and the Unbanked. A study of the unbanked population in Chicago and best practices for their inclusion in bike-sharing. Master's thesis from the University of Illinois at Chicago

Center for Disease Control. CDC Health Disparities and Inequalities Report — United States, 2013. (2013). Accessible online at https://www.cdc.gov/mmwr/preview/ind2013_su.html\#HealthDisparities2013

Clark, J. and Curl, A. (2016). Bicycle and Car Share Schemes as Inclusive Modes of Travel? A SocioSpatial Analysis in Glasgow, UK. Social Inclusion, 4(3), 83-99.

Community Cycling Center (2012). Understanding Barriers to Bicycling Project. Final Report. Accessed at http://www.communitycyclingcenter.org/wp-content/uploads/2012/07/Understanding-BarriersFinal-Report.pdf.

Daddio, D. W. Maximizing Bicycle Sharing: An Empirical Analysis of Capital Bikeshare Usage. Master's Project. University of North Carolina at Chapel Hill, 2012.

Dewey, C. (2013). The 60 Million Americans Who Don't Use the Internet, in Six Charts. The Washington Post, 19 Aug. 2013. 
Dixon, I., J. Tanzman, and M.L. Hoffman. (2015). Diverse Bicyclists, Diverse Needs: Cycles for Change Community Conversations. Report for Cycles for Change.

Federal Deposit Insurance Corporation (2015). FDIC National Survey of Unbanked and Underbanked Households. n.p., 2015. Web. 07 Apr. 2017. Feb. 2016. Accessible at https://www.fdic.gov/householdsurvey.

Fishman, E. (2016). Bikeshare: A Review of Recent Literature. Transport Reviews, 36(1), 92 - 113.

Fuller, D., Gauvin, L., Kestens, Y., Daniel, M., Fournier, M., Morency, P., and Drouin, L. (2011). Use of a new public bicycle share program in Montreal, Canada. American Journal of Preventive Medicine, 41(1), 80-83.

Goodman, A, and Cheshire, J. (2014). Inequalities in the London bicycle sharing system revisited: impacts of extending the scheme to poorer areas but then doubling prices. Journal of Transport Geography, Vol. 41, 272-279.

Hannig, J. (2015). Perceptions of Bike Sharing in Underserved Communities Within Milwaukee and the Twin Cities. Master's thesis from the University of Wisconsin-Milwaukee

Hoe, N. and Kaloustian, T. (2014). Bike Sharing in Low-Income Communities: An Analysis of Focus Groups Findings. Temple University Institute for Survey Research. Accessible at http://b.3cdn.net/bikes/fc16c31cbff25139a1_3cm6bfs04.pdf.

Hoe, Nina. (2015a). Bike Sharing in Low-Income Communities: Results from a Spring 2015 Baseline Survey. Temple University Institute for Survey Research Report. July 2015.

Hoe, Nina. (2015b). Bike Sharing in Low-Income Communities: Perceptions and Knowledge April — October 2015. Temple University Institute for Survey Research Report. December 2015.

Howland, S., N. McNeil, J. Broach, K. Rankins, J. MacArthur, and J. Dill. (2017). Breaking Barriers to Bike Share: Insights on Equity from a Survey of Bike Share System Owners and Operators. NITC-RR-884a. Portland, OR: Transportation Research and Education Center (TREC).

King, Abby C. (2001). Interventions to Promote Physical Activity by Older Adults. Journals of Gerontology: Series A, 56A (Special Issue II), 36-46.

Kodransky, M. and Lewenstein, G. (2014). Connecting Low-Income People to Opportunity with Shared Mobility. Final Report and Case Studies. Institute for Transportation and Development Policy.

Levine, J. A. Poverty and Obesity in the U.S. Diabetes 2011 Nov; 60(11): 2667-2668

Lusk, A.C., Anastasio, A., Shaffer, N., Wu, J., Li, Y., (in press). Biking practices and preferences in a lower income, primarily minority neighborhood: Learning what residents want, Preventive Medicine Reports, doi:10.1016/j.pmedr.2017.01.006

Ma, T., Lui, C., Erdoğan, S. (2015). Bicycle Sharing and Transit: Does Capital Bikeshare Affect Metrorail Ridership in Washington, D.C.? Transportation Research Board Annual Meeting, 2015.

Molina-García, J., Castillo, I., Queralt, A., and Sallis, J.F. (2013). Bicycling to university: Evaluation of a bicycle-sharing program in Spain. Health Promotion International. 30(2), 350-358. 
Monsere, C., Dill, J., McNeil, N., Clifton, K., Foster, N. and Goddard, T. (2014). Lessons from the Green Lanes: Evaluating Protected Bike Lanes in the U.S. National Institute for Transportation and Communities, Portland, OR, 2014.

Murphy, E., and J. User (2015). The Role of Bicycle-sharing in the City: Analysis of the Irish Experience. International Journal of Sustainable Transportation, 9:2, 116-125.

National Association of City Transportation Officials (NACTO) (2105). Can Monthly Passes Improve Bike Share Equity? NACTO Bike Share Equity Practitioners’ Paper \#2. Accessible at https://nacto.org/wp-content/uploads/2015/09/NACTO Can-Monthly-Passes-Improve-BikeShare-Equity.pdf.pdf.

National Association of City Transportation Officials (NACTO) (2105). Walkable Station Spacing is Key to Successful, Equitable Bike Share. NACTO Bike Share Equity Practitioners’ Paper \#1. Accessible at https://nacto.org/wp-content/uploads/2015/09/NACTO Walkable-Station-SpacingIs-Key-For-Bike-Share_Sc.pdf.

National Association of Realtors (NAR) and Portland State University (PSU) (2015). Community and Transportation Preferences Survey, 2015. Accessible at http://nitc.trec.pdx.edu/research/project/668/.

Ogilvie, F., and Goodman, A. (2012). Inequalities in usage of a public bicycle sharing scheme: sociodemographic predictors of uptake and usage of the London (UK) cycle hire scheme. Preventive Medicine, 55(1), 40-45.

PeopleForBikes. U.S. Bicycling Participation Benchmarking Study Report. Conducted by Breakaway Research Group. March 2015.

Perrin, A., and Duggan, M. (2015). Americans’ Internet Access: 2000-2015. Pew Research Center, June.

Pew Research Center. (2015). The Smartphone Difference. April. http://www.pewinternet.org/2015/04/01/us-smartphone-use-in-2015/

Rau, H. and R. Manton. (2016). Life Events and Mobility Milestones: Advances in mobility biography theory and research. Journal of Transport Geography. No. 52, pp 51-60.

Rixey, R. A. (2013). Station-level forecasting of bikesharing ridership. Transportation Research Record: Journal of the Transportation Research Board, 2387(1), 46-55.

Ryley, T. (2006). Use of non-motorised modes and life stage in Edinburgh. Journal of Transport Geography. Vol 14, No. 5, pp 367-375.

Scheiner, J. (2014). Gendered key events in the life course: effects on changes in travel mode choice over time. Journal of Transport Geography. 37, S. 47-60.

Shaheen, S., M. J. Christensen, and I. Viegas de Lima. (2015). Bay Area Bike Share Casual Users Survey Report: A comparative analysis of existing and potential bikesharing users. Report to Transportation Sustainability Research Center, University of California, Berkeley, 2015.

Shaheen, S., Martin, E., Chan, N.D., Cohen, A.P., and Pogodzinki, M. (2014). Public Bikesharing in North America During a Period of Rapid Expansion: Understanding Business Models, Industry Trends and User Impacts. San Jose, CA: Mineta Transportation Institute. 
Shaheen, S., Martin, E., Cohen, A.P., and Finson, R. (2012). Public bikesharing in North America: Early operator and user understanding. San Jose, CA: Mineta Transportation Institute.

Shaheen, S. A., Martin, E.W., and Cohen, A.P. (2013). Public Bikesharing and Modal Shift Behavior: A Comparative Study of Early Bikesharing Systems in North America. International Journal of Transportation, Vol.1, No.1 2013

Sharpe, D. (2015). Your Chi-Square Test Is Statistically Significant: Now What? Practical Assessment, Research \& Evaluation, 20(8), 1-10.

Smith, C. S., J.S. Oh, and C. Lei. Exploring the Equity Dimensions of US Bicycle Sharing Systems. Report TRCLC 14-01. Transportation Research Center for Livable Communities. 2015.

Stewart, S.K., Johnson, D.C., and Smith, W.P. (2013). Bringing bike share to a low-income community: Lessons learned through community engagement, Minneapolis, Minnesota, 2011. Preventing Chronic Disease, DOI:10.5888/pcd10.120274.

Strath, Scott, Isaacs, R., and Greenwald, M.J. (2007). Operationalizing Environmental Indicators for Physical Activity in Older Adults. Journal of Aging and Physical Activity, 15(4), 412-424.

Transportation Research Integrated Database [TRID]. Search results "Bike Share/Sharing”, "Bicycle Share/Sharing”, or "Public Bikes” in the title. Accessed on February 19, 2015. http://trid.trb.org.

Ursaki, J. and L. Aultman-Hall. (2016). Quantifying the Equity of Bikeshare Access in U.S. Cities. Transportation Research Board Annual Meeting, 2016. Paper \# 16-0426.

Virginia Tech. (2012). Capital Bikeshare study: A closer look at casual users and operation. Arlington: Virginia Tech.

Woodcock, J., Tainio, M., Cheshire, J., O’Brien, O., and Goodman, A. (2014). Health effects of the London bicycle sharing system: Health impact modelling study. British Medical Journal, 348, 425. 


\section{APPENDIX}

These documents will be available as separate online resources at http://trec.pdx.edu/research/project/884 and by following the links provided below

\section{1 Survey Instruments}

See the following pages for a sample generic survey instrument, which was adapted to each city. The actual survey instrument used in each city is available online - see link below.

Appendix A1 is available at the following URL:

http://trec.pdx.edu/sites/default/files/BreakingBarriersResident_AppendixA1_Instruments.pdf

\section{2 Response Frequencies}

Frequencies of survey responses by city (with separate tables for control neighborhoods in Chicago and Brooklyn) are available online - see link below. The frequencies represent all responses received for each area, including those over 65 years old and those unable to ride a bicycle, and are not broken down by the groupings used in the full report.

Appendix A2 is available at the following URL:

http://trec.pdx.edu/sites/default/files/BreakingBarriersResident_AppendixA2_Frequencies.pdf 
(1) Complete this paper survey and the enclosed gift slip. Return in the postage paid envelope; $\underline{\text { OR }}$

(2) Complete the online survey and gift slip at:

To take the online survey,

you will need to enter this code: [Unique Code]

TIME SENSITIVE: Please complete the survey by the date given in your letter.

\section{About your travel}

In the past week, how did you get around [CityName]?

Drove a personal car

Got a ride from a friend or family member

Taxi / Uber / Lyft

Car Share (Zipcar, Car2Go, etc.)

Public transit (bus, rail, [paratransit], etc.)

Walking

Bicycling - bike share/[BssName]

Bicycling - personal bike

Other:

\section{About your neighborhood}

Do you agree or disagree with the following statements?

I am satisfied with my options for getting where I need to go

I usually know about community and social events in my neighborhood

I know about services provided by community or faith-based organizations in my neighborhood

I have noticed changes in my neighborhood in the past 12 months

Recent changes make my neighborhood more appealing to me

I may have to leave my neighborhood because it is getting too expensive

I have provided input on decisions affecting my neighborhood

Concerns of people like me are considered in decisions affecting my neighborhood

My city government does a good job of serving people like me

I can usually get to and from home and where I need to go easily enough

My options for getting around have gotten better in that past 12 months

The public transit agency does a good job serving people like me

\begin{tabular}{|c|c|c|}
\hline No Trips & Some Trips & Most Trips \\
$\square_{1}$ & $\square_{2}$ & $\square_{3}$ \\
$\square_{1}$ & $\square_{2}$ & $\square_{3}$ \\
$\square_{1}$ & $\square_{2}$ & $\square_{3}$ \\
$\square_{1}$ & $\square_{2}$ & $\square_{3}$ \\
$\square_{1}$ & $\square_{2}$ & $\square_{3}$ \\
$\square_{1}$ & $\square_{2}$ & $\square_{3}$ \\
$\square_{1}$ & $\square_{2}$ & $\square_{3}$ \\
$\square_{1}$ & $\square_{2}$ & $\square_{3}$ \\
$\square_{1}$ & $\square_{2}$ & $\square_{3}$ \\
\hline
\end{tabular}

[SurveyURL] 


\section{Your opinions about bicycling}

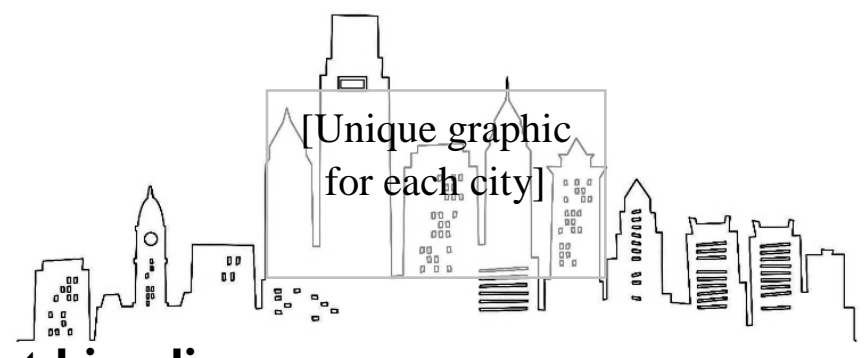

Do you agree or disagree with the following statements about bicycling?

Getting more people to ride bikes is good for the environment

Getting more people to ride bikes will help make the community healthier

[CityName] should invest in projects (such as bike lanes) that make riding bikes safer and easier

People on bikes make roads less safe for others

Bike lanes make it harder to get around my neighborhood Riding a bike is a convenient way for people to get places in [CityName]

\begin{tabular}{|c|c|c|c|c|}
\hline $\begin{array}{c}\text { Strongly } \\
\text { Disagree }\end{array}$ & Disagree & Agree & $\begin{array}{c}\text { Strongly } \\
\text { Agree }\end{array}$ & $\begin{array}{c}\text { No } \\
\text { Opinion }\end{array}$ \\
$\square_{1}$ & $\square_{2}$ & $\square_{3}$ & $\square_{4}$ & $\square_{9}$ \\
$\square_{1}$ & $\square_{2}$ & $\square_{3}$ & $\square_{4}$ & $\square_{9}$ \\
$\square_{1}$ & $\square_{2}$ & $\square_{3}$ & $\square_{4}$ & $\square_{9}$ \\
$\square_{1}$ & $\square_{2}$ & $\square_{3}$ & $\square_{4}$ & $\square_{9}$ \\
$\square_{1}$ & $\square_{2}$ & $\square_{3}$ & $\square_{4}$ & $\square_{9}$ \\
$\square_{1}$ & $\square_{2}$ & $\square_{3}$ & $\square_{4}$ & $\square_{9}$ \\
\hline
\end{tabular}

Whether or not you ride a bicycle, do you agree or disagree with the following statements about bicycling?

\begin{tabular}{|l|}
\hline I am familiar with the bike lanes in my neighborhood \\
I often see people like me riding bikes in my \\
neighborhood \\
I would like to ride a bicycle (for transportation) more \\
than I currently do \\
\hline There are better ways for me to get around than by biking \\
Riding a bike would make me more independent in \\
getting around \\
Riding a bike would help me spend less on transportation \\
Riding a bike would be a good way for me to get exercise \\
\hline Riding a bike would be a good way for me to spend time \\
with friends or family \\
I'm bicycling more now than I did a year ago \\
\hline I plan to ride a bicycle more often in the next year \\
\hline There is a bike shop that is convenient for me to go to
\end{tabular}

\begin{tabular}{|c|c|c|c|c|}
\hline $\begin{array}{c}\text { Strongly } \\
\text { Disagree }\end{array}$ & Disagree & Agree & $\begin{array}{c}\text { Strongly } \\
\text { Agree }\end{array}$ & $\begin{array}{c}\text { Does } \\
\text { Apply } \\
\square_{1}\end{array}$ \\
$\square_{1}$ & $\square_{2}$ & $\square_{3}$ & $\square_{4}$ & $\square_{9}$ \\
$\square_{1}$ & $\square_{3}$ & $\square_{4}$ & $\square_{9}$ \\
$\square_{1}$ & $\square_{2}$ & $\square_{3}$ & $\square_{4}$ & $\square_{9}$ \\
$\square_{1}$ & $\square_{2}$ & $\square_{3}$ & $\square_{4}$ & $\square_{9}$ \\
$\square_{1}$ & $\square_{2}$ & $\square_{3}$ & $\square_{4}$ & $\square_{9}$ \\
$\square_{1}$ & $\square_{2}$ & $\square_{3}$ & $\square_{4}$ & $\square_{9}$ \\
$\square_{1}$ & $\square_{2}$ & $\square_{3}$ & $\square_{4}$ & $\square_{9}$ \\
$\square_{1}$ & $\square_{2}$ & $\square_{3}$ & $\square_{4}$ & $\square_{9}$ \\
$\square_{1}$ & $\square_{2}$ & $\square_{3}$ & $\square_{4}$ & $\square_{9}$ \\
$\square_{1}$ & $\square_{2}$ & $\square_{3}$ & $\square_{4}$ & $\square_{9}$ \\
\hline
\end{tabular}




\section{About riding a bicycle}

\begin{tabular}{|l|l|l|l|}
\hline Do you know how to ride a bike? & $\square_{1}$ Yes & $\square_{2}$ No & $\square_{3}$ Not well \\
Are you physically able to ride a bike? & $\square_{1}$ Yes & $\square_{2}$ No & $\square_{3}$ Temporarily Unable \\
When did you last ride a bicycle? $\quad \begin{array}{l}\square_{1} \text { In the past 12 months } \square_{3} \text { More than 5years ago } \\
\square_{2} \text { 1-5 years ago }\end{array}$ & $\square_{4}$ Never \\
\hline
\end{tabular}

\section{Reasons for not bicycling}

For each item below, please indicate whether it is something that keeps you from riding a bike (or from biking more):

I don't have a bike or related gear (such as a helmet/lock/ lights)

It is too expensive to buy a bike or related gear

I don't know a good place for me to get a bike fixed

I don't have a safe place to store a bike at home

There might not be a safe place to leave a bike at the places I go

The places that I need to go are too far away to reach on a bike

I don't know how to get where I need to go by bike

Traffic makes riding a bike in my neighborhood feel dangerous

My bike is not good for riding around the city

I am too old to ride a bike

I am too out of shape to ride a bike

Biking might aggravate my personal health issues

Carrying things on bike is too difficult

Riding a bike with my kids is a hassle

Something could go wrong with a bike (such as a flat tire)

My friends and family wouldn't want me to ride a bike

Riding a bike is not viewed as a cool activity by my friends

People might think that I can't afford a car

Riding a bike could make me a target for police attention

Riding a bike could cause me to be harassed or a victim of crime

Riding a bike could mess up my hair or appearance

The clothes I wear are not appropriate for biking

Riding a bike could make me sweaty

\begin{tabular}{|c|c|c|c|}
\hline $\begin{array}{c}\text { Not a } \\
\text { barrier }\end{array}$ & $\begin{array}{c}\text { Small } \\
\text { barrier }\end{array}$ & $\begin{array}{c}\text { big } \\
\text { barrier }\end{array}$ & $\begin{array}{c}\text { Does not } \\
\text { apply }\end{array}$ \\
$\square_{1}$ & $\square_{2}$ & $\square_{3}$ & $\square_{9}$ \\
$\square_{1}$ & $\square_{2}$ & $\square_{3}$ & $\square_{9}$ \\
$\square_{1}$ & $\square_{2}$ & $\square_{3}$ & $\square_{9}$ \\
$\square_{1}$ & $\square_{2}$ & $\square_{3}$ & $\square_{9}$ \\
$\square_{1}$ & $\square_{2}$ & $\square_{3}$ & $\square_{9}$ \\
$\square_{1}$ & $\square_{2}$ & $\square_{3}$ & $\square_{9}$ \\
$\square_{1}$ & $\square_{2}$ & $\square_{3}$ & $\square_{9}$ \\
$\square_{1}$ & $\square_{2}$ & $\square_{3}$ & $\square_{9}$ \\
$\square_{1}$ & $\square_{2}$ & $\square_{3}$ & $\square_{9}$ \\
$\square_{1}$ & $\square_{2}$ & $\square_{3}$ & $\square_{9}$ \\
$\square_{1}$ & $\square_{2}$ & $\square_{3}$ & $\square_{9}$ \\
$\square_{1}$ & $\square_{2}$ & $\square_{3}$ & $\square_{9}$ \\
$\square_{1}$ & $\square_{2}$ & $\square_{3}$ & $\square_{9}$ \\
$\square_{1}$ & $\square_{2}$ & $\square_{3}$ & $\square_{9}$ \\
$\square_{1}$ & $\square_{2}$ & $\square_{3}$ & $\square_{9}$ \\
$\square_{1}$ & $\square_{2}$ & $\square_{3}$ & $\square_{9}$ \\
$\square_{1}$ & $\square_{2}$ & $\square_{3}$ & $\square_{9}$ \\
$\square_{1}$ & $\square_{2}$ & $\square_{3}$ & $\square_{9}$ \\
$\square_{1}$ & $\square_{2}$ & $\square_{3}$ & $\square_{9}$ \\
$\square_{1}$ & $\square_{2}$ & $\square_{3}$ & $\square_{9}$ \\
$\square_{1}$ & $\square_{2}$ & $\square_{3}$ & $\square_{9}$ \\
$\square_{2}$ & $\square_{3}$ & $\square_{9}$ \\
\hline
\end{tabular}




\section{Questions about [BssName] - [CityName]'s bike share system}

[BssName] is [CityName]'s public bike share system. People can check out a bike (like the one pictured at right) from any [BssName] station, ride it wherever they want, and return it to any other station.

How much would you say you know about [BssName]?
$\square_{1}$ Know nothing about it
$\square_{2}$ Know some things
about it
$\square_{3}$ Know quite a bit about it

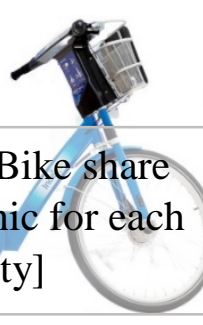

[Unique Bike share bike graphic for each
Where have you gotten information about [BssName]? Check all that apply .
$\square$ Have not heard anything about it before
$\square$ Radio
$\square$ Television
$\square \quad$ At a bike share station / kiosk
$\square \quad$ Talked to someone at an event
$\square \quad$ Got something in the mail
$\square$ Ads on buses or bus shelters
$\square \quad$ Newspaper
$\square$ On the internet
$\square$ Talked to someone from [CityPartner]
$\square \quad$ On a billboard
$\square \quad$ Information at work or school
$\square$ Friends or family
$\square$ At a community center or faith-based organization
$\square$ Other:

Please explain specifically where and how you first learned about [BssName]:

Tell us a little more about [BssName] and you:

Have you noticed a [BssName] station in your neighborhood?

Have you ridden a [BssName] bike?

Are you currently a [BssName] member?

$\longrightarrow$ If no: Have you ever been a [BssName] member?

Did you receive a coupon for a free [BssName] ride or day-use?

Have you gone on an organized bike ride where you learned about [BssName]?

Have any of your friends or family used [BssName]?

Do you follow [BssName] on Instagram, Twitter, Facebook, or Email?

Have you ever talked to someone who works with [BssName]?

Have you attended special events related to [BssName]?

Do you expect that you will be a [BssName] pass holder 12 months from now?

\begin{tabular}{|c|c|c|}
\hline Yes & No & Not sure \\
$\square_{1}$ & $\square_{2}$ & $\square_{3}$ \\
$\square_{1}$ & $\square_{2}$ & $\square_{3}$ \\
$\square_{1}$ & $\square_{2}$ & $\square_{3}$ \\
$\square_{1}$ & $\square_{2}$ & $\square_{3}$ \\
$\square_{1}$ & $\square_{2}$ & $\square_{3}$ \\
$\square_{1}$ & $\square_{2}$ & $\square_{3}$ \\
$\square_{1}$ & $\square_{2}$ & $\square_{3}$ \\
$\square_{1}$ & $\square_{2}$ & $\square_{3}$ \\
$\square_{1}$ & $\square_{2}$ & $\square_{3}$ \\
$\square_{1}$ & $\square_{2}$ & $\square_{3}$ \\
$\square_{1}$ & $\square_{2}$ & $\square_{3}$ \\
\hline
\end{tabular}

In the next 6 months, how likely are you to...

Seek more information about using [BssName]?

Tell someone you know about [BssName]?

Ride an [BssName] bike?

\begin{tabular}{|c|c|c|c|}
\hline $\begin{array}{c}\text { Not at all } \\
\text { likely }\end{array}$ & $\begin{array}{c}\text { Not } \\
\text { likely }\end{array}$ & $\begin{array}{c}\text { Somewhat } \\
\text { likely }\end{array}$ & $\begin{array}{c}\text { Very } \\
\text { likely }\end{array}$ \\
$\square_{1}$ & $\square_{2}$ & $\square_{3}$ & $\square_{4}$ \\
$\square_{1}$ & $\square_{2}$ & $\square_{3}$ & $\square_{4}$ \\
$\square_{1}$ & $\square_{2}$ & $\square_{3}$ & $\square_{4}$ \\
\hline
\end{tabular}




\section{What do you know about [BssName] - [CityName]'s bike share system?}

Please rate each statement from false to true*:

A debit or credit card is required to use [BssName]

People can pay monthly for a [BssName] membership

A helmet is required to check out an [BssName] bike

Non-members can check out bikes by the hour

Non-members can buy a 24-hour pass for $\$ 12$

[BssName] members can use a bike longer than nonmembers (before extra charges apply)

An [BssName] membership costs [Membership Price]

A reduced price pass for [ is available for $\$ 5$ per month

Only [Sponsor] customers can use [BssName]

You have to have a smart phone to use [BssName]

If you exceed a time limit, the [BssName] bicycle will lock

You have to return the bike to the same station where you check it out

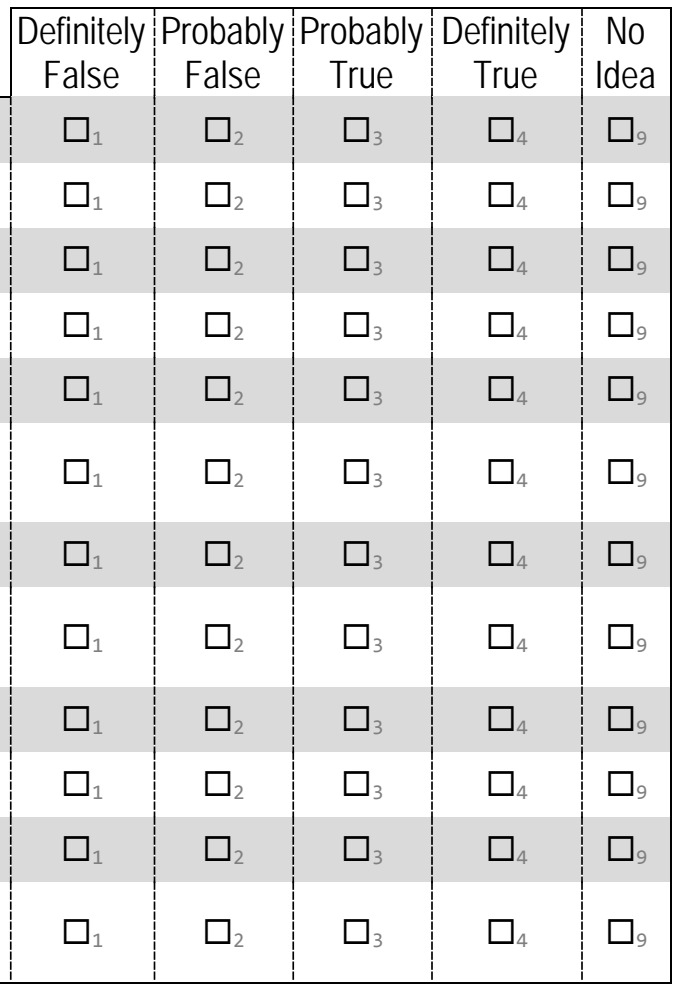

*True-False Questions varied slightly between cities - see electronic appendix for actual survey instruments.

\section{Your opinions about [BssName] - [CityName]'s bike share system}

Whether or not you have used bike share, please indicate if you agree or disagree with each statement:

[BssName] is useful for people like me
I would like to use [BssName] more than I currently do
Having nearby [BssName] stations will attract new people
to move into the neighborhood
Having [BssName] will make it more expensive to live in
the neighborhood
Using [BssName] is a good way to spend less money on
transportation
Using [BssName] is a good alternative to using public
transportation
[BssName] is a good way to get to public transportation
I see people like me using [BssName] in my neighborhood
I consider [BssName] to be part of the city's public
transportation system
Concerns of people like me were addressed in decisions
about [BssName] in my neighborhood
[BssName] stations take up street and sidewalk space that
would be better used for other things

\begin{tabular}{|c|c|c|c|c|}
\hline $\begin{array}{c}\text { Strongly } \\
\text { Disagree }\end{array}$ & Disagree & Agree & Strongly & $\begin{array}{c}\text { No } \\
\text { Agree }\end{array}$ \\
$\square_{1}$ & $\square_{2}$ & $\square_{3}$ & $\square_{4}$ & $\square_{9}$ \\
$\square_{1}$ & $\square_{2}$ & $\square_{3}$ & $\square_{4}$ & $\square_{9}$ \\
$\square_{1}$ & $\square_{2}$ & $\square_{3}$ & $\square_{4}$ & $\square_{9}$ \\
$\square_{1}$ & $\square_{2}$ & $\square_{3}$ & $\square_{4}$ & $\square_{9}$ \\
$\square_{1}$ & $\square_{2}$ & $\square_{3}$ & $\square_{4}$ & $\square_{9}$ \\
$\square_{1}$ & $\square_{2}$ & $\square_{3}$ & $\square_{4}$ & $\square_{9}$ \\
$\square_{1}$ & $\square_{2}$ & $\square_{3}$ & $\square_{4}$ & $\square_{9}$ \\
$\square_{1}$ & $\square_{2}$ & $\square_{3}$ & $\square_{4}$ & $\square_{9}$ \\
$\square_{1}$ & $\square_{2}$ & $\square_{3}$ & $\square_{4}$ & $\square_{9}$ \\
$\square_{1}$ & $\square_{2}$ & $\square_{3}$ & $\square_{4}$ & $\square_{9}$ \\
$\square_{1}$ & $\square_{2}$ & $\square_{3}$ & $\square_{4}$ & $\square_{9}$ \\
\hline
\end{tabular}


Whether or not you have used bike share, please indicate if you agree or disagree with each statement:

There is a focused effort to make [BssName] better for all residents in my neighborhood

Over time, the [BssName] program is getting better at serving the needs of people like me

Overall, [BssName] is good for the city

Overall, [BssName] is good for my neighborhood

\begin{tabular}{|c|c|c|c|c|}
\hline $\begin{array}{c}\text { Strongly } \\
\text { Disagree }\end{array}$ & Disagree & Agree & $\begin{array}{c}\text { Strongly } \\
\text { Agree }\end{array}$ & $\begin{array}{c}\text { No } \\
\text { Opinion }\end{array}$ \\
\hline$\square_{1}$ & $\square_{2}$ & $\square_{3}$ & $\square_{4}$ & $\square_{9}$ \\
$\square_{1}$ & $\square_{2}$ & $\square_{3}$ & $\square_{4}$ & $\square_{9}$ \\
$\square_{1}$ & $\square_{2}$ & $\square_{3}$ & $\square_{4}$ & $\square_{9}$ \\
$\square_{1}$ & $\square_{2}$ & $\square_{3}$ & $\square_{4}$ & $\square_{9}$ \\
\hline
\end{tabular}

What are some reasons why you use or would consider using [BssName]? Check all that apply.

\begin{tabular}{|ll|}
\hline$\square$ Want to try biking & $\square$ To ride with friends/family \\
$\square$ Saves me money compared to other & $\square$ Stations are near my home/ work/ school \\
transportation options & $\square$ To help the environment \\
$\square$ Saves me time compared to other & $\square$ Don't need a bike of my own \\
transportation options & $\square$ To get to jobs more easily \\
$\square$ To get exercise & $\square$ To get to social services \\
$\square$ For fun & $\square$ Other \\
$\square$ To get to bus or rail stops & $\square$ Nothing $-\overline{\text { I }}$ wouldn't consider using \\
$\square$ Don't want to rely on transit & [BssName] bike share \\
$\square$ It's an easy way to get around &
\end{tabular}

Would the following changes make you more likely to use [BssName]?

Discounted membership or use options

More short-term membership or pass options (e.g. daily,

weekly, or monthly instead of yearly)

Easier way to pay with cash

Option to sign up or buy passes at a store instead of online

Access to free or low cost helmets and other gear

Organized rides for people like me

If more of my friends or family could use [BssName] with me

If [BssName] users were more diverse

Help finding safe ways to get where I need to go

Free transfers between public transportation and [BssName]

More [BssName] stations close together

More [BssName] stations where I want to go

\begin{tabular}{|c|c|c|c|}
\hline $\begin{array}{c}\text { No more } \\
\text { likely }\end{array}$ & Somewhat & Much more & Does not \\
$\square_{1}$ & $\square_{2}$ & $\square_{3}$ & $\square_{9}$ \\
$\square_{1}$ & $\square_{2}$ & $\square_{3}$ & $\square_{9}$ \\
$\square_{1}$ & $\square_{2}$ & $\square_{3}$ & $\square_{9}$ \\
$\square_{1}$ & $\square_{2}$ & $\square_{3}$ & $\square_{9}$ \\
$\square_{1}$ & $\square_{2}$ & $\square_{3}$ & $\square_{9}$ \\
$\square_{1}$ & $\square_{2}$ & $\square_{3}$ & $\square_{9}$ \\
$\square_{1}$ & $\square_{2}$ & $\square_{3}$ & $\square_{9}$ \\
$\square_{1}$ & $\square_{2}$ & $\square_{3}$ & $\square_{9}$ \\
$\square_{1}$ & $\square_{2}$ & $\square_{3}$ & $\square_{9}$ \\
$\square_{1}$ & $\square_{2}$ & $\square_{3}$ & $\square_{9}$ \\
$\square_{1}$ & $\square_{2}$ & $\square_{3}$ & $\square_{9}$ \\
$\square_{1}$ & $\square_{2}$ & $\square_{3}$ & $\square_{9}$ \\
\hline
\end{tabular}

Describe the one thing that would make you more likely to use [BssName]: 


\section{Reasons for not using [BssName] - [CityName]'s bike share system}

When considering whether you might use [BssName], how much of a barrier are the following for you?

I worry that I'll have to pay for the bike if anything happens to it

I don't know enough about how to use it

Membership or use costs are too high

I worry that there might not be an available bike at a station to check out, or a free space at a station when returning a bike

I worry that the [BssName] bikes wouldn't adjust to fit me

I don't want to use a credit card to use bike share

I don't have a smart phone

There aren't [BssName] stations near where I want to go

There aren't [BssName] stations near my home

I don't know where other stations are to drop off a bike

I don't want to be seen on an [BssName] bike

Signing up for [BssName] is too complicated

Checking out and returning [BssName] bikes is too complicated

I can't use [BssName] with my child(ren)

I just don't want to support the [BssName] program

I just prefer to ride my own bike

\begin{tabular}{|c|c|c|c|}
\hline $\begin{array}{c}\text { Not a } \\
\text { barrier }\end{array}$ & $\begin{array}{c}\text { Small } \\
\text { barrier }\end{array}$ & $\begin{array}{c}\text { Big } \\
\text { barrier }\end{array}$ & $\begin{array}{c}\text { Does not } \\
\text { apply }\end{array}$ \\
$\square_{1}$ & $\square_{2}$ & $\square_{3}$ & $\square_{9}$ \\
$\square_{1}$ & $\square_{2}$ & $\square_{3}$ & $\square_{9}$ \\
$\square_{1}$ & $\square_{2}$ & $\square_{3}$ & $\square_{9}$ \\
$\square_{1}$ & $\square_{2}$ & $\square_{3}$ & $\square_{9}$ \\
$\square_{1}$ & $\square_{2}$ & $\square_{3}$ & $\square_{9}$ \\
$\square_{1}$ & $\square_{2}$ & $\square_{3}$ & $\square_{9}$ \\
$\square_{1}$ & $\square_{2}$ & $\square_{3}$ & $\square_{9}$ \\
$\square_{1}$ & $\square_{2}$ & $\square_{3}$ & $\square_{9}$ \\
$\square_{1}$ & $\square_{2}$ & $\square_{3}$ & $\square_{9}$ \\
\hdashline$\square_{1}$ & $\square_{2}$ & $\square_{3}$ & $\square_{9}$ \\
\hline$\square_{1}$ & $\square_{2}$ & $\square_{3}$ & $\square_{9}$ \\
\hline$\square_{1}$ & $\square_{2}$ & $\square_{3}$ & $\square_{9}$ \\
\hline$\square_{1}$ & $\square_{2}$ & $\square_{3}$ & $\square_{9}$ \\
\hline$\square_{1}$ & $\square_{2}$ & $\square_{3}$ & $\square_{9}$ \\
\hline$\square_{1}$ & $\square_{2}$ & $\square_{3}$ & $\square_{9}$ \\
\hline$\square_{1}$ & $\square_{2}$ & $\square_{3}$ & $\square_{9}$ \\
\hline
\end{tabular}

Tell us about the most important barrier keeping you from using [BssName] (or using it more)?

In general, would you say that your health is ... ?

Excellent

${ }_{2} \square$ Very good

${ }_{3} \square$ Good

${ }_{4} \square$ Fair

${ }_{5} \square$ Poor
In general, how physically active are you?

$\square$ Not active at all

${ }_{2} \square$ Not very active

${ }_{3} \square$ Somewhat active

${ }_{4} \square$ Very active

${ }_{5} \square$ Don't know/ not sure

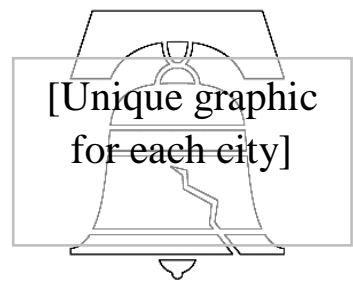


Please answer a few questions about you and your household. Then you're all done!

\section{Check all that apply.

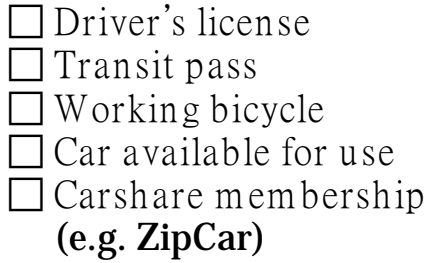

Do you currently have a . . . ?

$\square$ Smart phone
$\square$ Credit card
$\square$ Debit card
$\square$ Reliable
internet access
$\square$ None of these

How old are you? years

Are you...? ${ }_{1} \square$ Male ${ }_{2} \square$ Female

Do you currently work . . . ?
1 job
2 or more jobs
$\square$ Not employed
${ }_{4} \square$ Retired

If employed, how many hours per week?

35 hours or more ${ }_{2} \square$ Less than 35 hours

Are you currently a student?

${ }_{1} \square$ Full time ${ }_{2} \square$ Part time ${ }_{3} \square$ Not a student

What is the highest level of school you have completed?
${ }_{1} \square$ Less than high school
${ }_{2} \square$ High school diploma/ GED
${ }_{3} \square$ Some college, no degree
${ }_{4} \square$ Associate's degree
${ }_{5} \square$ Bachelor's degree
${ }_{6} \square$ Graduate or professional degree

Do you consider yourself . . . ?

Check all that apply.

Hispanic, Latino, or Spanish origin

American Indian or Alaska Native

$\square$ Asian

$\square$ Black or African American

$\square$ White

$\square$ Prefer not to say

$\square$ Other:

\section{Do you rent or own your home?}

$\square$ Rent $\quad{ }_{2} \square$ Own $\quad{ }_{3} \square$ Other

\section{If renting, are you receiving a housing} subsidy or discount?

(Such as Section 8, public housing, or subsidized housing [e.g., paying a set percentage of your income for rent])

$$
{ }_{1} \square \text { Yes }{ }_{0} \square \text { No }
$$

\section{What is your home zip code?}

\section{How long have you lived...}

At your current address? years

In your current neighborhood?

years

Including yourself, how many people are there in your household?

$$
\begin{aligned}
& \text { \# Adults } \\
& \text { \#Children }
\end{aligned}
$$

\section{What is your annual household income?}
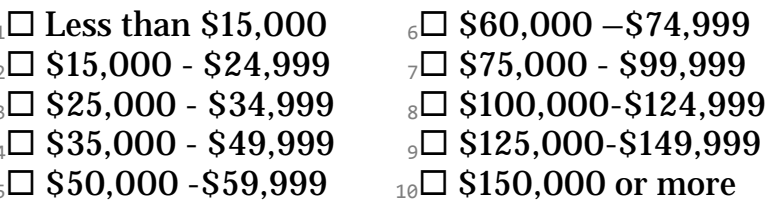

Which one of the following four statements best describes your ability to get along on your household income?

${ }_{1} \square$ I/ we can't make ends meet

${ }_{2} \square$ I/ we have just enough, no more

${ }_{3} \square$ I/ we have enough, with a little extra sometimes

I/ we always have money left over

Is there anything else you would like to add or explain? 
Transportation Research and Education Center

Portland State University

1900 S.W. Fourth Ave., Suite 175

Portland, OR 97201 